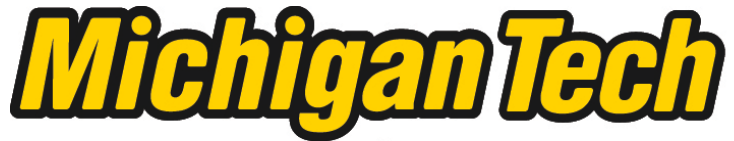 \\ Michigan Technological University Create the Future Digital Commons @ Michigan Tech
}

\section{Compatibility of ultra high performance concrete as repair material : bond characterization with concrete under different loading scenarios}

Miguel Ángel Carbonell Muñoz

Michigan Technological University

Follow this and additional works at: https://digitalcommons.mtu.edu/etds

Part of the Civil and Environmental Engineering Commons

Copyright 2012 Miguel Ángel Carbonell Muñoz

\section{Recommended Citation}

Carbonell Muñoz, Miguel Ángel, "Compatibility of ultra high performance concrete as repair material : bond characterization with concrete under different loading scenarios", Master's Thesis, Michigan Technological University, 2012.

https://doi.org/10.37099/mtu.dc.etds/225

Follow this and additional works at: https://digitalcommons.mtu.edu/etds

3 Part of the Civil and Environmental Engineering Commons 
COMPATIBILITY OF ULTRA HIGH PERFORMANCE CONCRETE AS REPAIR MATERIAL: BOND CHARACTERIZATION WITH CONCRETE UNDER DIFFERENT LOADING SCENARIOS

\title{
By
}

Miguel Ángel Carbonell Muñoz

\begin{abstract}
A THESIS
Submitted in partial fulfillment of the requirements for the degree of MASTER OF SCIENCE

(Civil Engineering)

MICHIGAN TECHNOLOGICAL UNIVERSITY

2012
\end{abstract}


This thesis, "Compatibility of Ultra High Performance Concrete as Repair Material: Bond Characterization with Concrete under Different Loading Scenarios," is hereby approved in partial fulfillment of the requirements for the Degree of MASTER OF SCIENCE IN CIVIL ENGINEERING.

Department of Civil and Environmental Engineering

Signatures:

Thesis Advisor

Dr. Devin K. Harris

Department Chair

Dr. David W. Hand, P.E.

Date 


\section{Table of Contents}

List of Figures ................................................................................................... vi

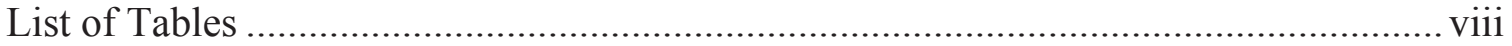

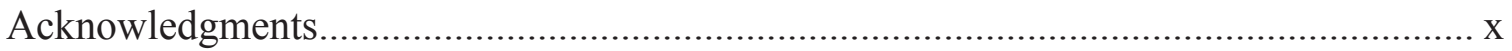

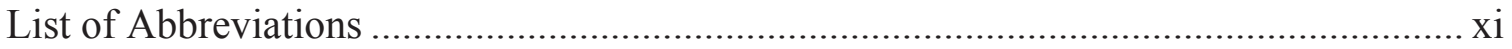

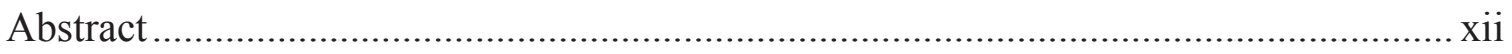

1 Introduction and Motivation.................................................................................. 1

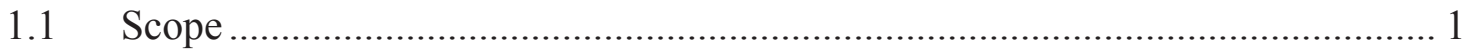

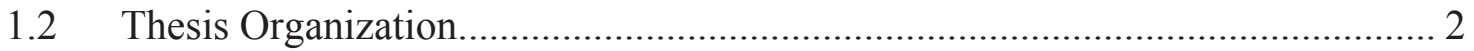

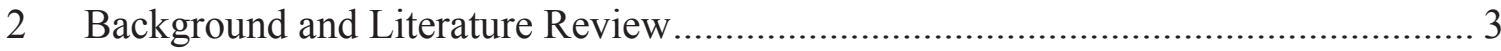

2.1 Ultra High Performance Concrete (UHPC) ……….......................................... 3

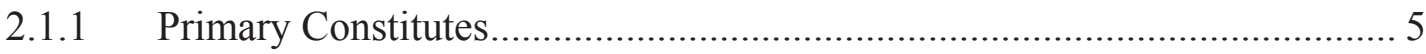

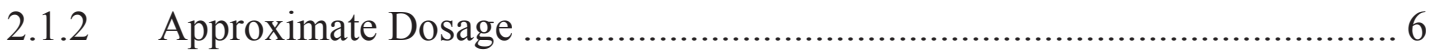

2.1.3 Material Properties ........................................................................... 9

2.2 Rehabilitation of Concrete Structures ......................................................... 16

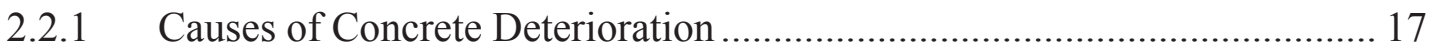

2.2.2 Compatibility between Repair Material and Concrete Substrate................ 17

2.2.3 Common Repair Materials .................................................................. 20

2.2.4 Rehabilitations of Concrete Structures using UHPC ……………………... 22

2.3 Factors that affecting the Bond Strength......................................................... 26

2.3.1 Tests Methods to evaluate Bond Strength ................................................. 27

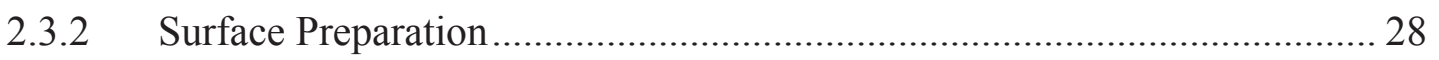

2.3.3 Failure Envelope of the Bond Interface ……………................................ 30

2.3.4 Bond between two concrete materials ..................................................... 35

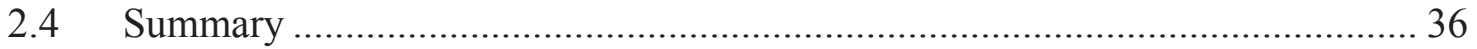

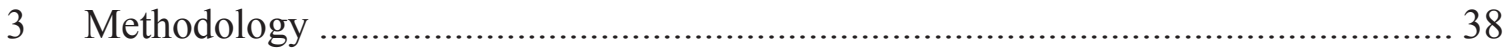

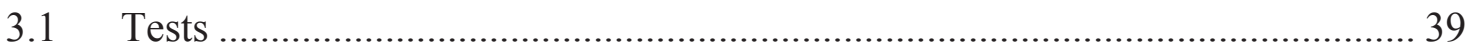

3.1.1 Combination of Splitting Tensile Test with Freeze-Thaw Cycles.............. 39 iii 


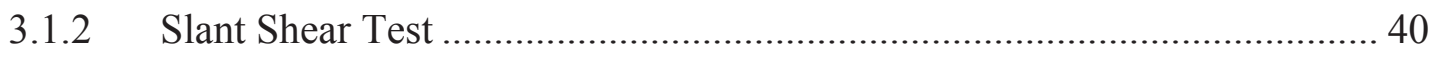

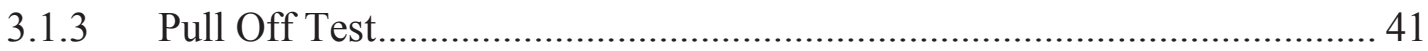

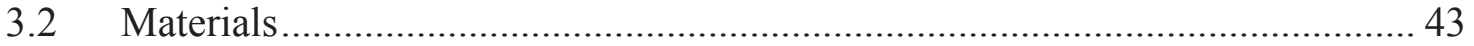

3.2.1 UHPC mixing ................................................................................. 43

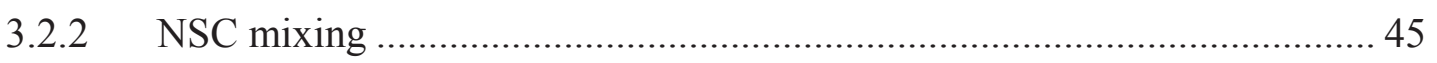

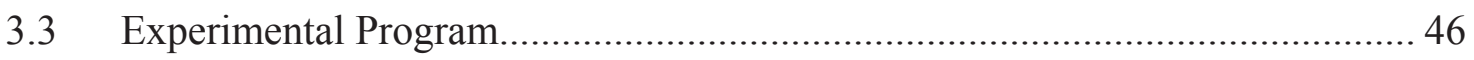

3.3.1 Combination of Splitting Tensile Test with Freeze-Thaw Cycles............... 46

3.3.2 Slant-shear test .................................................................................... 49

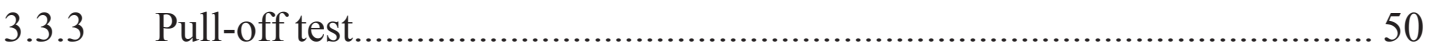

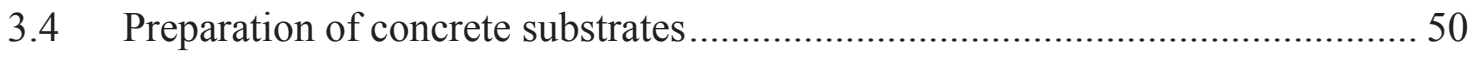

3.4.1 Combination of Splitting Tensile Test with Freeze-Thaw Cycles............... 51

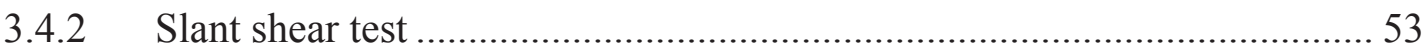

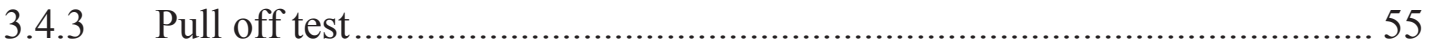

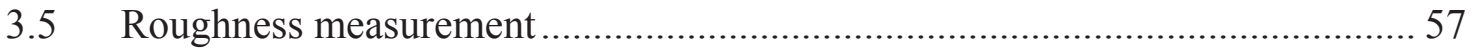

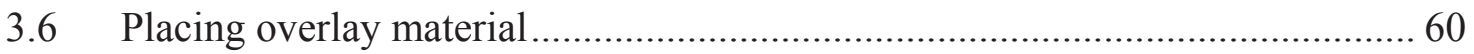

3.6.1 Combination of Splitting Tensile Test with Freeze-Thaw Cycles............... 60

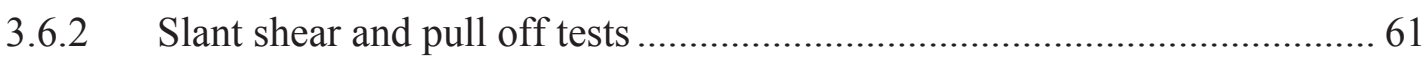

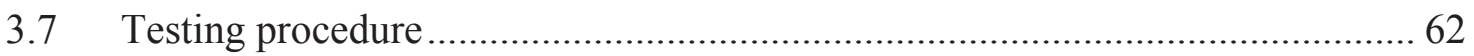

3.7.1 Combination of Splitting Tensile Test with Freeze-Thaw Cycles............... 62

3.7.2 Slant-shear test ......................................................................................... 65

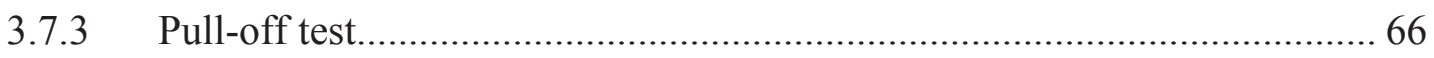

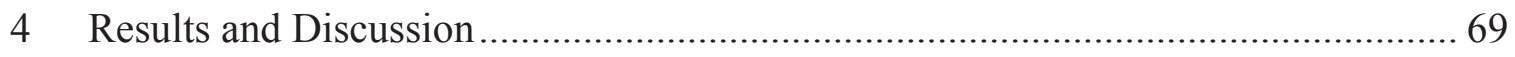

4.1 Combination of Splitting Tensile Test with Freeze-Thaw Cycles ...................... 70

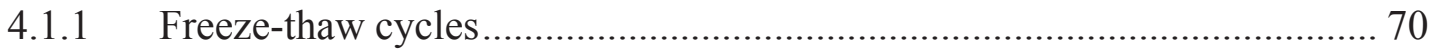

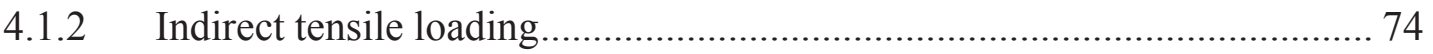

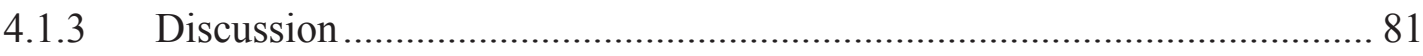

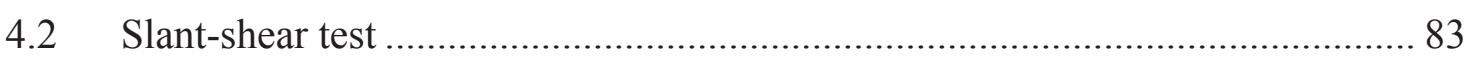

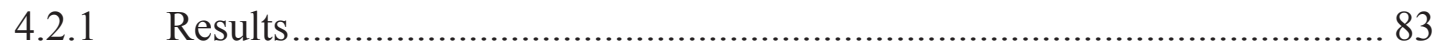

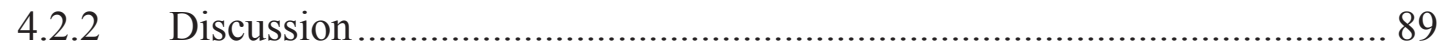

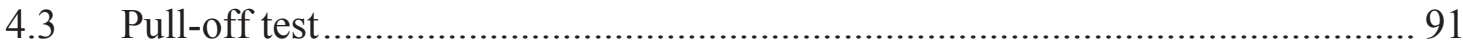

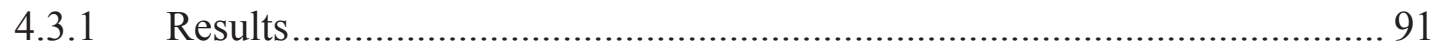




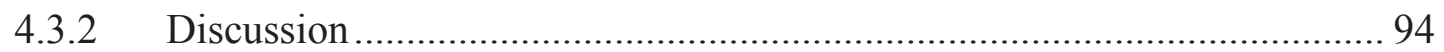

5 Conclusions and further research .............................................................. 95

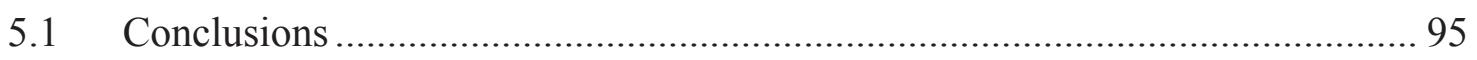

5.1.1 Combination of Splitting Tensile Test with Freeze-Thaw Cycles.............. 96

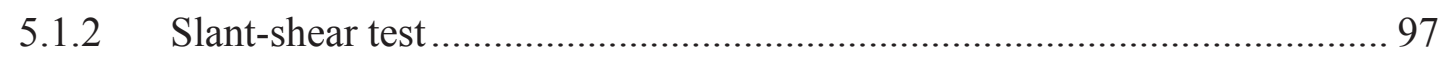

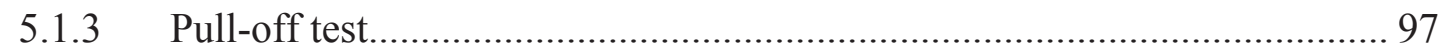

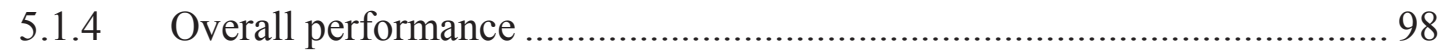

5.2 Criticism of the bonding test and recommendations ................................... 99

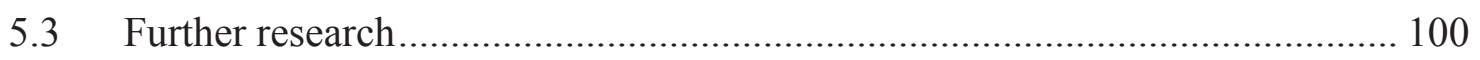

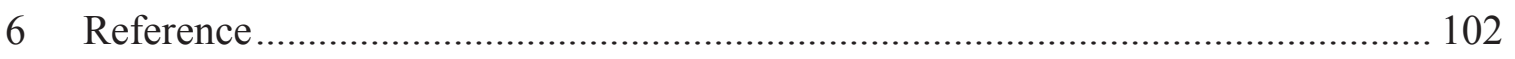

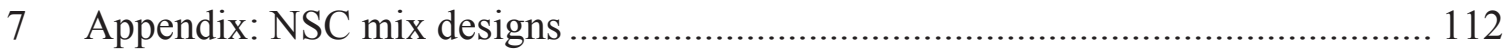

8 Appendix: Concrete retarder information. .................................................... 119

9 Appendix: Macrotexture Depth test information. ........................................ 121

10 Appendix: Splitting tensile prisms after failure ............................................. 126

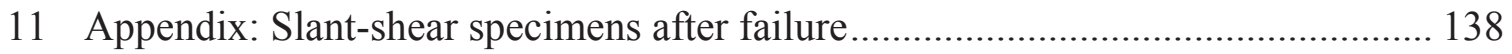

12 Appendix: Pull-off specimens after failure .................................................. 141

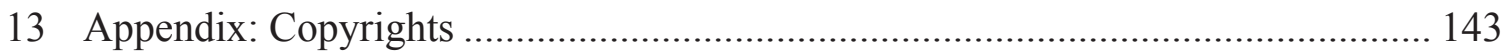




\section{List of Figures}

Figure 2.1 Typical Composition of UHPC. Modified from Denarié (2004) .................... 4

Figure 2.2 Methodology to design a UHPC mix. Adapted from Marković (2006)........... 8

Figure 2.3 Dissipated power and degree of hydration of the RPC sample as a function of

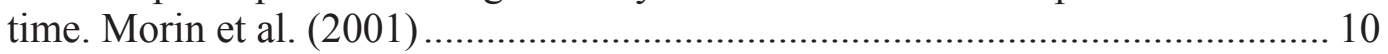

Figure 2.4 Comparison of different cross sectional areas of equal load carrying capacity. Courtesy of Lafarge North America 11

Figure 2.5 Graphic stress strain behavior of cementitious matrices under tension loading. Fischer (2004) 13

Figure 2.6 Durability property of UHPC with respect to Normal Concrete and HPC. Suleiman et al. (2008) .................................................................................. 15

Figure 2.7 Most common bond strength tests. Espeche and Leon (2011)..................... 28

Figure 2.8 Upper bounds to determine the bond failure envelope. Modified from Robins

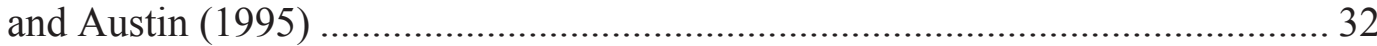

Figure 2.9 Representative failure envelopes from rock mechanics based on bi-linear model and empirical criterion. Austin et al. (1999) ............................................ 33

Figure 2.10 Equilibrium of stresses in the slant shear test and Mohr circle. Modified from

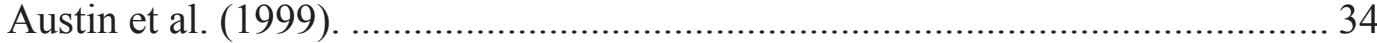

Figure 2.11 Representation of the interface between old and new concretes. Espeche and

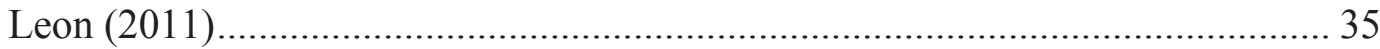

Figure 3.1 Equipment and material to cast UHPC ................................................... 43

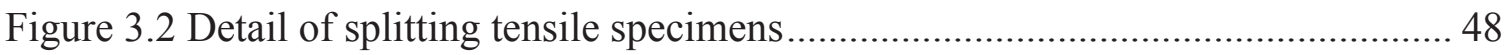

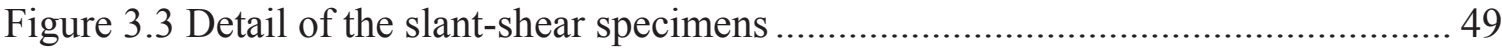

Figure 3.4 Detail of pull off specimen and location of coring holes ............................. 50

Figure 3.5 Different stages in the preparation of the splitting tensile samples................ 51

Figure 3.6 Different NSC substrate surfaces for splitting tensile samples .................... 52

Figure 3.7 NSC substrates after demoulding and during the surface treatment .............. 52

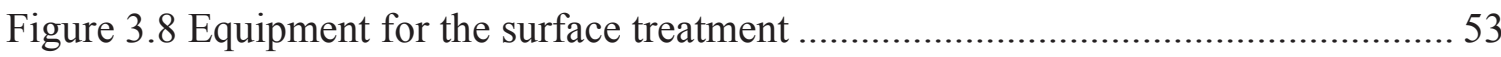

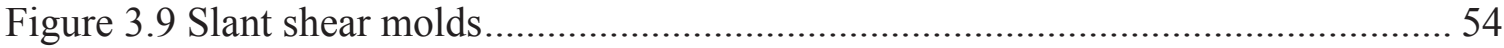

Figure 3.10 Different NSC substrate surfaces for slant shear and pull off samples ........ 55

Figure 3.11 NSC substrates for the pull off test......................................................... 56

Figure 3.12 Tests to measure the degree of roughness of the concrete substrate ............ 57

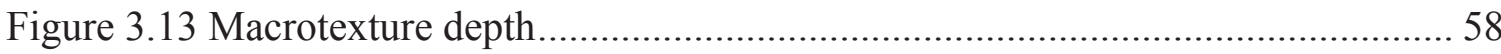




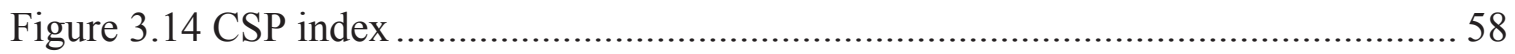

Figure 3.15 Composite splitting tensile specimen casting process ................................... 61

Figure 3.16 Composite splitting tensile specimen casting process................................... 62

Figure 3.17 Several steps of the splitting tensile test........................................................ 64

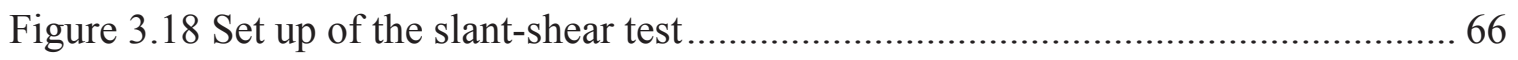

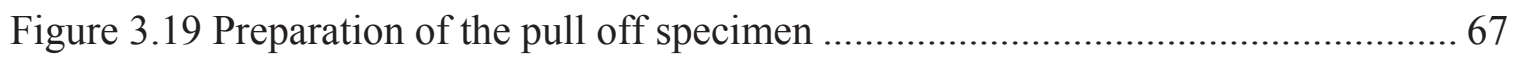

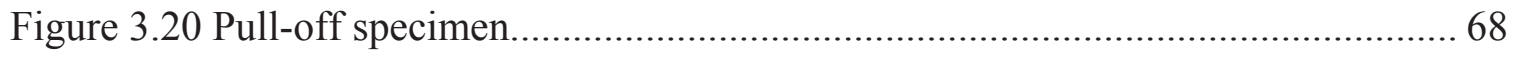

Figure 4.1 Weight of composite samples, cast in wetting conditions, subjected to 300

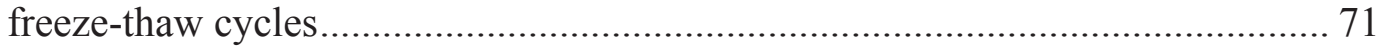

Figure 4.2 Fundamental transverse frequency of composite samples, cast in wetting conditions, subjected to 300 freeze-thaw cycles................................................. 72

Figure 4.3 Relative Dynamic Modulus of composite samples, cast in wetting conditions, subjected to 300 freeze-thaw cycles .............................................................. 72

Figure 4.4 Weight of NSC samples subjected to 300 freeze-thaw cycles ........................ 73

Figure 4.5 Transversal frequency of NSC samples subjected to 300 freeze-thaw cycles 73

Figure 4.6 Relative Dynamic Modulus of NSC samples subjected to 300 freeze-thaw

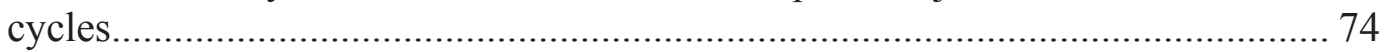

Figure 4.7 Representative failure modes of composite specimens for the splitting tensile

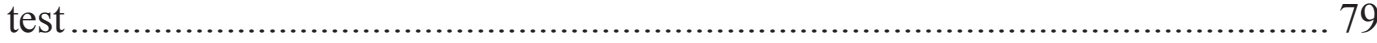

Figure 4.8 Failure modes per case study in the splitting tensile test under wetting

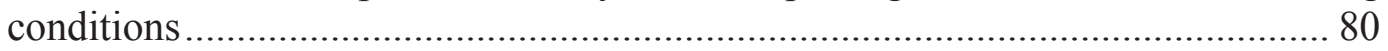

Figure 4.9 Bond strength per case study obtained in the splitting tensile test................. 81

Figure $4.10 \mathrm{COV}$ per case study obtained in the splitting tensile test .............................. 81

Figure 4.11 Failure modes for the slant-shear test....................................................... 86

Figure 4.12 Bond strength per case study obtained in the slant-shear test with an interface

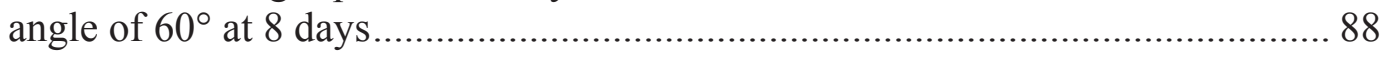

Figure 4.13 Bond strength per case study obtained in the slant-shear test with an interface

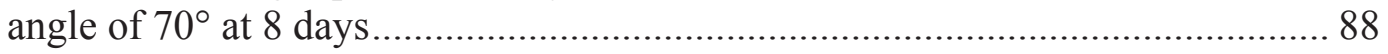

Figure 4.14 Evolution of the bond strength per case study obtained in the slant-shear test 89

Figure 4.15 Failure modes in the pull-off test............................................................... 93

Figure 4.16 Tensile strength per case study obtained in pull-off test at 10-11 days......... 93

Figure 8.1 Concrete retarder information [1]. Euclid Chemical (2012) ....................... 119

Figure 8.2 Concrete retarder information [2]. Euclid Chemical (2012) ......................... 120 


\section{List of Tables}

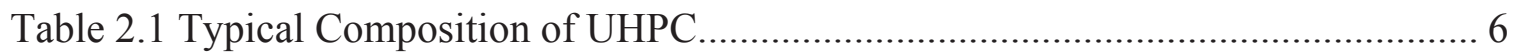

Table 2.2 Particle packing models. Adapted from Jones et al. (2002) ............................... 7

Table 2.3 Comparison of UHPC material properties to NSC and HPC (High Performance Concrete). Modified from Misson (2008) and Peuse (2008)............................... 12

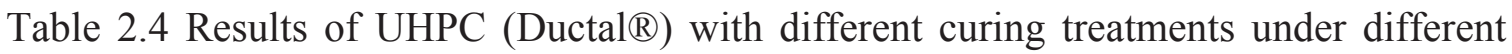
tests about durability. Adapted from Graybeal and Tanesi (2007) ........................ 14

Table 2.5 Comparison of the most common repair materials. Adapted from ACI 546R-04 21

Table 2.6 Friction angles (in degrees) as a function of the degree of roughness of the concrete substrate. Adapted from Espeche and Leon (2011) ............................... 31

Table 3.1 Ductal ${ }^{\circledR}$ (JS1000-Grey Premix) mix proportions for $0.65 \mathrm{ft}^{3}$........................ 43

Table 3.2 Ductal ${ }^{2}($ BS1000-Grey Premix) mix process ................................................... 44

Table 3.3 Different variables between the splitting tensile test and slant-shear and pull-off

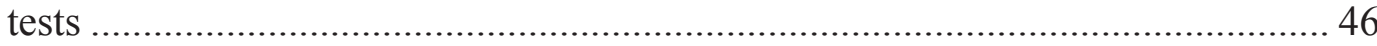

Table 3.4 Splitting tensile slabs distribution for each case study .................................... 47

Table 3.5 Classification of different surface treatments according to CSP. Adapted from

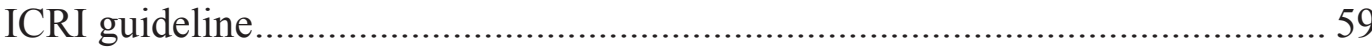

Table 3.6 Results of the macrotexture depth test for the splitting tensile samples and classification of the surfaces according to CSP ……………………………....... 59

Table 3.7 Results of the macrotexture depth test for the slant shear and pull off tests and classification of the surfaces according to CSP 59

Table 3.8 Composite sample ages for the freeze-thaw cycles and indirect tensile loading 63

Table 4.1 ACI bond strength range for different bond test configurations. Adapted from ACI 546R-04

Table 4.2 Age and compressive strength of overlay and substrate materials on the day indirect tension test 75

Table 4.3 Age and compressive strength of overlay and substrate materials on the day indirect tension test 75

Table 4.4 Percentage of prisms that failed prematurely under dry concrete substrate

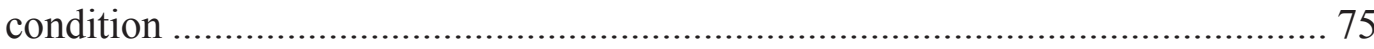

Table 4.5 Results of grooved surface under dry concrete substrate condition ................. 76

Table 4.6 Summary of indirect tensile strength composite sample results under saturated concrete substrate. 
Table 4.7 Summary of indirect tensile strength monolithic NSC sample results 79

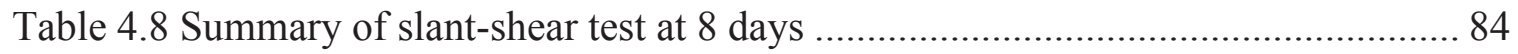

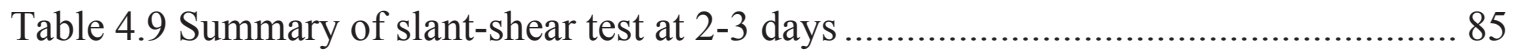

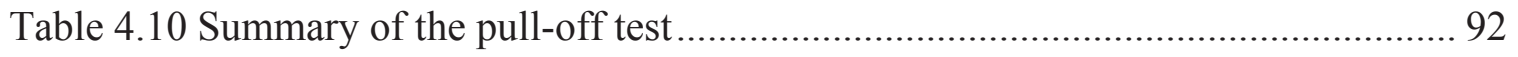

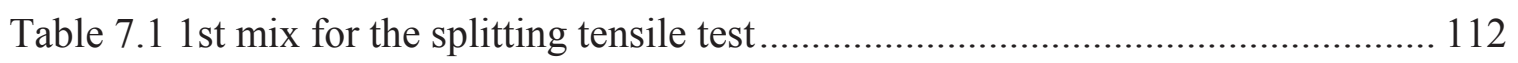

Table 7.2 2nd mix for the splitting tensile test.......................................................... 113

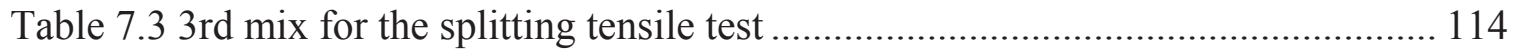

Table 7.4 th mix for the splitting tensile test ...................................................... 115

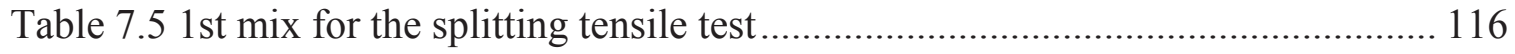

Table 7.6 2nd mix for the splitting tensile test........................................................ 117

Table 7.7 3rd mix for the splitting tensile test ......................................................... 118

Table 9.1 Macrotexture depth results for the splitting tensile samples in wetting

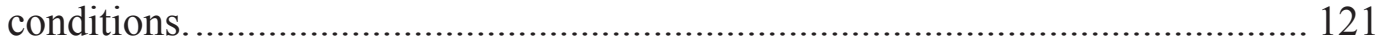

Table 9.2 Macrotexture depth results for the slant-shear and pull-off samples............. 123

Table 10.1 Splitting tensile composite prisms after failure (in wetting conditions)....... 126

Table 10.2 Splitting monolithic NSC prisms after failure .......................................... 136

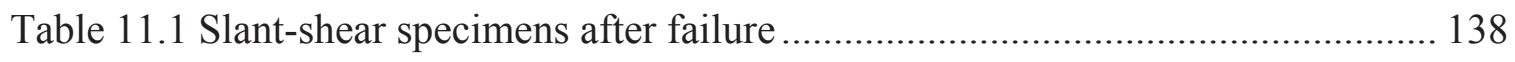

Table 12.1 Pull-off specimens after failure.......................................................... 141 


\section{Acknowledgments}

I would like to thank my advisor Dr. Devin Harris for his mentoring and supervision throughout the project, for the detailed reviews and constructive comments on the manuscript. I am fortunate to work under his supervision. Dr. Tess M. Ahlborn and Peter Seibert for their suggestions, and being part of my committee. My project team members, Sarah Shann, Jason Flietstra, Eric Krieger and Jean Leav for their assistance throughout the duration of this research. David Froster deserves a special thank for helping with the experimental work.

This research was possible with the donation of material from Lafarge North America. I would also like to thank Polytechnic University of Valencia (Spain) for giving me the opportunity of studying at Michigan Tech University.

I would like to express my gratitude to my parents, Juan and Rosa, for the values that they have taught me: the only way to success is hard work and honesty. I wish to express my thankfulness to my wife, Anieri Morales Rivera for her support, encouragement and love. Without her, it would have been impossible to finish this report. I as well remain thankful to my siblings, Juale, Pablo and Rosa, and my new family from Puerto Rico.

Finally, I would like to dedicate this thesis to the memory of my grandparents, Juan and Pedro, they are always in my mind and prayers. 


\section{List of Abbreviations}

\begin{tabular}{|l|l|}
\hline ACI. & American Concrete Institute. \\
\hline AFt & Ettringite \\
\hline ASTM. & American Society for Testing and Materials. \\
\hline COV. & Coefficient Of Variation \\
\hline CTE. & Coefficient of Thermal Expansion \\
\hline C A. & Tricalcium Aluminate \\
\hline ECC. & Engineered Cementitious Composite \\
\hline FEA. & Finite element analysis. \\
\hline FEM. & Finite element model. \\
\hline FRC. & Fiber reinforced concrete. \\
\hline LMC. & Latex modified concrete. \\
\hline LSDC. & Low slump dense concrete. \\
\hline HPC. & High performance concrete. \\
\hline HPFRC. & High Performance Fibre Reinforced Cement Composites. \\
\hline NSC. & Normal strength concrete. \\
\hline PC. & Polymer concrete. \\
\hline RDM. & Relative dynamic modulus \\
\hline RH. & Relative Humidity. \\
\hline RPC. & Reactive Power Concrete. \\
\hline SIFCOM. & Slurry-Infiltrated-Fibered Concrete \\
\hline SFRC. & Steel Fibre Reinforced Concrete. \\
\hline UHPC. & Ultra high performance concrete. \\
\hline UHPFRC. & Ultra high performance fiber reinforced concrete. \\
\hline W/C. & Water-to-cement ratio. \\
\hline lbs & Pounds \\
\hline yd & Yard \\
\hline kips & kilo-pounds \\
\hline psi & pounds per square inch \\
ksi & kilo-pounds per square inch \\
\hline
\end{tabular}




\begin{abstract}
The rehabilitation of concrete structures, especially concrete bridge decks, is a major challenge for transportation agencies in the United States. Often, the most appropriate strategy to preserve or rehabilitate these structures is to provide some form of a protective coating or barrier. These surface treatments have typically been some form of polymer, asphalt, or low-permeability concrete, but the application of UHPC has shown promise for this application mainly due to its negligible permeability, but also as a result of its excellent mechanical properties, self-consolidating nature, rapid gain strength, and minimal creep and shrinkage characteristics. However, for widespread acceptance, durability and performance of the composite system must be fully understood, specifically the bond between UHPC and NSC often used in bridge decks. It is essential that the bond offers enough strength to resist the stress due to mechanical loading or thermal effects, while also maintaining an extended service-life performance.

This report attempts to assess the bond strength between UHPC and NSC under different loading configurations. Different variables, such as roughness degree of the concrete substrates, age of bond, exposure to freeze-thaw cycles and wetting conditions of the concrete substrate, were included in this study. The combination of splitting tensile test with 0,300, 600 and 900 freeze-thaw cycles was carried out to assess the bond performance under severe ambient conditions. The slant-shear test was utilized with different interface angles to provide a wide understanding of the bond performance under different combinations of compression and shear stresses. The pull-off test is the most accepted method to evaluate the bond strength in the field. This test which studies the direct tensile strength of the bond, the most severe loading condition, was used to provide data that can be correlated with the other tests that only can be used in the laboratory.

The experimental program showed that the bond performance between UHPC and NSC is successful, as the strength regardless the different degree of roughness of the concrete substrate, the age of the composite specimens, the exposure to freeze-thaw cycles and the different loading configurations, is greater than that of concrete substrate and largely satisfies with ACI 546.3R-06.
\end{abstract}




\section{Introduction and Motivation}

Currently, civil engineers have to face a new issue in the concrete industry: the increasing need for rehabilitation of many concrete structures that were constructed in the second part of the last century. Thus far, most of the efforts of the engineers were addressed to design new infrastructures. However, after the construction boom in developed countries over the last few decades, the repair of structures is becoming increasingly necessary. The latter represents an important environmental concern: if we are able to design successful repairs, the material and cost saving can represent a significant achievement for the sustainability of the concrete industry, increasing the service live of the existing concrete structures with the lowest consumption of material. The experimental results show that UHPC would have an excellent performance under severe environmental conditions due to its negligible permeability. This makes UHPC have almost no penetration of chlorides and sulphides. Further, its high abrasion and freeze-thaw resistances make this material suitable as overlay that protects the rest of the structure from extreme environmental conditions. Nonetheless, for widespread use of UHPC as repair material, the bond between UHPC and Normal Strength Concrete (NSC) needs to be assessed. It is essential that the bond offers enough strength to resist the stress due to mechanical loading or thermal effects, while also maintaining an extended service-life performance.

\subsection{Scope}

The major objective of this project is to study the potential use of UHPC as repair material of concrete structures. The main goals of this research are outlined below:

- To study the bond strength between UHPC and NSC under different loading conditions, such as indirect tension, shear-compression and direct tension.

- To evaluate the influence of the freeze-thaw cycles on the bond strength.

- To assess the effect of the different degrees of roughness of the substrate on the bond strength. 
- To evaluate the grade of compatibility of UHPC with the normal strength concrete.

The experimental results obtained in this project are based on tests performed on

Ductal ${ }^{\circ} J \mathrm{~S} 1000$. This is a commercially available brand in the United States provided by Lafarge North America.

\subsection{Thesis Organization}

The aim of this research is to characterize the bond between UHPC and NSC for potential applications of UHPC as repair material. This report is organized as follows:

- Chapter 2 is a literature review containing the principles of UHPC, its material properties and the potential benefit that this advanced cementitious material can suppose to the environment. This chapter as well describes the compatibility that has to exist between the repair material and concrete substrate to ensure the success of the rehabilitation.

- Chapter 3 defines the experimental program.

- Chapter 4 presents the experimental results and a discussion of them.

- Chapter 5 closes with the conclusions and proposals for the further research.

The author, Miguel Ángel Carbonell Muñoz, prepared this thesis, firstly as exchange student from Polytechnic University of Valencia (Spain). During this period, the splitting tensile test with 0 and 300 freeze-thaw cycles were finalized. Lastly, the study was completed with inclusion of the splitting tensile test with 600 and 900 cycles, slant-shear test with different interface angles and the pull-off test as part of the requirements for the Master of Science degree at Michigan Technological University. 


\section{Background and Literature Review}

This chapter presents the most significant properties of UHPC, the factors that have to be assessed to assure a good compatibility between two different materials and the bond failure envelop concept. A special attention was given to the hydration process of UHPC, due to the fact that it widely differs from that of NSC and it is related to the mechanical properties development. From a point of view of structures rehabilitation, the overlay's setting time has a great importance owing to the economical saving that can be achieved by a short down time of the infrastructure.

\subsection{Ultra High Performance Concrete (UHPC)}

Currently in the United States, the formal definition of UHPC is under development within the American Concrete Institute (ACI), but a general description of this material is presented in this section.

UHPC is a cementitious composite material composed of an optimized gradation of granular constituents, a water-to-cementitious materials ratio less than 0.25 , and a high percentage of discontinuous internal fiber reinforcement. The Association Française de Génie Civil defines UHPC in its document about recommendations for Ultra High Performance Fibre Reinforced concretes (2002) as those materials with the following properties (Peuse 2008):

- Compressive strength greater than $22 \mathrm{ksi}$

- Nonbrittle behavior achieved by internal fiber reinforcement

- High binder content with special aggregates

UHPC is a new class of concrete that offers high compressive strength and a negligible permeability. The latter makes UHPC as excellent protection against freeze-thaw deterioration, corrosion of embedded steel and chemical ingress. This new material is the result of important developments in the cementitious materials technology that have taken place in the last decades, such as, the development of puzzolanic admixtures and superplastizicers. The idea was to develop concretes with a homogenous and dense 
cement matrix to avoid the growth of microcracks inside the structure when undergoing loading. The excellent durability performance features and elevated mechanical properties of UHPC are based upon on the following principles (Schmidt and Fehling 2005):

- A reduced water/cement ratio of approximately 0.14 to 0.27 , that results in a dense structure with negligible capillary pores.

- A high packing density achieved by optimizing the granular size, eliminating coarse aggregate and addition of quartz and ground quartz.

- Use of high amounts of superplasticizers to regulate the workability.

- Addition of steel fibers to increase the strength and ductility of the UHPC

UHPC can be also referred as Reactive Power Concrete (RPC) or Ultra High Performance Fibre Reinforced Concrete (UHPFRC) due to the fact that after the first plain RPC (without fibers) mixtures which showed a very high brittleness behavior, all researches started to add short fibers to increase the ductility. If the previously mentioned basic principles are carried out, all the performances that characterize UHPC should be attained. The optimum packing of particle initially used in the mixture design of plain RPC should probably be optimized in a different way due to the disturbance that the fibres causes on the granular skeleton (Markovic 2006). Figure 2.1 classifies UHPC between others cementititous materials.

Cementitious materials (concrete, mortar)

FRC- Fibre Reinforced Concretes (e.g SFRC- Steel Fibre Reinforced Concrete)

HPFRCC- High Performance Fibre Reinforced Cement Composites (e.g. ECC, SIFCON)

UHPFRC- Ultra High Performance Fibre Reinforced Concretes (e.g RPC, CEMTEC, Ductal ${ }^{\circ}$, UHPC)

Figure 2.1 Typical Composition of UHPC. Modified from Denarié (2004) 


\subsubsection{Primary Constitutes}

The main constituents of UHPC are cement, water, sand, silica fume, superplasticizer and fibres. The following points explain briefly these main ingredients (Denarié 2004).

Cement. The amount of cement used, higher than $1180 \mathrm{lbs}$, to produce $1 \mathrm{yd}^{3}$ of UHPC is more than two times higher than that for NSC. In most cases, Portland Cement V is used due to its low tricalcium aluminate content $\left(\mathrm{C}_{3} \mathrm{~A}\right)$, no more than $5 \%$, what provides a high sulfate resistance and low water demand.

Water. As previously mentioned, one of characteristics of UHPC is its low water-cement ratio. The amount of water used is the rigorously required to hydrate the cement thus the formation of pores is fairly reduced, avoiding the interconnection between them. Therefore, the absence of a capillary structure improves the strength and the impermeability of this material.

Sand. The sand used needs to have excellent qualities, both in strength and low absorption. The particle sizes have to be small, frequently lesser that $1 \mathrm{~mm}$, to achieve an adequate homogeneity in the mix. Quartz sand with a maximum size of $1 \mathrm{~mm}$ is typically used. It is important that the aggregates used exhibit high strength and low absorption.

Silica fume. The addition of silica fume increases the mechanical strengths and gains the compactness and microstructure of UHPC. The optimum ratio between silica fume and cement is 25\% (Denarié 2004; Richard and Cheyrezy 1995). Silica fume has three main functions in the UHPC:

- Filling the voids between cement grains $(100 \mu \mathrm{m})$ since silica fume grains are smaller particles $(8 \mu \mathrm{m})$.

- Improvement of rheological characteristics due its perfect sphericity of the basic particles that produce lubrication effect.

- Formation of hydration products by puzzolanic activity with the lime, producing an increase of the final strength.

Superplastizicer. Due to the low water-cement ratio, the addition of superplastizicers is indispensable to obtain an adequate workability helping the fine particles to fill the void 
spaces and to decrease the amount of water in the mix. In most cases, the superplastizicers based on polycarboxylate are used.

Fibres. Fibers are added to the concrete to increase the ductility and mechanical properties. The amount of fibers influences on the workability of the final product. The usual amount varies from $1 \%$ to $4 \%$ in volume but for special applications this amount can be increased.

\subsubsection{Approximate Dosage}

An itemization of the basic constituents of a Ductal ${ }^{\circledR} \mathrm{JS} 1000$ UHPC mix is shown in Table 2.1. Ductal®JS1000 is a commercially brand available in the US provided by Lafarge North America.

Table 2.1

Typical Composition of UHPC.

\begin{tabular}{cc}
\hline Constitute & Proportion $\left(\mathbf{l b} / \mathbf{y d} \mathbf{d}^{\mathbf{3}}\right)$ \\
\hline Ductal ${ }^{\mathrm{G}}$ Gray Premix & 3700 \\
Metallic Fibers & 263 \\
$\left(8 \times 10^{-3}\right.$-in dia. by 0.5 -in long) & 219 \\
Water & 51 \\
\hline Superplasticizer & \\
\hline
\end{tabular}

It has to be emphasized that the grain size distributions of the premix consisting of cement, sand and silica fume must be optimized in order to attain minimum voids ratio. Marković (2006) described a methodology for mixture design of hybrid fibre concrete. The first step is to choose a water-binder ratio and the second step is to determine the combination of different types and quantities of steel fibers. The following step is to determine the maximum diameter of the aggregate, $\mathrm{D}_{\max }$, based on fiber geometry, and from this data, the aggregate grading is chosen by using granular grading packing models. Marković (2006) used Compressible packing model by DeLarrard, but Denarié (2004) stated that other particle packing models are also applicable. Jones et al. (2002) compared four different particle models to produce a maximum packing density. The 
models used with their corresponding material parameters required are given in Table 2.2. The results shown the models gave broadly the same output and propose equivalent combinations of aggregates to give the maximum packing density. An adequate particle size distribution is essential in order to decrease the capillary porosity of the hardened concrete, and consequently, to increase the compressive strength.

Table 2.2

Particle packing models. Adapted from Jones et al. (2002)

\begin{tabular}{cc}
\hline Model & Material Parameters Required \\
\hline Dewar Model & Mean size and voids ratio \\
\hline Toufar Model & Characteristic diameter and packing density \\
\hline De Larrad LPM & Eigenpacking density \\
\hline De Larrad CPM & Compaction index and virtual packing density \\
\hline Modified CPM & Compaction index and virtual packing density \\
\hline acking Model. CPM: Compressible Packing Model
\end{tabular}

After mixing, several workability studies on fresh mixtures need to be done in order to determine the suitable amount of aggregate and superplasticizer. This process is shown in Figure 2.2. 


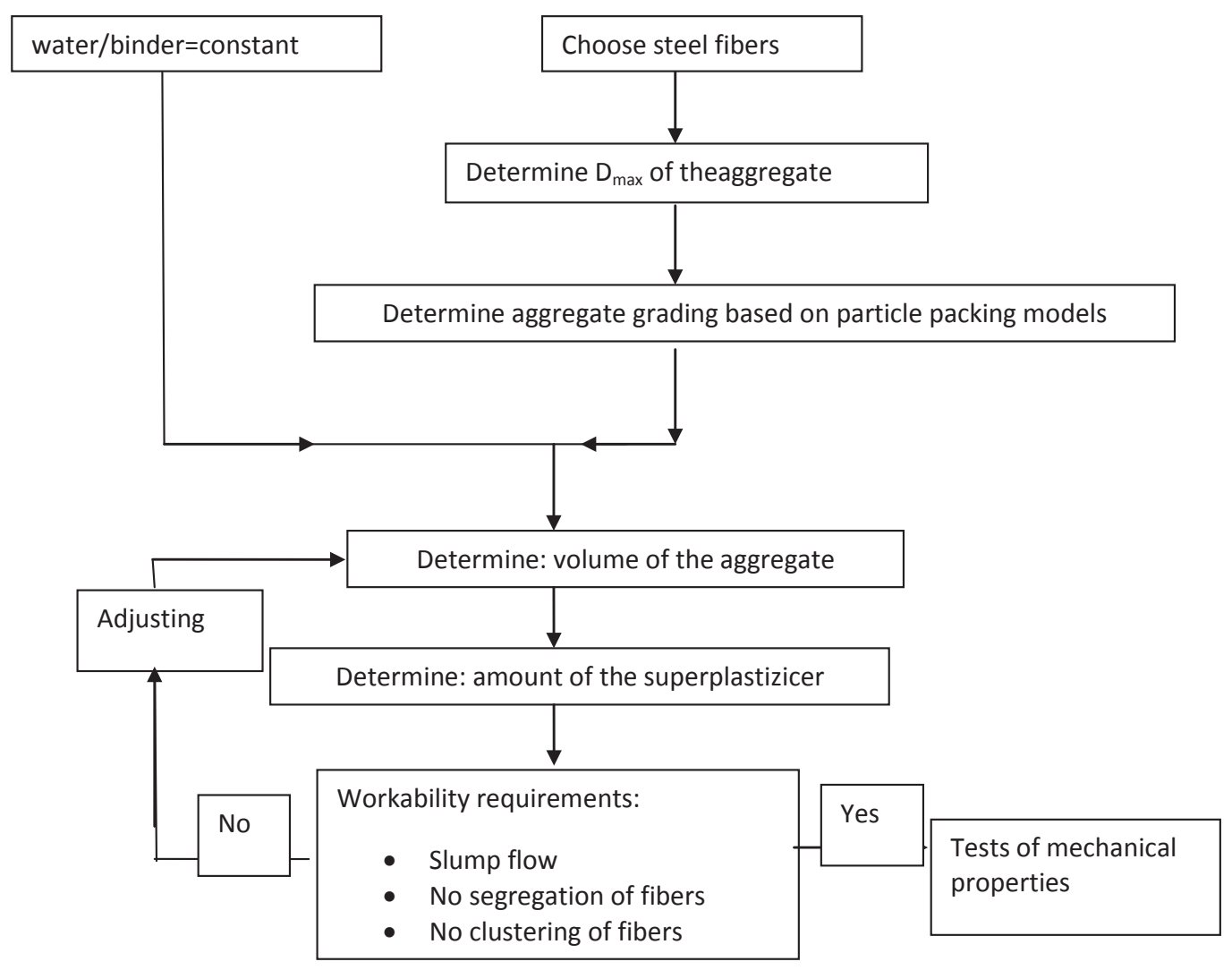

Figure 2.2 Methodology to design a UHPC mix. Adapted from Marković (2006)

Denarié et al. (2009a) used another methodology for the design of a UHPC recipe. The first three steps are:

- to choice the fibre dosage (length, shape, aspect ratio, material, amount of fibers)

- to choice the type and dosage of the binder, mineral additions and ultrafines

- to choice the superplasticiser

After them, the aggregates and paste content are chosen according to fibre dosage and workability requirements. The last step is to adjust water/fines, ultrafines/fines, fibrous matrix and paste content to accomplish with the requirements of permeability, mechanical properties and workability.

Denarié et al. (2009a) emphasized the need of develop UHPC with local components in order to facilitate the use of this material, and specially, to reduce its high cost. The author highlighted the initial potential problems on the workability of UHPC due the replacement of cement and superplasticizer from existing optimized UHPC formulations 
by locally accessible ones. Nonetheless, a new UHPC, in which the half of the cement was replaced by local limestone, was attained. The different tests to characterize its mechanical and protective properties showed comparable or even better results to those of the initial optimized formulation (Denarié et al. 2009a).

\subsubsection{Material Properties}

This new cementitious material offers a new designing scenario for Architects and Engineers: the use of more complex structural forms, removal of passive reinforcement, lighter and larger structures. For this to come true, and due to the significant differences between the mechanical properties of NSC and UHPC, the development of new professional codes and specifications are essential. Several countries, such as France, Japan and Australia have made steps to address this issue but USA is still behind (Misson 2008). A new ACI committee was formed in October 2011 with the goal to develop design guidelines for UHPC in North America.

This section describes the main UHPC characteristics as construction material. The hydration process, mechanical properties and durability performance of this new material are presented. A brief description of sustainable feature of UHPC is given, owing to the environmental impact is becoming an essential factor when deciding between different constructive alternatives.

\subsubsection{Hydration}

Morin et al. (2001) and Morin et al. (2002) described the hydration process of Reactive Powder Concrete (RPC) at early age. The authors pointed out the existence of a dormant period of approximately $30 \mathrm{~h}$ after adding water, followed by a strong heat released which lasts for around $12 \mathrm{~h}$. This dormant period was due to the high amount of superplastizicer (Morin et al. 2001; Morin et al. 2002). The degree of hydration at $70 \mathrm{~h}$ was $18 \%$ for a RPC with w/c equal to 0.21 and superplasticizer dry extract $1.5 \%$ as shown in Figure 2.3. This low degree of hydration is due to the low water/ binder ratio of 
UHPC formulations and provides a self-healing capacity for microcracks (Denarié et al. 2005).

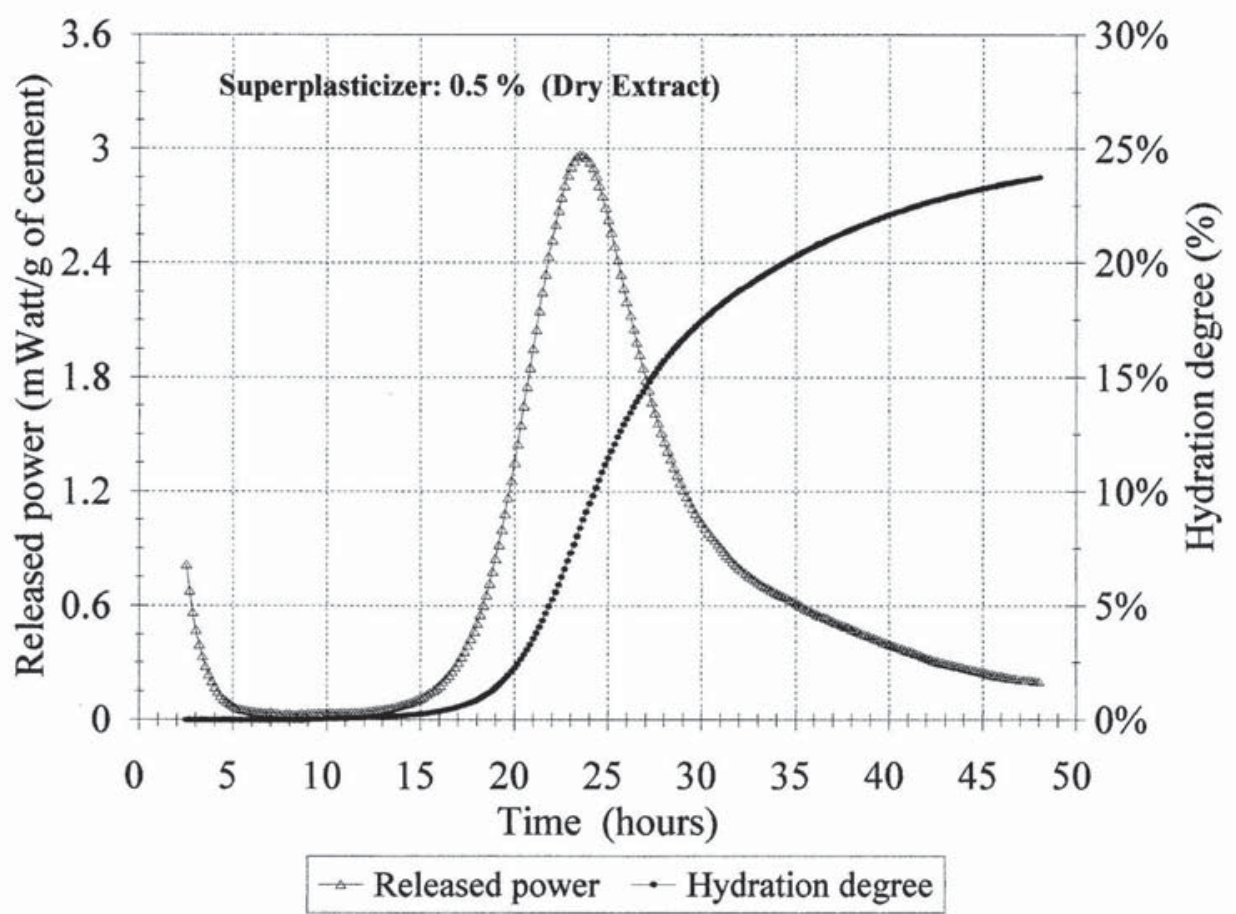

Figure 2.3 Dissipated power and degree of hydration of the RPC sample as a function of time. Morin et al. (2001)

\subsubsection{Mechanical Properties}

UHPC is an advanced cementitious material with remarkable mechanical properties: shows strain-hardening behavior under uniaxial tension and compression strength greater than $18 \mathrm{ksi}$ and tensile strength over $0.8 \mathrm{ksi}$ without heat treatment (Graybeal 2006). These characteristics make possible to considerably reduce the cross section of the structures, upon significantly decreasing the self-weight of the structures. Figure 2.4 shows clearly this material reduction that can be achieved by using UHPC. 


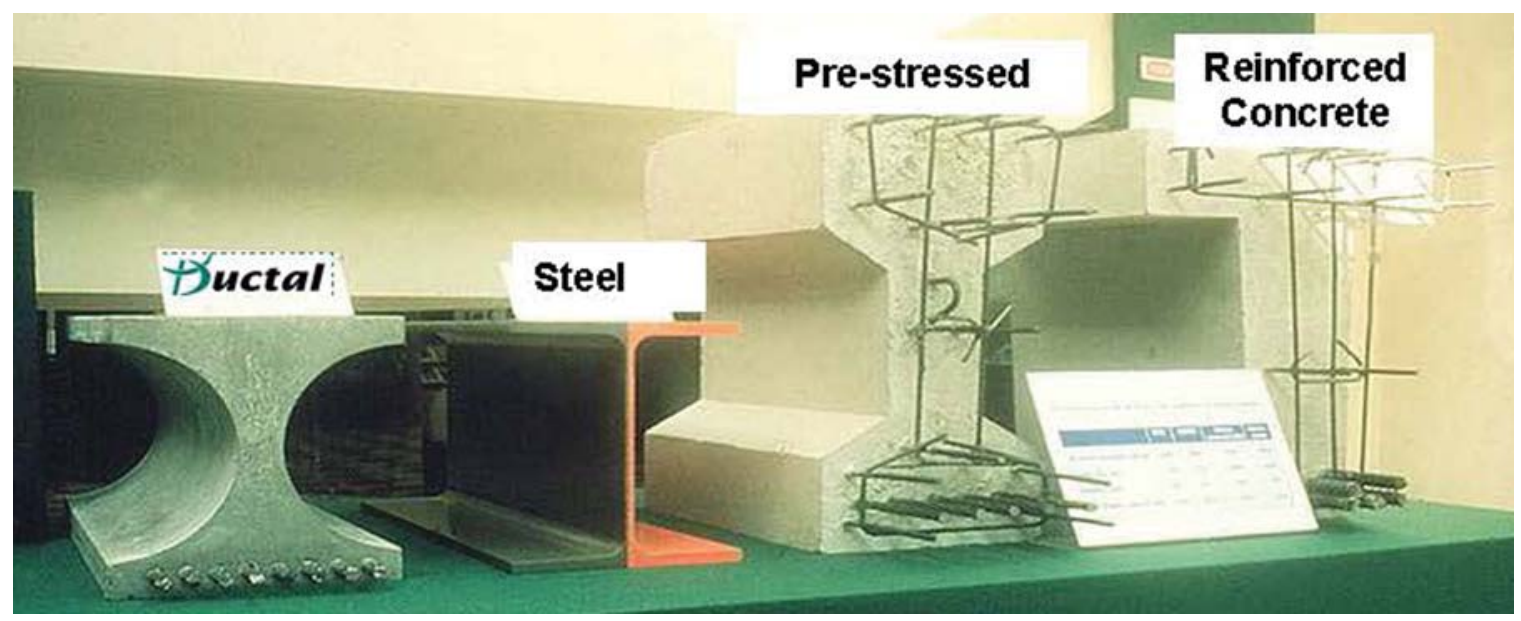

Note: UHPC cross section has not been optimize yet.

Figure 2.4 Comparison of different cross sectional areas of equal load carrying capacity. Courtesy of Lafarge North America

The main mechanical properties, along with other material properties of UHPC, are compared to those of NSC and HPC in Table 2.3. It can be seen that UHPC widely surpasses the compressive, tensile and flexural strengths of those of NSC and HPC. Besides this, it exhibits a ductile behavior (250 greater than NSC). UHPC has a higher density and a much lower porosity than other cementitious materials. 
Table 2.3

Comparison of UHPC material properties to NSC and HPC (High Performance Concrete). Modified from Misson (2008) and Peuse (2008)

\begin{tabular}{|c|c|c|c|}
\hline Mechanical Properties & NSC & HPC & UHPC \\
\hline Compression Strength, (ksi) & $3.0-6.0$ & $6.0-14.0$ & $25.0-33.0$ \\
\hline Tensile Strength, (ksi) & $0.36-0.45$ & $0.5-0.8$ & $1.2-1.4$ \\
\hline Poisson's Ratio & $0.11-0.21$ & $0.19-0.22$ & $0.19-0.24$ \\
\hline Creep Coefficient, $\mathrm{Cu}$ & 2.35 & $1.6-1.9$ & $0.2-0.8$ \\
\hline Porosity & $20-25 \%$ & $10-15 \%$ & $2-6 \%$ \\
\hline Fracture Energy, (k-in/in2) & $\begin{array}{l}0.00057- \\
0.00086\end{array}$ & - & $0.057-0.228$ \\
\hline Young's Modulus, (ksi) & $\begin{array}{l}2000- \\
6000\end{array}$ & $4500-8000$ & $8000-9000$ \\
\hline Modulus of Rupture 1st crack, (ksi) & $0.4-0.6$ & $0.8-1.2$ & $2.4-3.2$ \\
\hline Flexure Strength - ultimate, (ksi) & - & - & $3.0-9.0$ \\
\hline \multirow{2}{*}{ Shrinkage } & \multirow{2}{*}{-} & \multirow{2}{*}{$\begin{array}{l}\text { Post Cure 40- } \\
80 \times 10-5\end{array}$} & $\begin{array}{l}\text { Post Cure }<1 \times 10-5 \text {, } \\
\text { No Autogenous }\end{array}$ \\
\hline & & & $\begin{array}{l}\text { Shrinkage After } \\
\text { Cure }\end{array}$ \\
\hline Coefficient of Thermal Expansion (per ${ }^{\circ} \mathrm{F}$ ) & $\begin{array}{l}4.1- \\
7.3 \times 10-6\end{array}$ & - & $7.5-8.6 \times 10-6$ \\
\hline Ductility & - & - & 250 Times $>$ NSC \\
\hline Density (pcf) & 150 & $150-153$ & $153-159$ \\
\hline
\end{tabular}

Note: $1 \mathrm{ksi}=6.89 \mathrm{MPa} ; 1 \mathrm{in}=25.4 \mathrm{~mm} ; 1 \mathrm{in}-\mathrm{k}=0.113 \mathrm{kN}-\mathrm{m} ; 1 \mathrm{ft}=0.305 \mathrm{~m}$

One of the most distinctive properties of UHPC, as already mentioned, is its strainhardening behavior under tensile loading achieved by adding steel fibers in the mix. As shown in Figure 2.5, the strain-hardening behavior provides an ultimate strength greater than the first cracking strength. Other fiber reinforced concretes such as Engineered Cementitious Composites (ECC) or Slurry infiltrated composites exhibit this strain hardening response under tension, but do not exhibit negligible permeability. 
Consequently, while these materials have high mechanical performance due to its ability to develop finely distributed cracks, UHPC material involves a greater benefit for durability purposes (Denarié et al. 2005). It should be emphasized that not all UHPC materials present hardening behavior. As previously mentioned, the first RPC's exhibited a brittle behavior, due to this fact, the researchers started adding fibers to obtain a more ductile material. Kim et al. (2011) stated that is hard to obtain strain-hardening behavior using relatively small volume of fibers. They indicated that there is limited experimental evidence about the effect of matrix features on the overall pullout behavior of a single deformed steel fiber and its corresponding influence in the tensile response of the cement composite. The effect of the matrix strength and the different steel fibers on the tensile behavior of HPFRCC is still being studied by different researchers (Kim et al. 2011).

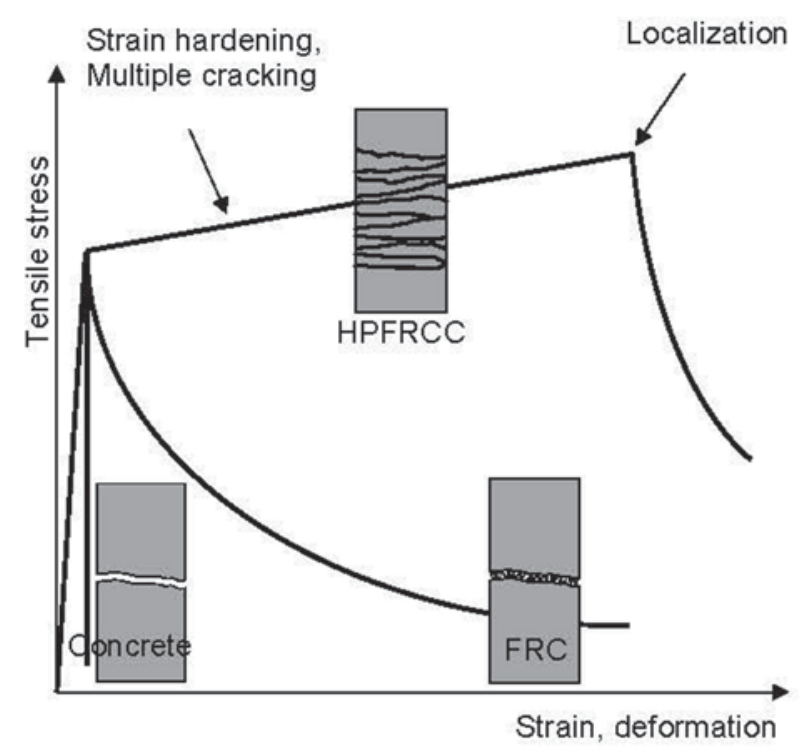

HPFRCC: High-performance fiber-reinforced cementitious composites (UHPC). FRC: Fiber-reinforced concrete

Figure 2.5 Graphic stress strain behavior of cementitious matrices under tension loading. Fischer (2004)

\subsubsection{Durability of UHPC}

Graybeal and Tanesi (2007) carried out an extensive experimental plan to evaluate the durability properties of UHPC through six standardized durability tests. All experimental 
results obtained in this project were based on tests performed on Ductal®JS1000. The results of the investigation are summarized in Table 2.4.

Table 2.4

Results of UHPC (Ductal®) with different curing treatments under different tests about durability. Adapted from Graybeal and Tanesi (2007)

\begin{tabular}{|c|c|c|c|c|}
\hline Test & Steam & Untreated & $\begin{array}{l}\text { Tempered } \\
\text { Steam }\end{array}$ & $\begin{array}{c}\text { Delayed } \\
\text { Steam }\end{array}$ \\
\hline $\begin{array}{c}\text { ASTM C1202-05; } \\
\text { Chloride Ion } \\
\text { Penetrability (coulombs) }\end{array}$ & $\begin{array}{l}\text { Negligible } \\
\text { (18) at } 28 \\
\text { days }\end{array}$ & $\begin{array}{c}\text { Very low } \\
\text { (360) at } 28 \\
\text { days } \\
\text { Negligible } \\
\text { (76) at } 56 \text { days }\end{array}$ & $\begin{array}{l}\text { Negligible } \\
(39) \text { at } 28 \\
\text { days } \\
\text { Negligible } \\
\text { (26) at } 56 \\
\text { days } \\
\end{array}$ & $\begin{array}{l}\text { Negligible } \\
\text { (18) at } 28 \text { days }\end{array}$ \\
\hline $\begin{array}{l}\text { AASHTO T259-80; } \\
\text { Chloride Ion } \\
\text { Permeability (kg/m3). } \\
\text { NSC average: } 0.051 \\
\text { kg/m3 }\end{array}$ & $\begin{array}{l}\text { Extremely } \\
\text { low }\end{array}$ & Extremely low & $\begin{array}{l}\text { Extremely } \\
\text { low }\end{array}$ & Extremely low \\
\hline $\begin{array}{l}\text { ASTM C 627-03: Scaling } \\
\text { resistance }\end{array}$ & No scaling & No scaling & No scaling & No scaling \\
\hline $\begin{array}{l}\text { ASTM C 944-99: } \\
\text { Abrasion resistance. } \\
\text { Weight Loss }(\mathrm{g}) \text { per } \\
\text { abrading }\end{array}$ & $\begin{array}{c}0.13 \text { (Cast) } \\
0.30 \text { (Blasted) } \\
0.17 \text { (Ground) }\end{array}$ & $\begin{array}{c}1.00 \text { (Cast) } \\
2.20 \text { (Blasted) } \\
0.73 \text { (Ground) }\end{array}$ & $\begin{array}{c}0.07 \text { (Cast) } \\
0.30 \text { (Blasted) } \\
0.20 \text { (Ground) }\end{array}$ & $\begin{array}{c}0.10 \text { (Cast) } \\
0.13 \text { (Blasted) } \\
0.13 \text { (Ground) }\end{array}$ \\
\hline $\begin{array}{c}\text { ASTM C 666-03 } \\
\text { (Procedure A): Freeze- } \\
\text { Thaw Degradation } \\
\text { Resistance. Relative } \\
\text { dynamic modulus after } \\
690 \text { cycles }\end{array}$ & $\begin{array}{c}\text { RDM: }>95 \% \\
\text { Deterioration: } \\
\text { nonexistent }\end{array}$ & $\begin{array}{c}\text { RDM: }>110 \% \\
\text { Deterioration: } \\
\text { nonexistent }\end{array}$ & $\begin{array}{l}\text { RDM: around } \\
100 \% \\
\text { Deterioration: } \\
\text { nonexistent }\end{array}$ & $\begin{array}{c}\text { RDM: around } \\
100 \% \\
\text { Deterioration: } \\
\text { nonexistent }\end{array}$ \\
\hline $\begin{array}{c}\text { ASTM C 1260-05: } \\
\text { Alkali-silica reaction } \\
\text { (ASR). Expansion at } 14 \\
\text { days }\end{array}$ & 0.013 & $\begin{array}{l}0.013 \text { with } 28 \\
\text { of curing } \\
\text { treatment }\end{array}$ & 0.005 & 0.001 \\
\hline
\end{tabular}

The conclusions that were drawn in this study were consistent with the results obtained by other authors, such as that UHPC had a high resistance to chemical penetration due to its very low level of water absorption, concretes with a low water/binder ratios and 
elevated silica fume content had a high scaling resistance and UHPC has excellent behavior under freeze-thaw cycling (Graybeal and Tanesi 2007).

As is well known, durability can be defined as the ability to resist weathering action, chemical attack and abrasion while maintaining desired engineering properties. On the basis of the above results, it is reasonable to state that one of the most beneficial features of UHPC is its excellent durability. This new extraordinary performance construction material is suitable to address the problems of rapidly deteriorating transportation infrastructures.

UHPC, due to its outstanding durability properties, could help to reduce waste and the environmental impacts that the construction industry produces, especially, in the repair field, where UHPC could be used on a protective barrier that prevents water or chemical penetration into infrastructure components, potentially resulting in a significant increase in service-life. As shown in Figure 2.6, UHPC is a breakthrough in the durability performance of concrete structures and entails a marked advancement even to HPC.

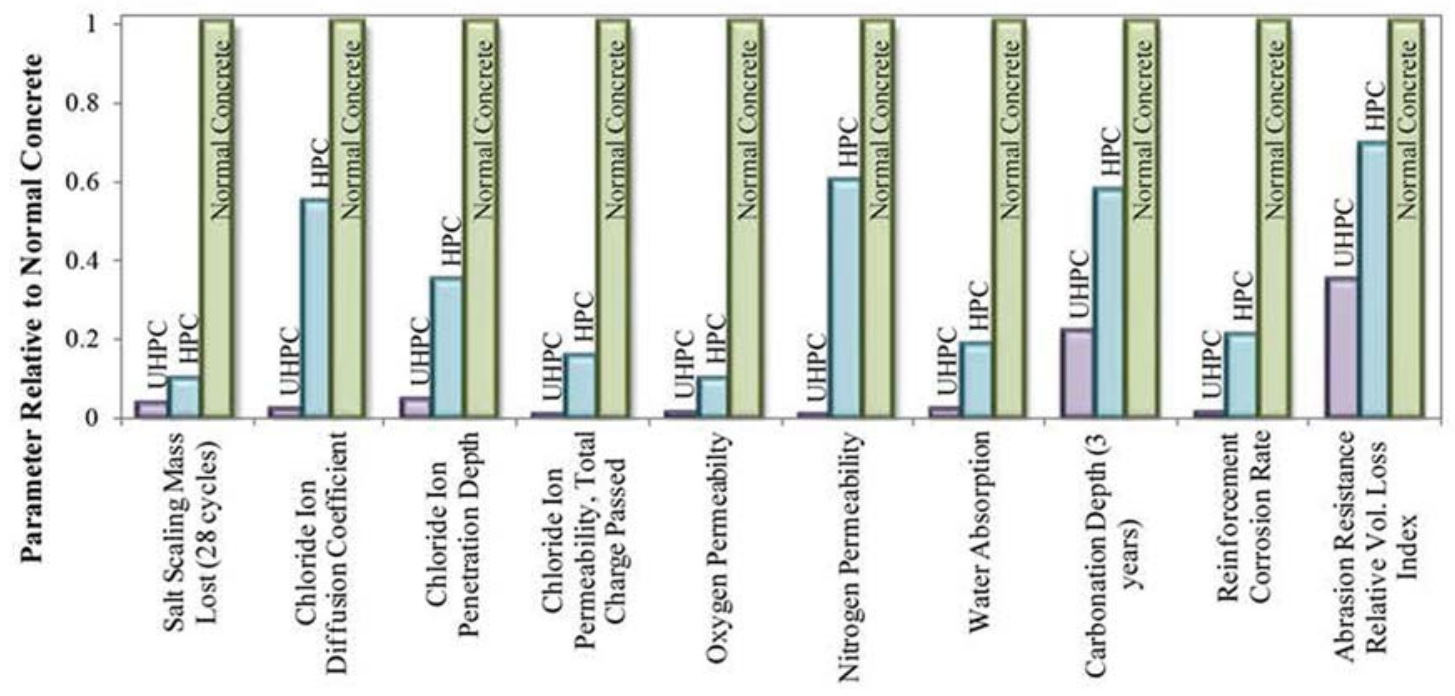

Figure 2.6 Durability property of UHPC with respect to Normal Concrete and HPC. Suleiman et al. (2008) 


\subsubsection{Environmental Impact of UHPC}

As previously described, the use of UHPC allows building cross sections with the same bearing capacity as those of reinforced concrete with significant reduction of dimensions. Consequently, it seems reasonable to state that the use of UHPC reduces the environmental impact of the construction industry. Nonetheless a further analysis needs to be done in order to draw that conclusion due to the fact that to yield $1 \mathrm{yd}^{3}$ of UHPC, large amounts of cement and superplasticizer need to be used. The Global Warning Potential (GWP), which is a relative measure that compares the greenhouse gas, is usually used for a realistic environmental analysis. Several researchers have compared, in terms of GWP, UHPC constructive solutions against others conventional alternatives such as a steel girder bridge with a cast-in-place concrete deck (Perry 2011) or a layer of normal concrete with waterproofing membrane (Denarié et al. 2009b). Their analysis showed that a reduction of raw materials consumption and of the emissions of $\mathrm{CO}_{2}$ can be achieved by using UHPC. Denarié et al. (2009b) stated that if durability of rehabilitation is taken into consideration, a UHPC, developed with common materials, would produce around the $50 \%$ of GWP of that of conventional solution (normal concrete with waterproofing membrane). In addition, UHPC will further increase the service life in order of magnitude higher than normal concrete.

\subsection{Rehabilitation of Concrete Structures}

Transportation agencies are spending a significant portion of their budgets to repair infrastructures that have failed prematurely due to rapid deterioration. There is an increasing need to develop better repair techniques that guarantee the success of the rehabilitation and keep the number of repeat interventions to a minimum. Currently, there is a wide range of solutions that have been used for the rehabilitation of concrete structures that are yielding excellent results for some specific applications, but still there is a need to develop a material capable of extending the service life longer than 20 years in harsh environmental with a minimum of maintenance. UHPC with its remarkable characteristics as a repair material for concrete structures in harsh environmental 
conditions and high loads could be an answer to this issue. However, a number of performance characteristics, such as bond and compatibility, need to be addressed.

\subsubsection{Causes of Concrete Deterioration}

It is convenient to recall the primary causes whereby a concrete structure might need to be repaired. The key for prolonging the service life of the repairs is to design a repair system that overcomes the causes whereby the concrete structure initially failed. These causes can be classified as:

- Errors in the phases of design or construction. The addition of excessive amount of water in concrete mixtures, insufficient concrete, inadequate joints, or construction defects are typical examples that fall into this group.

- Excessive deterioration due to chemical attack or aggressive environment. The most common causes of deterioration that form part of this group are alkaliaggregate reaction, sulfate attack, carbonation and freezing-thawing cycles.

- Corrosion of reinforcing steel. Corrosion usually takes place when the concrete exhibits cracks that allow the entrance of water or the passivity around steel bars created by the alkalinity of the portland cement is damaged through carbonation or bar damage. The corrosion of the steel creates additional cracking and/or delimitation that accelerates the corrosion process.

- Structural loads. Fatigue caused by continuous high loads or overload by heavy vehicles.

- Extraordinary actions: Damage caused by impacts, earthquakes or fire.

- Abrasion and erosion: Erosion is the progressive disintegration of the concrete by the abrasive or cavitation action of gases, fluids, or solids in motion, while abrasion is the wearing away of the concrete surface by rubbing and friction.

\subsubsection{Compatibility between Repair Material and Concrete Substrate}

Most of the failure in repairs are due to incompatibility between the new and old concretes or high shrinkage levels that lead debonding and cracking (Decter and Keeley 
1997). Emmons and Vaysburd (1996) defined the compatibility between two different materials as an equilibrium of physical, chemical and electrochemical properties and sizes between the new overlay and the old concrete substrate that will guarantee the success of the rehabilitation. The composite system has to bear up the different stresses caused by variations in the overlay material volume and chemical and electrochemical effects without delamination or cracking over the specific service life of the rehabilitation (Emmons and Vaysburd 1996). According to Morgan (1996), the dimensional compatibility is the most significant aspect above all mentioned, that is, the capacity of the rehabilitated region to withstand volume variations without loss of bond and delimitation and to transfer the applied loads without distress. Chemical compatibility implies that the new material does not stimulate alkali-aggregate reactivity (AAR) or affect in the reinforcing steel corrosion inhibition in the substrate (Morgan 1996). The main parameters of the repair material to take into consideration to decide which one to use for the rehabilitation of a concrete structure are discussed in the following points:

a) Bond strength at interface

The bond strength between the new and old materials is crucial for the success of the repair. A satisfactory bond provides strength under different loadings scenarios at least equal to that of the substrate. Some repairs materials need to use adhesives, such as epoxies or slurries, to ensure an acceptable bond with the substrate. The interface has to bear the stresses that may be caused by restrained volume changes or loads.

b) Curing requirement

It is desirable that the repair material harden as soon as possible in order to reduce the down time of the structure. In today's economic climate, rapid setting materials are highly advantageous for accelerated construction and repair scenarios.

c) Dimensional stability

Significant variations in the overlay material volume might cause cracking in the new material and increase of shear stresses in the interface, increasing the risk of delamination and cracking. 


\section{i. Shrinkage}

Permanent tensile stresses are developed in the concrete substrate due to the shrinkage restrained of the overlay material. These stresses can cause cracks or the delamination at the interface between the new and old materials (Rangaraju et al. 2008). ACI 546R-96 recommends the use of overlay materials that are shrinkage-free or capable of shrinking without losing bond and highlights that cementitious materials with a very low-cement ratio usually have a reduced shrinkage.

\section{ii. Creep}

Creep is defined as the deformation over time caused by a sustained load. Rangaraju et al. (2008) stated that the repair material must usually exhibit low creep except if the material is going to be loaded in tension, since in that situation, creep can compensate the negative effect of shrinkage.

\section{iii. Coefficient of thermal expansion}

If thermal expansion coefficient of the repair material differs significantly from that of the substrate, it might result in the failure of the rehabilitation due to stresses transferred to the bond interface in areas exposed to significant temperature variations. ACI 546R-04 (2004) stated that this factor is most important in those repairs which are going to be frequently subject to large temperature changes (ACI 546R-04 2004).

\section{iv. Modulus of elasticity}

A repair material with higher modulus of elasticity than that of the substrate attracts more loads causing an irregular stress distribution. For this reason, many researchers, such as Rangaraju et al. (2008) and Morgan (1996), usually recommend that the new material has a similar modulus of elasticity to that of the concrete substrate to ensure a uniform distribution of stress and minimize the potential failure of the new material.

d) Mechanical properties

The repair material has to exhibit adequate mechanical properties to bear and transfer the loads. 


\section{e) Constructability}

It is recommendable to use repair materials with similar construction methods to that of normal concrete in order to reduce the potential failures due to mistakes in the phase of construction. Properties such as self-consolidating behavior allow material to be placed without the need for vibration and often have good adhesion to the substrate without using any bonding agents have proven advantageous. Generally, fewer steps in the construction process can be correlated with a reduction in potential mistakes.

f) Durability properties

The overlay materials have to offer protection against all the different process that can deteriorate the structure such as chemical or water penetration, abrasion and freeze-thaw deterioration. The success of the repair and its final service life depends largely on the performance of the repair material as a barrier. Therefore, it is advisable that the repair material has a low permeability, but it needs to be emphasized that all protection that an overlay with a low permeability offers, it would be in vain if there are cracks along it (Emmons and Vaysburd 1996).

g) Cost

Cost of the repair material has a significant impact on the final choice of the material used for the rehabilitation, but it should not be put before the performance characteristics. A poor choice of repair material would cause the earlier failure of the rehabilitation. Cost needs to be tied to the expected service life in order to have an adequate economic analysis of the repair.

\subsubsection{Common Repair Materials}

ACI 546R-04 sorts the available materials to rehabilitation of concrete structures into two different groups: cementitious materials and polymer materials. Table 2.5 summarizes some of the most common repair materials used in current practice. 
Table 2.5

Comparison of the most common repair materials. Adapted from ACI 546R-04

\begin{tabular}{|c|c|c|c|c|}
\hline & Material & Advantages & Limitations & Applications \\
\hline \multirow{12}{*}{ 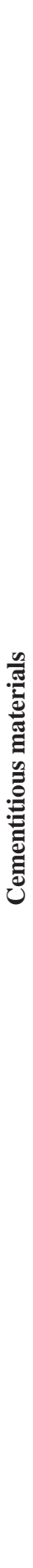 } & $\begin{array}{l}\text { Conventional } \\
\text { concrete }\end{array}$ & Easy to handle. Low cost. & $\begin{array}{l}\text { Not appropriate in harsh } \\
\text { environment. Potential problems } \\
\text { due to shrinkage. }\end{array}$ & $\begin{array}{l}\text { For thick sections } \\
\text { and large volumes } \\
\text { of materials. }\end{array}$ \\
\hline & $\begin{array}{l}\text { Conventional } \\
\text { mortar }\end{array}$ & Easy to handle. Low cost. & $\begin{array}{l}\text { Greater drying shrinkage. Not } \\
\text { adequate in harsh environment. }\end{array}$ & $\begin{array}{l}\text { Same applications } \\
\text { as conventional } \\
\text { concrete but for } \\
\text { small repairs. }\end{array}$ \\
\hline & Dry pack & $\begin{array}{l}\text { Minimum shrinkage. } \\
\text { Durable. }\end{array}$ & $\begin{array}{c}\text { Performance depends on curing. } \\
\text { Not adequate for shallow } \\
\text { depressions. }\end{array}$ & $\begin{array}{l}\text { For large or small } \\
\text { cavities if } \\
\text { compactions allows } \\
\text { it. For Vertical and } \\
\text { overhead surfaces. }\end{array}$ \\
\hline & Ferrocement & $\begin{array}{l}\text { High tensile strength-to- } \\
\text { weight ratio and cracking } \\
\text { behavior. No formwork } \\
\text { required. }\end{array}$ & $\begin{array}{l}\text { It merely is restricted by the nature } \\
\text { of the repair. }\end{array}$ & $\begin{array}{c}\text { Particularly } \\
\text { appropriate for } \\
\text { curved surfaces. }\end{array}$ \\
\hline & $\begin{array}{l}\text { Fiber-reinforced } \\
\text { concrete }\end{array}$ & $\begin{array}{l}\text { High resistance to plastic } \\
\text { shrinkage. The addition of } \\
\text { fibers provides reinforcing } \\
\text { in thin sections. }\end{array}$ & $\begin{array}{l}\text { Low workability. Potential } \\
\text { corrosion. }\end{array}$ & $\begin{array}{c}\text { Overlays of } \\
\text { concrete pavements, } \\
\text { slope stabilization, } \\
\text { repair of structures } \\
\text { subjected to } \\
\text { vibration loading. }\end{array}$ \\
\hline & Cement grouts & $\begin{array}{l}\text { Easy to handle. Low cost. } \\
\text { Minimum shrinkage. }\end{array}$ & $\begin{array}{l}\text { Usually the minimum crack width } \\
\text { should be about } 1 / 8 \text { in. }\end{array}$ & $\begin{array}{c}\text { To fill large } \\
\text { dormant cracks } \\
\text { around or under a } \\
\text { concrete structure. }\end{array}$ \\
\hline & Chemical grouts & $\begin{array}{l}\text { Short setting time. } \\
\text { Moist Environments. }\end{array}$ & $\begin{array}{l}\text { Expensive. Skilled labor. Short } \\
\text { working time. }\end{array}$ & To fill fine cracks. \\
\hline & $\begin{array}{c}\text { Low Slump } \\
\text { Dense Concrete }\end{array}$ & $\begin{array}{l}\text { Rapid gain strength. } \\
\text { Service live up to } 20 \\
\text { years. Reduced } \\
\text { permeability. }\end{array}$ & $\begin{array}{c}\text { Consolidation problems. } \\
7 \text { days moist curing. Galvanic } \\
\text { corrosion. Drying shrinkage } \\
\text { cracks. }\end{array}$ & $\begin{array}{l}\text { Overlay due to its } \\
\text { high abrasion } \\
\text { resistance and good } \\
\text { quality. }\end{array}$ \\
\hline & $\begin{array}{l}\text { Magnesium } \\
\text { phosphate } \\
\text { concrete and } \\
\text { mortars }\end{array}$ & $\begin{array}{l}\text { Similar handling to NSC. } \\
\text { Rapid strength gain. Short } \\
\text { setting times. }\end{array}$ & $\begin{array}{l}\text { Potential carbonation problems. } \\
\text { Poor strength against impacts. }\end{array}$ & $\begin{array}{l}\text { When short down } \\
\text { time is essential } \\
\text { (overlays, airports). } \\
\text { Cold weather. }\end{array}$ \\
\hline & $\begin{array}{l}\text { Preplaced- } \\
\text { aggregate } \\
\text { concrete }\end{array}$ & $\begin{array}{c}\text { Low shrinkage. No } \\
\text { segregation. Underwater } \\
\text { repairs. }\end{array}$ & Skilled labor. & $\begin{array}{c}\text { Extensive repairs. } \\
\text { When placing might } \\
\text { be an issue. }\end{array}$ \\
\hline & $\begin{array}{l}\text { Rapid-Setting } \\
\text { Cements }\end{array}$ & Short setting times. & $\begin{array}{l}\text { Not appropriate in harsh } \\
\text { environment. }\end{array}$ & $\begin{array}{l}\text { When short down } \\
\text { time is essential. }\end{array}$ \\
\hline & Shotcrete & $\begin{array}{l}\text { Transported several } \\
\text { hundred feet to area with } \\
\text { restricted access. }\end{array}$ & $\begin{array}{l}\text { High skilled labor. High sensitive } \\
\text { to surface preparation of the } \\
\text { substrate. }\end{array}$ & $\begin{array}{l}\text { Economical in thin } \\
\text { section with large } \\
\text { surface area with } \\
\text { irregular shapes }\end{array}$ \\
\hline
\end{tabular}


Table 2.5, continued

\begin{tabular}{|c|c|c|c|c|}
\hline \multirow{2}{*}{ 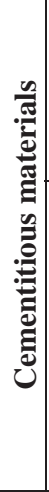 } & $\begin{array}{l}\text { Shrinkage- } \\
\text { compensating } \\
\text { concrete }\end{array}$ & $\begin{array}{l}\text { Minimum shrinkage } \\
\text { cracking, joints to control } \\
\text { shrinkage are not necessary }\end{array}$ & $\begin{array}{l}\text { Not appropriate in harsh } \\
\text { environment. Skilled labor for } \\
\text { mixing, placing and curing. }\end{array}$ & $\begin{array}{l}\text { Minimum } \\
\text { shrinkage in slabs, } \\
\text { pavements, bridge } \\
\text { decks and } \\
\text { structures. }\end{array}$ \\
\hline & $\begin{array}{l}\text { Silica-Fume } \\
\text { Concrete }\end{array}$ & $\begin{array}{c}\text { High Strength. High } \\
\text { abrasion-erosion resistance. } \\
\text { High durability. Similar } \\
\text { handling to NC. }\end{array}$ & $\begin{array}{l}\text { Potential shrinkage problems. Wet } \\
\text { curing for } 7 \text { days with minimum } \\
\text { temperature of } 40^{\circ} \mathrm{F} \text {. }\end{array}$ & $\begin{array}{l}\text { Hydraulic } \\
\text { structures } \\
\text { subjected to } \\
\text { abrasion-erosion. } \\
\text { Overlays and } \\
\text { parking subjected } \\
\text { to chloride } \\
\text { penetration. }\end{array}$ \\
\hline \multirow{3}{*}{ 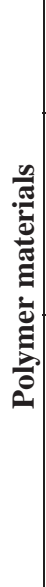 } & $\begin{array}{l}\text { Polymer- } \\
\text { impregnated } \\
\text { concrete }\end{array}$ & $\begin{array}{l}\text { Improvement of durability } \\
\text { characteristics. }\end{array}$ & $\begin{array}{c}\text { Durability issues if not all cracks are } \\
\text { sealed. }\end{array}$ & $\begin{array}{l}\text { Wide range of } \\
\text { applications. Long- } \\
\text { term performance. }\end{array}$ \\
\hline & $\begin{array}{l}\text { Polymer- } \\
\text { modified } \\
\text { concrete (Latex } \\
\text { Modified } \\
\text { Concrete) } \\
\end{array}$ & $\begin{array}{l}\text { Excellent long-term } \\
\text { performance. Minimum } \\
\text { bond failure. Similar } \\
\text { handling to NSC except the } \\
\text { curing treatment. }\end{array}$ & $\begin{array}{l}\text { Placing and curing at } 45 \text { to } 85^{\circ} \mathrm{F} \text {. } \\
\text { Susceptible to shrinkage cracking } \\
\text { during placement. Modulus of } \\
\text { elasticity lower than that of } \\
\text { concrete. }\end{array}$ & $\begin{array}{l}\text { Mostly used in } \\
\text { overlays for bridge } \\
\text { decks, parkings } \\
\text { and floors. }\end{array}$ \\
\hline & $\begin{array}{l}\text { Polymer } \\
\text { concrete }\end{array}$ & $\begin{array}{l}\text { Rapid curing. High } \\
\text { strength. Similar handling } \\
\text { to NSC. }\end{array}$ & $\begin{array}{l}\text { High coefficient of thermal } \\
\text { expansion. Modulus of elasticity } \\
\text { might be lower than that of concrete. } \\
\text { Poor performance at high } \\
\text { temperatures. }\end{array}$ & $\begin{array}{l}\text { When short down } \\
\text { time is essential. } \\
\text { Repairs where only } \\
\text { thin sections can } \\
\text { be applied. High } \\
\text { protection against } \\
\text { chemical attack. }\end{array}$ \\
\hline
\end{tabular}

Normal concrete solution does not exhibit a good performance in harsh environments. The main shortcomings of the polymer materials are usually the mismatch of their thermal expansion coefficients with that of concrete substrate, their sensitivity to curing conditions and their poor performance at high temperatures. These features highlight the potential for alternative solutions. UHPC offers high mechanical properties and a rapid setting behavior.

\subsubsection{Rehabilitations of Concrete Structures using UHPC}

This section describes some UHPC applications as repair material and discusses briefly the potential compatibility between UHPC and NSC. 


\subsubsection{UHPC applications as repair material}

UHPC was used in the repairs of locks damaged by abrasion-erosion, in the Netherlands in 1988 and 1989. Inspections carried out in 2003 showed that those floors with a layer of 1 in $(25 \mathrm{~mm})$ UHPC did not exhibit any wear, but unprotected concrete did. This finding was attributed to resistance of UHPC against extreme cavitation erosion (Buitelaar 2004).

Buitelaar (2004) as well highlighted the success of a rehabilitation made with UHPC of concrete piles of a jetty in Venezuela which were deteriorated by chloride corrosion. The piles strengthened with UHPC did not show any visible damage after 13 years while repairs made with conventional concrete in similar conditions exhibited damage after 2-5 years. After the success of this experience, which demonstrated that UHPC has outstanding performance against chloride penetration and high bearing capacity, other offshore concrete structures have been repaired in Venezuela and the North Sea (Norway).

SAMARIS and ARCHES, researches as part of an extensive European research program, that aimed investigating the potential use of UHPC for the rehabilitation and strengthening of reinforced concrete structures, carried out several full scale field applications (Denarié 2004; Denarié et al. 2005; Denarié et al. 2009b; Denarié et al. 2009a). These applications were deemed successful and confirmed the promise of using UHPC for rehabilitation and strengthening. A summary of these applications is provided below (Denarié et al. 2009b):

- Rehabilitation of a bridge over river "La Morge" (2004): The bridge was built in the 1940's and had a span length of $10 \mathrm{~m}$. UHPC was used to replace the downstream and upstream curbs and the upper surface of the bridge deck because they were in poor conditions due to chloride induced corrosion.

- UHPC protection layer on a crash barrier wall: a layer of UHPC was applied to cover the concrete crash barrier walls of a highway bridge in Zürich (Switzerland) in 2006 . 
- Rehabilitation of a bridge pier using prefabricated UHPC shell elements in Zurich (Switzerland) in 2007: 1.57 in thick prefabricated UHPC shell elements were used to protect the existing 40 year old reinforced concrete bridge pier.

- Strengthening of an industrial floor in Geneva (Switzerland) in 2007: 1.57 in thick UHPC layer with rebars was poured on the top of the remaining reinforced concrete slab for the floor of a fire bridage building that had insufficient load carrying capacity.

- Repair of the Dalvazza Bridge (Switzerland) in 2008: UHPC was used to repair the deck of the bridge. Gravel was sprayed on the fresh UHPC to create the adequate surface for the traffic instead of using a bituminous pavement.

\subsubsection{Compatibility between UHPC and Concrete Substrate}

The potential compatibility of UHPC with the normal concrete substrate is presented.

a) Bond strength with the substrate

The success of any rehabilitation depends on the bond performance. Lee et al. (2005) combined the slant-shear test with freeze-thaw cycling conditions to assess the bond strength and bond durability of RPC with regular concrete. Results showed a good bond between both materials that is affected negatively by the inclusion of freeze-thaw cycles. However, further research is needed due to the fact that the slant-shear specimens had an interface angle of $45^{\circ}$. Several researchers have shown that a greater joint angle from horizontal produces a more severe state of shear and compression stresses along the interface.

b) Curing requirement / setting properties

Graybeal (2006) showed that the compressive strength of UHPC in ambient curing is almost non-existent at 1 day after casting. Once initial set takes place, UHPC promptly gains strength up to $9.4 \mathrm{ksi}$ at 48 hours approximately. This rapid strength gain would offer the possibility of using the infrastructure in a short time after repairing.

c) Dimensional stability 
Denarié et al. (2005) stated that restrained shrinkage tests on UHPC samples at early ages resulted in the development of stresses of approximately the $45 \%$ of the first crack tensile strength. The higher modulus of elasticity of UHPC to that of NSC is compensated by its higher compressive, bending and tensile strengths. Namely, the UHPC can absorb most part of the loads without failing due to its outstanding mechanical properties. Furthermore, Denarié et al. (2005) highlighted the strain hardening behavior of UHPC as another characteristic that could help compensate for its higher modulus of elasticity.

d) Mechanical properties

As previously mentioned, UHPC has sufficient mechanical properties to bear and transfer the loads to which it is going to undergo.

\section{e) Constructability}

Aside from different mixing process, UHPC has a similar placing and curing treatment practices normal concrete due to its cementitious character. Denarié et al. (2005), based on the experience of several bridge rehabilitations, highlighted that several difficult steps, such as installation of waterproofing membranes and compaction by vibration, can be skipped by using UHPC. Therefore, the self-consolidating behavior of UHPC provides and advantageous feature when considering placing. Nevertheless it is required that UHPC accommodates to specific slopes in some occasions, such as the longitudinal or transversal slopes of bridge, for these situations, it is possible to develop different formulations of UHPC in order to capable them of accommodate to different slopes of the substrate (Denarié et al. 2009b).

\section{f) Durability properties}

As previously stated, UHPC exhibits extraordinary performance under harsh environments that are markedly better than other materials, such as normal concrete or high performance concrete, as shown in Table 2.4. It must be stressed that UHPC still offers these outstanding protective properties under ambient curing treatment (Graybeal and Tanesi 2007).

g) Cost 
UHPC is a cost-effective solution if the service life is taken into consideration, as shown by Denarié et al. (2005) in his economic analysis of the rehabilitation of bridge over La Morge River in which the cost of the rehabilitation by using UHPC was compared to that that would have cost by a traditional solution composed of mortar and waterproofing membrane. They stated that the UHPC solution is only $12 \%$ more expensive that the "traditional" alternative. If factors such as the longer service-life of UHPC and short down time are into consideration, it would be expected that the use of UHPC is cheaper from a life-cycle perspective. Furthermore, the UHPC alternative would be even cheaper if it starts to become a common practice among engineers.

Denarié et al. (2009b) developed new UHPC recipes in which the 50\% of the amount of cement from the optimize formulation (CEMTECmultiscale ${ }_{\mathbb{B}}$ ) was replaced by local limestone filler, reducing considerably the cost and environmental impact. Fidjestol et al. (2012) also succeeded in developing a UHPC made up with local sand, cement, fly ash and admixtures. The author emphasized the reduction of the logistics cost if locally available materials are used.

\subsection{Factors that affecting the Bond Strength}

The bond strength between two different concrete materials is influenced by many factors, such as substrate surface (wetting conditions, roughness, presence of microcracks, cleanliness), compaction method, curing process, concrete substrate (strength and aggregate gradation), use of bonding agents, age of the bond, and overlay material (strength and thickness), (Beushausen 2010; Momayez et al. 2005; Silfwerbrand 1990). There is a broad consensus among researchers that substrate surface preparation methods influence the bond. For example, hydrodemolition followed by power washing has been shown to be the best unsound concrete removal and surface preparation technique. Impact methods (scabbling, milling, scarifying) present the advantage of being the most economical treatment to remove the damaged concrete, but one major shortcoming is that they fracture the remaining concrete surface, causing a low fracture tensile strength. Substrate surfaces prepared by these methods usually achieve half of the bond strength of that prepared by hydrodemolition method (Hindo 1990; International 
Concrete Repair Institute 1997; Silfwerbrand 1990; Sprinkel 1997). On the other hand, there are conflicting opinions between engineers about how other factors affect the bond. The moisture condition of the substrate material is one example. It is hard to draw a general conclusion about how the saturated concrete substrate helps to improve the bond strength because it depends on the sorptivity and porosity characteristics of the substrate material. A large porosity could produce a weak interface zone due to the lack of water for proper hydration, but in contrast a low porosity could reduce the mechanical interlock between the substrate and overlay materials (Beushausen 2010). Momayez et al. (2005) stated that the bond strength as well depends on the loading scenario. According to his experimental results, the measured bond strength decreases with the test method in the next order: slant shear, bi-surface shear, splitting and pull off.

\subsubsection{Tests Methods to evaluate Bond Strength}

The actual tests used for assessing the bond strength between concrete substrate and overlay material are classified into three main categories according to the stress measured: tension, pure shear, and a combined state of shear and compression stresses (Espeche and Leon 2011; Momayez et al. 2005).

The first group includes all those tests that evaluate the bond strength under tension stress, being the pull off test (a), splitting tensile test $(m, n)$ and direct tension test (l) the most accepted methods of this first group (Espeche and Leon 2011).

The second category covers all those tests that measure the pure shear stress. Torsion bond test (b), the direct shear test (c), the modified vertical shear bond test (f), the pushout test (j), the bisurface shear test (k), and the guillotine test (g, h, i) fall in this group. The main challenge with the pure shear tests is properly subjecting the interface between both materials to only shear stress without transmitting any bending stress (Espeche and Leon 2011). One example of this is given by Sprinkel (1997) who states that the guillotine should not be considered as a reliable indicator of adhesion strength due that its results highly depend on the alignment of the bond line, if it is not perfectly centered, the 
apparatus will measure the shear strength of either the overlay and old materials. Due to this, the pull off test is more suitable test to carry out in situ rather than the guillotine.

The third category of bond strength tests includes all those tests in which the bond is under a combined state of shear and compression stresses. The shear-compression test (d) and the slant shear test $(\mathrm{k})$ belong to this category (Espeche and Leon 2011).

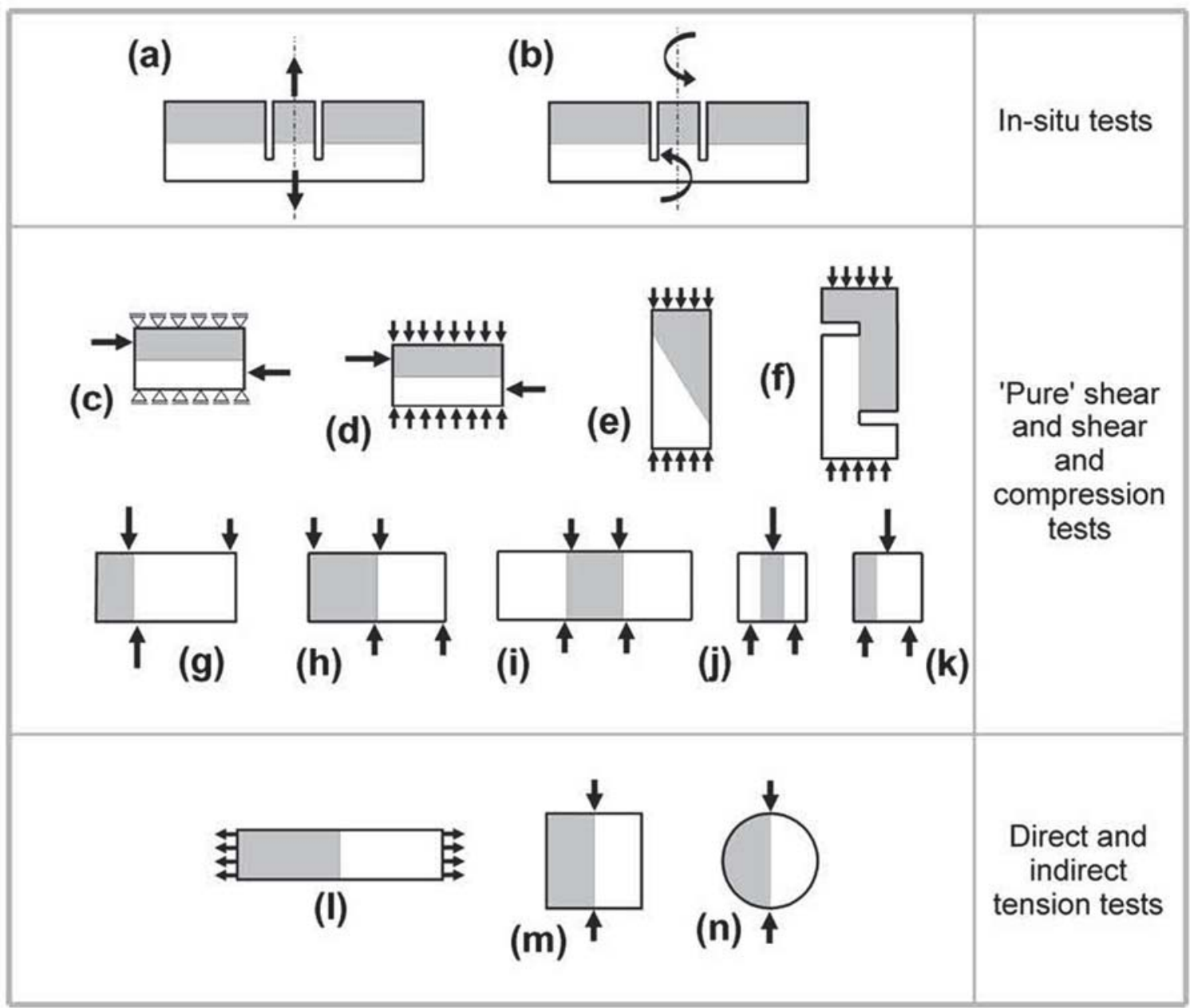

Figure 2.7 Most common bond strength tests. Espeche and Leon (2011)

\subsubsection{Surface Preparation}

One of the most critical steps in the rehabilitation of concrete structures is the removing of the unsound concrete and preparation of the substrate surface. An adequate surface treatment does not damage the substrate and provides sufficient roughness assure a good 
bond between the substrate and the overlay materials. International Concrete Repair Institute (1997) categorizes the different mechanisms to remove damaged concrete into the following groups:

- Erosion (grinding, high-pressure water jetting)

Hydro-demolition, also called hydro-jetting or hydro-blasting, followed by power washing creates an outstanding bonding surface with no microcracks in the treatment surface. Because of this, this method has arisen as the most effective way to remove damage concrete and also provides an irregular wavy surface profile. The water pressure applied is often in the range from 12,000 to 35,000 psi. This technique presents the advantage that does damage in the reinforcing steel when removing concrete from underneath, and also removes rust accumulation. Another advantage is the increase of micropores in the cement paste (Hindo 1990; Silfwerbrand 1990; Sprinkel 1997).

Grinding methods are used to remove deposit and to smooth a surface profile. This method consists in applying a grinding stone or disc under pressure to the surface until a flat surface is obtained (International Concrete Repair Institute 1997).

- Impact (scarifying, scabbling, milling/rotomilling, needle scaling)

Milling treatments consist of numerous teeth mounted on a rotating drum impacting on the concrete surface. This technique presents the advantage of being the most economical method to remove the concrete. Its main shortcoming is that it fractures the concrete surface that remains, causing a low fracture tensile strength. The overlay material frequently delaminates if the repair material is placed on the milled surface without applying a shotblasted, or another surface treatment to remove all of the microfractured surface on the concrete (Sprinkel 1997).

Scarifying and needle scaling are similar methods to milling treatment and are based on impacting the concrete surface by means of rotatory action of thoothed washers (scarifying) and pointed tips of a pile of steel rods pulsed by compressed air (needle scaling). Both of them have a moderate risk of creating a bruised layer in the remaining 
substrate while the scarifying method has a high risk of introducing microcraks (International Concrete Repair Institute 1997).

- Pulverization (steel shotblasting, abrasive blasting)

Shot-blasting treatment is a useful surface treatment to remove concrete up to a depth of $1 / 4$ inch, providing a roughed surface without dust. The treatment consists of blasting steel shot at high velocity onto the concrete surface. Based on bonding tests in the field, a macrotexture of $1.5 \mathrm{mn}$ suggests that the surface has been enough shot-blasted to provide an adequate roughness (International Concrete Repair Institute 1997; Sprinkel 1997).

Sandblasting or abrasive blasting methods use compressed air mixed with an abrasive medium to remove damaged concrete surfaces or to clean the steel bars. Shot-blasting and sand blasting have a low risk of producing microcracks in the remaining concrete (International Concrete Repair Institute 1997).

- Expansive pressure (steam: flame blasting, water: high-pressure water jetting)

Flame scaling or flame blasting method consists in creating tensile stress near the concrete surface that fracture both matrix and aggregate by means of the expansive force of superheated pore water. This method might cause a bruised layer in the remaining concrete (International Concrete Repair Institute 1997).

\subsubsection{Failure Envelope of the Bond Interface}

Austin et al. (1999) stated that each different bonding test provides a narrow representation of bond behavior, therefore, in order to fully understand the characteristics of bonded materials, diverse bonding tests that produce different stress states should be applied. A bond failure envelope can be drawn from the different states combinations

obtained by means of the different loading configurations. For this purpose, Robins and Austin (1995) proposed a simplified failure envelope of straight line based on an adhesion-friction relationship, where the adhesion is the tensile adhesive strength between the new and old materials and the friction is a degree of the shearing resistance, namely, friction and interlock effects. It can be noted that the compressive stress normal 
to the bond interface is directly proportional to the shear stress along the interface in order obtain the bond failure.

The cohesion value between old and new concretes is usually 2-3 greater than the direct shear strength. Austin et al. (1999) obtained that the pure shear bond strength is 2.13 times the tensile bond strength, while Silfwerbrand (2003) stated that the ratio between pure shear stresses (torsion test) and direct tensile strength varies between 1.9 and 3.1 for cast-in-place objects.

Espeche and Leon (2011) stated that the friction angle is a function of the roughness of the concrete substrate and can be estimated from the graphical slope of the failure envelope constructed mainly from carrying out the slant shear test with different joint angles. Note that the failure of the samples has to occur along the interface (slinding mode) in order to use the data for drawing the failure envelope as stated by Robins and Austin (1995) who only drew the failure envelope for those composite samples in which failures occurred along the interface. Espeche and Leon (2011) summarized the different friction angles for concrete-to-concrete given by several authors for the interface between two cementitious materials, as shown in Table 2.6.

Table 2.6

Friction angles (in degrees) as a function of the degree of roughness of the concrete substrate. Adapted from Espeche and Leon (2011)

\begin{tabular}{cccc}
\hline \multirow{2}{*}{ Roughness degree } & Surface treatment & $\begin{array}{c}\text { ICRI } \\
\text { profiles }\end{array}$ & $\begin{array}{c}\text { Friction } \\
(\phi)\end{array}$ \\
\hline Low & Natural wooden mould, saw-cut surface & $1-3$ & $37-40$ \\
\hline Medium & Sandblasted, steel brushed & $4-6$ & $43-46$ \\
\hline High & $\begin{array}{c}\text { Splitting, hydro-demolition, hammering } \\
\text { procedure with energy control }\end{array}$ & $7-9$ & $50-53$ \\
\hline
\end{tabular}

Robins and Austin (1995) stated that the Mohr's circle, for a given material strength in compression, fixes the maximum shear stress that can be obtained in the bond interface before the failure in the material takes place. The intersection of the Mohr's circle in compression with the $\tau / \sigma$ ratio straight line, fixed by the inclination of the bond interface in the slant shear test, set an upper bound to the bond strength that can be measured by 
such test configuration, this upper bound is represented by point $\mathrm{u}_{\mathrm{b} 1}$ in Figure 2.8. Another way to explain it, if the bond failure envelope intercepts with the $\tau / \sigma$ ratio straight line outside the Mohr's circle in compression, the bond strength cannot be determined due to the fact that the failure will occur in the material instead of the bond interface. The same concept can be applied to the Mohr's circle in direct tension or pure shear, represented by points $\mathrm{u}_{\mathrm{b} 2}$ and $\mathrm{u}_{\mathrm{b} 3}$.

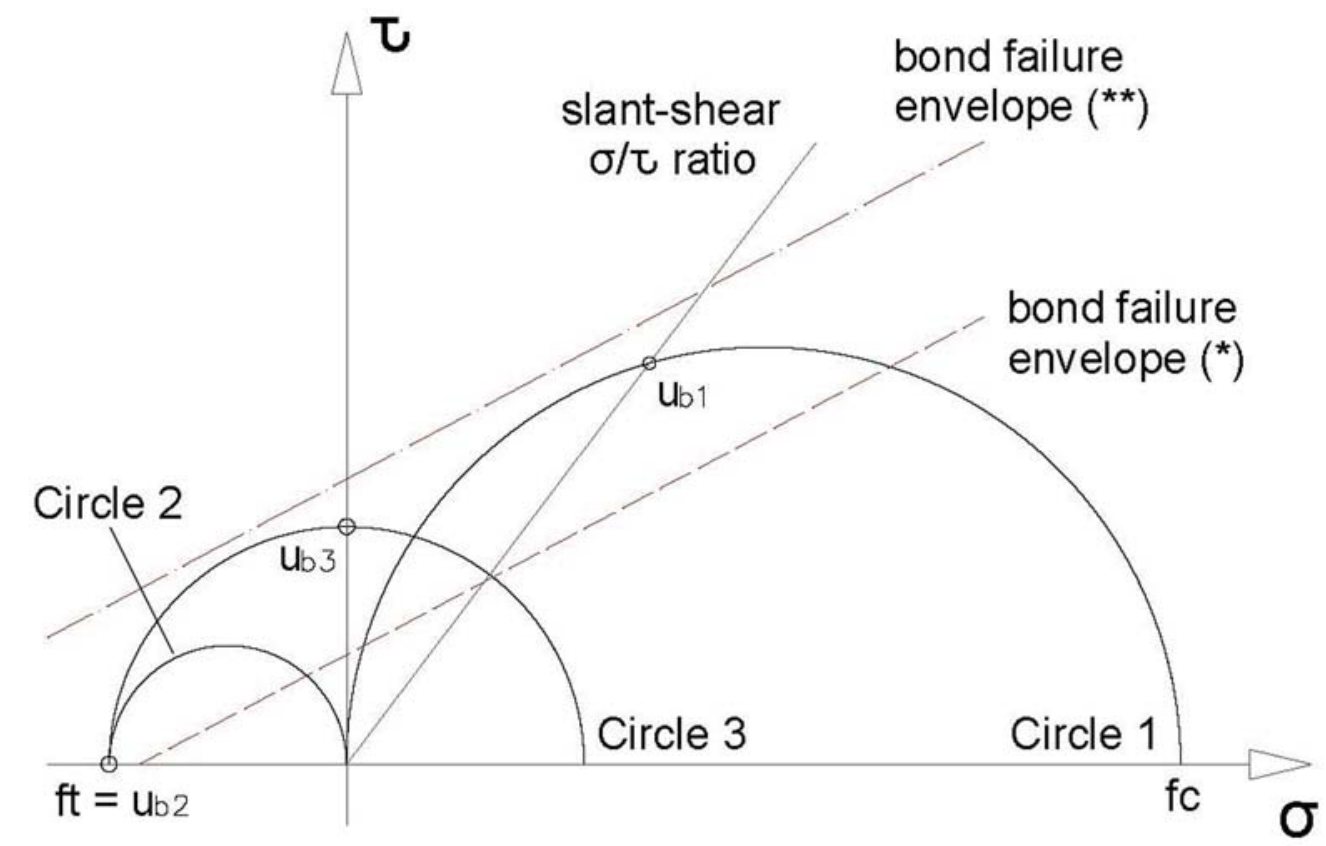

Morh's circles from: 1 compressive strength, 2 direct tensile test, 3 pure shear. Bond/material failure criterion (ub1, ub2, ub3, upper bounds for failure at the joint plane). Bond failure envelope (*) can be defined while Bond failure envelope (**) cannot be defined due to its strength its greater than that of the material.

Figure 2.8 Upper bounds to determine the bond failure envelope. Modified from Robins and Austin (1995)

Robins and Austin (1995), and Austin et al. (1999) carried out the slant-shear test with three different interface angles, the direct tension test (pull-off), patch test and the tensile shear test in order to accurately understand the bond strength of cementitious materials. The authors stated that the Mohr criterion in its basic shear-compression relationship with a tensile cut-off overestimates the shear strength area as it was demonstrated in the study of rock mechanics and the better fits to the experimental data achieved from the different 
loading configurations are attained by the use of an envelope to the Mohr's circles, as shown in Figure 2.9.

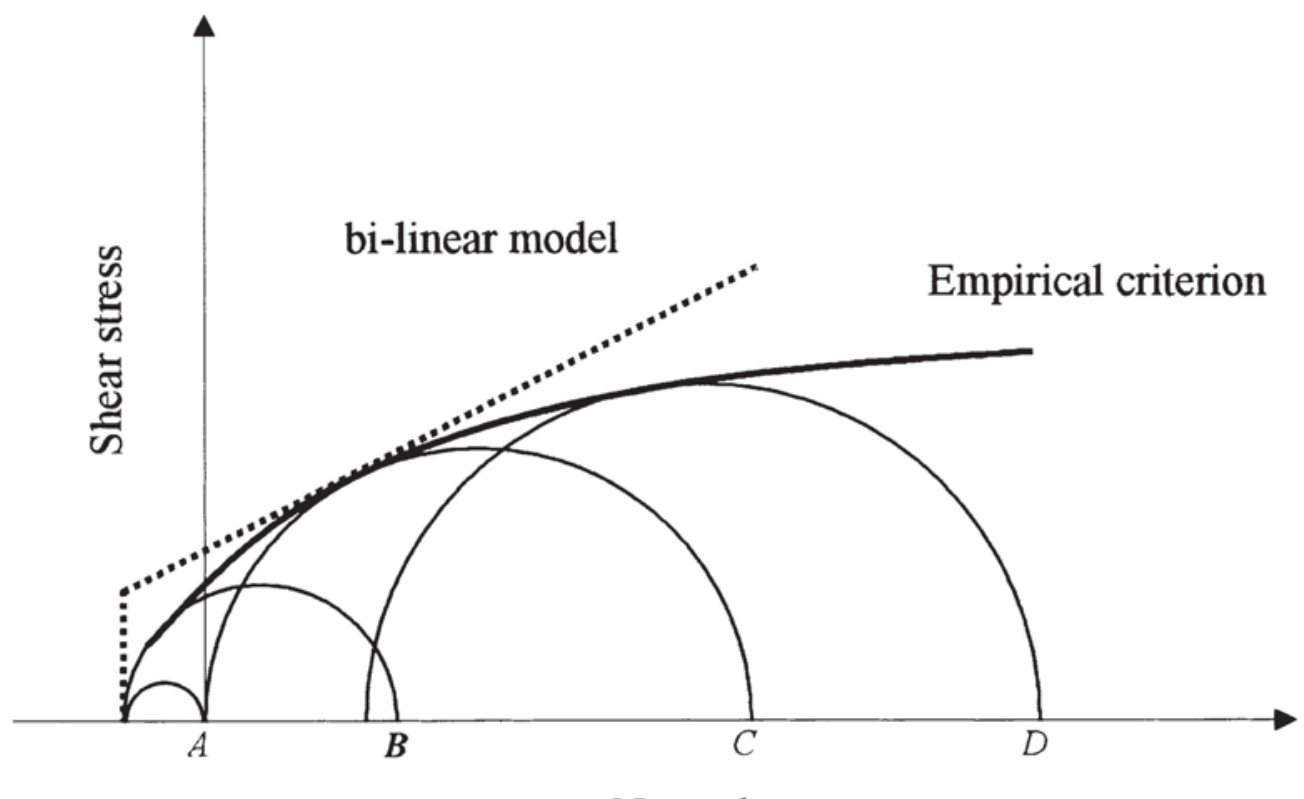

Normal stress

Morh's circles from: A direct tension test, $B$ indirect tension test, $C$ unconfined compression test and $D$ triaxial compression test.

Figure 2.9 Representative failure envelopes from rock mechanics based on bi-linear model and empirical criterion. Austin et al. (1999)

Climaco and Regan (2001) expressed that according to the Coulomb criterion, the sliding failure at the bond interface accomplish the following combination of shear and normal stresses:

$$
\tau=\mathrm{c}+\sigma * \tan \phi
$$

Equation 2.1

where $\tau$ is the shear stress at the bond interface, $\sigma$ is the normal stress at the bond interface and $\phi$ is the angle of friction. Espeche and Leon (2011) and Austin et al. (1999) used different expressions such as trigonometric functions or the origin of $\alpha$, however the expressions are equivalent. 
From the equilibrium of forces of Figure 2.10, $\tau_{n}$ and $\sigma_{n}$ can be expressed in terms of compressive force, $\mathrm{P}$, cross section, $\mathrm{A}$, and the angle between the interface and the horizontal, $\alpha$, as:

$$
\begin{gathered}
\sigma_{\mathrm{n}}=\frac{\mathrm{P}}{\mathrm{A}} * \cos ^{2}(\alpha) \\
\tau_{\mathrm{n}}=\frac{\mathrm{P}}{\mathrm{A}} * \sin (\alpha) * \cos (\alpha)
\end{gathered}
$$
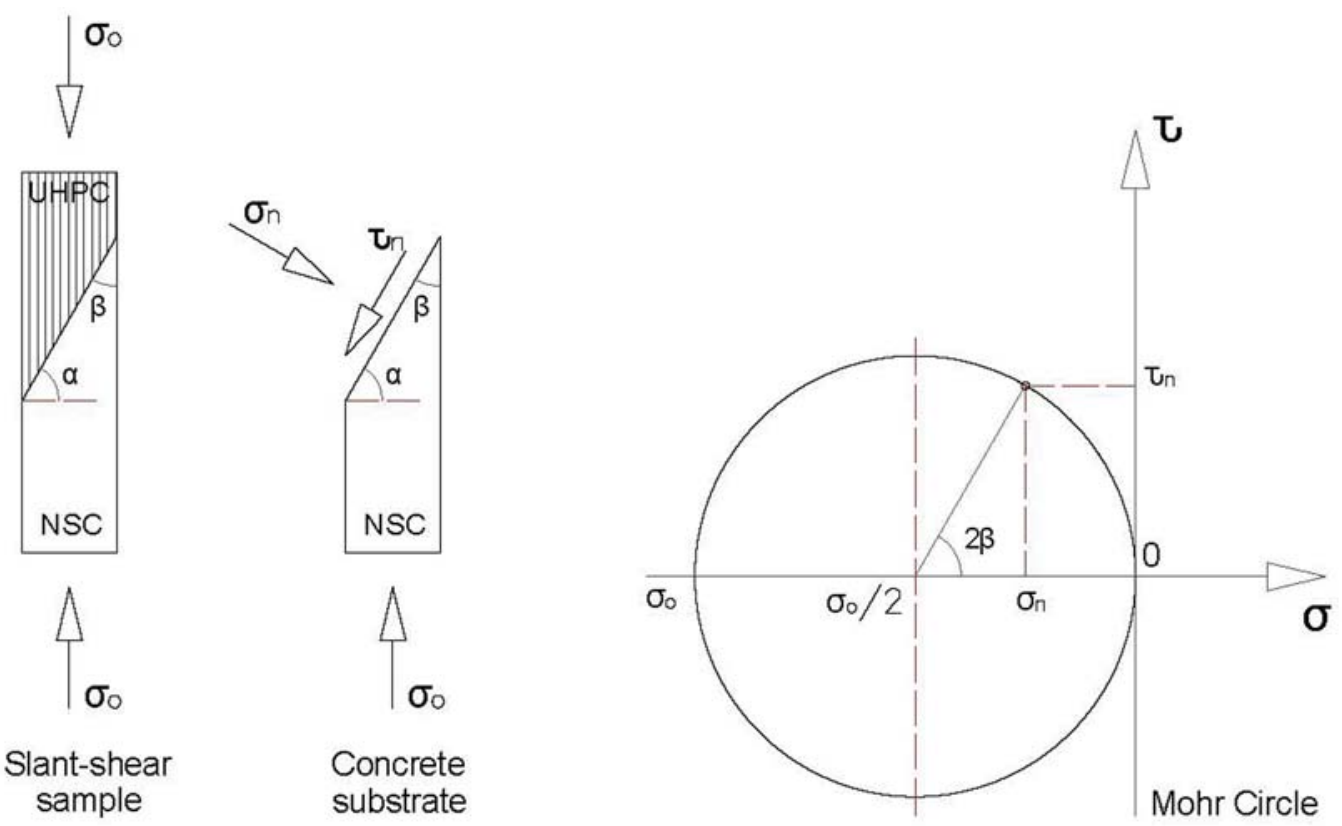

Figure 2.10 Equilibrium of stresses in the slant shear test and Mohr circle. Modified from Austin et al. (1999).

From Equation 2.1, Equation 2.2 and Equation 2.3, the applied compressive force required to produce shear failure along the interface is:

$$
\sigma_{0}=\frac{P}{\mathrm{~A}}=c * \frac{1+\tan ^{2}(\alpha)}{\tan (\alpha)-\mu}
$$

The most critical interface angle corresponding to a minimum applied stress, $\sigma_{0}$, is calculated by means of the derivative of the previous equation respected $\alpha$. 


$$
\begin{array}{cc}
\alpha_{\text {crit }}=\arctan \left(\mu+\sqrt{\mu^{2}+1}\right)=\frac{\phi}{2}+\frac{\pi}{4} & \text { Equation 2.5 } \\
\sigma_{0 . \text { crit }}=c * \frac{1+\left(\mu+\sqrt{\mu^{2}+1}\right)^{2}}{\sqrt{\mu^{2}+1}}=\frac{2 * c * \cos (\phi)}{1-\sin (\phi)} \quad \text { Equation 2.6 }
\end{array}
$$

\subsubsection{Bond between two concrete materials}

Espeche and Leon (2011) described that there are two different mechanisms that provide the bond strength between two cementitious materials: bond-adhesive (micro-scale) and bond-cohesion (macro-scale). The bond-adhesive concept results from chemical forces acting at the micro-scale. Some researchers have described the existence of three different layers to explain the adhesion between the old and new concretes, as shown in Figure 2.11 .

(a) Macro scale

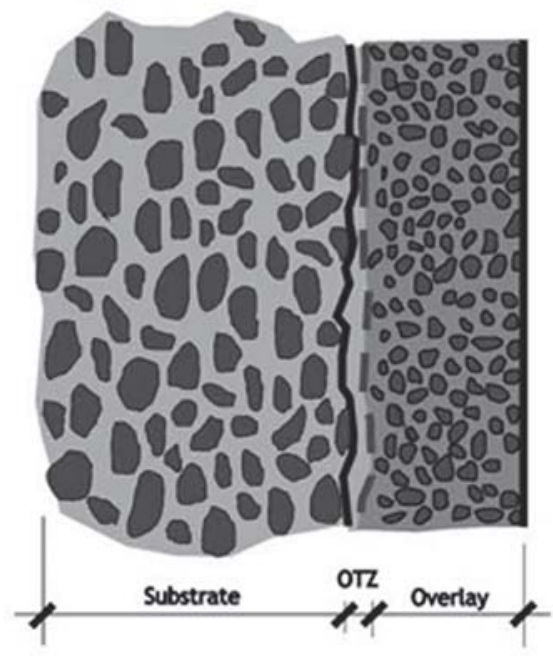

(b) Meso scale

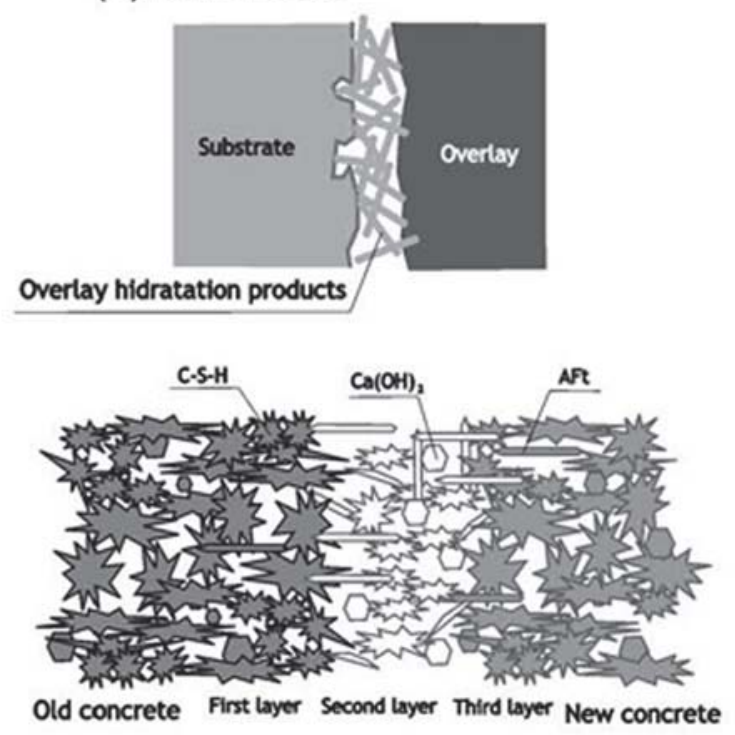

(c) Micro scale

Figure 2.11 Representation of the interface between old and new concretes. Espeche and Leon (2011) 
The first layer, also called penetration layer, is made inside the old cementitious material and it composed of new constituents (calcium silica hydrate with lesser amounts of AFt or calcium hydroxide) that respond chemically with active constituents in the old substrate. The second layer has high porosity and it is composed of calcium hydroxide and Aft crystals highly oriented. The third layer approximately has a very similar microstructure as the bulk new cementitious material. At the macro-scale, the bond-cohesive concept is a material property connected to the overlay transition zone of the new cementitious material.

A good bond can be achieved by casting new concrete (rapid-hardening portland) against old concrete with no bonding agents (Climaco and Regan 2001). Momayez et al. (2005) found that tensile bond strength for cementitious materials is approximately $40 \%$ of that of a monolithic sample and the slant shear strength is about $67 \%$ of that of a monolithic sample. In the same research, the bond strength to the concrete substrate obtained by four different sand-cement mortars containing $0 \%, 5 \%, 7 \%$ and $10 \%$ of silica fume was compared. It was concluded that the content of silica fume in the overlay material significantly increases the bond strength regardless the loading test (pull-off, bi-surface shear, splitting prism, slant shear). Nevertheless, the beneficial effect of silica fume seems to have a peak at 7\% and any added silica fume content beyond this does not improve the bond strength noticeably. Julio et al. (2005) stated that the use of bonding agent does not improve the bond strength between two cementitious materials if a surface treatment has been effectively applied to the concrete substrate.

\subsection{Summary}

The potential use of UHPC as repair material has been shown throughout this chapter. UHPC exhibits several properties that make it appropriate for this purpose. Its negligible permeability makes this material suitable as protective barrier that prevents any water or chemical penetration into the substrate. In addition, its ultra-high compressive strength and post-cracking tensile capacity would suppose an improvement of the bearing capacity. Its cementitious character and its ability to self-consolidate facilite its application in the field. However, for extensive acceptance, it has to be demonstrated that 
the bond between UHPC and NSC will offer a good performance without the help of any bonding agent. It is necessary that the UHPC-NSC interface exhibits high strength under tensile, shear and compression loads, since early to old ages and in harsh environmental conditions. The success of the rehabilitation will depend on whether the bond interface can stand the different combination of stresses that it will be subjected to throughout its service-life due to different process such as overlay's shrinkage, CTE mismatch or carrying loads. 


\section{Methodology}

This report aims to study the interface bond characteristics of UHPC and NSC using a variety of bond tests including the slant shear, splitting prism and the pull off configurations. The effects of surface preparation treatment, pre-wetting conditions and freeze-thaw cycles were included. In this investigation, the slant shear test was used with different interfacial angles making possible to draw the failure envelope by means of the Coulomb criterion, while the splitting prism test allowed for the inclusion of the effects of freeze-thaw cycling. Inclusion of the pull off scenario provided a direct measurement of the tensile strength necessary for defining the complete failure envelope, while providing a correlation with the other tests. Results from this study provide insight into the feasibility of using UHPC as a rehabilitation material.

Different surface treatments were used to assess the influence of surface roughness on the bond strength. The first step of the research consisted of a combination of splitting tensile test with freeze-thaw cycles. Five different surfaces (smooth, brushed, chipped, sandblasted and grooved) were included in this study of the indirect tensile strength. On the basis of the results of this test, it was concluded that the smooth, brushed and chipped surfaces had similar degree of roughness, therefore only one representative surface of these three was included in the second stage of the research (the slant shear and pull off tests). A new surface treatment was utilized to achieve a rougher surface. This new method consisted of using a concrete retarder in to obtain a surface with high aggregate exposure. To sum up, four different surfaces (brushed, sandblasted, grooved and rough) were included in the slant shear and pull off tests. 


\subsection{Tests}

\subsubsection{Combination of Splitting Tensile Test with Freeze-Thaw Cycles}

Freeze-thaw cycling is one of the most common causes of repair failure in a bridge deck; therefore, a proper performance evaluation of the bond between concrete materials should include this effect. Li et al. (1999) and Geissert et al. (1999) presented a new method based on the ASTM C 666 (Standard Test Method for Resistance of Concrete to Rapid Freezing and Thawing) and a modification of ASTM C 496 (Standard Test Method for Splitting Tensile Strength of Cylindrical Concrete Specimens) to study how freeze-thaw cycling influences the bond strength between the old and repair concretes because there are currently no ASTM standard tests for assessing this. The method consisted of casting composite specimens, $4 \times 3 \times 16$ in $(102 \times 76 \times 406 \mathrm{~mm})$, that fit within the freeze-thaw apparatus. The specimens were cut into four small prisms, $4 \times 3 \times 3$ in $(102 \times 76 \times 76 \mathrm{~mm})$, after being subjected to 300 freeze-thaw cycles according to ASTM C 666. Finite element

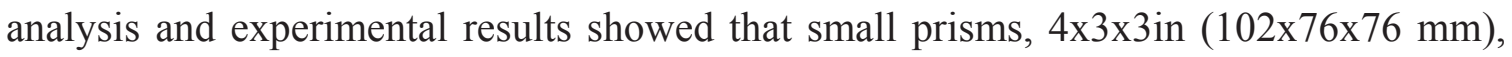
had a more uniform distribution along the bond surface than that of large prisms, $3 \times 4 \times 7$ in $(76 \times 102 \times 178 \mathrm{~mm})$, due to the width-height ratio. They concluded that four cast specimens, which produced 16 test prism samples, provided a reasonable estimation of the indirect tensile strength. Previously, Ramey and Strickland (1984) studied the splitting tensile strength between two different materials using composite cylinders instead of monolithic ones. Wall et al. (1986) and Momayez et al. (2005) used composite splitting prisms, $4 \times 4 \times 4$ in $(102 \times 102 \times 102 \mathrm{~mm})$ and $5.9 \times 5.9 \times 5.9$ in $(150 \times 150 \times 150 \mathrm{~mm})$ respectively, to assess indirect tensile strength between concrete substrate and repair materials, without including freeze-thaw cycles as made by Li et al. (1999) and Geissert et al. (1999). The splitting tensile results obtained in these different studies were consistent, verifying that the splitting tensile test is an appropriate method to assess the bond strength between overlay and substrate materials. Figure 3.2 shows a diagram of the test. All these studies used Equation 3.1, based on elasticity theory, to estimate the indirect tensile strength: 


$$
\mathrm{f}_{\mathrm{sp}}=\frac{2 * \mathrm{P}}{\mathrm{A} * \pi} \text { in } p s i
$$

Equation 3.1

where $f_{\text {sp }}$ is the splitting tensile strength, $P$ is the maximum applied load and $A$ is the area of the bonding plane.

\subsubsection{Slant Shear Test}

Climaco and Regan (2001) stated that the slant shear method is widely accepted to assess the bond strength between concrete substrate and the overlay material due to its realistic representation of the stress states in the real structures and its simplicity. This method consists in applying a compressive force to a composite sample which is composed of two different materials bonded together along an interface arranged at some inclination to the direction of the applied load (Eyre and Campos 1996). Therefore, the interface between both materials is subjected to compression and shear stresses during the loading. This bond test method gives consistent results for both cementitious and noncementitious overlays (Abu-Tair et al. 1996).

There are various configurations used for the test, such as the sample sizes and the angle of the bond plane. BS EN 12615:1999 (British Standard 1999) utilizes prisms of $3.9 \times 3.9 \times 15.7$ in $(100 \times 100 \times 400 \mathrm{~mm})$ or $1.6 \times 1.6 \times 6.3$ in $(40 \times 40 \times 160 \mathrm{~mm})$ with a bond surface inclined at an angle of $30^{\circ}$ from vertical while ASTM C 882 (Bond Strength of Epoxy-Resin Systems With Concrete By Slant Shear) recommends the use of cylinders with 3 in diameter and 5.6 in height with a bond interface inclined at an angle of $30^{\circ}$ from vertical. The French standard NFP $18-872$ uses prisms measuring $3.9 \times 3.9 \times 11.8$ in $(100 \times 100 \times 300 \mathrm{~mm})$ at an angle of $30^{\circ}$ from vertical while the Italian standard adopts prisms of $2.8 \times 2.8 \times 7.9 \mathrm{in}(70 \times 70 \times 200 \mathrm{~mm})$ with a joint angle of $17^{\circ}$ from vertical (Climaco and Regan 2001; Pacheco-Torgal et al. 2008). Robins and Austin (1995) cast prisms of $2 \times 2.2 \times 5.9$ in $(50 \times 55 \times 150 \mathrm{~mm})$ with a bond interface forming an angle of $30^{\circ}$, $45^{\circ}, 60^{\circ}$ with the vertical. Naderi (2009) utilized prims of $3.9 \times 3.9 \times 9.8$ in $(100 \times 100 \times 250$ $\mathrm{mm}$ ) with a bond surface angle of $30^{\circ}$. Sooriyaarachchi et al. (2002) cast cylinders of 3 in 
$(75 \mathrm{~mm})$ diameter and 5.9 in $(150 \mathrm{~mm})$ long with a bond interface inclined $30^{\circ}$ to the longitudinal direction.

Climaco and Regan (2001) obtained similar results between prisms of 5.9x5.9x39.4 in $(150 \times 150 \times 1000 \mathrm{~mm})$ and $4 \times 4 \times 12$ in $(102 \times 102 \times 305 \mathrm{~mm})$ showing that there is not any significant effect due to the variation of the sample dimensions. However, the inclination of the bond interface does; Austin et al. (1999) emphasized that this bond strength method has a serious shortcoming in its dependency on the angle of the interface. Namely, the standard tests, such as BS EN 1265:1999 and ASTM C882 fix the joint angle with an inclination of $30^{\circ}$ from the vertical excluding the likelihood of attaining a bond failure on a different plane.

The slant shear test is sensitive to the degree of roughness of the substrate (Abu-Tair et al. 1996). In contrast, Robins and Austin (1995) showed that the pull off is more sensitive to the roughness of the substrate than the slant shear test. According to Robins and Austin (1995), this might be explained due the fact that the tensile bond strength is sensitive to the existence of surface defects which cause the reduction in the effective bond area and stress concentration at the tips of microcracks, which accelerate their extension.

Robins and Austin (1995), and Santos and Julio (2011), developed finite element models to study how the stiffness mismatch between the overlay and subtract materials affect the distribution of stresses along the interface. Both showed that there is an increase in both normal and shear at the ends of the bond plane, with the maximum stresses taking place at the side with least overlay material depth.

\subsubsection{Pull Off Test}

The pull off tests consists of applying a direct tensile force to a core advanced through the overlay material and into the underlying concrete until failure takes place (Issa et al. 2008). Sprinkel (1997) stated that the pull off test, as well called direct tensile method, is the best technique to assess the bond strength in the field. The pull off has been widely used in research applications due to its potential correlation to in situ results and the fact 
that the bond interface, in this loading configuration, undergoes direct tension which is the most severe stress state (Robins and Austin 1995).

Sprinkel (1997) described that the tensile failures that take place at a depth lower than $1 / 4$ inch into the substrate material often is a sign of that the substrate surface had microcracks after the surface treatment. In the same way, tensile failures that occur at a depth equal or greater than $1 / 4$ inch indicate that the substrate surface was prepared correctly.

Cleland and Long (1997) carried out an extensive experimental program to assess the variability of this method. Five overlay materials, four surface treatments and two conditions for the substrate (cast surface and fractured surface) were used. The author concluded that the coefficient of variation (COV) is typically about $20 \%$. Whereas Robins and Austin (1995) obtained coefficients of variation from $8 \%$ to $40 \%$ with an average of $19 \%$ in his study of the bond strength under direct tension between concrete substrate with sand/cement and polymer-modified mortars.

ASTM C 1583 (Standard Test Method for Tensile Strength of Concrete Surfaces and the Bond Strength or Tensile Strength of Concrete Repair and Overlay Materials by Direct Tension) establishes that the steel disk has to have a 2 in diameter and at least a 1 in thickness and the core has to penetrate at least 0.5 in depth below the interface. The tensile strength is estimated according to Equation 3.2.

$$
f_{t}=\frac{\mathrm{T}}{\mathrm{A}} \text { in } p s i
$$

Equation 3.2

where $\mathrm{f}_{\mathrm{t}}$ is the direct tensile strength, $\mathrm{T}$ is the tensile load and $\mathrm{A}$ is the area of test specimen. Figure 3.4 shows a diagram of the test.

Issa et al. (2008) showed by means of FEA that the bond tensile strength increases rapidly for overlay thickness of less than 1.5 in and a mild increase after this value for overlay material compressive strengths from $4000 \mathrm{psi}$ to $7000 \mathrm{psi}$. 


\subsection{Materials}

Composite specimens were composed of UHPC and conventional concrete for all tests. This section describes the main characteristics of the UHPC and NSC mixes done to cast all composite samples.

\subsubsection{UHPC mixing}

Ductal ${ }^{\circledR} J S 1000$ brand UHPC manufactured by Lafarge North America was used as overlay material. Graybeal (2006) presented an extensive mechanical and durability characterization of this material. A Doyon BFT-060 planetary mixer was used to make all UHPC mixes. The proportions of the UHPC constituents shown in Table 3.1 were used to cast all UHPC batches of $0.65 \mathrm{ft}^{3}$ (18 1). Figure 3.1 shows details of the mixer, paddle, steel fibers and the flow test equipment.

Table 3.1

Ductal ${ }^{\circledR}\left(J S 1000-G r e y\right.$ Premix) mix proportions for $0.65 \mathrm{ft}^{3}$

\begin{tabular}{lcc}
\hline \multicolumn{1}{c}{ Constituents } & Amount (lbs) & Amount (kgs) \\
\hline Ductal ${ }^{\circ}$ Grey Premix & 87.06 & 39.48 \\
Steel Fibers (8x10 ${ }^{-3}$-in dia. by 0.5-in long) & 6.19 & 2.81 \\
Superplastizer (Chryso Premia 150) & 1.19 & 0.54 \\
Water & 5.11 & 2.32 \\
\hline
\end{tabular}
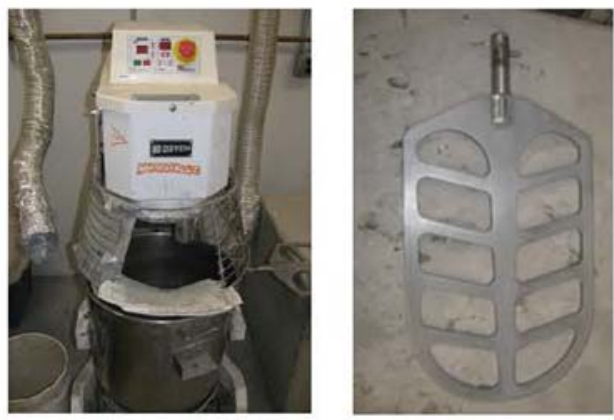

(a) Doyon BFT-060 planetary mixer.

(b) Mixer paddle.

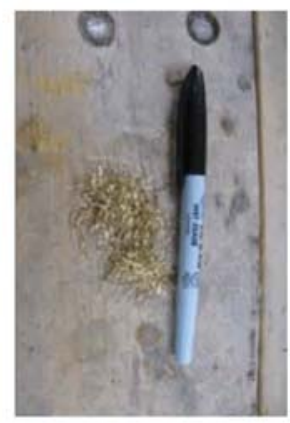

(c) Steel fibers.

Figure 3.1 Equipment and material to cast UHPC

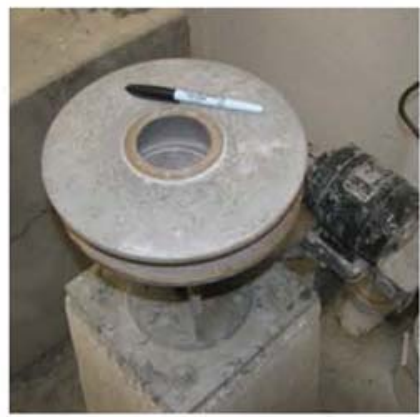

(d) Equipment for the Slump test. 
Ductal ${ }^{\circledR}$ premix is typically comprised of Portland cement, silica fume, ground quartz and quartz sand already mixed. The constituents (Ductal ${ }^{\circledR}$ premix, water, superplasticizer and steel fibers) that were added are described in Table 3.2 along with the mixing schedule. To obtain a proper UHPC material, it is essential to prolong the mix to ensure that the turning point is reached. This point is defined as the time at which all of the Ductal ${ }^{\circledR}$ premix, water and half of the superplasticizer are entirely mixed so that the UHPC begins clumping together and falling from the sides of the mixing bowl (Kollmorgen 2004).

Table 3.2

Ductal® (BS1000-Grey Premix) mix process

\begin{tabular}{cc}
\hline Process & $\begin{array}{c}\mathbf{1 8} \text { l batch } \\
\text { estimate }\end{array}$ \\
\hline $\begin{array}{c}\text { up any clumps } \\
\text { Add Premix, time start mixing with Speed 1 over two minutes to break }\end{array}$ & $0: 00$ \\
Add water blended with half of the superplasticizer over 2 mins & $2: 00$ \\
Increase to Speed 3, mix for 30 secs & $4: 15$ \\
Increase to Speed 4, mix for 2 min and 30 secs & $4: 45$ \\
Increase to Speed 5, mix 3 min and 30 secs & $7: 15$ \\
Increase to Speed 6, mix until the turning point/mixer attains 12 amps & $11: 15$ \\
When mixer attains 12 amps (turning point), add the other half of & variable \\
Superplasticizer & variable \\
Slow speed 3, add fibers over 2 mins & variable \\
Slow speed 1, mix for 2 mins & variable \\
\hline
\end{tabular}

The flow test was utilized after mixing UHPC in order to control the quality of the concrete in its plastic state. The equipment utilized is shown in Figure 3.1. The test was carried according to ASTM C230/C230M-08 (Standard Specification for Flow Table for Use in Tests of Hydraulic Cement). The cut down steel cone was filled with UHPC. Afterwards, the cone lifted off slowly to allow UHPC to flow evenly on the table. Four measurements of the flow diameter were taken. The static flow of the material is the average of these measurements. Afterwards, 20 shocks were applied to the sample, and the diameter was measured four times again. The dynamic flow of the material is the 
average of these values. The flow measurements after 20 blows was between 7.9-9.8 in (200-250 mm) for all UHPC mixes cast. Lafarge North America (2003) defines this range as fluid mixture. Besides this control test, cylinders, $3 \times 6$ in, were cast and tested under compression from each UHPC mix done. The cylinders were demould at 3 days after casting and were exposed to ambient conditions until the day of testing. These values are shown throughout Chapter 4.

\subsubsection{NSC mixing}

NSC mixes were designed to satisfy the requirements given by Michigan Department of Transportation (2009). These requirements consist of:

- 28-day compressive strength greater than $4500 \mathrm{psi}(31 \mathrm{MPa})$

- minimum cement content of $657 \mathrm{lb} / \mathrm{yd}^{3}\left(390 \mathrm{~kg} / \mathrm{m}^{3}\right)$

- $\quad$ an entrained air of $4.5 \pm 1.5 \%$

- slump between 1 and 6 in (25-150 mm)

The cement content of the NSC mix was $664 \mathrm{lb} / \mathrm{yd}^{3}\left(394 \mathrm{~kg} / \mathrm{m}^{3}\right)$. The seven mixes of conventional concrete met the requirements previously mentioned except one mix that exceeded slightly the slump value (6.5 in) and another that surpassed the entrained air $(6.4 \%)$; therefore, it can be stated that the concrete substrate of the samples for the splitting tensile, slant shear and pull off tests accomplish with the MDOT specified mix requirements. Fine and coarse aggregate met the requirements of section 902 of the MDOT 1996 Standard Specification for Construction (Michigan Department of Transportation 1996). The maximum size for the coarse aggregate used in the NSC mixes for the splitting tensile test was $1 / 2$ in to avoid compaction problems while the NSC aggregate size for the slant-shear and pull-off samples was 1 in. The coarse aggregate distribution was according to size number 7 for the splitting tensile samples and to size number 67 for the slant shear and pull off samples, specified in ASTM C33 (Standard Specification for Concrete Aggregates).

Information regarding the design of the four NSC mixes used to cast all splitting tensile samples and the three NSC mixes for the slant-shear and pull-off samples, along with 
associated test results (temperature, slump, pressure air and unit weight) carried out right after mixing can be found in the Appendixes. Several compressive strength tests were carried out with companion cylinders, $4 \times 8$ in, at different ages to assess the strength of the concrete. These compressive strength values are shown through Chapter 4.

\subsection{Experimental Program}

The experimental program was carried out in two different steps. Firstly, the splitting tensile test was conducted. Once the results of this test were obtained, the slant-shear and pull off tests were designed. For this reason, there are some differences between the variables studied in the splitting tensile test with respect to the slant-shear and pull off tests. These main differences are shown in Table 3.3:

Table 3.3

Different variables between the splitting tensile test and slant-shear and pull-off tests

\begin{tabular}{ccc} 
Variable & Splitting tensile test & $\begin{array}{c}\text { Slant-shear and pull off } \\
\text { tests }\end{array}$ \\
\hline $\begin{array}{c}\text { Moisture condition of the } \\
\text { concrete substrate }\end{array}$ & $\begin{array}{c}\text { Both dry and } \\
\text { saturated conditions } \\
\text { were studied }\end{array}$ & $\begin{array}{c}\text { All composite samples } \\
\text { were cast on moisture } \\
\text { saturated concrete } \\
\text { substrate }\end{array}$ \\
\hline Concrete surfaces & $\begin{array}{c}\text { Smooth, chipped, } \\
\text { brushed, sandblasted } \\
\text { and grooved }\end{array}$ & $\begin{array}{c}\text { Brushed, sandblasted, } \\
\text { grooved and rough }\end{array}$ \\
\hline Age of the composite & Long term:185-298 \\
samples & days & Short term: $2-12$ days \\
\hline
\end{tabular}

\subsubsection{Combination of Splitting Tensile Test with Freeze-Thaw Cycles}

To assess how different surface treatments, substrate moisture conditions and freeze-thaw cycles affect the splitting tensile bond strength, 90 composite and 14 monolithic specimens were cast and tested. Table 3.4 lists the number of composite and monolithic specimens assigned to each case study. The composite specimens, with a nominal dimension of $4 \times 3 \times 15.5$ in, were made up of NSC and UHPC layers of 1.5 in each. Four composite prisms were obtained from each beam for testing under indirect tension. This test was defined to study the bond strength in long-term performance since the age of the 
composite samples varied from 185 to 298 days. Figure 3.2 describes the process of the splitting tensile test and the approximate tensile stress distribution along the interface.

Table 3.4

Splitting tensile slabs distribution for each case study

\begin{tabular}{|c|c|c|c|}
\hline \multicolumn{4}{|c|}{ MONOLITHIC SLABS } \\
\hline $\begin{array}{l}\text { Without freeze- } \\
\text { thaw cycling }\end{array}$ & $\begin{array}{l}300 \text { freezing- } \\
\text { thawing cycles }\end{array}$ & $\begin{array}{l}600 \text { freezing- } \\
\text { thawing cycles }\end{array}$ & $\begin{array}{l}900 \text { freezing- } \\
\text { thawing cycles }\end{array}$ \\
\hline 3 specimens & 3 specimens & 3 specimens & 3 specimens \\
\hline \multicolumn{4}{|c|}{ COMPOSITE SLABS } \\
\hline \multicolumn{4}{|c|}{ Dry Substrate } \\
\hline \multicolumn{2}{|c|}{ Without freeze-thaw cycling } & \multicolumn{2}{|c|}{300 freezing-thawing cycles } \\
\hline \multicolumn{2}{|c|}{3 specimens per each surface treatment } & \multicolumn{2}{|c|}{3 specimens per each surface treatment } \\
\hline \multicolumn{4}{|c|}{ Saturated Substrate } \\
\hline $\begin{array}{l}\text { Without freeze- } \\
\text { thaw cycling }\end{array}$ & $\begin{array}{l}300 \text { freezing- } \\
\text { thawing cycles }\end{array}$ & $\begin{array}{l}600 \text { freezing-thawing } \\
\text { cycles }\end{array}$ & $\begin{array}{l}900 \text { freezing-thawing } \\
\text { cycles }\end{array}$ \\
\hline $\begin{array}{c}3 \text { specimens per } \\
\text { each surface } \\
\text { treatment }\end{array}$ & $\begin{array}{c}3 \text { specimens per } \\
\text { each surface } \\
\text { treatment }\end{array}$ & $\begin{array}{l}3 \text { specimens per each } \\
\text { surface treatment }\end{array}$ & $\begin{array}{l}3 \text { specimens per each } \\
\text { surface treatment }\end{array}$ \\
\hline
\end{tabular}



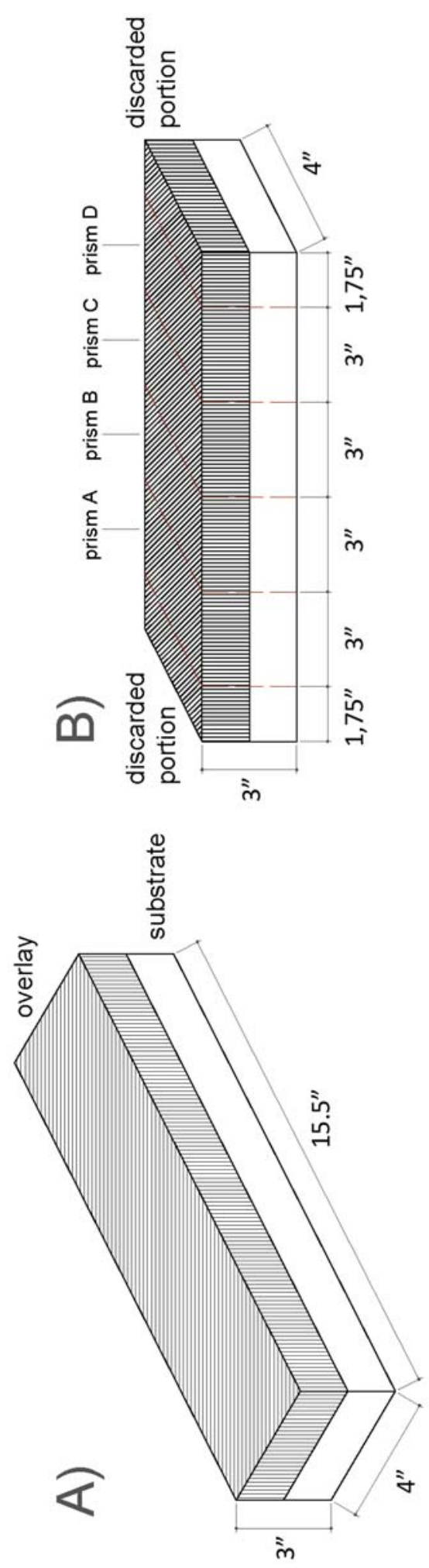

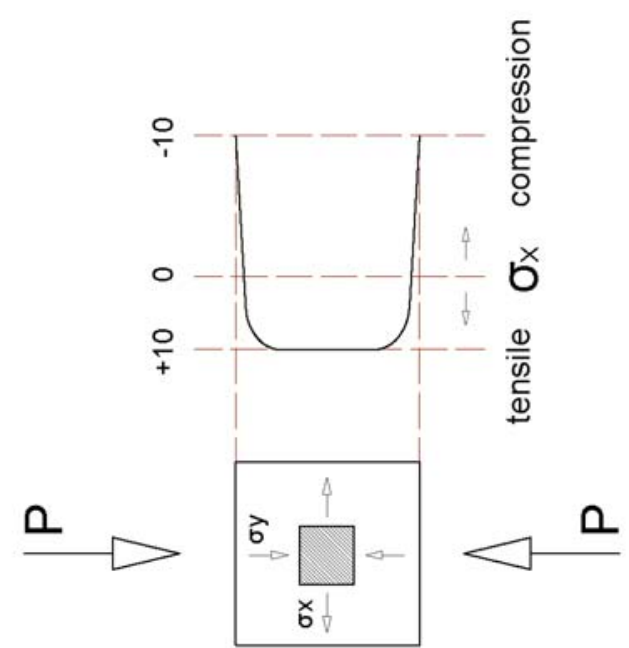

$\widehat{0}$
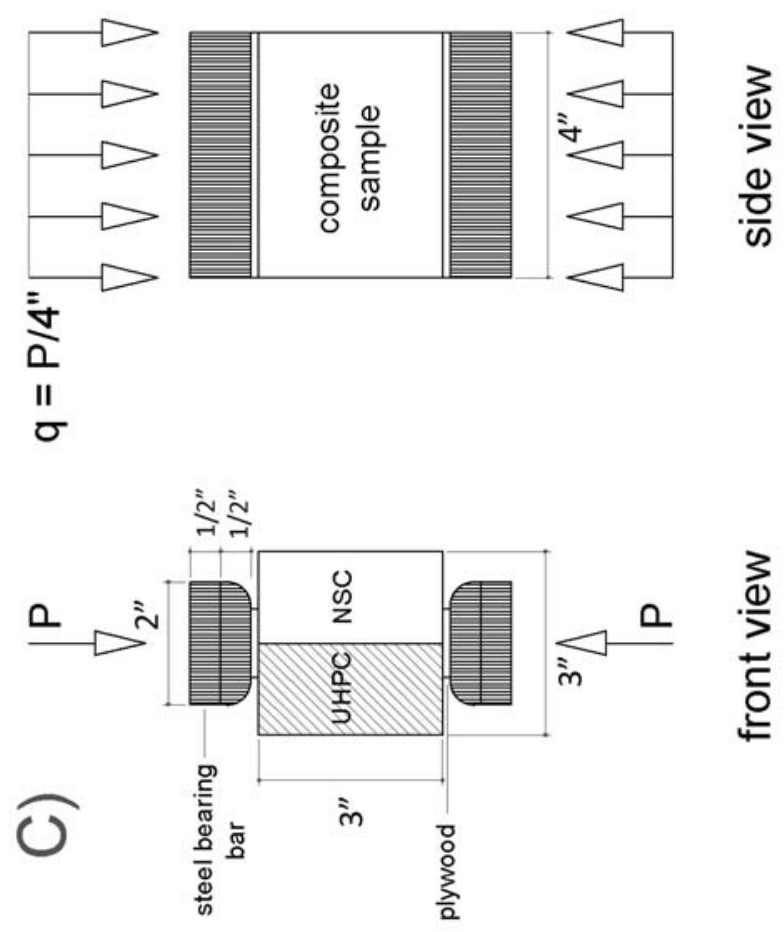

Figure 3.2 Detail of splitting tensile specimens 


\subsubsection{Slant-shear test}

The slant-shear test was designed to assess the bond strength under compression and shear at early age due to the excellent results for the bond obtained from the splitting tensile test in a long-term performance. The main purpose of the test was to study the bond strength at 8 days with a bond interface inclined at an angle of $60^{\circ}$ and $70^{\circ}$ from horizontal. Composite prisms, with a nominal dimension of $3.5 \times 3.5 \times 14$ in, were made up of NSC and UHPC layers. At least, four samples were cast for each case study at 8 days. Besides this, more specimens were cast to study the bond strength at earlier age (2 or 3 days) with a joint angle of $55^{\circ}, 60^{\circ}$ and $70^{\circ}$ from horizontal. A full summary of the tested samples is found in Chapter 4. Figure 3.3 shows the dimension of the composite slant shear samples.

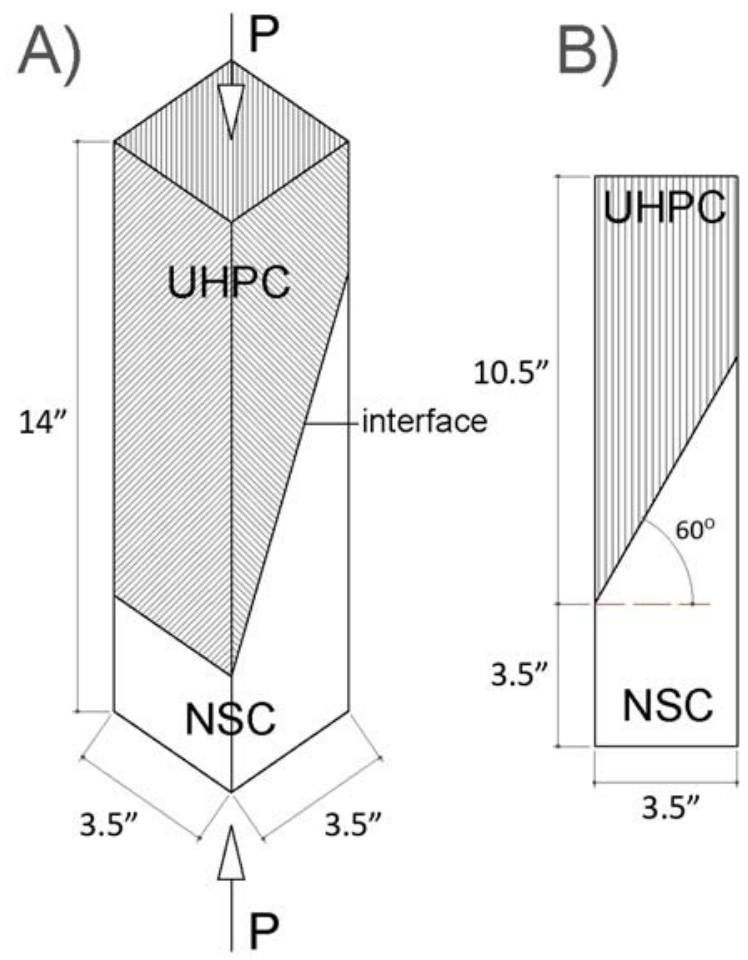

C)

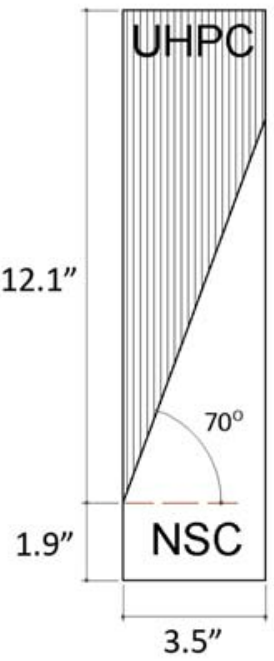

D)

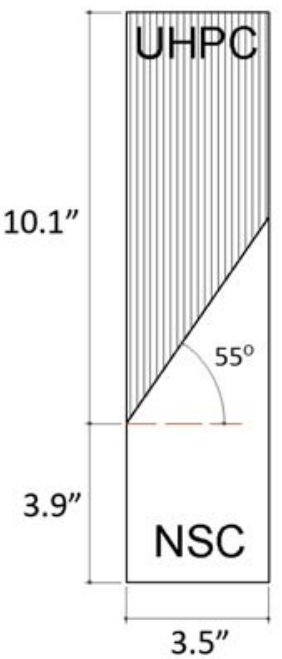

Figure 3.3 Detail of the slant-shear specimens 


\subsubsection{Pull-off test}

Pull off test was designed to study the bond strength at early age, similarly to slant-shear test. All pull off samples were tested at age of 11-12 days. NSC blocks, with $13 \times 7 \times 4$ in dimensions, were cast and a UHPC layer of 1 in were poured afterwards, obtaining final composite slabs of $13 \times 7 \times 5$ in. These dimensions were chosen based on the following criteria for constructability: the rectangular shape is convenient to facilitate the moulds fabrication, the dimensions were large enough to obtain three cores as established by the requirement of ASTM C 1583, and the specimens could also be moved easily. For each case study at least six cores were tested. Figure 3.4 shows the size of the composite specimens and the distance between the three different cores obtained from each. The centers of core tests positions were 4.1 in apart and at least 2.5 in from an edge.

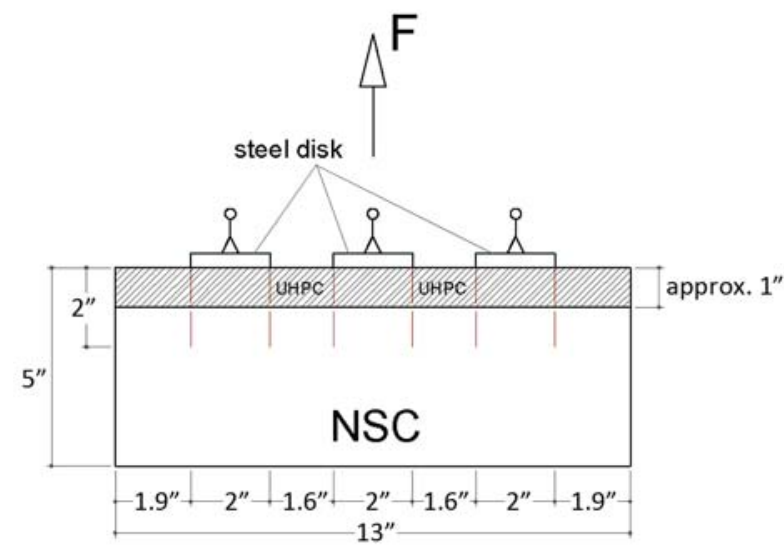

frontal view

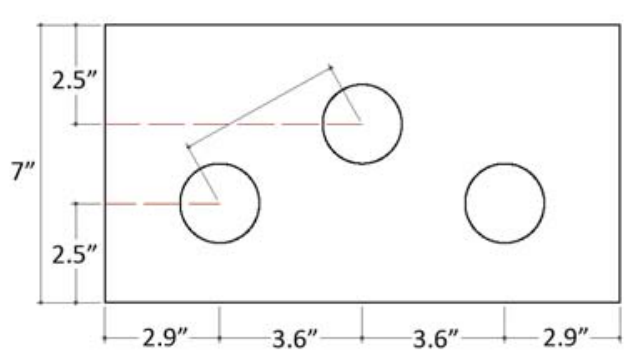

top view

Figure 3.4 Detail of pull off specimen and location of coring holes

\subsection{Preparation of concrete substrates}

Four NSC mixes were needed to cast all samples for the splitting tensile test while three other NSC mixes were realized to cast all slant-shear and pull-off samples. 


\subsubsection{Combination of Splitting Tensile Test with Freeze-Thaw Cycles}

The three first NSC mixes of a total of four NSC mixes were used to cast substrates for the composite samples. The fourth NSC mix was used to cast monolithic specimens with the same size as those of composite specimens. Moulds were made of timber without applying any varnish coat, but the bottom piece was covered with plastic to facilitate an easier demolding process. After casting, all concrete substrates underwent a 24 hour moist cure, according to ASTM C31/C31M. Afterwards, the samples were demoulded and cured in a lime water tank for 28 days. Figure 3.5 shows several stages of concrete substrate preparation.

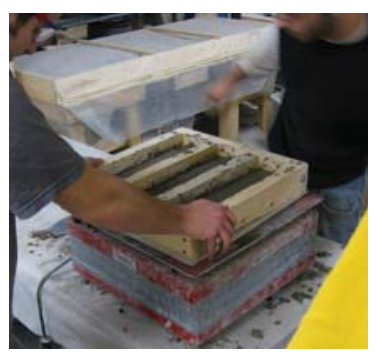

(a) Vibration for 5-10 seconds was applied once NSC was placed into moulds.

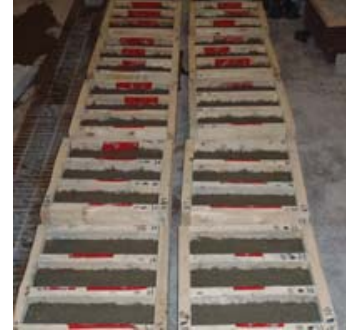

(b) Moulds before covering them with plastic.

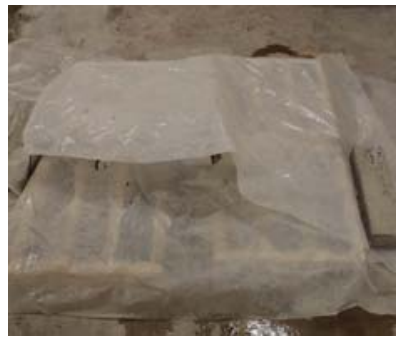

(c) Moist cure: cylinders with water were placed before covering with plastic.

Figure 3.5 Different stages in the preparation of the splitting tensile samples

When the concrete substrates reached 28 days of age, the surface preparation was carried out. Smooth, chipped, grooved, brushed and sandblasted surfaces were chosen in order to cover a broad range of different roughness profiles and to represent some of the most widespread surface preparation techniques (Julio et al. 2005; Silfwerbrand 1990). It should be pointed out that the surfaces that were treated were those cast against the bottom piece of the moulds covered with plastic.

Figure 3.6 shows the different surfaces obtained after the surface treatment. The grooves had dimensions at approximately $0.24-0.43$ in $(6-11 \mathrm{~mm})$ wide by $0.28-0.43$ in $(7-11$ $\mathrm{mm}$ ) deep. 


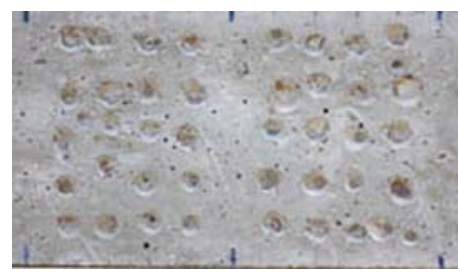

(a) Chipped surface, slightly brushed.

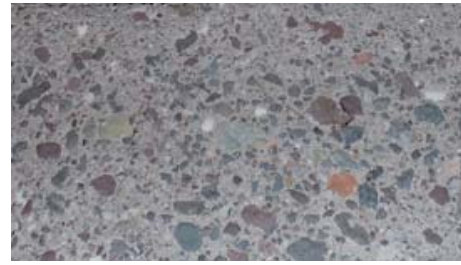

(d) Sandblasted surface.

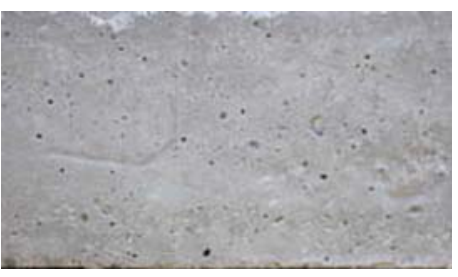

(b) Smooth surface, slightly brushed.

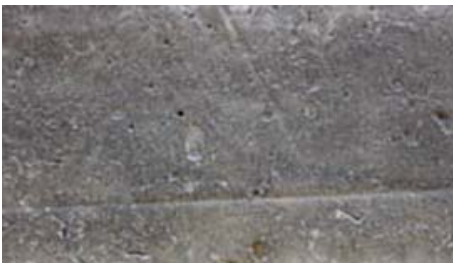

(e) Brushed surface.

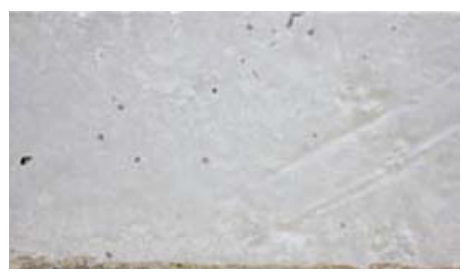

(c) Smooth surface, no dust removal treatment applied.

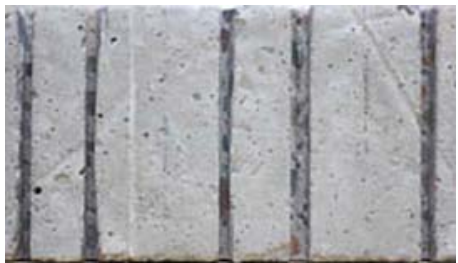

(f) Grooved surface.

Figure 3.6 Different NSC substrate surfaces for splitting tensile samples

It is necessary to mention that at first the smooth surface was considered to be without any surface treatment and the chipped surface to be only with small holes produced by a hand drill, but after casting the UHPC for the samples in the dry moisture condition, all the composite specimens where the concrete surface was chipped or smooth failed prematurely after demoulding. This was due to the fact that no dust removal method was applied to these surfaces; therefore, no bond was achieved between new and old materials. These samples were slightly brushed, and a new layer of UHPC was poured on them, obtaining composite specimens that did not split right after demoulding. Figure 3.6 and Figure 3.7 are clear examples of the difference between a slight brushed and no brushed.

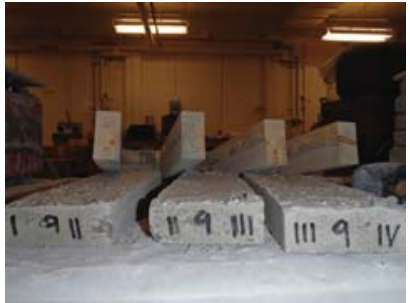

(a) Samples after demoulding.

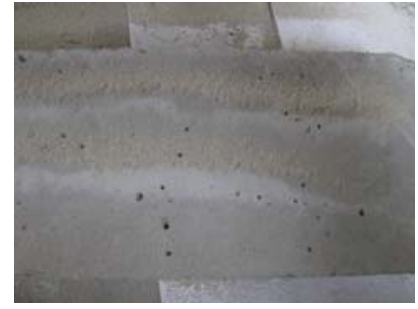

(b) Sample in the middle of the brushing treatment.

Figure 3.7 NSC substrates after demoulding and during the surface treatment

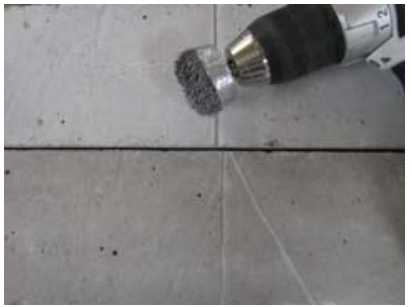

(c) Difference between a surface without any treatment and a surface slightly brushed. 
The equipment used in the surface preparation is shown in Figure 3.8. A steel brush was employed to remove the dust on the surface and the chipped surface was obtained by using a steel drill-bit. The saw was used to make the grooves in the slabs, and a sandblasting equipment was utilized to attain the sandblasted surface.

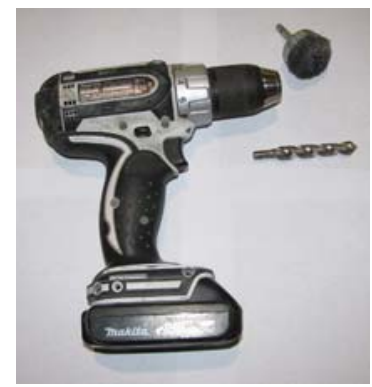

(a) Cordless Drill with a metallic brush and a drillbit.

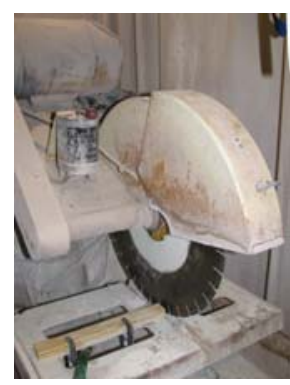

(b) Saw to make the grooves.

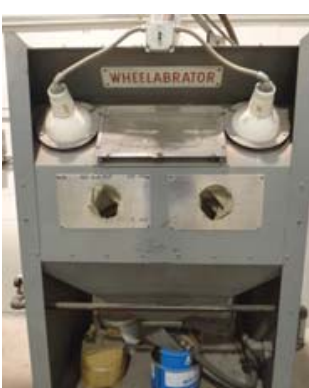

(c) Sandblasting equipment (outside view).

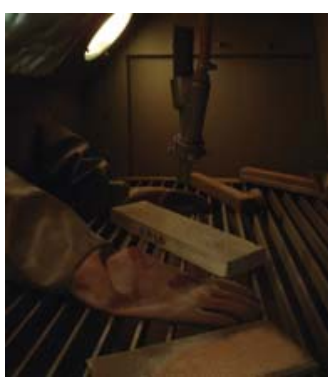

(d) Sandblasting equipment (inside view).

Figure 3.8 Equipment for the surface treatment

\subsubsection{Slant shear test}

Three different NSC mixes were made to cast all composite prisms. The composite prisms were $3.5 \times 3.5 \times 14$ in, fitting in the size range used by other researches and previously described in 3.1.2. These dimensions are large enough to allow casting concrete substrate contrasting ASTM C 882 that use mortar substrate. Different methods can be used to obtain the inclined surface in the concrete substrate. ASTM C 882 recommends the use of dummy sections that are made up of epoxy-resin mortar, fit the mold, and are equal to half the volume of the specimen with an angle of $30^{\circ}$ from vertical. In a similar way, Climaco and Regan (2001) utilized oiled wooden inserts in their steel beam molds to form the slant surfaces in the substrate. Abu-Tair et al. (1996) and BS EN 12615:1999 (British Standard 1999) cast concrete prisms and later cut them at $30^{\circ}$ to the vertical. The constructive process chosen for this research consisted of working with wooden inserts in timber molds to obtain an inclined surface, as shown in Figure 3.9. 


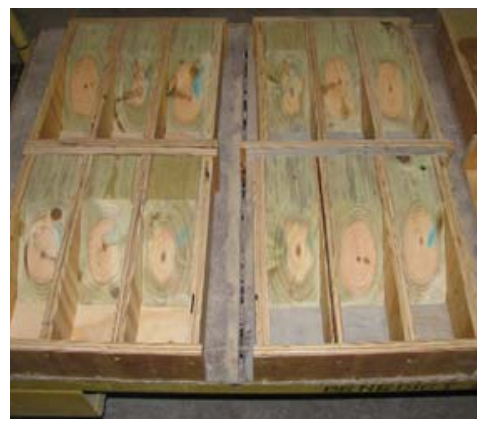

(a) Molds to cast slant shear specimens.

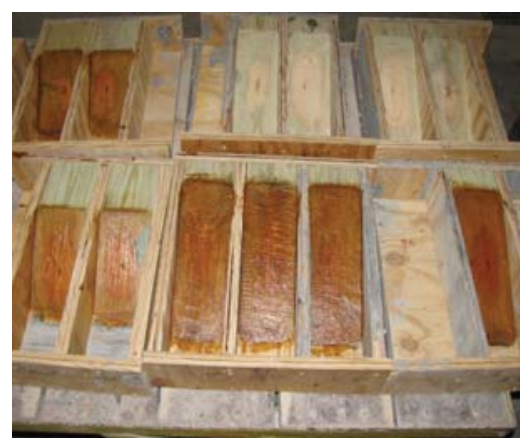

(b) Molds after applying a concrete surface retarder to obtain a rough surface.

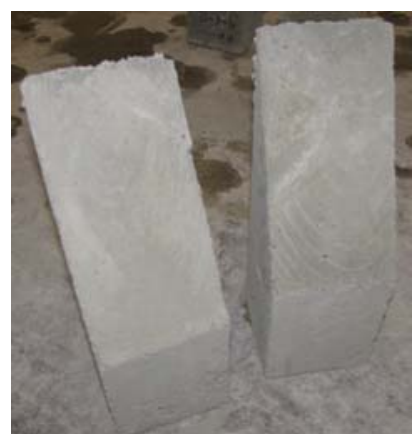

(c) NSC substrate for slant shear samples after demolding.

Figure 3.9 Slant shear molds

Normal concrete was poured in the free corner of the moulds. A steel bar was used to improve the compaction of the concrete during its placing and a vibration of 5-10 seconds was applied once the mold was totally filled. After casting, all concrete substrates underwent a 24 hour moist cure, according to ASTM C31/C31M. Afterwards, the samples were demoulded and cured in a lime water tank for 28 days. Figure 3.5 shows slant shear substrates after demoulding.

The surface treatments for the slant shear test were different to those of the splitting tensile test due to the fact that the smooth, brushed and chipped surfaces obtained for the indirect tensile test had similar profile. It was decided to work only with the brushed surface because it is the most representative. A new surface was introduced in order to obtain a higher contrast with respect the other surfaces (brushed, sandblasted and grooved).

For obtaining the rough surface, a concrete retarder was applied to the wooden inserts in order to delay the set of the concrete surface, facilitating the creation of exposed aggregate surface. The concrete retarder Formula F provided by The Euclid Chemical Company was used. This product does not affect the mechanical properties of the concrete and offers the advantage that is applied directly to forms instead of applying to concrete surfaces. This retarder was applied around 24 hours before casting concrete. Several layers had to be applied. More information about the concrete retarder used is 
found in the Appendixes. Figure 3.5 shows various molds coated with the retarder. These molds were also dissembled 24 hours after pouring the concrete on them. The retarded mortar surface was easily removed by scrubbing with a metallic stiff brush. The surface obtained with this treatment was called rough surface and it is characterized for its high aggregate exposure. For the rest of surfaces, the same procedure as in the splitting tensile samples was followed. Figure 3.10 shows the four concrete surfaces for slant shear test.

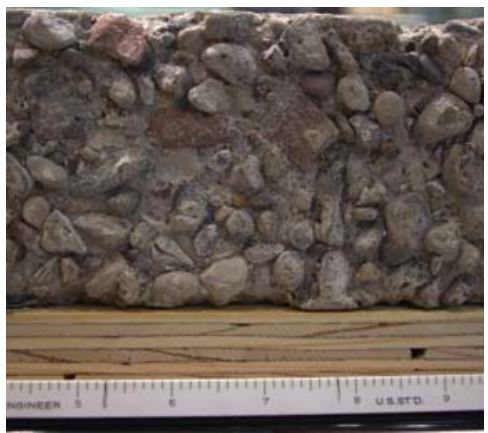

(a) Rough surface.

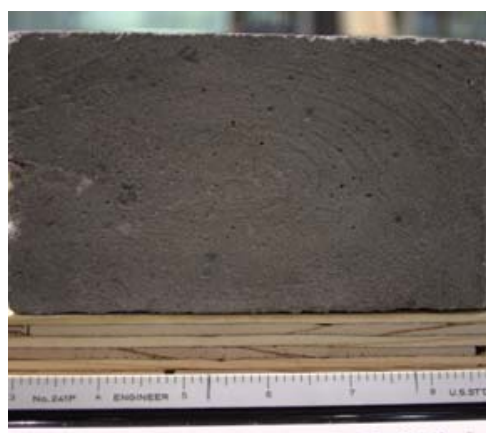

(c) Brushed surface.

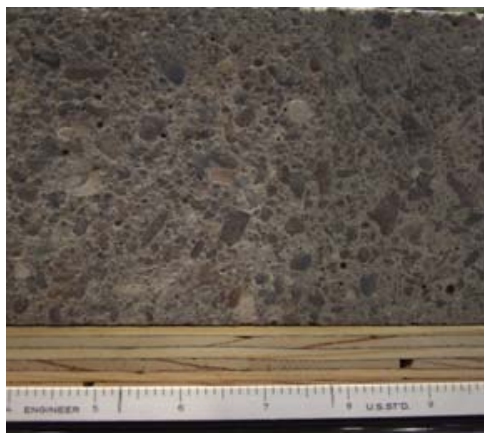

(b) Sandblasted

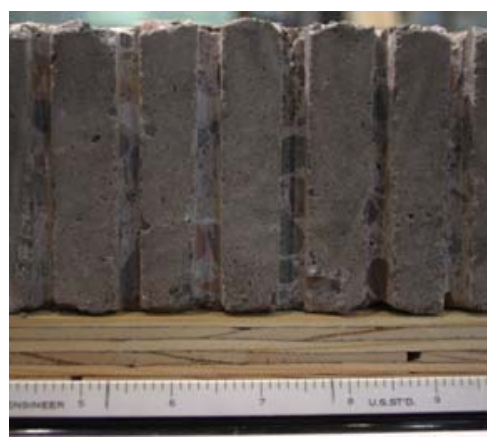

(d) Grooved surface.

Figure 3.10 Different NSC substrate surfaces for slant shear and pull off samples

\subsubsection{Pull off test}

Pull off slabs were cast at the same time as slant shear samples. ASTM C 1583 was followed with the exception that the test site (surface of the composite samples: $13 \times 7$ in) is smaller than 3 by $3 \mathrm{ft}$ ( 1 by $1 \mathrm{~m}$ ) specified in the code due to the fact that this standard test method is addressed to test in the field. The distances between cores and the depth of the circular cut through overlay below the interface was accomplished using the standard method. Figure 3.4 shows the dimension of the slabs and the distance between cores. 
Timber moulds were used to cast the concrete substrate. Normal concrete was poured into the moulds. Due to the high depth of the concrete substrates (4 in) two vibrations of 5-10 seconds each were carried out; the first one when the half of the concrete had been poured and the second one when all the concrete had been placed.

After placing NSC into the moulds, the same procedure as the slant shear samples was followed. Namely, a 24 hour moist cure, demoulding and cure in a lime water tank for 28 days. The identical substrate surfaces as those of the slant shear test were obtained. It has to be mentioned that the treated surfaces were those cast against the bottom part of the moulds in order to be able to obtain the same degree of roughness between those treated with the same method. Figure 3.11 shows several concrete slabs before demoulding.

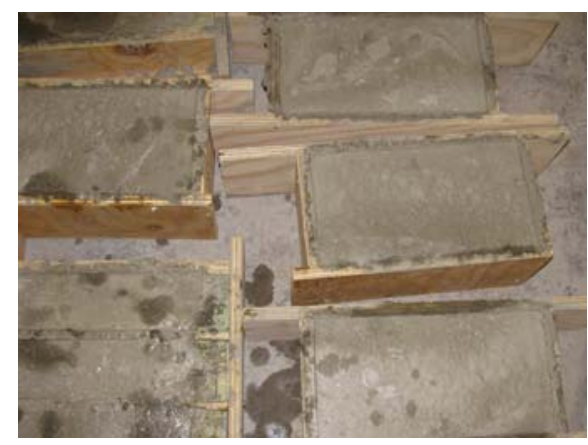

(a) Concrete substrates for the pull off test before demoulding.

Figure 3.11 NSC substrates for the pull off test 


\subsection{Roughness measurement}

Two methods were used to evaluate the degree of roughness obtained by each surface treatment: the macrotexture depth test and the Concrete Surface Preparation index (CSP) given by ICRI guide (International Concrete Repair Institute 1997). Figure 3.12 shows both roughness tests.

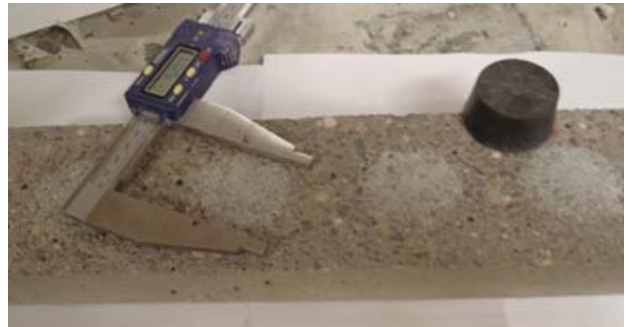

(a) Sample macro texture depth of concrete beams

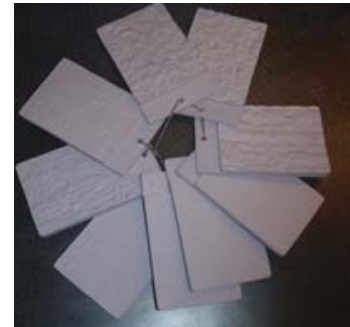

(b) Concrete Surface Preparation index

Figure 3.12 Tests to measure the degree of roughness of the concrete substrate

The macrotexture depth, according to ASTM E965-96 "Standard Test Method for Measuring Pavement Macotexture Depth Using a Volumetric Technique" determines the area covered by a known volume of glass spheres spread on the concrete surface. The volume of the glass beads used in the test was $2 \mathrm{ml}$, although the minimum value specified is $25 \mathrm{ml}$, due to the size of the samples were not large enough. The test apparatus consists of a known volume of glass beads, a flat rubber disk for spreading the beads on the surface, and a ruler for determining the area covered by the glass beads. For that, four different measurements of the diameter were taken. The test was repeated four times over different surfaces locations of each concrete specimen. The Equation 3.3 was used in order to determine the average macro texture depth from the measured diameters.

$$
M T D=\frac{4 * \mathrm{~V}}{\mathrm{D}^{2} * \pi}
$$

where $M T D$ is the mean texture depth of macro texture (in), $V$ is the sample volume $\left(\mathrm{in}^{3}\right)$, $D$ is the average diameter of the area covered by the glass beads. More information about the macrotexture depth test can be found in the Appendixes. It should be noted that the 
macrotexture depth was measured in all samples for the splitting tensile test. However, basis on the low variation of the results obtained between surfaces treated with the same method, only the roughness of random samples for the pull off and slant shear tests was measured.
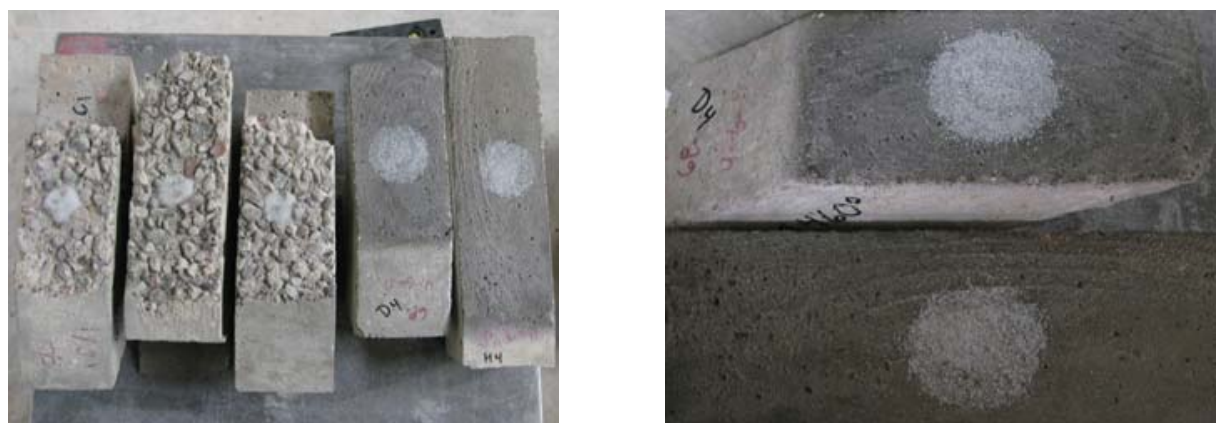

Sample macro texture depth of concrete substrates for the slant shear test.

Figure 3.13 Macrotexture depth

The CSP index provides 9 different rubber profiles that replicate different degrees of roughness. Figure 3.14 shows the ICRI profiles 7,8 and 9 compared to the rough surface. Table 3.5 classifies the different preparation methods according to CSP (International Concrete Repair Institute 1997).

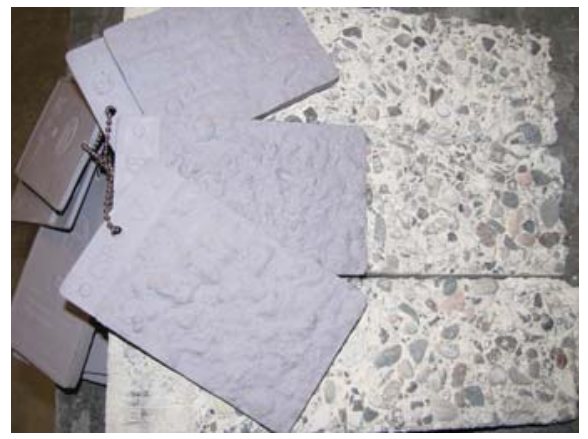

Comparing different ICRI profiles for the rough surface.

Figure 3.14 CSP index 
Table 3.5

Classification of different surface treatments according to CSP. Adapted from ICRI guideline

\begin{tabular}{|c|c|c|c|}
\hline Preparation method & $\begin{array}{c}\text { ICRI } \\
\text { Profile }\end{array}$ & Preparation method & $\begin{array}{c}\text { ICRI } \\
\text { Profile }\end{array}$ \\
\hline Detergent scrubbing & 1 & Scarifying & $4-9$ \\
\hline Acid etching & $1-2$ & Needle scaling & $5-7$ \\
\hline $\begin{array}{l}\text { Low-pressure water } \\
\text { cleaning }\end{array}$ & 1 & $\begin{array}{c}\text { High/ultrahigh } \\
\text { pressure water jetting }\end{array}$ & $6-9$ \\
\hline Grinding & $1-3$ & Scabbling & $7-9$ \\
\hline $\begin{array}{l}\text { Abrasive (sand) } \\
\text { blasting }\end{array}$ & $2-5$ & Flame blasting & $8-9$ \\
\hline Steel shotblasting & $3-8$ & Milling/rotomilling & 9 \\
\hline
\end{tabular}

The results of both tests are summarized in Table 3.6 for the splitting tensile samples and in Table 3.7 for the slant-shear and pull-off samples.

Table 3.6

Results of the macrotexture depth test for the splitting tensile samples and classification of the surfaces according to CSP

\begin{tabular}{cccc}
\hline $\begin{array}{c}\text { Surface } \\
\text { treatment }\end{array}$ & ICRI Profile & Macrotexture Depth (in) & $\begin{array}{c}\text { Macrotexture Depth } \\
(\mathbf{m m})\end{array}$ \\
\hline Smooth & 1,2 & 0.02 & 0.60 \\
Brushed & 1,3 & 0.03 & 0.74 \\
Chipped & Not applicable & 0.04 & 0.92 \\
Sandblasted & 4,5 & 0.04 & 1.06 \\
Grooved & Not applicable & Not applicable & Not applicable \\
\hline
\end{tabular}

Table 3.7

Results of the macrotexture depth test for the slant shear and pull off tests and classification of the surfaces according to CSP

\begin{tabular}{cccc}
\hline $\begin{array}{c}\text { Surface } \\
\text { treatment }\end{array}$ & ICRI Profile & Macrotexture Depth (in) & $\begin{array}{c}\text { Macrotexture Depth } \\
(\mathbf{m m})\end{array}$ \\
\hline Brushed & 1,3 & 0.03 & 0.72 \\
Sandblasted & 4,5 & 0.03 & 0.86 \\
Grooved & Not applicable & Not applicable & Not applicable \\
Rough & $\begin{array}{c}\text { Aggregate } \\
\text { exposure }>8,9\end{array}$ & 0.09 & 2.18 \\
\hline
\end{tabular}


As shown in the above tables, the macrotexture depth and ICRI profile results were similar in the brushed and sandblasted surfaces for all splitting tensile, slant shear and pull off samples. The introduction of the retarder concrete method proved to be effective in obtaining a rough surface.

\subsection{Placing overlay material}

The main difference between placing UHPC on the concrete substrate between the splitting tensile test and pull off and slant shear tests is that in the indirect tensile test, both dry and saturated conditions for the concrete substrate were used while for the pull off and slant shear tests, the saturated condition for the concrete substrate was always used. This is due to the fact that the initial splitting tensile results showed higher bond strength in saturated conditions than in dry conditions.

\subsubsection{Combination of Splitting Tensile Test with Freeze-Thaw Cycles}

As previously mentioned, two different moisture conditions were used. Dry concrete substrate is considered as the concrete substrate that was kept in environmental conditions for a period longer than 28 days. Saturated concrete substrate is defined as the concrete substrate that was submerged in a water tank for a period of at least 24 hours, and then covered by a damp cloth to keep the moisture until placing the overlay material, as shown in Figure 3.15. The surface was wet, however with no free water on it. UHPC was placed into the moulds by putting it in one corner and allowing it to flow into the mould. Vibration for 5-10 seconds was applied once UHPC was filling most parts of the mould. After pouring the overlay material, the composite specimens were covered by plastic sheets for three days before demoulding. 


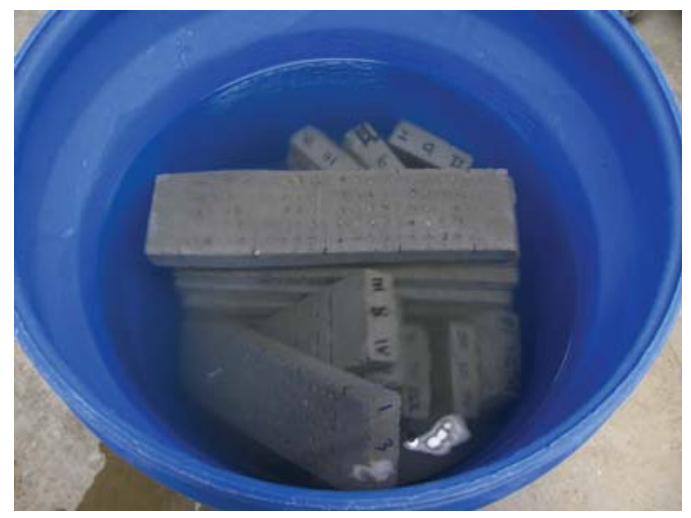

(a) Concrete substrate under water for 24 hours before placing the overlay material

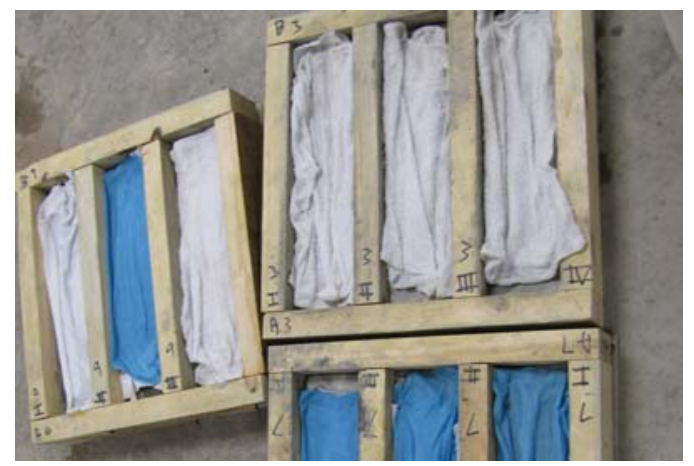

(c) Wet cloths covering the concrete substrate

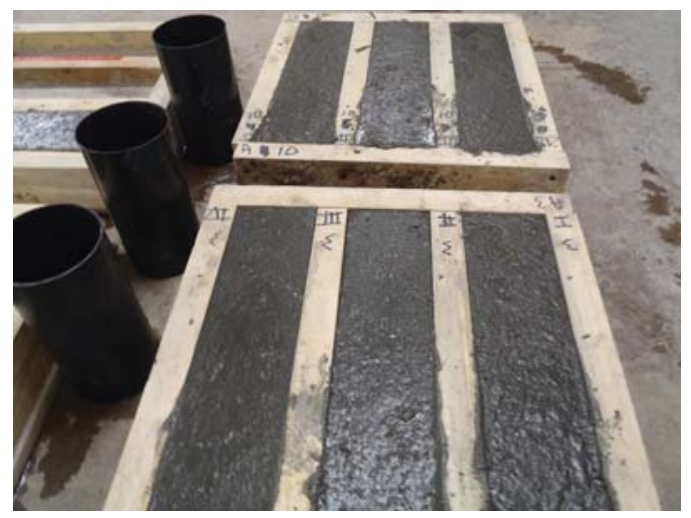

(b) Composite samples right after placing UHPC; before covering them with plastic.

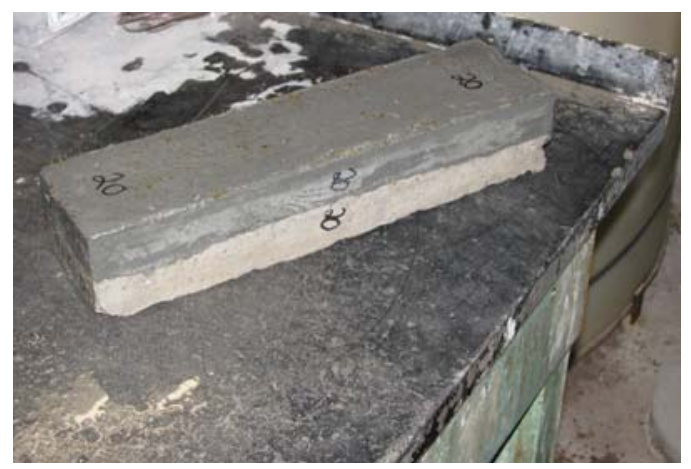

(d) Composite specimen after demolding.

Figure 3.15 Composite splitting tensile specimen casting process

\subsubsection{Slant shear and pull off tests}

All concrete substrates were submerged into water for at least 24 hours before mixing UHPC. Approximately, one hour before casting UHPC, the substrates were taken out of the water tank and placed back into the moulds. The moulds were covered by wet cloth after assembling, as shown in Figure 3.16. For the slant shear samples, UHPC was placed into the moulds by filling from the deepest corner to the shallow one while for the pull off test, UHPC was placed into the moulds by putting it in one corner and allowing it to flow into the mould. Vibration for 5-10 seconds was applied once UHPC was filling most part of the mould. After pouring the overlay material, the composite specimens were covered by plastic sheets for three days before demoulding; except a small number of slant-shear samples that were demoulded and tested at 2 days. 


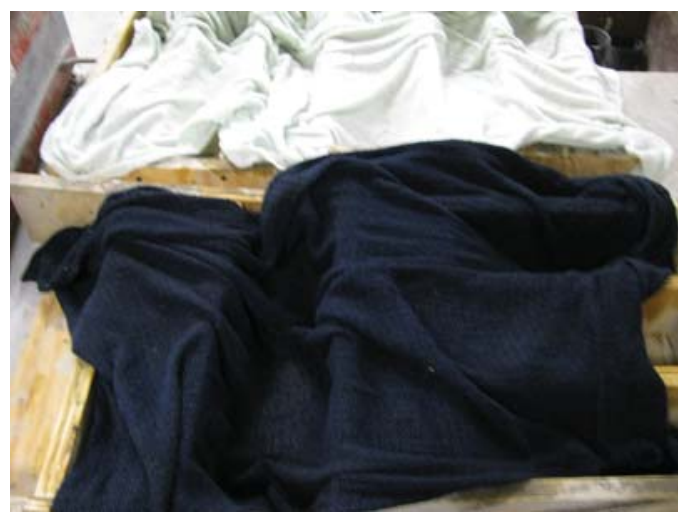

(a) Concrete substrate under water for 24 hours before placing the overlay material

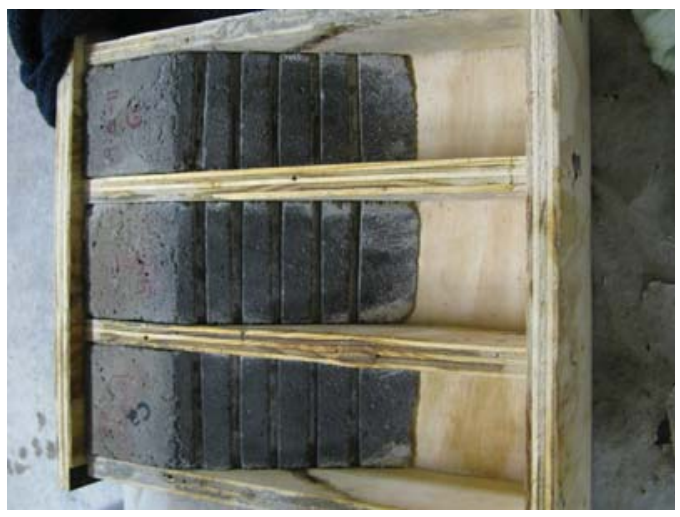

(b) Concrete substrate under water for 24 hours before placing the overlay material

Figure 3.16 Composite splitting tensile specimen casting process

\subsection{Testing procedure}

This section describes the main steps followed to subject the composite samples to the different loading configurations: indirect tensile stress, compression-shear stress and direct tensile stress.

\subsubsection{Combination of Splitting Tensile Test with Freeze-Thaw Cycles}

The aim of this test was to evaluate how the exposure to freeze-thaw cycling of the composite systems made up of UHPC and NSC affects the bond strength between both materials.

\subsubsection{Freeze-thaw cycling}

Those samples which were subjected to freeze-thaw cycles were cured in ambient air for at least 14 days prior to testing according to ASTM C 666, Procedure B. The difference between the Procedure B and Procedure A is that the samples are frozen in air and thawed in water in the Procedure B while in the Procedure A the samples are frozen and thawed in water. Table 3.8 summarizes the age of samples when they were put in the freeze-thaw chamber and the age at load testing. The samples were under ambient conditions $\left(68-72^{\circ} \mathrm{F}\right.$ and $\left.15-25 \% \mathrm{RH}\right)$ in the lab except that time that they were inside the chamber. 
Table 3.8

Composite sample ages for the freeze-thaw cycles and indirect tensile loading

\begin{tabular}{lcccc}
\hline \multicolumn{1}{c}{ Batch } & FT test starting (age in days) & \multicolumn{2}{c}{ Loading test (age in days) } \\
\hline Dry Substrate, w/o FT cycles & \multicolumn{2}{c}{ Not applicable } & NSC:270-278 & UHPC:221-231 \\
Dry Substrate, 300 FT cycles & NSC: $94 \quad$ UPHC:37-55 & NSC:270-278 & UHPC:221-231 \\
Wet Substrate, w/o FT cycles & \multicolumn{2}{c}{ Not applicable } & NSC:278-280 & UHPC:185-186 \\
\multicolumn{1}{c}{ Wet Substrate, 300 FT cycles } & NSC: $111 \quad$ UHPC:17-18 & NSC:278-280 & UHPC:185-186 \\
Wet Substrate, 600 FT cycles & NSC:278 $\quad$ UHPC:157-159 & NSC:417 & UHPC:296-298 \\
Wet Substrate, 900 FT cycles & NSC:278 $\quad$ UHPC:157-159 & NSC:417 & UHPC:296-298 \\
Monolithic, w/o FT cycles & Not applicable & & NSC: 227-228 \\
Monolithic, 300 FT cycles & NSC: 36 & & NSC: 227-228 \\
Monolithic, 600 FT cycles & NSC:175 & & NSC:314 \\
Monolithic, 900 FT cycles & NSC:175 & NSC:314 \\
\hline
\end{tabular}

The equipment used for the freeze-thaw cycling test was a 80-specimen Scientemp freeze-thaw chamber, as shown in Figure 3.17. The chamber needs to be filled with 80 samples for the proper performance, therefore, dummy specimens were used to maintain a full-load of the chamber. The set up heating/cooling rate was inside the limits established by ASTM C 666. Approximately, one cycle of freeze-thaw was completed in 3 hours. All samples (300, 600 and 900 freeze-thaw cycles) were removed from the chamber in a thawed condition, at approximately $40^{\circ} \mathrm{F}$, at intervals not exceeding 36 cycles and placed in a different place inside the chamber to offset slight variations of temperature inside the chamber. Measurements of the fundamental transverse frequency and mass of those samples that were subjected to 300 freeze-thaw cycles were taken each time that the samples were shifted. However, some issues with the frequency sensor prevented taking these measurements in intervals shorter than 36 cycles with the samples subjected to 600 and 900 cycles although. The frequency was taken according to ASTM C 215-02- Fundamental Transverse, Longitudinal, and Torsional Frequencies of Concrete Specimens" with the exception that the hammer impact was a slightly different due to the fact that the specimens were composed of two materials. A precision weighted steel impact hammer, an accelerometer to measure the dynamic response of the specimen and a 2 in thick Styrofoam pad to dampen any potential external frequency interference were 
used, as shown in Figure 3.17. A fast-Fourier transform method in DASYLab (version 8.0) was utilized to calculate the fundamental transverse frequency, and from this value, the Relative Dynamic Modulus (RDM) of the composite sample was estimated as shown in Equation 3.4. In this research, the RDM was defined as the ratio between the fundamental transverse frequency of a sample after $\mathrm{n}$ cycles and the first fundamental frequency of the specimen taken after being in the chamber for 33 cycles. Note that the ASTM C 666 recommends using the fundamental frequency at 0 cycles; however, this measurement was discarded due to the fact that it was taken in dry instead of moisture conditions. The mass measure was recorded with a precision of $0.01 \mathrm{lbs}(4.5 \mathrm{~g})$ using a calibrated scale.

$$
R D M_{c}=\frac{100 * n_{1}^{2}}{n^{2}}
$$

Equation 3.4

where $R D M$ is the Relative Dynamic Modulus at c cycles, $n_{1}$ is the fundamental transverse frequency after c cycles and $n$ is the initial fundamental transverse frequency.

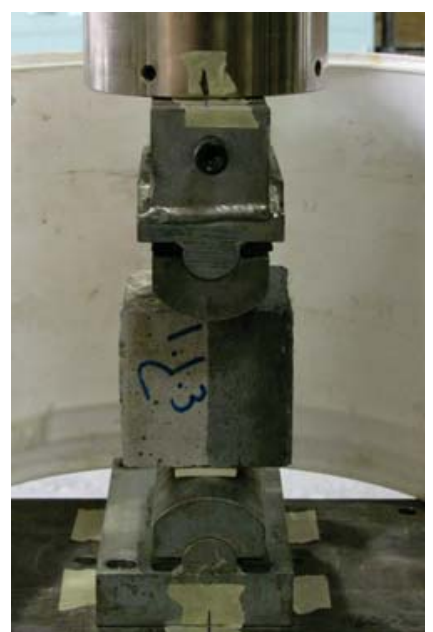

(a) The set-up for the splitting tensile test.

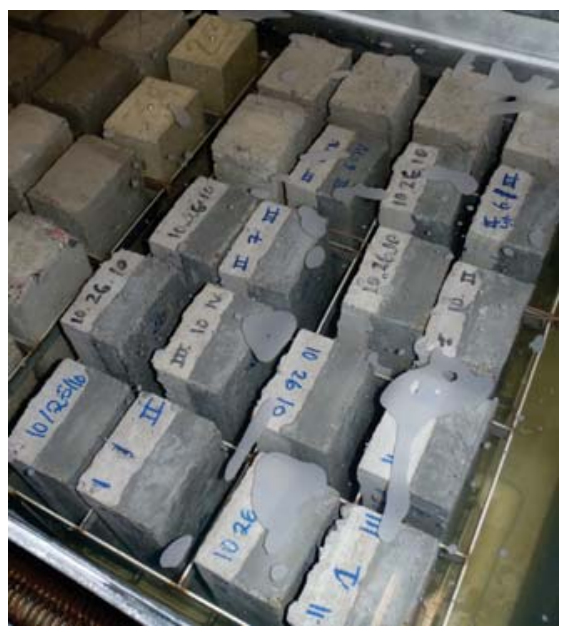

(b) Composite samples in the chamber.

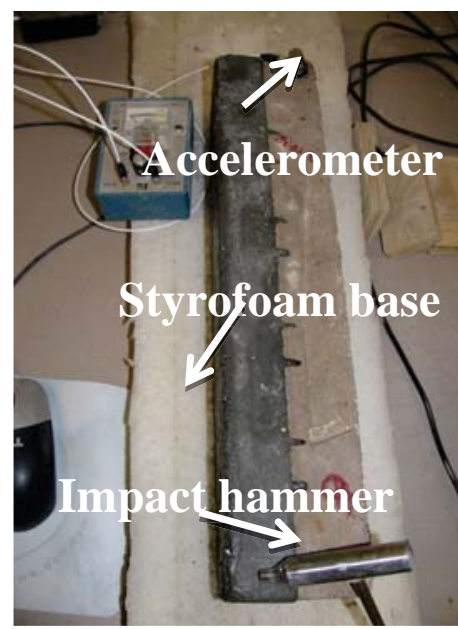

(c) Determining the fundamental longitudinal frequency of the composite specimen.

Figure 3.17 Several steps of the splitting tensile test 


\subsubsection{Indirect tensile loading}

Once the freeze-thaw test was completed, the samples were stored under ambient laboratory conditions until one week before the loading test. At this point they were cut into four small prisms, $4 \times 3 \times 3$ in, discarding approximately 1.75 in of each end, as described by $\mathrm{Li}$ et al. (1999) and Geissert et al. (1999) and shown in Figure 3.2. Compression loading was applied using the 55-kip 810 Material Test System (MTS) machine at a constant rate of $1800 \mathrm{lbf} / \mathrm{min}(8 \mathrm{kN} / \mathrm{min})$ until the sample was split, as shown in Figure 3.13.a. This loading rate would produce an indirect tensile stress of about $95 \mathrm{psi} / \mathrm{min}$ in a monolithic NSC sample which is the same as that applied by Geissert et al. (1999) and slightly lower than that recommended by ASTM C 496 (100$200 \mathrm{psi} / \mathrm{min}$ ). All samples were exposed to the same environmental conditions when they were not in the freeze-thaw chamber. As shown in Table 3.8, the differential shrinkage between samples was kept constant between 0 and 300 cycles and as well between 600 and 900 cycles, with the purpose of minimizing the introduction of a new variable into the test matrix (Julio et al. 2005). To estimate the indirect tensile stress along the bond interface, Equation 3.1 was applied despite the fact that the prisms were made up of two different materials. The nominal area, $4 \times 3$ in, was used for the samples subjected to 0 and 300 cycles while the real area was measured for those samples subjected to 600 and 900 cycles. Figure 3.2.c shows the dimension of the steel bars and plywood strips used to held the prisms and transmit the stress evenly along the bond interface during the loading test. Figure 3.2.d gives an approximately distribution of indirect tensile stress along the interface based on Geissert et al. (1999).

\subsubsection{Slant-shear test}

After demoulding, the composite samples were cured under ambient conditions $\left(68-77^{\circ} \mathrm{F}\right.$ and $25-40 \% \mathrm{RH}$ ) until the day of testing. If the surface of NSC was not perfectly flat, a small cut in the corner was made to obtain a regular surface. Different measures of the cross area of all prisms were taken. The load rate was 35 psi/s according to ASTM C 39. A calibrated Baldwin CT 300 hydraulic load frame was utilized to apply the load. 
Equation 2.2 and Equation 2.3 were used to estimate the combination of compressive and shear stresses along the interface that produce the failure of the composite samples. Figure 3.18 shows the compressive machine utilized and two composite specimens during the loading test.

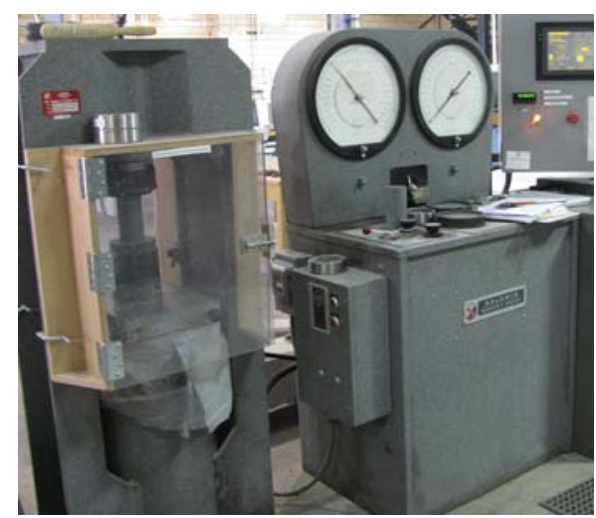

(a) Compressive machine for the slant-shear test

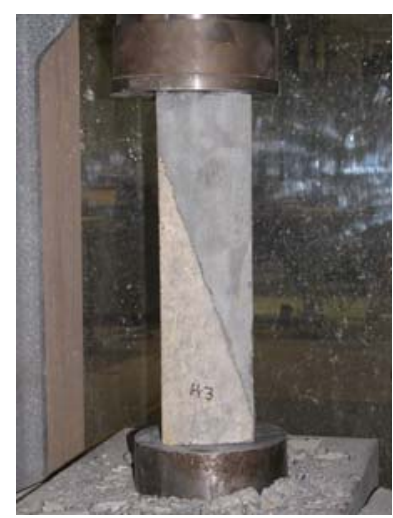

(b) Specimen with rough surface during loading test

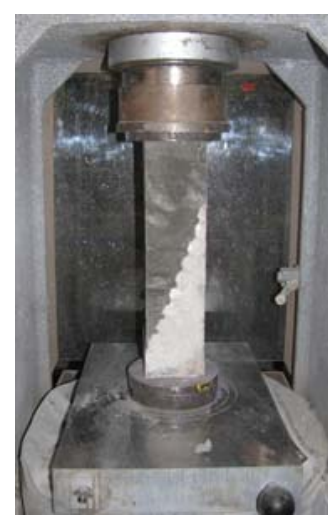

(c) Specimen with grooved surface during loading test

Figure 3.18 Set up of the slant-shear test

\subsubsection{Pull-off test}

This test determines the weakest tensile strength between the overlay material, bond interface and substrate. The main steps are to core the composite sample perpendicularly to the surface, to prepare the overlay surface, to glue the steel disk onto the sample and to apply a tensile force on the sample until failure.

The composite beams were kept in ambient conditions in the laboratory from demoulding until the testing day. The test was performed according to ASTM C 1583. The test specimen was obtained by drilling a core of 2 in depth into and perpendicular to the surface. The equipment used to produce the shallow core was a 2 in inside diameter wet cut diamond core bit fitted on a Milwaukee Dymorig coring rig, as shown Figure 3.19.a. The diameter of several cores was measured, obtaining constantly a value of 2 in. All cores were drilled between 7 and 8 days after casting the overlay material. After drilling the core, the UHPC surface was brushed by means of a cordless drill with a metallic brush. The surface was clean and generally flat but with some steel fibers incrusted on it. 
The following step was to glue the steel disk of 2 in diameter to the UHPC surface. For that, a rapid setting adhesive was used. The chosen epoxy adhesive was Scotch-WeldTM DP100 Plus Clear provided by 3M Company. The adhesive applicator is shown in Figure 3.19.b. The adhesive was carefully placed in the UHPC surface so that the epoxy did not run down the side of the specimen into annular cut and thereby not producing any interference in the results. To ensure the proper adhesion of the steel disk to the overlay surface, the disk was pressed against the overlay surface for $4 \mathrm{~min}$. If there was some excessive adhesive along the border of the steel disk, it was removed. The loading test started one day after gluing the disk to the overlay.

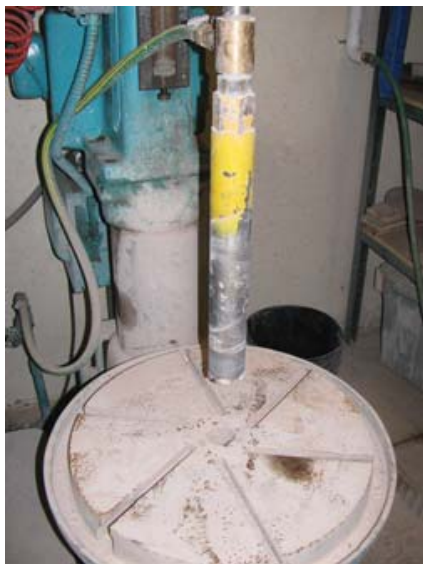

(a) Drilling rig

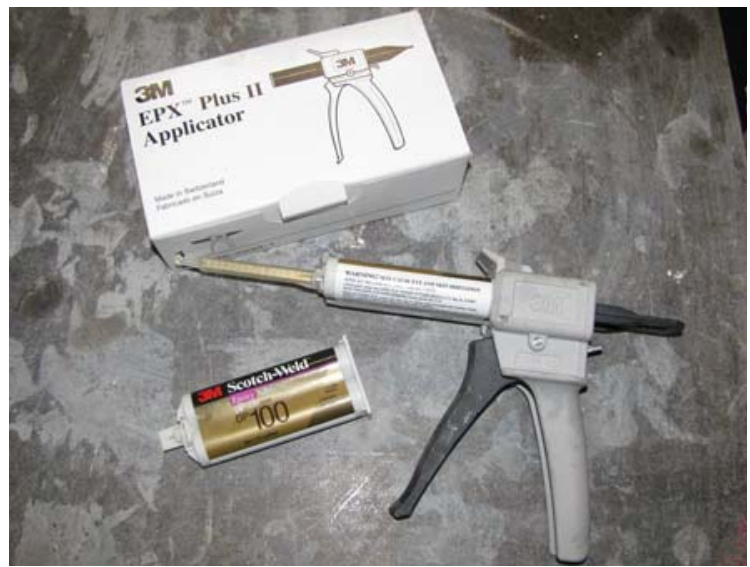

(b) Adhesive to glue the steel disk to the overlay surface

Figure 3.19 Preparation of the pull off specimen

The DYNA Pull-off Tester Type Z16 was used to apply the vertical force. Figure 3.20 shows three steel disks glued to the UHPC surface and the pull off tester. The tensile force was applied by moving the crank, therefore, the load rate was applied manually. ASTM C 1583 recommends to apply the tensile stress constantly at a rate of $5 \pm 2 \mathrm{psi} / \mathrm{s}$; however, due to the difficult of applying the load manually a constant rate, the rate applied was $50 \pm 20 \mathrm{psi}$ in intervals of $10 \mathrm{~s}$ with the help of a timer. The failure load and failure mode were recorded from each test specimen. Equation 3.2 was used to calculate the tensile strength. Some disks broke away from overlay surfaces at the beginning of the loading phase showed a poor adhesion to UHPC. This is explained due the fact that the steel fibers pushed up the steel disk during the first minutes after applying the adhesive. The test was repeated in those samples that failed on epoxying coating. 


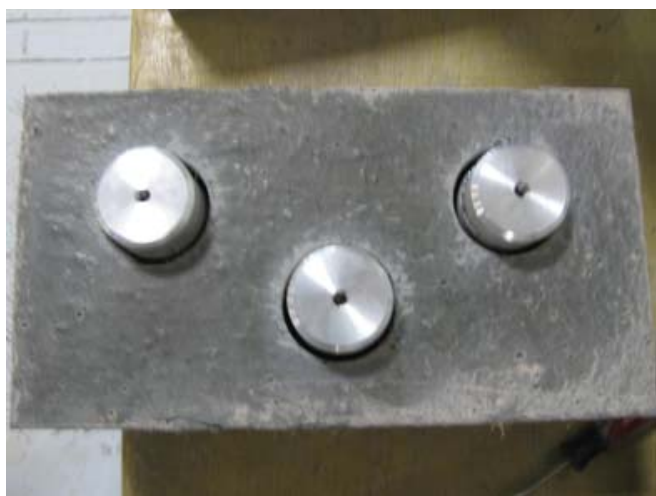

(a) Steel disks glued to the UHPC surface

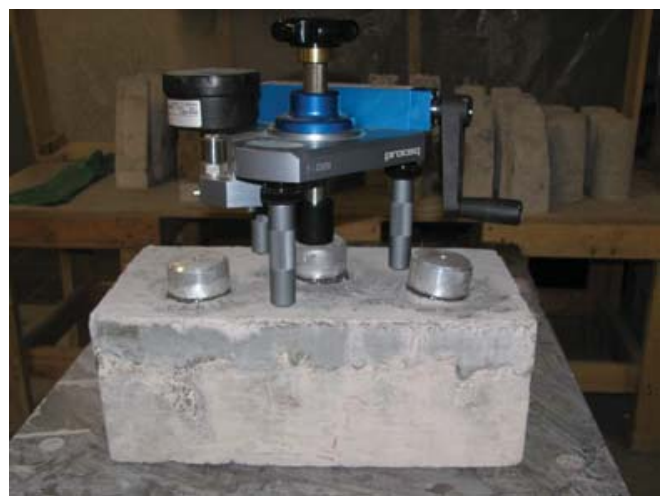

(b) The set up for the pull off test

Figure 3.20 Pull-off specimen 


\section{Results and Discussion}

This chapter presents the results obtained from different loading configurations. The experimental program was made up of three different bonding test methods, including, splitting tensile test combined with freeze-thaw cycles, slant-shear test and pull-off test. The failure stress and the failure mode were taken from each composite sample. The location of the failure provides valuable information about the quality of the bond between the repair and substrate materials. In general, if the failure takes place in the substrate, it can be stated that the bond strength is at least as high as that of the concrete substrate. If the failure occurs at the bond interface, the failure strength estimated is the bond strength. Therefore, a failure that occurs in the concrete substrate indicates that the bond strength is greater than that of the substrate concrete. The failure mode of each tested sample was visually examined and classified as the bond, concrete substrate, overlay or a mixture failure of these. ACI specified a bond strength range to select the repair materials in Guide for the Selection of Materials for the Repair of Concrete (2004) (ACI 546R-04) depending on the bond testing, as shown in Table 4.1. These values are considered as the minimum acceptable bond strength.

Table 4.1

ACI bond strength range for different bond test configurations. Adapted from ACI 546R-04

\begin{tabular}{llll}
\multicolumn{1}{c}{ Description } & \multicolumn{3}{c}{ Bond strength } \\
\hline \multirow{2}{*}{ Slant-Shear Bond } & 1 days: & 400 to $1,000 \mathrm{psi}$ & 3 to $7 \mathrm{MPa}$ \\
\cline { 2 - 4 } & 7 days: & 1,000 to $1,800 \mathrm{psi}$ & 7 to $12 \mathrm{MPa}$ \\
\cline { 2 - 4 } Direct Tensile Bond & 28 days: & 2,000 to $3,000 \mathrm{psi}$ & 14 to $21 \mathrm{MPa}$ \\
\hline \multirow{2}{*}{ Direct Shear Bond } & 1 days: & 70 to $150 \mathrm{psi}$ & 0.5 to $1 \mathrm{MPa}$ \\
\cline { 2 - 4 } & 7 days: & 150 to $250 \mathrm{psi}$ & 1 to $1.7 \mathrm{MPa}$ \\
\cline { 2 - 4 } & 28 days: & 250 to $300 \mathrm{psi}$ & 1.7 to $2 \mathrm{MPa}$ \\
\hline & 1 days: & 150 to $300 \mathrm{psi}$ & 1 to $2 \mathrm{MPa}$ \\
\hline & 7 days: & 300 to $400 \mathrm{psi}$ & 2 to $3 \mathrm{MPa}$ \\
\hline
\end{tabular}

The highest bond strength expected is that of the slant-shear in which a combined state of shear and compression stresses is produced along the bond interface. While the lowest strength is obtained under direct tension (the most severe loading condition). This coincides with the experimental results provided by Momayez et al. (2005) that ranked the different tests according to the bond strength average obtained, from the greatest 
value to the lowest one in the following order: slant-shear, Bi-Surface (direct shear), the splitting tensile and pull-off tests.

\subsection{Combination of Splitting Tensile Test with Freeze-Thaw Cycles}

This section presents the results of the freezing and thawing performance and indirect tensile strength of the composite and monolithic samples. ASTM C 666 gives a degree of deterioration of the specimens subjected to a repetitive freeze-thaw cycling exposure. Measurements of the transverse frequency and mass were taken throughout the test. The decrease of these values indicates the deterioration due to the freeze-thaw cycles in the samples. It is commonly stated that the ASTM C 666 method is more severe than most natural exposures (Kosmatka and Wilson 2011).

As the stress distribution of the splitting tensile test shows in Figure 3.2, there is a uniform tensile stress distribution along the interface plane except for a small area at the corner that is subjected to compressive stress. Momayez et al. (2005) demonstrated that the results of the splitting test are equal or slightly greater than that obtained with the pull-off test.

\subsubsection{Freeze-thaw cycles}

The repetitive effect of successive freeze thaw cycles can produce the deterioration of the concrete due to the disruption of paste and aggregate. The freezing of the water causes a hydraulic pressure in the capillaries and pores of the cement paste and aggregate that might exceed the tensile strength of the surrounding paste or aggregate resulting in the dilatation and rupture of the cavity (Kosmatka and Wilson 2011).

This test focused on the fundamental transverse frequency and mass measurements of the samples. The decrease of a RDM is a sign of microcrack formation and the reduction in mass measurements shows the disintegration of material (Misson 2008). 
Figure 4.1 shows the mass variation of those composite samples subjected to 300 freezethaw cycles. The slight increase between the two first measurements is due to the fact that the initial measure was taken in dry conditions while the specimens were saturated in the following measurements. The slight variation between different samples is due to the different thickness of the new and substrate layers. It can be stated that no spalling occurred in the samples. Figure 4.2 shows the fundamental transverse frequency evolution of these composite samples. As the weight variation, the initial increment was due to the saturation of the samples. It can be appreciated that the fundamental transverse frequency increased slightly with the exposure of the samples to the freeze-thaw cycles. This is explained due to continuation of the hydration as Misson (2008) stated in his study of the UHPC performance under freeze-thaw cycling. The samples underwent an ambient air curing regime and it is believed that they had abundant amounts of unhydrated cement particles that could get hydrated in the presence of water. Graybeal (2006) also noted the gain in strength of UHPC during the freeze thaw process.

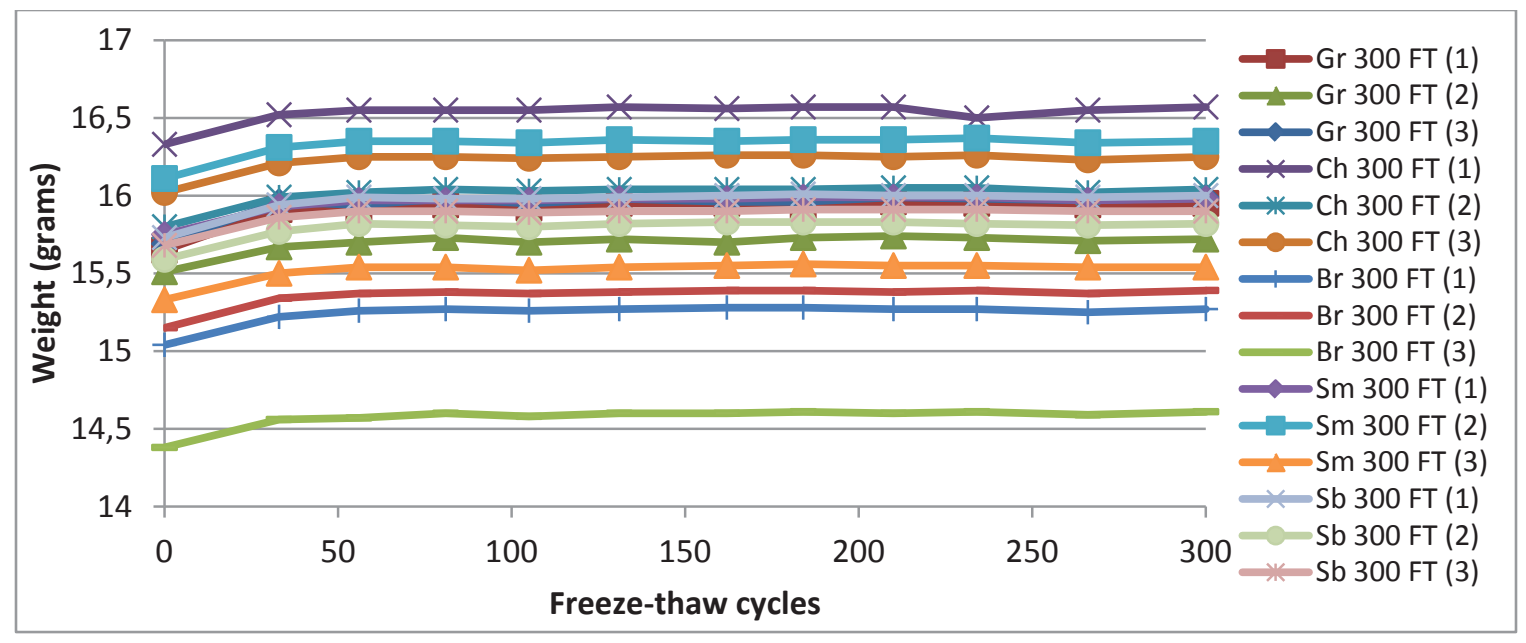

Figure 4.1 Weight of composite samples, cast in wetting conditions, subjected to 300 freeze-thaw cycles 


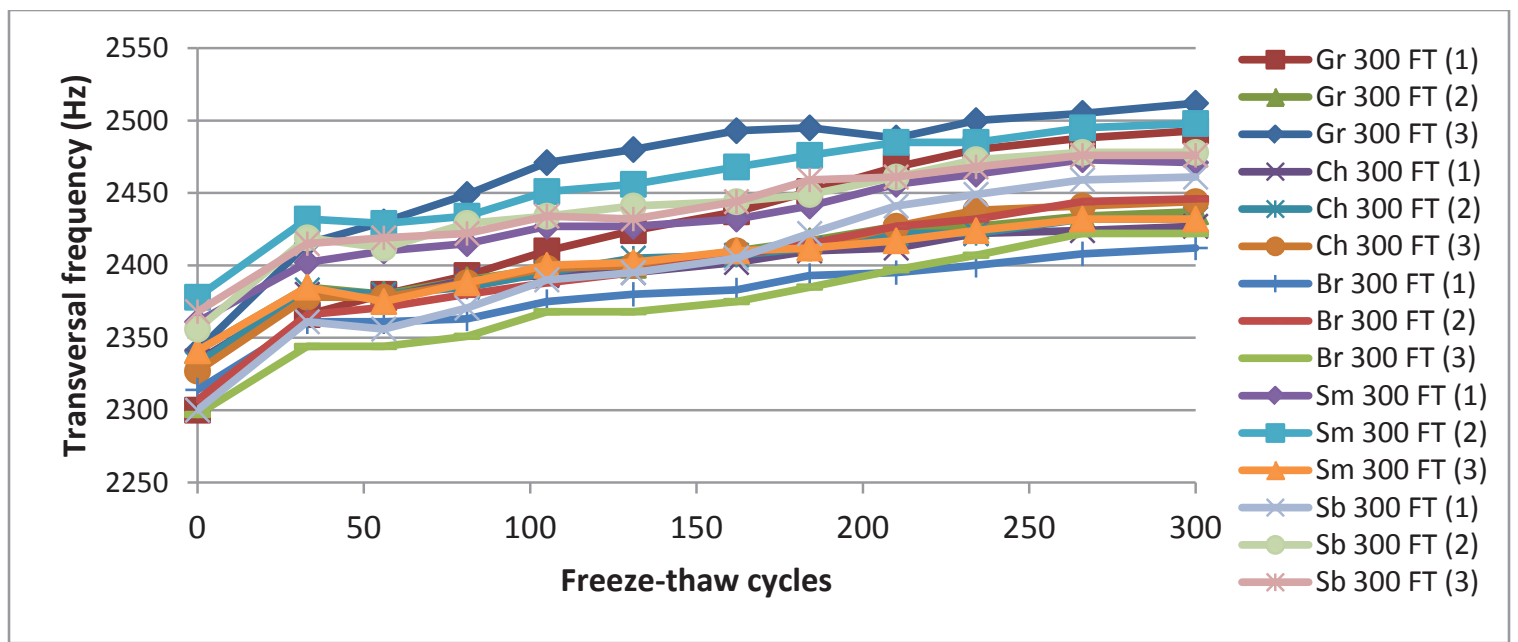

Figure 4.2 Fundamental transverse frequency of composite samples, cast in wetting conditions, subjected to 300 freeze-thaw cycles

Figure 4.3 shows the RDM considering that the initial transverse frequency is at 33 cycles. All specimens had higher RDM's than at the beginning of testing, suggesting that the samples did not suffer any deterioration at all.

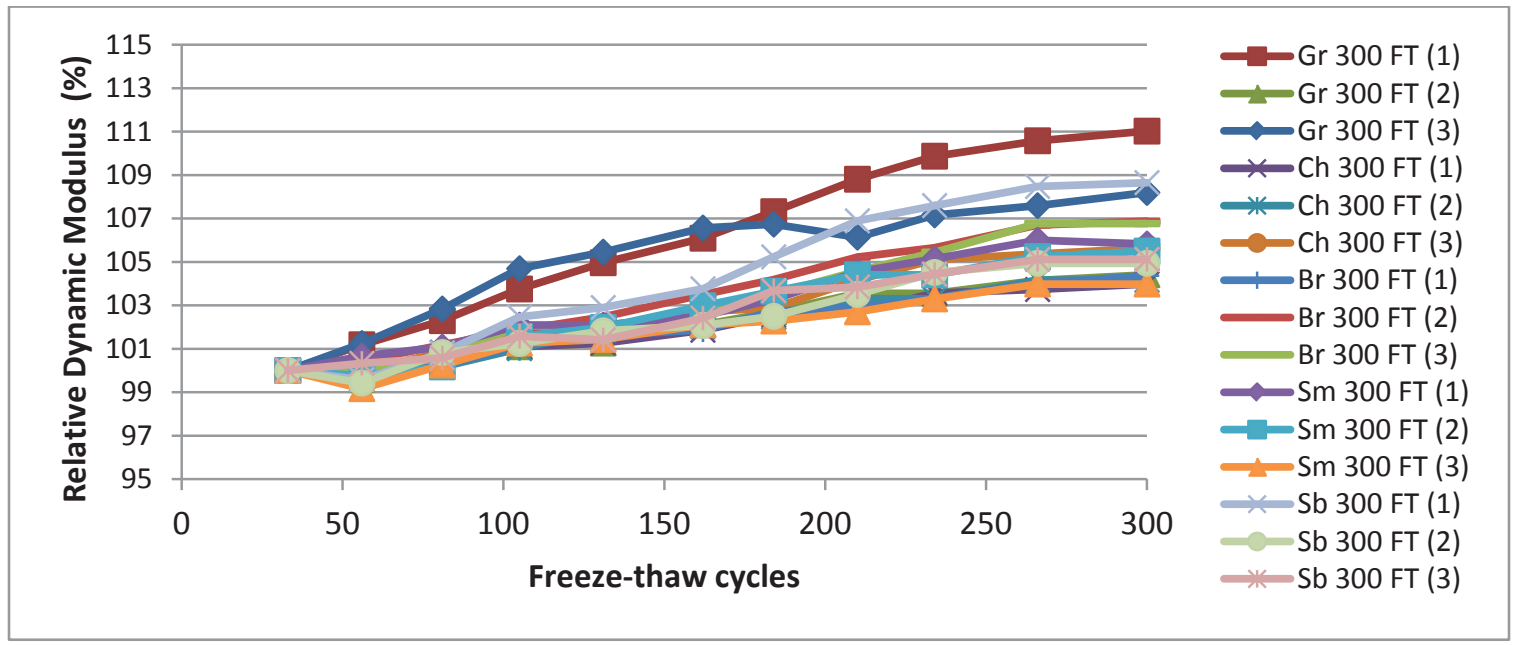

Figure 4.3 Relative Dynamic Modulus of composite samples, cast in wetting conditions, subjected to 300 freezethaw cycles

Figure 4.4, Figure 4.5 and Figure 4.6 show the variation of weight, the evolution of the transversal frequency and the increase of the RDM, respectively, of the NSC specimens that were subjected to 300 freeze-thaw cycles. All of them show a similar behavior as that of the composite specimens: the exposure to repetitive freeze-thaw cycling did not deteriorate the specimens at all. This might be explained due to the fact that the NSC 
mixes were designed according to the requirements given by Michigan Department of Transportation (2009). This involves an entrained air of $4.5 \pm 1.5 \%$. The addition of airentraining admixtures intensely improves the performance of concrete exposed to cycles of freezing and thawing.

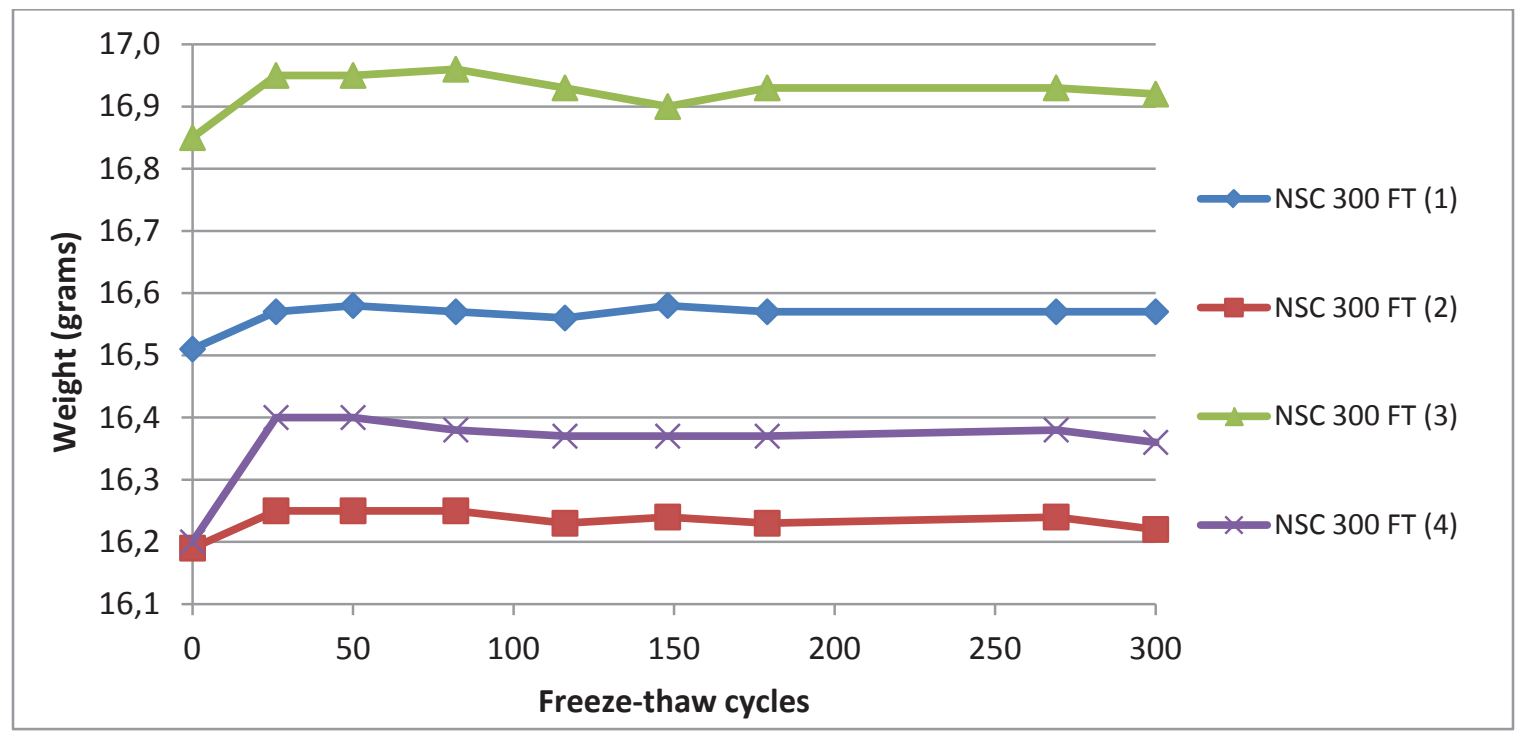

Figure 4.4 Weight of NSC samples subjected to 300 freeze-thaw cycles

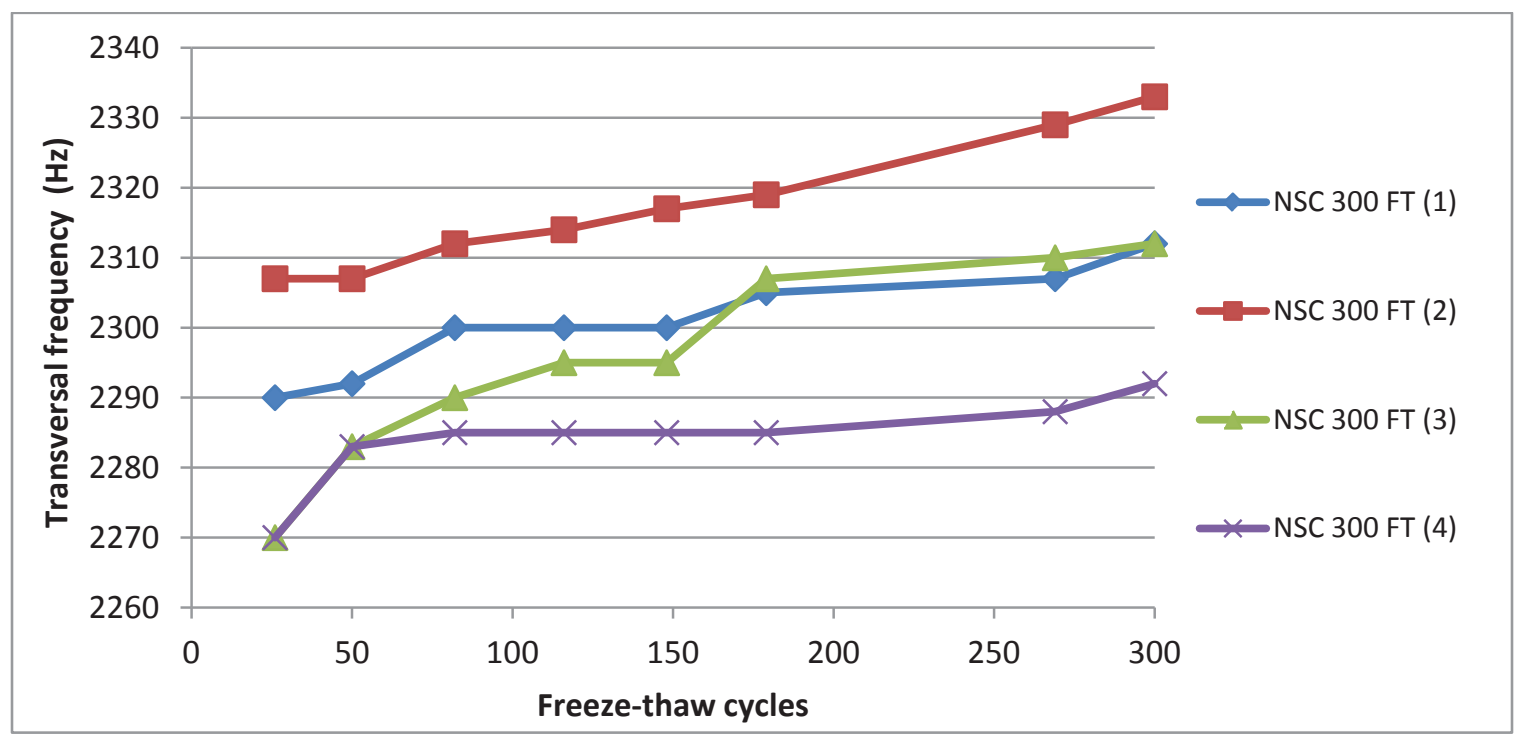

Figure 4.5 Transversal frequency of NSC samples subjected to 300 freeze-thaw cycles 


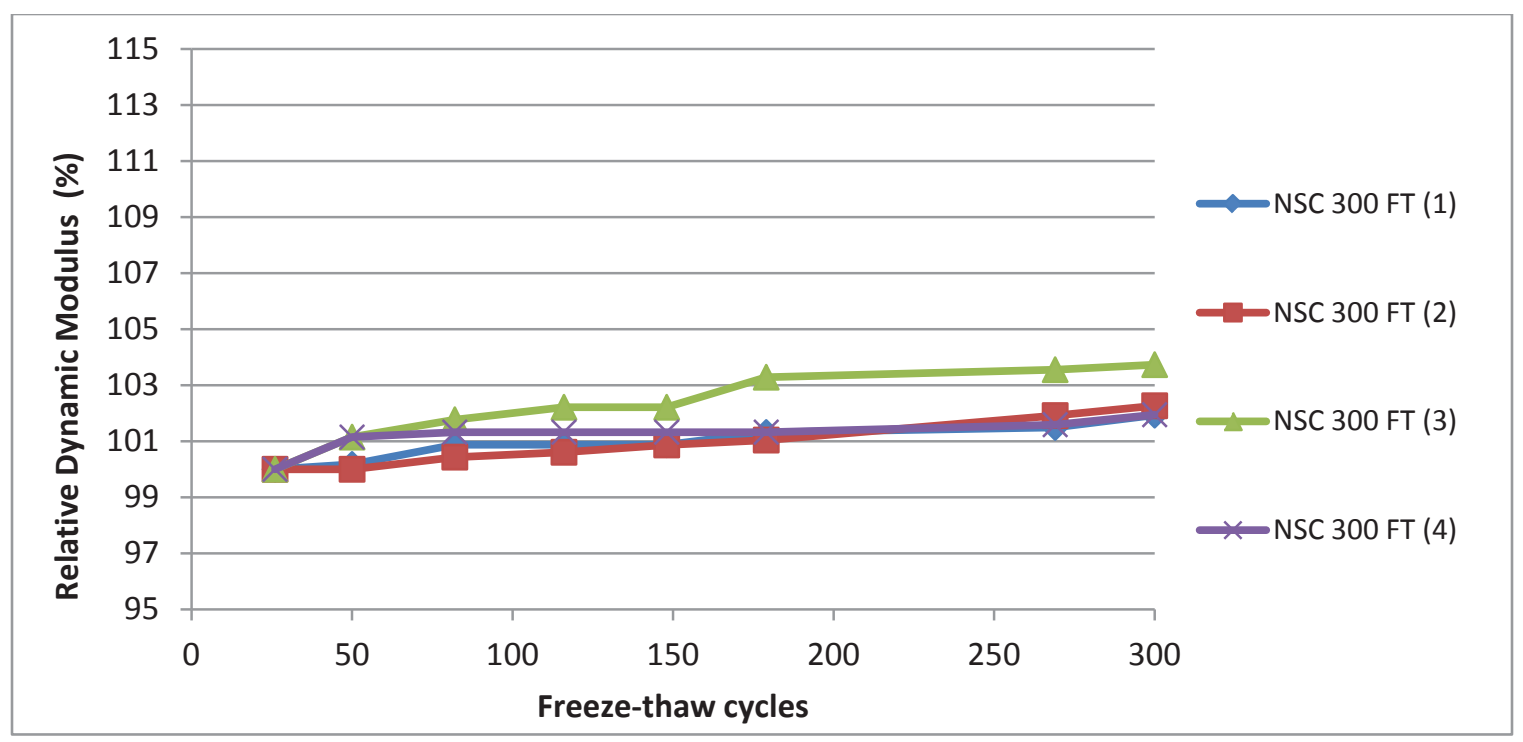

Figure 4.6 Relative Dynamic Modulus of NSC samples subjected to 300 freeze-thaw cycles

\subsubsection{Indirect tensile loading}

Several cylinders were cast from each NSC and UHPC mixes in order to assess the quality of both materials. Table 4.2 gives the compressive strength of the repair and old layers on the same day as the splitting test was carried, in order to have a measure of the quality of both materials. By using Equation 4.1, given by ACI318-11, the splitting tensile strength for the concrete substrate was as well estimated.

$$
f_{c t}=6.7 * \sqrt{f_{c}} \text { in psi }
$$

Equation 4.1

where $f_{c t}$ is the splitting tensile strength and $f_{c}$ is the compressive strength.

It should be mentioned that both $f_{c}$ and $f_{c t}$ do not represent the influence that the freezethaw cycles could have on the overlay and substrate strengths of the composite specimens due to the fact that these values are calculated from cylinders that were not exposed to freeze-thaw cycling conditions. 
Table 4.2

Age and compressive strength of overlay and substrate materials on the day indirect tension test

\begin{tabular}{ccccccccc}
\hline \multirow{2}{*}{ Batch } & \multicolumn{3}{c}{ NSC Substrate } & \multicolumn{4}{c}{ UHPC overlay } \\
\cline { 2 - 8 } & $\mathrm{N}^{\circ}$ & Age & $f_{c}$ & $\mathrm{f}_{\mathrm{ct}}$ & $\mathrm{N}^{\circ}$ & Age & $f_{c}$ \\
\hline Dry Substrate, w/o and 300 FT & 5 & $270-278$ & 6.78 & 0.55 & 10 & $221-231$ & 22.46 \\
Wet Substrate, w/o and 300 FT & 4 & $278-280$ & 6.46 & 0.54 & 6 & $185-186$ & 22.14 \\
Wet Substrate, 600 FT & 2 & $417-418$ & 7.88 & 0.59 & 6 & $296-298$ & 22.44 \\
Wet Substrate, 900 FT & 4 & $437-438$ & 7.79 & 0.59 & 6 & $317-319$ & 22.20 \\
Monolithic, w/o and 300 FT & 2 & $227-228$ & 8.61 & 0.62 & & No applicable \\
Monolithic, 600 and 900 FT & 4 & $314-315$ & 8.27 & 0.61 & & No applicable \\
\hline
\end{tabular}

Note: $N^{\circ}$ : number of cylinders, w/o: without freeze-thaw cycles, FT: freeze-thaw cycles. Age in days. Strength in ksi.

Table 4.3 sorts out the different NSC mixes with the corresponding samples cast from each and gives their compressive strengths at the age of 28 days.

Table 4.3

Age and compressive strength of overlay and substrate materials on the day indirect tension test

\begin{tabular}{|c|c|c|c|c|}
\hline \multirow{2}{*}{ Mix } & \multirow{2}{*}{ Batch } & \multicolumn{3}{|c|}{ NSC Substrate } \\
\hline & & $\mathrm{N}^{\circ}$ & Age(days) & Strength(ksi) \\
\hline $1^{\text {st }} \mathrm{NSC}$ mix & Dry Substrate, w/o and 300 FT & 2 & 28 & 6.51 \\
\hline $2^{\text {nd }} \mathrm{NSC}$ mix & Wet Substrate, w/o and $300 \mathrm{FT}$ & 2 & 28 & 6.30 \\
\hline $3^{\text {rd }} \mathrm{NSC} \operatorname{mix}$ & Wet Substrate, 600 and 900 FT & 2 & 28 & 6.85 \\
\hline $4^{\text {th }} \mathrm{NSC}$ mix & Monolithic: w/o , 300, 600 and 900 FT & 2 & 28 & 7.40 \\
\hline
\end{tabular}

The splitting tensile test was carried out as described in 3.7.1.2. A large number of the composite specimens cast with the old substrate being dry failed during the cutting process, indicating a general failure of the bond from construction (Austin et al. 1999) shows the percentage of prisms that split before the loading test with the dry concrete substrate.

Table 4.4

Percentage of prisms that failed prematurely under dry concrete substrate condition

\begin{tabular}{cccc}
\hline Case & Percentage of failure (\%) & Case & Percentage of failure (\%) \\
\hline $\mathrm{Sb} \mathrm{300} \mathrm{FT}$ & 50 & $\mathrm{Sm} \mathrm{300} \mathrm{FT}$ & 50 \\
$\mathrm{Sb} \mathrm{w} / \mathrm{o}$ & 16.7 & $\mathrm{Sm} \mathrm{w} / \mathrm{o}$ & 75 \\
$\mathrm{Br} \mathrm{300} \mathrm{FT}$ & 83.3 & $\mathrm{Ch} \mathrm{300} \mathrm{FT}$ & 100 \\
$\mathrm{Br} \mathrm{w} / \mathrm{o}$ & 66.7 & $\mathrm{Ch} \mathrm{w/o}$ & 100 \\
\hline
\end{tabular}

Note: Sb: sandblasted, Br: brushed, Sm: smooth, Ch: chipped, w/o: without freeze-thaw cycles, FT: freezethaw cycles. 
Only those specimens with a grooved substrate surface were fully successful in the dry substrate condition, due to the fact that the bond was achieved by fitting UHPC in the grooves rather than any adhesive mechanism since no dust removal treatment was applied in the grooved surface, as shown in Figure 3.6.f. The tensile strength of prisms with grooved substrate surface and the COV are given in Table 4.5.

Table 4.5

Results of grooved surface under dry concrete substrate condition

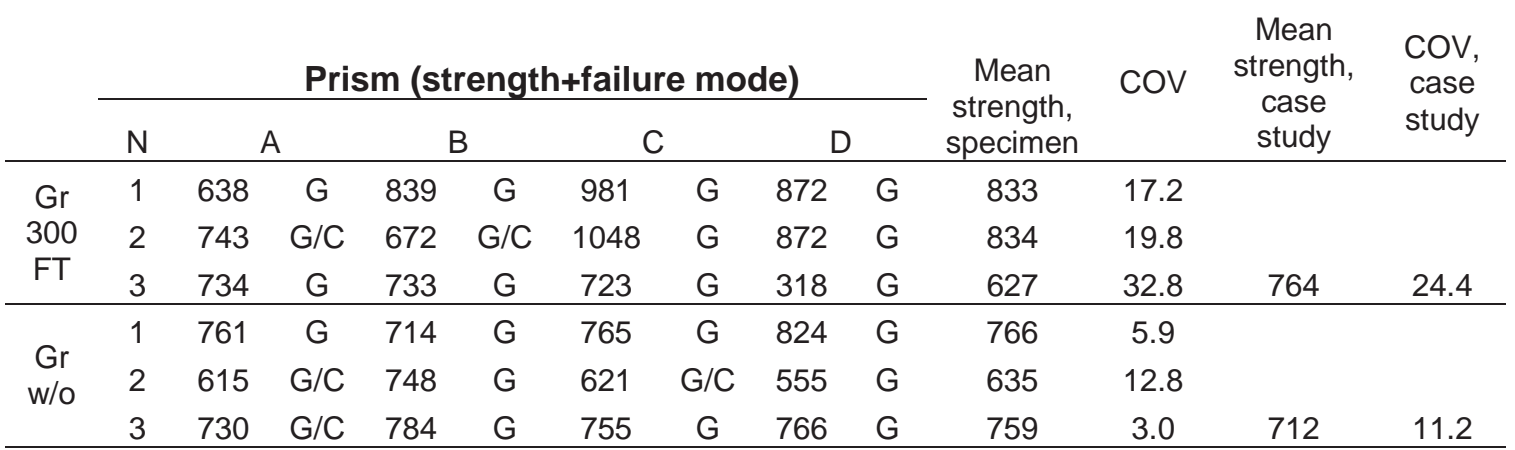

Note: N: number of the specimen, Gr: grooved, w/o: without freeze-thaw cycles, FT: freeze-thaw cycles, G: failure in the grooves, G/C: mixture failure between bond and concrete. Strength in psi.

However, excellent bond performance was achieved under saturated concrete substrate, with the exception of four composite specimens that presented scattered results. The test results for the saturated substrate samples are presented in Table 4.6 along with descriptions of the failure modes. The four specimens with high COV were highlighted in grey. The rest of the samples widely satisfied the range of 250 to $300 \mathrm{psi}$ (1.7 to $2 \mathrm{MPa}$ ) at 28 days specified in the ACI 546.3R-06 for acceptable bond strength and 300 psi (2.1 MPa) that (Sprinkel and Ozyildirim 2000) defined as an excellent bond. These values refer to direct tensile bond. This comparison with indirect tensile strength is based on results from Momayez et al. (2005) that demonstrated the bond strength obtained with the pull-off test (direct tensile strength) to be equal or slightly lower than that of the splitting test (indirect tensile strength). 
Table 4.6

Summary of indirect tensile strength composite sample results under saturated concrete substrate.

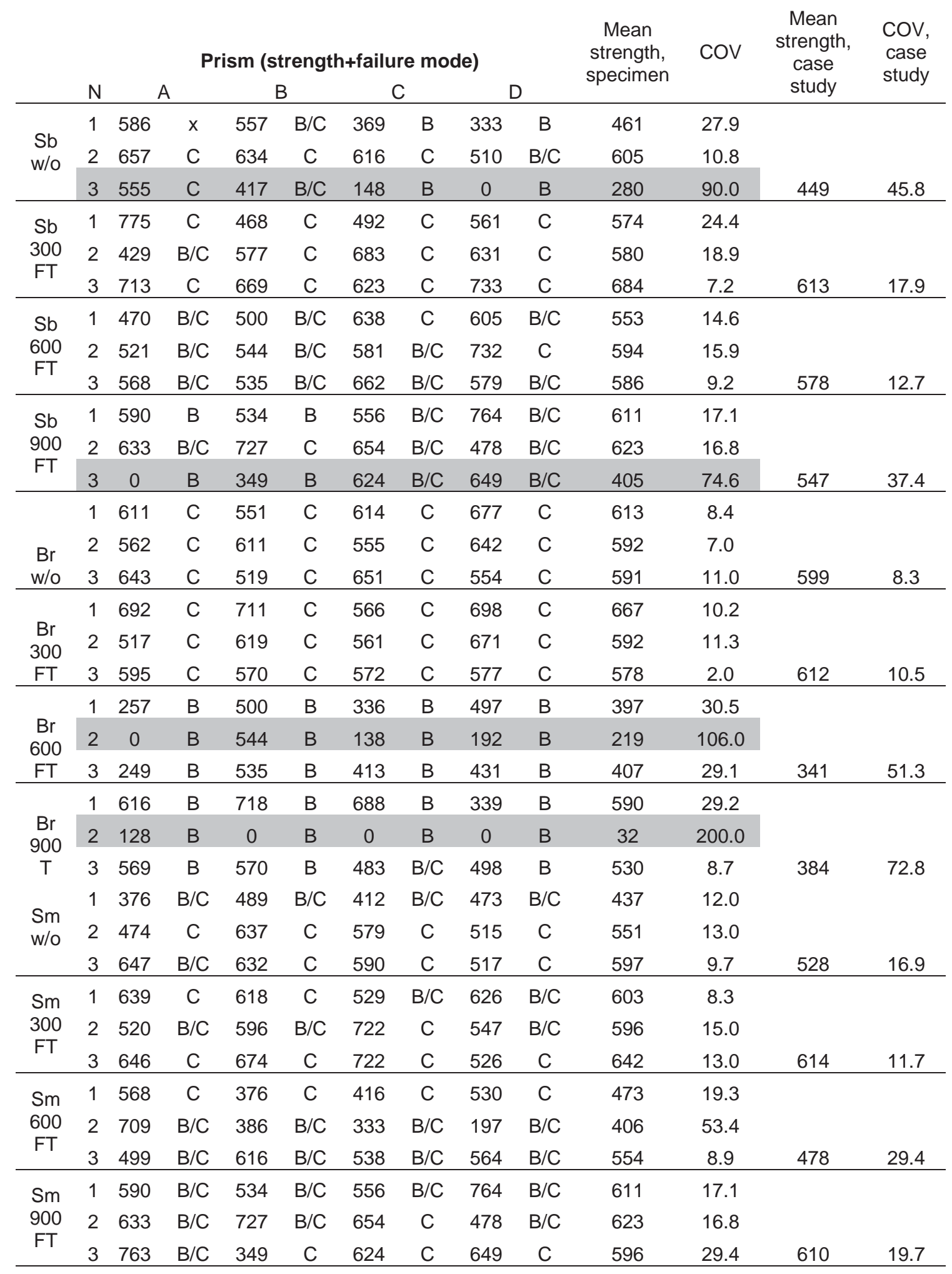


Table 4.6, continued.

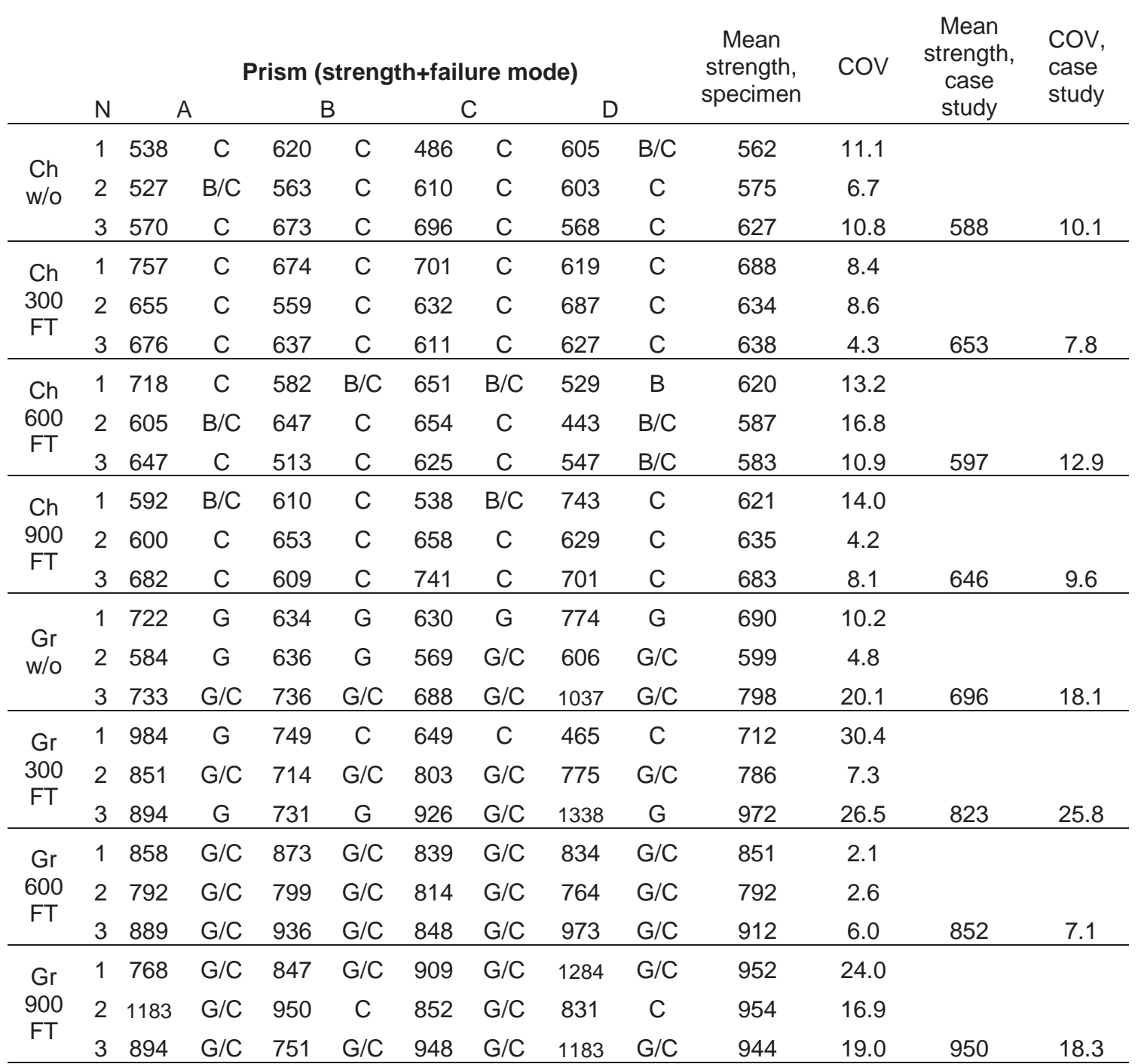

Note: N: number of the specimen, Sb: sandblasted, Br: brushed, Sm: smooth, Ch: chipped, Gr: grooved, w/o: without freeze-thaw cycles, FT: freeze-thaw cycles, C: failure in the concrete, B: failure in the bond, $B / C$ : mixture failure between bond and concrete, $G$ : failure in the grooves, G/C: mixture failure between bond and grooves. In Sb W/o, N 1, prism A, the load was removed before splitting of the prism. Strength in psi.

Table 4.7 shows the results of 14 monolithic NSC specimens that were cast for use as a benchmark to assess the quality of the bond. These samples were subjected to the same conditions as those of the composite specimens. The validity of this test is demonstrated by the similitude of the splitting tensile strengths obtained with the experimental program (Table 4.7) with the indirect tensile strengths estimated from Equation 4.1 (Table 4.2). 
Table 4.7

Summary of indirect tensile strength monolithic NSC sample results

\begin{tabular}{|c|c|c|c|c|c|c|c|c|c|c|c|}
\hline & $\mathrm{N}$ & $\begin{array}{c}\text { Mean } \\
\text { strength, } \\
\text { specimen }\end{array}$ & $\begin{array}{c}\text { COV, } \\
\text { specimen }\end{array}$ & $\begin{array}{c}\text { Mean } \\
\text { strength, } \\
\text { case } \\
\text { study }\end{array}$ & $\begin{array}{l}\text { COV, } \\
\text { case } \\
\text { study }\end{array}$ & & $\mathrm{N}$ & $\begin{array}{c}\text { Mean } \\
\text { strength, } \\
\text { specimen }\end{array}$ & $\begin{array}{c}\text { COV, } \\
\text { specimen }\end{array}$ & $\begin{array}{l}\text { Mean } \\
\text { strength, } \\
\text { case } \\
\text { study }\end{array}$ & $\begin{array}{l}\text { COV, } \\
\text { case } \\
\text { study }\end{array}$ \\
\hline \multirow{4}{*}{ w/o } & 1 & 678 & 8.6 & \multirow{4}{*}{649} & \multirow{4}{*}{12.9} & \multirow{4}{*}{$\begin{array}{l}300 \\
F T\end{array}$} & 1 & 710 & 6.4 & \multirow{4}{*}{705} & \multirow{4}{*}{6.7} \\
\hline & 2 & 655 & 14.3 & & & & 2 & 751 & 2.9 & & \\
\hline & \multirow[t]{2}{*}{3} & 614 & 16.9 & & & & 3 & 661 & 4.8 & & \\
\hline & & & & & & & 4 & 709 & 6.8 & & \\
\hline \multirow{4}{*}{$\begin{array}{c}600 \\
\mathrm{FT}\end{array}$} & 1 & 672 & 11.1 & \multirow{4}{*}{674} & \multirow{4}{*}{9.2} & \multirow{4}{*}{$\begin{array}{l}900 \\
\mathrm{FT}\end{array}$} & 1 & 661 & 9.7 & \multirow{4}{*}{677} & \multirow{4}{*}{9.3} \\
\hline & 2 & 673 & 6.3 & & & & 2 & 663 & 8.1 & & \\
\hline & 3 & 701 & 7.2 & & & & 3 & 706 & 10.8 & & \\
\hline & 4 & 640 & 11.9 & & & & & & & & \\
\hline
\end{tabular}

Note: N: number of the specimen, w/o: without freeze-thaw cycles, FT: freeze-thaw cycles. Strength in psi.

In the splitting tensile test, the bond interface is subjected to the greatest tensile stress in the specimen. It should be emphasized that when the failure of the composite prism takes place in the concrete substrate, the bond strength is considered greater than the failure stress of the sample. Only in the cases in which failure occurred fully in the bond that stress value can be taken as the bond strength. Figure 4.7 shows the different failure modes considered in this study. Pictures of all tested splitting tensile composite prisms, cast on saturated conditions, and monolithic prisms can be found in the Appendixes.

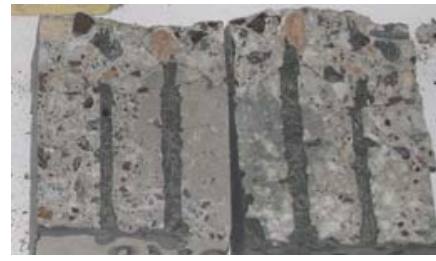

(a) G/C: groove-concrete.

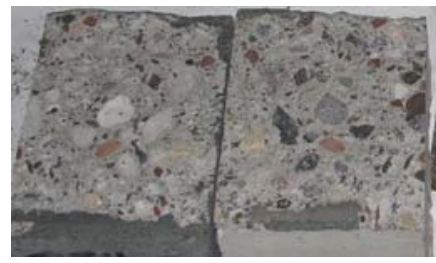

(d) C: concrete.

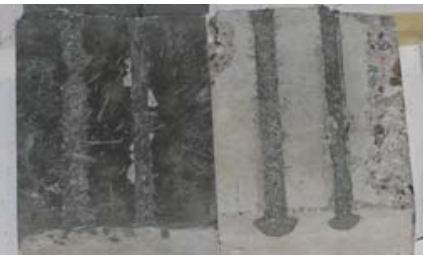

(b) G: grooved.

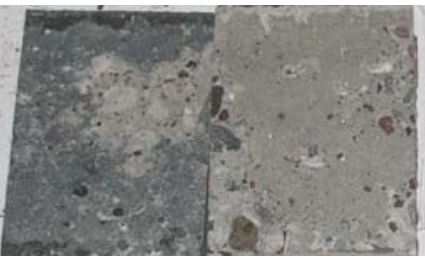

(e) B: bond.

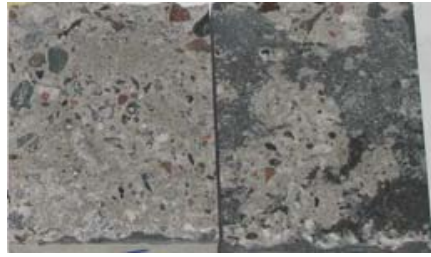

(c) B/C: bond-concrete.

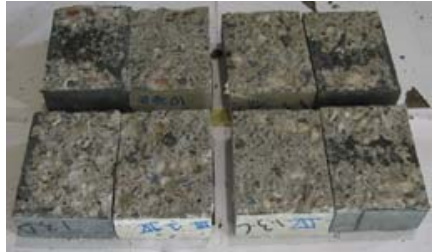

(f) Failed prism samples.

Figure 4.7 Representative failure modes of composite specimens for the splitting tensile test

Figure 4.8 represents the amount of failures according to the different modes and sorted out by the different case study. The values are obtained from Table 4.7. It can be stated that for sandblasted, chipped and smooth surfaces the predominant failure mode is 
concrete or bond/concrete while for brushed surface, all failures took place on the concrete substrate for 0 and 300 freeze-thaw cycles, however, the main failure mode for the 600 and 900 freeze-thaw cycles conditions was bond. In the case of grooved surface, the mixture failure on the concrete/grooved was the predominant one.

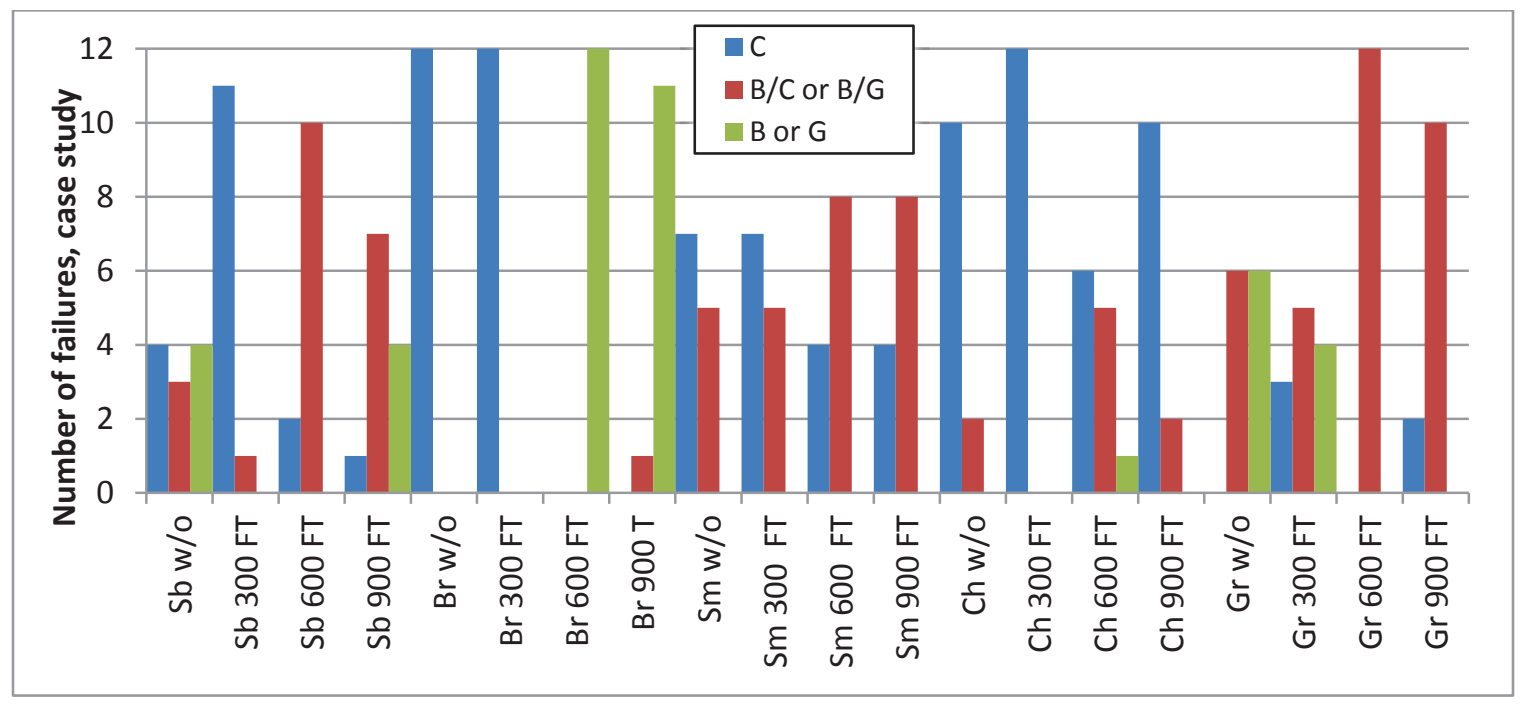

Figure 4.8 Failure modes per case study in the splitting tensile test under wetting conditions

Figure 4.9 represents the final average bond strength for each case study and Figure 4.10 gives the COV of the bond strength for each case study. It was decided not to include the four specimens that gave high values of COV and that are highlighted in Table 4.6 due to the fact that a potential error in the preparation of the samples could have taken place. $\mathrm{Sb}$ w/o 3 specimen is a clear example of the latter; two prisms obtained high values of tensile strength that surpass widely the requirements given by ACI 546.3R-06, however, no tensile bond strength was developed in the other two prisms. The authors can not specify the reason whereby this happened due to the large number of steps needed to prepare the splitting tensile samples. Further research needs to be done to understand the chemical process that takes place on the interface and provokes this high cohesion between both UHPC and NSC materials. A microanalysis of the transition zone between UHPC and NSC materials by using Scanning Electron Microscope (SEM) could help to understand the necessary conditions to obtain good bond strength. This study has concluded that a saturated concrete substrate have a strong beneficial effect on the development of the bond strength. However, additional research have to carry out in this aspect due to the 
fact that timber moulds without any varnish treatment were used to cast the composite specimens and might have influenced in creating a slight dryer condition.

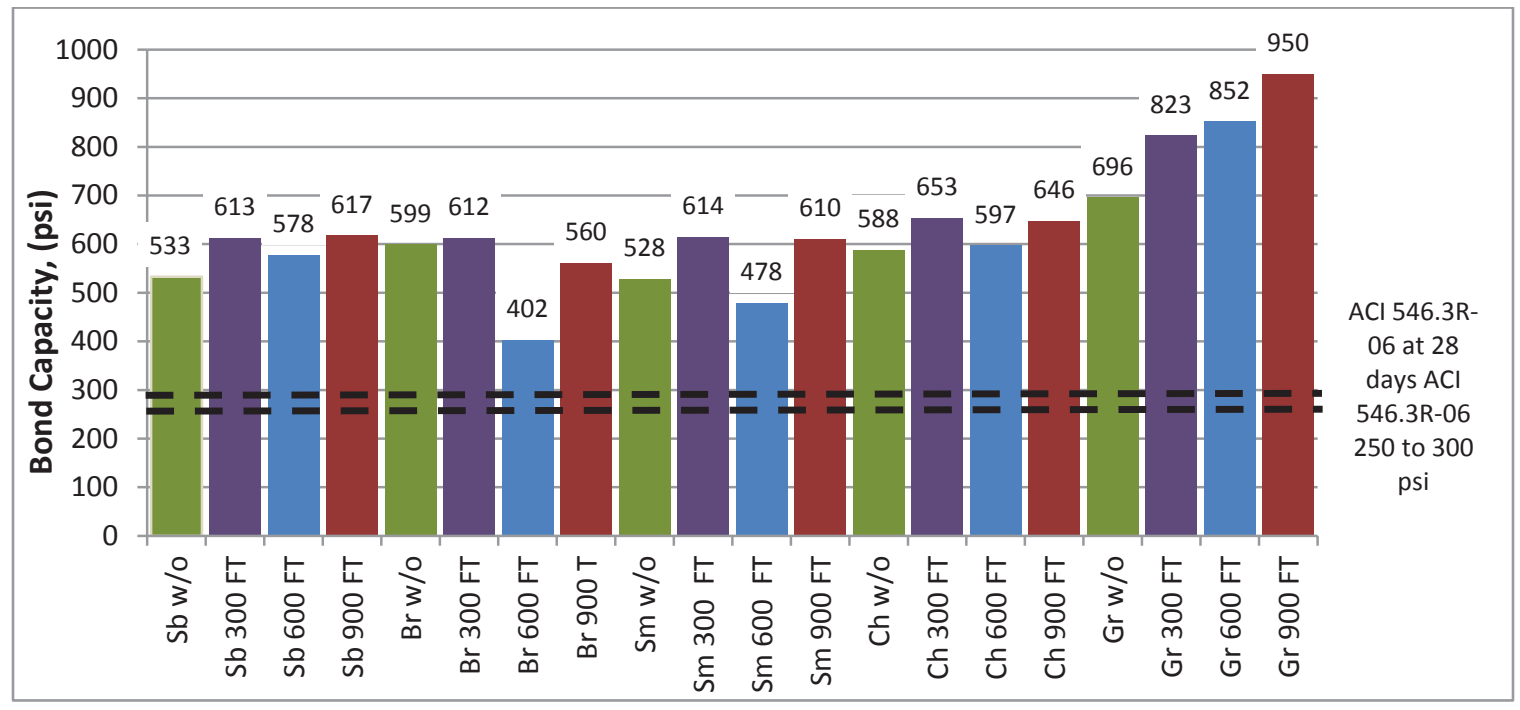

Figure 4.9 Bond strength per case study obtained in the splitting tensile test

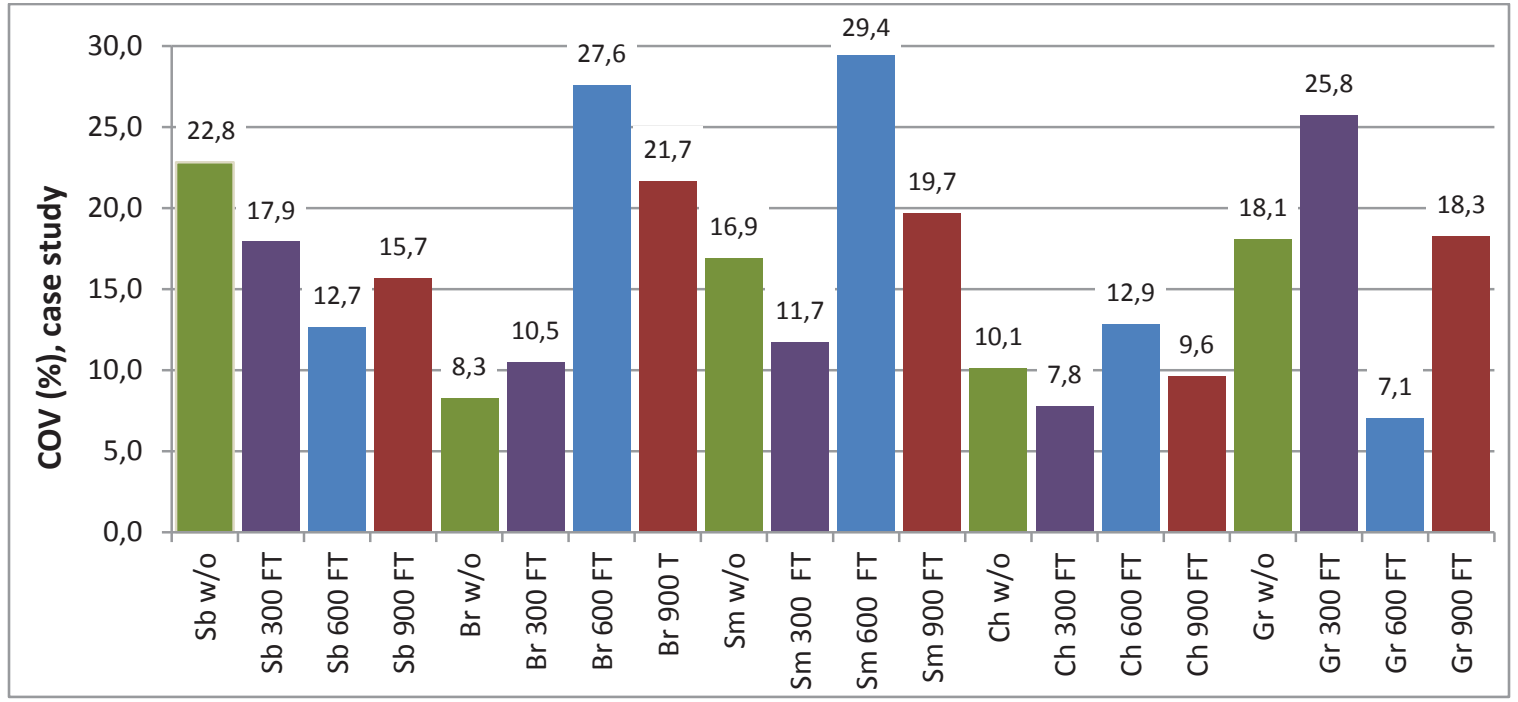

Figure 4.10 COV per case study obtained in the splitting tensile test

\subsubsection{Discussion}

The results from this study highlight that the moisture condition of the concrete substrate is a critical factor for achieving good bond performance. The bond between UHPC and NSC gives excellent results under indirect tensile stress if the moisture condition of the concrete substrate is saturated before placing the overlay material, regardless of the 
surface treatment applied. In contrast, a general premature failure occurred with those samples cast on a concrete substrate with a dry moisture condition. Smooth, sandblasted, brushed and chipped surfaces presented similar strengths which indicates that the surface treatment is not a critical factor, at least under this loading configuration. Macrotexture depths equal or greater than $1.5 \mathrm{~mm}$ are often related with good bond strength based on field experience (Sprinkel 1997), but in this research, the different substrate surfaces had macrotexture depths between 0.6 and $1.06 \mathrm{~mm}$, and all of them presented outstanding strengths. Therefore, it can be concluded that when UHPC is used as overlay material on a saturated substrate, a simple surface treatment that removes the dust from the concrete surface is enough to achieve a good bond that satisfies the bond strength ranges given by ((ACI 546.3R-06 2006), (Sprinkel and Ozyildirim 2000)).

In all cases, 300 freeze-thaw cycles have a beneficial effect on the bond strength. While the prolongation of the freeze-thaw cycles did not drastically affect the bond strength, having slightly greater or lower strengths that those obtained with 300 freeze-thaw cycles.

The low COV for the monolithic samples (from 6.7\% to 12.9\%) confirms the consistency of the splitting tensile test. Whereas the COV for the composite specimens was greater (from 7.1 to $29.4 \%$ ) but still can be considered as consistent. They are in the same range (2.4 to $29.5 \%$ ) as obtained by Santos and Julio et al. (2011) in his study of the bond between two concretes.

Comparing the tensile strength attained by the composite prisms with respect to that obtained by the monolithic samples and taking into consideration that the compressive strength tests showed that NSC mix used to cast the monolithic samples had higher strength than the rest of NSC mixes, it is reasonable to state that most of the composite prisms failed due to they have reached the maximum tensile capacity of the NSC substrate. The summary of the failure modes as well verifies the latter: most of the failures were in the concrete substrate or a mix failure of bond and concrete. Therefore, it can be drawn that the tensile strength of the bond interface is equal or greater than that of the substrate. 


\subsection{Slant-shear test}

The slant-shear test is the most broadly recognized method to assess the bond strength between two different materials and has been implemented by different international codes, such as, ASTM C 882 and BS EN 12615:1999 (British Standard 1999). An interface angle of $60^{\circ}$ from horizontal is usually used by standard codes or researchers, however, in this research, besides this inclination, another two joint angles were utilized to yield a better understanding of the bond performance under shear and compression stresses. The main aim of the experimental program was to study the bond strength at 8 days with four different degrees of roughness of the concrete substrate (brushed, sandblasted, grooved and high aggregate exposure, called, rough surface) and two different interface angles $\left(60^{\circ}\right.$ and $\left.70^{\circ}\right)$. Afterwards, with spare samples, it was possible to assess some specimens at earlier age (2-3 days) with three different interface angles $\left(55^{\circ}, 60^{\circ}\right.$ and $\left.70^{\circ}\right)$ to assess the evolution of the failure envelop with respect to time.

\subsubsection{Results}

Table 4.8 shows the results of the slant-shear test at 8 days and Table 4.9 presents the results obtained at 2 and 3 days. The bond capacity is estimated by using Equation 2.2 and Equation 2.3. The real angle and cross area were measured from each sample and used to calculate compressive and shear stresses. The compressive strength of NSC and UHPC at the age of testing was estimated by the compressive strength test of at least 2 cylinders of each material. Some slant-shear specimens did not have a perfect flat surface at the NSC corner. A small portion (0.1-0.3 in) was cut from these corners in order to obtain a regular surface. The failure mode was visually examined. Figure 4.11 exhibits the different failure modes considered in this test. Pictures of all slant-shear specimens after testing can be found in the Appendixes. 
Table 4.8

Summary of slant-shear test at 8 days

\begin{tabular}{|c|c|c|c|c|c|c|c|c|c|c|c|c|}
\hline & \multirow[b]{2}{*}{$\mathrm{N}$} & \multirow{2}{*}{$\begin{array}{l}\text { Angle } \\
\left({ }^{\circ}\right)\end{array}$} & \multirow{2}{*}{$\begin{array}{l}\text { Failure } \\
\text { load } \\
\text { (Ibf) }\end{array}$} & \multirow{2}{*}{$\begin{array}{c}\text { Area } \\
\left(i n^{2}\right)\end{array}$} & \multirow{2}{*}{$\begin{array}{l}\text { Failure } \\
\text { mode }\end{array}$} & \multicolumn{2}{|c|}{$\begin{array}{c}\text { Bond } \\
\text { capacity } \\
(p s i)\end{array}$} & \multicolumn{2}{|c|}{$\begin{array}{c}f_{c}(p s i) \text { of both } \\
\text { materials at } \\
\text { the age of } \\
\text { testing }\end{array}$} & \multicolumn{2}{|c|}{$\begin{array}{l}\text { Average } \\
\text { bond } \\
\text { strength } \\
(p s i)\end{array}$} & \multirow{2}{*}{$\begin{array}{l}\text { COV } \\
(\%) \\
\text { of } T\end{array}$} \\
\hline & & & & & & $T$ & $\sigma$ & NSC & UHPC & $\mathrm{T}$ & $\sigma$ & \\
\hline \multirow{4}{*}{$\begin{array}{l}0 \\
\infty \\
0 \\
0 \\
\vdots \\
\frac{1}{0}\end{array}$} & 1 & 59.9 & 62064 & 12.1 & C & 2233 & 1295 & 6460 & 15286 & \multirow{4}{*}{2339} & \multirow{4}{*}{1356} & \multirow{4}{*}{11.4} \\
\hline & 2 & 59.3 & 59961 & 12.7 & $\mathrm{C}$ & 2080 & 1237 & 6460 & 15286 & & & \\
\hline & $3^{*}$ & 59.8 & 75884 & 12.2 & C & 2705 & 1577 & 6460 & 15286 & & & \\
\hline & $4^{*}$ & 60.6 & 68358 & 12.5 & C & 2338 & 1316 & 6460 & 15286 & & & \\
\hline \multirow{4}{*}{$\begin{array}{l}\text { ס } \\
0 \\
1 \\
0 \\
1 \\
\overline{1}\end{array}$} & $1^{*}$ & 70.6 & 59404 & 12.9 & $\mathrm{~B}(\mathrm{C})$ & 1442 & 508 & 6460 & 15286 & \multirow{4}{*}{1757} & \multirow{4}{*}{614} & \multirow{4}{*}{12.6} \\
\hline & $2^{*}$ & 71.5 & 74075 & 12.5 & $\mathrm{~B}(\mathrm{C})$ & 1780 & 596 & 6460 & 15286 & & & \\
\hline & $3^{*}$ & 70.1 & 76855 & 12.6 & $\mathrm{~B}(\mathrm{C})$ & 1948 & 707 & 6460 & 15286 & & & \\
\hline & $4^{*}$ & 70.9 & 74027 & 12.4 & $B(C)$ & 1856 & 644 & 6460 & 15286 & & & \\
\hline \multirow{4}{*}{$\begin{array}{l}\text { D } \\
0 \\
0 \\
0 \\
1 \\
0\end{array}$} & 1 & 60.2 & 95559 & 12.3 & $\mathrm{C}$ & 3355 & 1925 & 8112 & 18353 & \multirow{4}{*}{3143} & \multirow{4}{*}{1785} & \multirow{4}{*}{4.9} \\
\hline & 2 & 60.2 & 89540 & 12.2 & C & 3158 & 1809 & 8112 & 18353 & & & \\
\hline & 3 & 60.4 & 87373 & 12.5 & C & 3000 & 1708 & 8112 & 18353 & & & \\
\hline & 4 & 61.0 & 90749 & 12.6 & $\mathrm{C}$ & 3060 & 1697 & 8112 & 18353 & & & \\
\hline \multirow{4}{*}{$\begin{array}{l}\text { D } \\
0 \\
1 \\
1 \\
\text { की }\end{array}$} & 1 & 71.4 & 87053 & 12.2 & $C$ & 2161 & 727 & 8112 & 18353 & \multirow{4}{*}{2124} & \multirow{4}{*}{719} & \multirow{4}{*}{2.8} \\
\hline & 2 & 70.8 & 87557 & 12.5 & $B / C$ & 2182 & 760 & 8112 & 18353 & & & \\
\hline & 3 & 71.1 & 85920 & 12.5 & C & 2107 & 722 & 8112 & 18353 & & & \\
\hline & 4 & 72.0 & 87600 & 12.6 & $\mathrm{C}$ & 2047 & 665 & 8112 & 18353 & & & \\
\hline \multirow{4}{*}{$\begin{array}{l}0 \\
\infty \\
1 \\
0 \\
\vdots \\
11\end{array}$} & 1 & 60.1 & 63477 & 12.8 & $\mathrm{C}$ & 2143 & 1233 & 6607 & 17888 & & & \\
\hline & 2 & 60.5 & 68767 & 12.5 & C & 2362 & 1337 & 6607 & 17888 & 2471 & 1360 & 111 \\
\hline & 3 & 61.7 & 79633 & 12.7 & $\mathrm{C}$ & 2609 & 1405 & 6607 & 17888 & 2481 & 1000 & $1 \perp .1$ \\
\hline & 4 & 62.1 & 86842 & 13.0 & $\mathrm{C}$ & 2769 & 1466 & 6607 & 17888 & & & \\
\hline & 1 & 70.8 & 70679 & 12.5 & $\mathrm{C}$ & 1756 & 612 & 6607 & 17888 & & & \\
\hline $\begin{array}{l}0 \\
\infty \\
0 \\
0\end{array}$ & 2 & 70.7 & 75175 & 12.5 & $\mathrm{C}$ & 1881 & 658 & 6607 & 17888 & 1765 & 618 & \\
\hline r & 3 & 71.6 & 70325 & 12.5 & C & 1689 & 561 & 6607 & 17888 & 1700 & 010 & +.0 \\
\hline & 4 & 69.7 & 67637 & 12.7 & $\mathrm{C}$ & 1735 & 642 & 6607 & 17888 & & & \\
\hline & $1^{*}$ & 59.6 & 66349 & 12.3 & $\mathrm{C}$ & 2356 & 1385 & 6460 & 15290 & & & \\
\hline $\begin{array}{l}\infty \\
1 \\
0\end{array}$ & $2^{*}$ & 59.9 & 79776 & 12.7 & $\mathrm{C}$ & 2727 & 1581 & 6460 & 15290 & 2545 & 1452 & 6.3 \\
\hline$\frac{1}{0}$ & $3^{*}$ & 61.3 & 78039 & 12.6 & C & 2612 & 1428 & 6460 & 15290 & & & \\
\hline & $4^{*}$ & 60.3 & 72565 & 12.6 & $\mathrm{C}$ & 2483 & 1415 & 6460 & 15290 & & & \\
\hline & $1^{*}$ & 69.9 & 77983 & 12.3 & $\mathrm{C}$ & 2047 & 750 & 6460 & 15290 & & & \\
\hline $\begin{array}{l}\infty \\
0 \\
0\end{array}$ & $2^{*}$ & 68.8 & 65735 & 12.4 & C & 1788 & 695 & 6460 & 15290 & 1634 & 628 & 239 \\
\hline$\frac{1}{0}$ & $3^{*}$ & 68.9 & 40961 & 12.3 & $\mathrm{~B}(\mathrm{C})$ & 1122 & 433 & 6460 & 15290 & & & \\
\hline & $4^{*}$ & 68.1 & 58461 & 12.8 & $\mathrm{C}$ & 1578 & 633 & 6460 & 15290 & & & \\
\hline
\end{tabular}

Note: N: number of the specimen, Br:brushed, R:rough, Sb:sandblasted, Gr:grooved, $r$ : tensile stress, $\sigma$ : compressive stress, $f_{c}:$ compressive strength, d:days, $C$ :concrete, $B(c): B o n d$ due to concrete layer, B/C:bond and concrete, *:a small portion of concrete was cut and discarded. 
Table 4.9

Summary of slant-shear test at 2-3 days

\begin{tabular}{|c|c|c|c|c|c|c|c|c|c|c|c|c|}
\hline & \multirow[b]{2}{*}{$\mathrm{N}$} & \multirow{2}{*}{$\begin{array}{c}\text { Angle } \\
\left({ }^{\circ}\right)\end{array}$} & \multirow{2}{*}{$\begin{array}{c}\text { Failure } \\
\text { load } \\
(I b f)\end{array}$} & \multirow{2}{*}{$\begin{array}{c}\text { Area } \\
\left(i n^{2}\right)\end{array}$} & \multirow[t]{2}{*}{$\begin{array}{c}\text { Failure } \\
\text { mode }\end{array}$} & \multicolumn{2}{|c|}{$\begin{array}{c}\text { Bond } \\
\text { capacity } \\
\text { (psi) }\end{array}$} & \multicolumn{2}{|c|}{$\begin{array}{c}f_{c}(p s i) \text { of both } \\
\text { materials at } \\
\text { the age of } \\
\text { testing }\end{array}$} & \multicolumn{2}{|c|}{$\begin{array}{l}\text { Average } \\
\text { bond } \\
\text { strength } \\
\text { (psi) }\end{array}$} & \multirow{2}{*}{$\begin{array}{l}\text { COV } \\
(\%) \\
\text { of T }\end{array}$} \\
\hline & & & & & & $\mathrm{T}$ & $\sigma$ & NSC & UHPC & $\mathrm{T}$ & $\sigma$ & \\
\hline \multirow{4}{*}{ 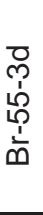 } & $1^{*}$ & 54.4 & 63832 & 12.2 & C & 2480 & 1773 & 8244 & 12298 & \multirow{4}{*}{2585} & \multirow{4}{*}{1856} & \multirow{4}{*}{15.5} \\
\hline & 2 & 54.5 & 59562 & 12.5 & C & 2254 & 1607 & 8244 & 12298 & & & \\
\hline & $3^{*}$ & 54.6 & 64269 & 12.4 & C & 2439 & 1734 & 8244 & 12298 & & & \\
\hline & 4 & 53.9 & 84925 & 12.8 & $\mathrm{C}$ & 3168 & 2310 & 8244 & 12298 & & & \\
\hline \multirow{4}{*}{$\begin{array}{l}0 \\
p \\
0 \\
0 \\
\frac{1}{n}\end{array}$} & 1 & 61.1 & 57207 & 12.4 & Cohes. & 1948 & 1077 & 8112 & 11688 & \multirow{4}{*}{2215} & \multirow{4}{*}{1220} & \multirow{4}{*}{8.2} \\
\hline & 2 & 61.6 & 65310 & 12.1 & C & 2256 & 1220 & 8112 & 11688 & & & \\
\hline & 3 & 61.3 & 67608 & 12.2 & C & 2330 & 1278 & 8112 & 11688 & & & \\
\hline & 4 & 60.7 & 65805 & 12.1 & Cohes. & 2325 & 1307 & 8112 & 11688 & & & \\
\hline \multirow{4}{*}{\begin{tabular}{l} 
ס \\
p. \\
0 \\
\multirow{1}{1}{} \\
$\frac{1}{0}$
\end{tabular}} & $1^{*}$ & 72.5 & 53914 & 12.2 & Cohes. & 1270 & 402 & 8112 & 11362 & \multirow{4}{*}{1375} & \multirow{4}{*}{449} & \multirow{4}{*}{22.4} \\
\hline & $2^{*}$ & 70.3 & 62628 & 12.2 & $\mathrm{~B}(\mathrm{UHPC})$ & 1624 & 582 & 8112 & 11362 & & & \\
\hline & $3^{*}$ & 71.3 & 66373 & 12.4 & $B / C$ & 1618 & 547 & 8112 & 11362 & & & \\
\hline & $4^{*}$ & 75.0 & 48120 & 12.2 & $B / C$ & 986 & 265 & 7282 & 12638 & & & \\
\hline 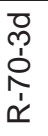 & $1^{*}$ & 68.4 & 50968 & 12.4 & C & 1403 & 556 & 7282 & 12298 & 1403 & 556 & - \\
\hline \multirow{4}{*}{ 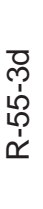 } & 1 & 54.2 & 73861 & 12.2 & C & 2870 & 2070 & 7282 & 12298 & \multirow{4}{*}{2428} & \multirow{4}{*}{1744} & \multirow{4}{*}{13.4} \\
\hline & $2^{*}$ & 54.3 & 58876 & 12.7 & C & 2195 & 1577 & 7282 & 12298 & & & \\
\hline & 3 & 54.9 & 59436 & 12.9 & C & 2175 & 1530 & 7282 & 12298 & & & \\
\hline & 4 & 53.9 & 66482 & 12.8 & C & 2472 & 1800 & 7282 & 12298 & & & \\
\hline 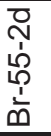 & 1 & 54.1 & 22575 & 12.5 & UHPC & 859 & 621 & 8112 & 11688 & 859 & 621 & - \\
\hline \multirow{3}{*}{ 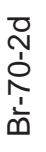 } & 1 & 69.6 & 18442 & 12.2 & B(UHPC) & 495 & 185 & 8112 & 11688 & \multirow{3}{*}{489} & \multirow{3}{*}{172} & \multirow{3}{*}{2.4} \\
\hline & 2 & 71.3 & 19447 & 11.9 & $\mathrm{~B}(\mathrm{UHPC})$ & 496 & 168 & 8112 & 11688 & & & \\
\hline & 3 & 71.1 & 19107 & 12.3 & $\mathrm{~B}(\mathrm{UHPC})$ & 475 & 163 & 8112 & 11688 & & & \\
\hline 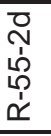 & 1 & 54.4 & 19590 & 12.3 & UHPC & 752 & 539 & 6607 & 11688 & 752 & 539 & - \\
\hline
\end{tabular}

Note: N: number of the specimen, Br:brushed, R:rough, Sb:sandblasted, Gr:grooved, $T$ : tensile stress, $\sigma$ : compressive stress, $f_{c}$ :compressive strength, d:days, C:concrete, B(UHPC):Bond due to UHPC layer, $B / C$ :bond and concrete,Cohes.: a general failure along the specimen *:a small portion of concrete was cut and discarded. 


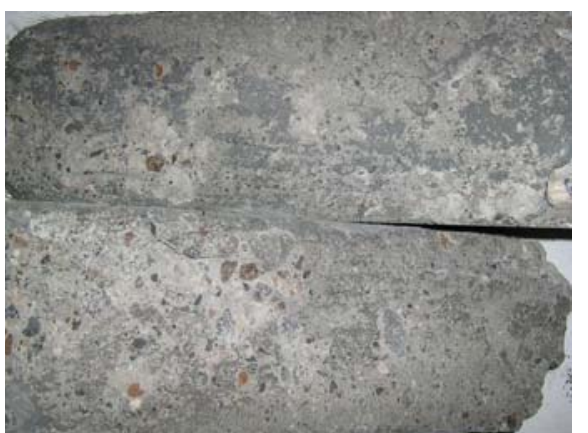

(a) $B(C)$ : Bond due to concrete failure.
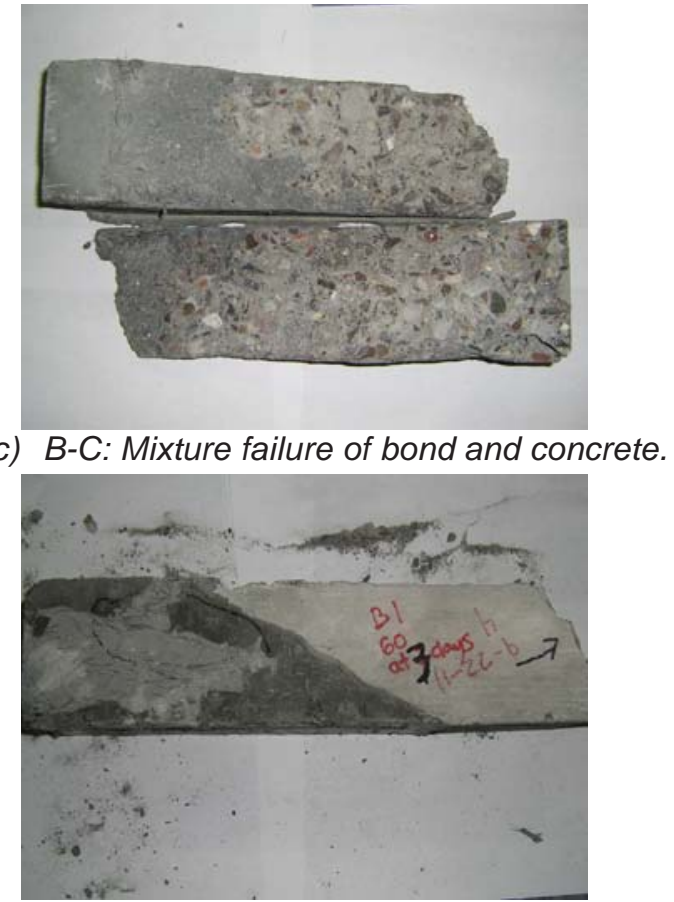

(e) Cohes: Cohesive failure.

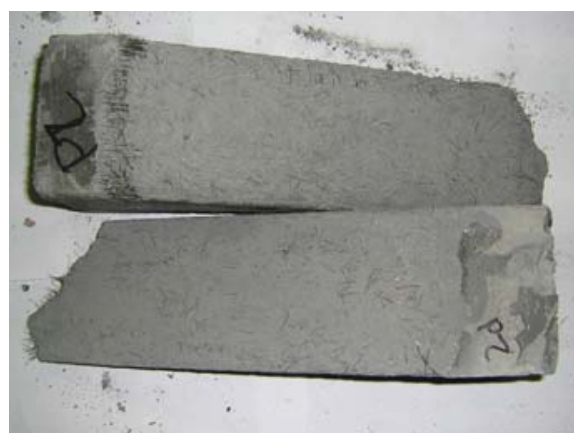

(b) $B(U H P C)$ : Bond due to UHPC failure.

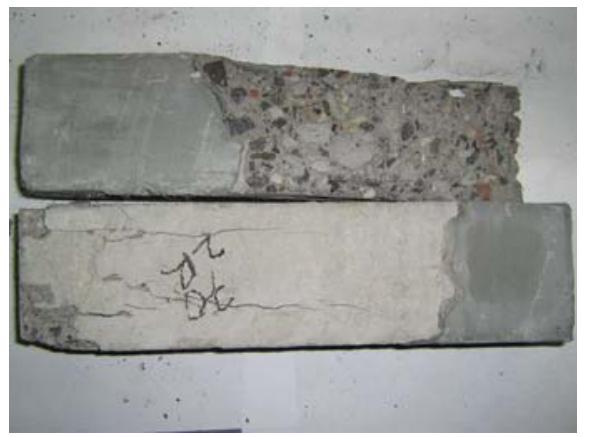

(d) C: concrete failure.

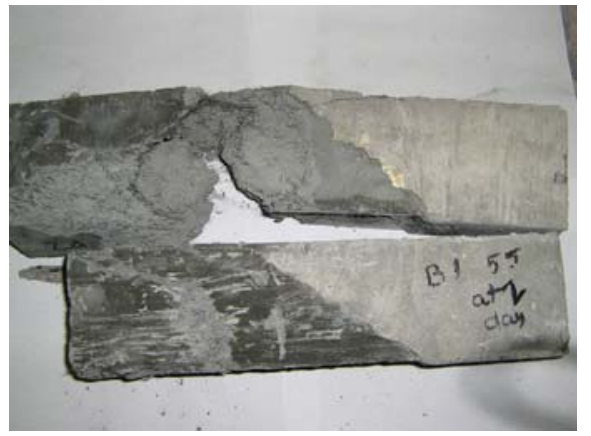

(f) UHPC: UHPC failure.

Figure 4.11 Failure modes for the slant-shear test

As shown in Figure 4.11, six different failure modes were used to define the failures that occurred in the slant-shear test. The bond failure (sliding mode) presented a significant difference between 8 and 2-3 days. At the age of the 8 days, Figure 4.11.a, there are concrete remnants embedded in the UHPC. From a micro scale, it could be stated that the failure in the bond interface occurred due to the cracking of the concrete layer. This is the same as the bond failure of the splitting tensile test which was carried out on older specimens. Whereas the bond failure mode at 2-3 days is due to the UHPC failure from a micro scale view. Another noteworthy comment is that at the age of 3 days seems to be a change of tendency of the weakest material of the composite samples. All specimens at 2 
days failed at UHPC or B(UHPC). While the failures at 3 days took place in the concrete substrate for all specimens with an interface angle of $55^{\circ}$, the least demanding angle for the interface, and in the bond, UHPC or a general failure for all specimens with interface angle of $60^{\circ}$ and $70^{\circ}$. Notice that the compressive strength at 2 days of UHPC cured in ambient conditions is still considered weak and is less than the $40 \%$ of the ultimate compressive strength at 28 days.

The assessment of the failure modes gives remarkable information about the quality of the bond and highlights the importance of the joint angle in the slant-shear test. All specimens at the age of 8 days with an interface angle of $60^{\circ}$ failed in the concrete substrate. Consequently, the bond capacity obtained only establishes a minimum of the actual strength of the bond. As shown in Figure 4.12, the highest shear stress was obtained with the sandblasted surface. This might lead to the wrong conclusion that the greater strength bond is attained with the sandblasting treatment. However, this deduction cannot be taken due to fact that the concrete substrate of the sandblasted specimens had higher compressive strength (8112 psi) than those of the other surfaces (6460 and 6607 psi). In contrast, the specimens with an interface angle of $70^{\circ}$ provide more information about the quality of the bond. All specimens with brushed surface failed in the bond. Hence, the bond capacity estimated is the actual one for this surface. The rest of specimens failed, mostly, in the concrete substrate, signifying that these bond interfaces might have resisted greater stresses. Figure 4.12 shows the bond capacity at 8 days for $60^{\circ}$. It is observed that the bond strength, at the age of 8 days, is well beyond the ACI 546.3R-06 requirements at 7 days and even satisfies the minimum bond strength at 28 days. 


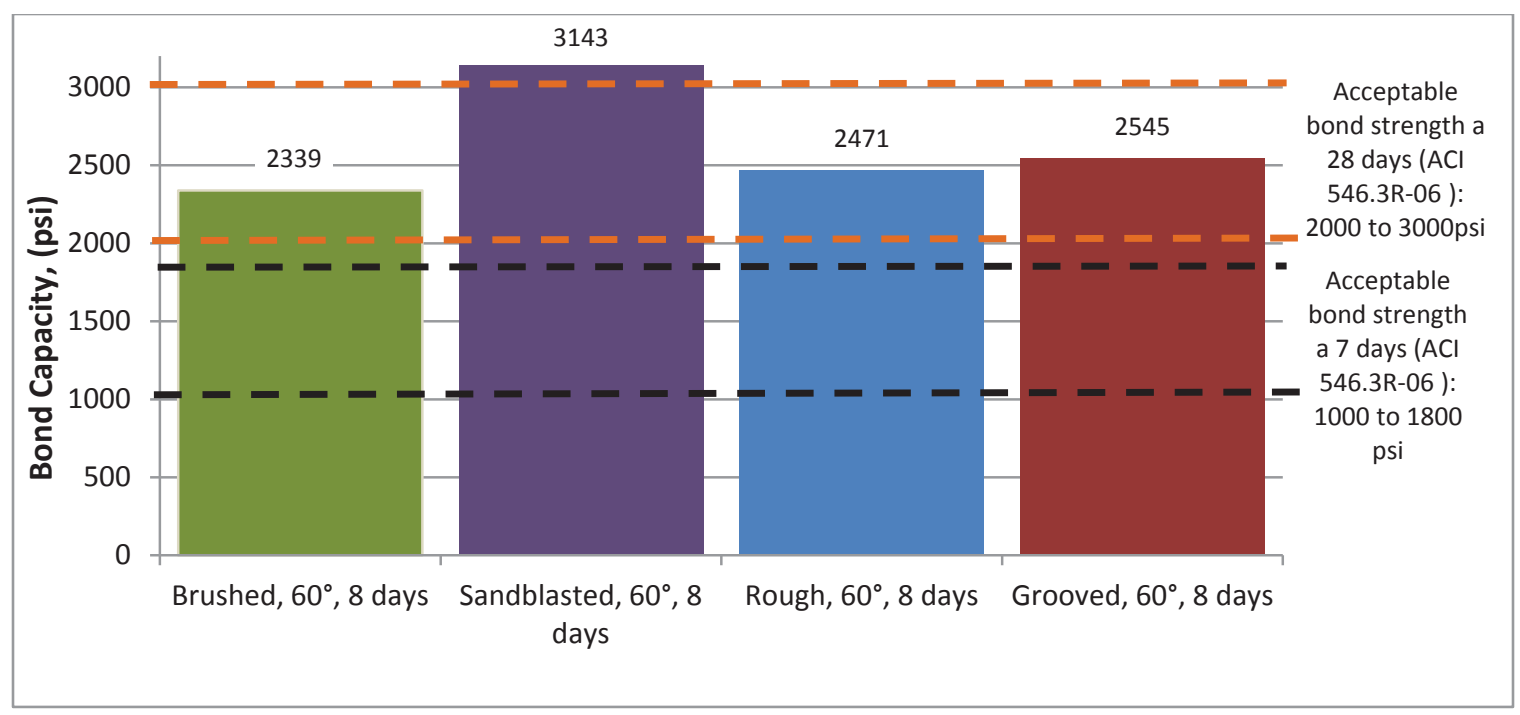

Figure 4.12 Bond strength per case study obtained in the slant-shear test with an interface angle of $60^{\circ}$ at 8 days Figure 4.13 presents the results obtained with a joint angle of $70^{\circ}$ at 8 days. The use of this more critical loading configuration presents the advantage that attains the actual bond capacity of the brushed surface treatment. It can be observed that all bond capacities decrease with the increment of the interface angle from the horizontal.

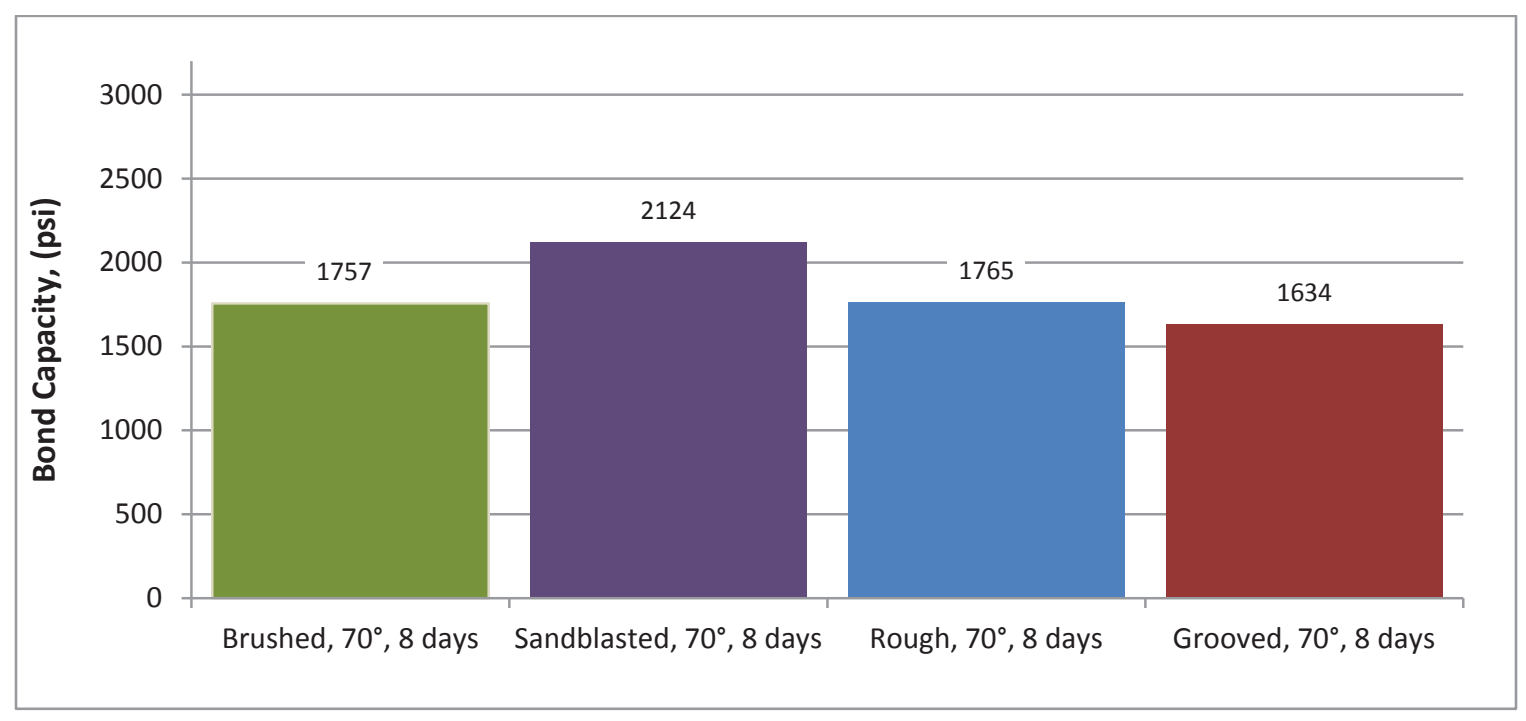

Figure 4.13 Bond strength per case study obtained in the slant-shear test with an interface angle of $70^{\circ}$ at 8 days

Figure 4.14 shows the evolution of different case study respect to time. It is significant to highlight that the specimens with brushed surfaces in the concrete substrate obtained a bond capacity, at the age of 3 days, greater than the requirements given by ACI 546.3R06 at 7 days and also satisfies the requirements at 28 days. As previously mentioned, the 
bond and UHPC strengths exhibit an important increase at 2-3 days. The minimum bond capacity achieved at the age of 2 days is substantially lower than that of 3 days, while the strength obtained at 8 days is slightly greater than that of 3 days. This has a similar parallelism with the UHPC hydration process, defined in 2.1.3: there is a dormant period followed by a strong energy release (Morin et al. 2002; Morin et al. 2001) and the hydration progress is narrowly associated to the compressive strength development (Kamen 2006). It seems reasonable to state that with this kind of UHPC formulation and under ambient condition the threshold to achieve excellent bond occurs at 3 days. As well, it is appropriate to spotlight that the bond capacity of B-60-3d is lower than that of B-55-3d.

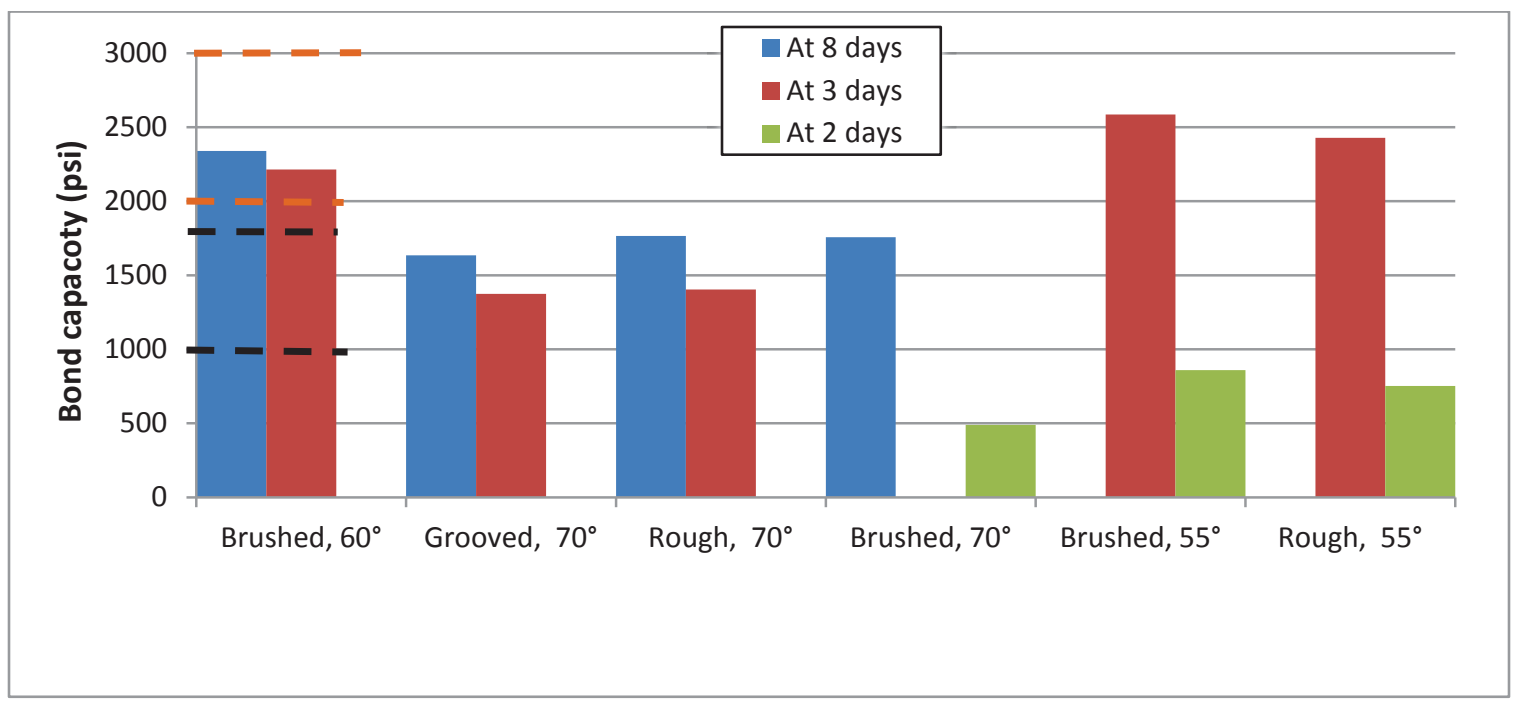

Figure 4.14 Evolution of the bond strength per case study obtained in the slant-shear test

\subsubsection{Discussion}

The results from this loading configuration show that the bond between UHPC and NSC has an excellent performance under a state of shear and compression stresses regardless the surface treatment applied in the concrete substrate. The bond capacity at 8 days largely exceeds with the requirements specified by ACI 546.3R-06 at 7 days and also satisfies the minimum bond requirements for 28 days. 
The different failure modes obtained throughout this experimental work show that the slant shear test method is highly dependent on the joint angle used: the bond capacity and failure mode can vary significantly from one interface angle to other.

As previously discussed, there is controversy between researchers about the sensitivity of this test to the degree of roughness of the concrete substrate. The excellent bond between UHPC and NSC prevents the development of a conclusive statement about this matter due to the fact that most of the specimens did not fail in the bond interface. Therefore, most of the bond capacities estimated are a lower bound of the real strength of the bond. However, there is some evidence that suggests the sensitivity of this test to the degree of roughness of the concrete substrate, such as the study case of specimens with bond interface of $70^{\circ}$ at 8 days, all specimens with brushed surface failed in the concrete substrate whereas that the most of other specimens still failed in the concrete substrate. In order to draw a definitive conclusion in this matter, it would be necessary to design concrete substrate with higher mechanical strengths to try to obtain more sliding failure modes (failure along the interface).

The evolution of the bond strength has a critical point between the 48 hours and 72 hours after casting the UHPC on the concrete substrate. During the second and third day, the UHPC and bond interface strengths exceed that of the NSC. This conclusion is applicable to the specified UHPC used in this research and under ambient conditions. This interval might vary with other UHPC formulations or under different curing treatments. The threshold of 3 days to acquire a UHPC and bond with higher strengths than that of NSC coincides with the recommendation given by Lafarge North America (the provider company of the UHPC material used in this project) which suggests not to apply any load until UHPC has developed a compressive strength of 14500 psi. Notice that the compressive strength under ambient conditions obtained in this research at 2 days was 11688 psi, at 3 days 12298 psi and at 8 days greater than 15286 psi.

The COV varies from $2.4 \%$ to $23.9 \%$ hence, the test can be considered as consistent. This range is similar to the different COV's obtained by other authors, such as (Santos and Julio 2011), from 2.1\% to $38.3 \%$, or Momayez et al. (2005), from 4.7 to $15.8 \%$. 
At the same time as this research was going on, (Sritharan et al. 2012) published an experimental investigation about the bond between UHPC and normal concrete. A total of 60 slant shear specimens were cast. The inclination angle chosen was $53.1^{\circ}$. Five different textures for the concrete surface (from $1.3 \mathrm{~mm}$ to $5 \mathrm{~mm}$ ) and three different concrete strengths (5000, 7500 and 10000 psi) were used. The bond capacity obtained varied, approximately, from 4250 psi with a concrete substrate of 10000 psi compressive strength to 2175 psi with a concrete substrate of 5000 psi. These results are similar to the obtained in this research for an angle of $60^{\circ}$ : from 3143 psi with a concrete substrate of 8112 psi compressive strength to 2339 psi with a concrete substrate of 6460 psi compressive strength. It should be recalled that a greater angle from the horizontal produces a more critical situation with a lower bond capacity as previously stated.

\subsection{Pull-off test}

The pull-off test consists in applying a direct tensile force to a core advanced into concrete substrate until failure takes place. Although an estimation of the tensile strength was obtained by means of the splitting tensile test, this method was carried out due to the fact that can be used in situ or in laboratory, making possible the future correlation of the bond strength between different loading tests.

\subsubsection{Results}

Table 4.10 summarizes the pull-off results. Equation 3.2 was used to estimate the direct tensile strength, $\mathrm{f}_{\mathrm{t}}$. A 2 in diameter was utilized to calculate the area of the cores. The NSC compressive strengths presented are those of the day of testing, however UHPC compressive strengths were estimated by testing two cylinders from each mix 2 or 3 days before the direct tensile test, exactly at 8 days after casting; therefore, the UHPC compressive strengths given have to be considered as a minimum of the true ones. All cores failed in the concrete substrate, except one that failed in the bond. Figure 4.15 shows these two different failure modes. All cores after failure can be found in the Appendixes. It should be emphasized that the averages of the tensile strengths shown in

Table 4.10 do not represent the actual tensile bond strength due to the fact that the 
failures occurred in the concrete substrate, it has to be considered as a lower bound of the actual value.

Table 4.10

Summary of the pull-off test

\begin{tabular}{|c|c|c|c|c|c|c|c|c|c|c|}
\hline \multirow[b]{2}{*}{ Slab } & \multirow[b]{2}{*}{$\mathrm{N}$} & \multirow{2}{*}{$\mathrm{T}(\mathrm{lbs})$} & \multirow{2}{*}{$\begin{array}{c}f_{t} \\
(\mathrm{psi})\end{array}$} & \multirow{2}{*}{$\begin{array}{l}\text { Failure } \\
\text { mode }\end{array}$} & \multicolumn{2}{|c|}{$\begin{array}{c}f_{c}(\mathrm{psi}) \text { of both } \\
\text { materials }\end{array}$} & \multirow{2}{*}{$\begin{array}{c}\text { Mean } \\
f_{t}, \\
\text { specimen }\end{array}$} & \multirow{2}{*}{$\begin{array}{l}\text { COV } \\
(\%)\end{array}$} & \multirow{2}{*}{$\begin{array}{c}\text { Mean } \\
f_{t}, \\
\text { case } \\
\text { study }\end{array}$} & \multirow{2}{*}{$\begin{array}{c}\text { COV } \\
(\%)\end{array}$} \\
\hline & & & & & NSC & UHPC & & & & \\
\hline \multirow{3}{*}{1} & 1 & 964 & 307 & $C$ & 7973 & 17888 & & & \multirow{6}{*}{318} & \multirow{6}{*}{18.4} \\
\hline & 2 & 917 & 292 & C & 7973 & 17888 & 286 & 8.6 & & \\
\hline & 3 & 814 & 259 & C & 7973 & 17888 & & & & \\
\hline \multirow{3}{*}{2} & 1 & 913 & 291 & C & 7973 & 17888 & \multirow{3}{*}{350} & \multirow{3}{*}{19.8} & & \\
\hline & 2 & 1340 & 426 & C & 7973 & 17888 & & & & \\
\hline & 3 & 1050 & 334 & C & 7973 & 17888 & & & & \\
\hline \multirow{4}{*}{1} & 1 & 728 & 232 & $C$ & 7973 & 18353 & \multirow{4}{*}{293} & \multirow{4}{*}{21.0} & \multirow{4}{*}{331} & \multirow{4}{*}{17.9} \\
\hline & 2 & 917 & 292 & B & 7973 & 18353 & & & & \\
\hline & 3 & 1115 & 355 & C & 7973 & 18353 & & & & \\
\hline & 1 & 1090 & 347 & C & 7973 & 18353 & & & & \\
\hline
\end{tabular}

$\begin{array}{lllllllll}2 & 2 & 1248 & 397 & C & 7973 & 18353 & 369 & 6.9\end{array}$

\begin{tabular}{llllllllll} 
& 3 & 1142 & 364 & $\mathrm{C}$ & 7973 & 18353 & & \\
\hline & 1 & 1050 & 334 & $\mathrm{C}$ & 6175 & 16860 & & \\
1 & 2 & 1230 & 391 & $\mathrm{C}$ & 6175 & 16860 & 370 & 8.5
\end{tabular}

Gr

$\begin{array}{llllll}3 & 1212 & 386 & \mathrm{C} & 6175 & 16860\end{array}$

$370 \quad 6.1$

$\begin{array}{lllllllll}2 & 2 & 1149 & 366 & \mathrm{C} & 6175 & 16860 & 369 & 1.4\end{array}$

\begin{tabular}{lllllllll}
\multicolumn{3}{c}{3} & & \multicolumn{6}{c}{6175} & 16860 & & \\
\hline & 1 & 1207 & 384 & C & 6716 & 16860 & & \\
1 & 2 & 1288 & 410 & C & 6716 & 16860 & 395 & 3.4
\end{tabular}

$\begin{array}{llllll}3 & 1230 & 391 & \mathrm{C} & 6716 & 16860\end{array}$

$\begin{array}{llllll}1 & 935 & 298 & C & 6716 & 16860\end{array}$

$\begin{array}{ccccccccccc}2 & 2 & 1167 & 371 & \text { C } & 6716 & 16860 & 357 & 15.0 & & \\ & 3 & 1263 & 402 & \text { C } & 6716 & 16860 & & & 352 & 13.9 \\ & 1 & 982 & 313 & \text { C } & 7282 & 17808 & & & & \\ 3 & 2 & 791 & 252 & \text { C } & 7282 & 17808 & 296 & 13.0 & & \\ & 3 & 1016 & 323 & \text { C } & 7282 & 17808 & & & \\ & 1 & 1021 & 325 & \text { C } & 7282 & 17808 & & & \\ & 4 & 2 & 1171 & 373 & \text { C } & 7282 & 17808 & 361 & 8.7 & \\ & 3 & 1207 & 384 & \text { C } & 7282 & 17808 & & & & \end{array}$

$\mathrm{R}$

Note: $N$ : number of the specimen, T:tensile force, Br:brushed, R:rough, Sb:sandblasted, Gr:grooved, $f_{t}$ : tensile strength, $f_{c}:$ compressive strength, C:concrete, B:bond. 


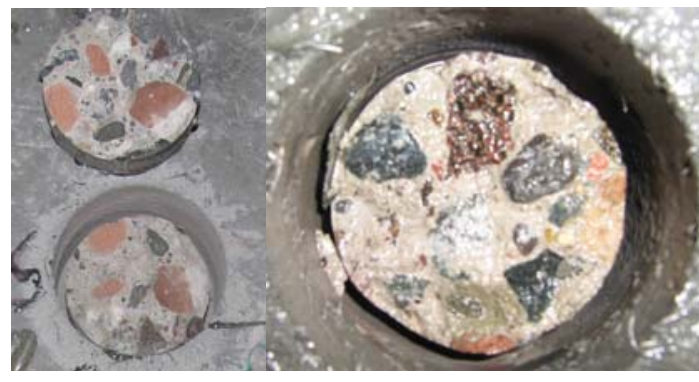

a) C: Concrete failure

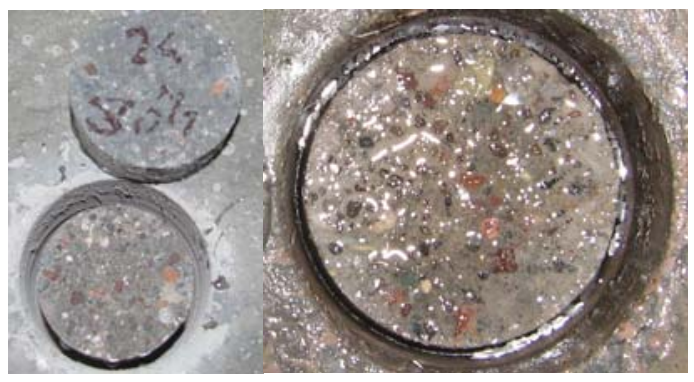

b) B: Bond failure

Figure 4.15 Failure modes in the pull-off test

The bond performance between UHPC and NSC can be considered successful, as the tensile strength of the bond and the overlay material are greater than that of the concrete substrate. As shown in Figure 4.16, the tensile strength obtained at 10-11 days, reach the requirements at 7 and 28 days.

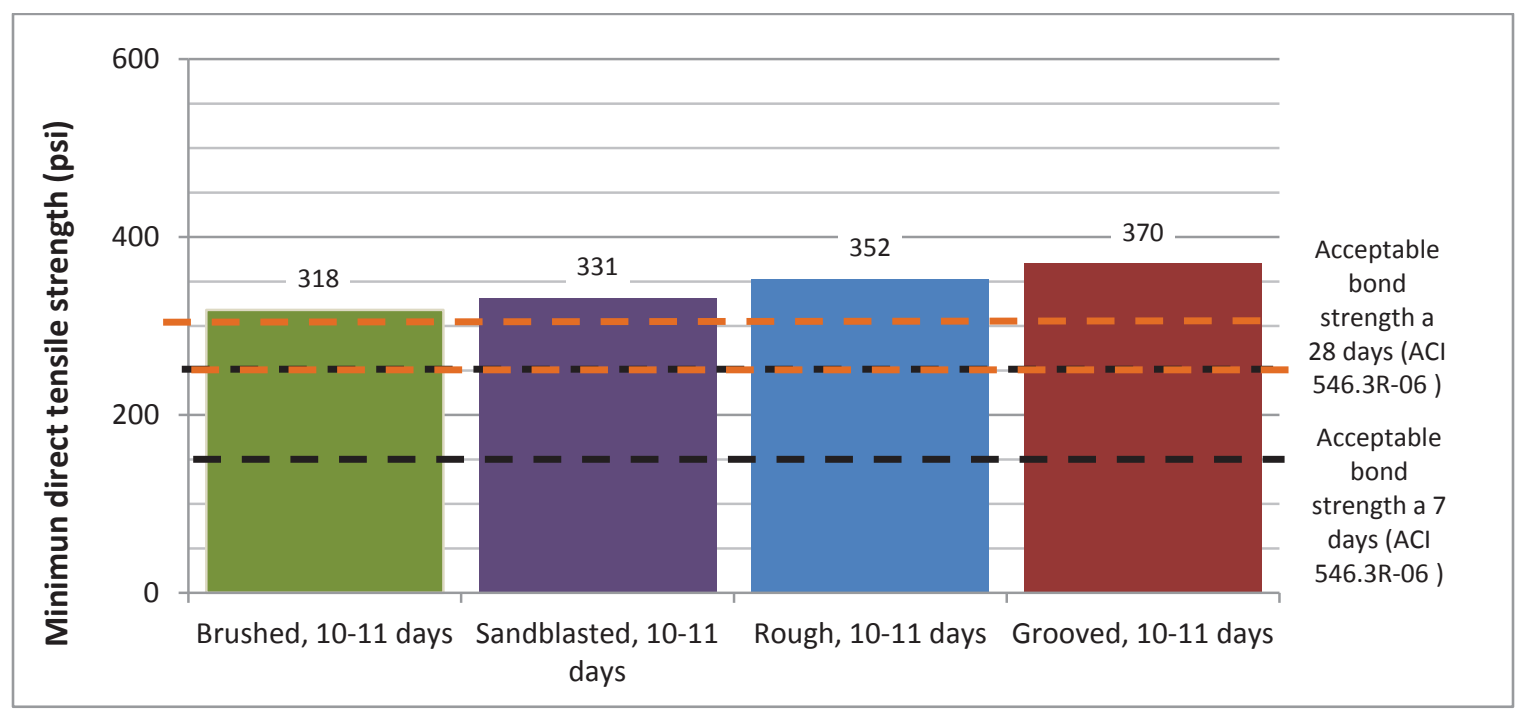

Figure 4.16 Tensile strength per case study obtained in pull-off test at 10-11 days

However, it should be noted that the failure stresses of the concrete substrate are lower than expected. By using Equation 4.1, given by ACI318-11, an estimation of the splitting tensile strength of the concrete substrate can be obtained from the compressive strength. The expected splitting tensile strength for the concrete substrate is between 526 and 598 psi. Momayez et al. (2005) demonstrated that the splitting tensile strength is equal or slightly greater than the direct tensile strength. The experimental results gave noticeably lower average tensile strengths, 318 to 370 psi. It is well known that the tensile strength 
property of the concrete has higher scatter than that of the compressive strength. Besides this, it has to be added that, in the pull off test, there are several factors that can affect the results, including the drilling process and the difficulty of applying a perpendicular force to the surface.

\subsubsection{Discussion}

The results of this test show that the bond tensile strength largely accomplishes with the minimum requirements for bond strength specified by ACI 546.3R-06. However, it was not possible to estimate the actual strength of the bond due to the fact that the concrete substrate failed at low tensile stress.

The COV's, attained in this study, varies from 6.1 to $18.4 \%$, for that reason, it can be stated that the results scattering is low. Bonaldo et al. (2005) carried out the pull-off using the same loading equipment as this research obtaining COV's up to $38.9 \%$. There are many factors that might influence in the pull off results, including the coarse aggregate (shape, maximum diameter and strength) of the concrete substrate, coring depth into substrate, the overlay thickness, concrete substrate strength, core diameter, load eccentricity and loading rate (Bonaldo et al. 2005). FEA seems to be necessary to understand the stress distribution along the core. A concentration of stress due to the elasticity mismatch might have taken place, resulting in a lower failure load. 


\section{Conclusions and further research}

Every year transportation agencies need to increase their budgets for maintaining and repairing infrastructure due to the large number of structures that are reaching their service lives. In response, the transportation industry needs to adapt this environment by developing new techniques to evaluate and repair this damage. The increasing need of rehabilitation is driving the development of new materials, such as, low slump dense concrete or polymer-impregnated concrete, which have potential advantages for the construction of new structures or their rehabilitation. The purpose of this research is not to demonstrate that UHPC has better qualities than other construction materials, but to show that this new advanced cementitious material exhibits outstanding properties that can result in great progress for the construction industry in some circumstances, such as harsh environments, in which most of the current construction materials fall short. The author recognizes that UHPC will not replace the general use of the traditional materials, e.g. portland cement or latex-modified concrete, because for some applications these meet all the requirements, but the proposed solution may offer a competitive alternative or even a superior one in some applications of the construction industry.

The results of this investigation provides information about the bond performance between UHPC and concrete. The evaluation is with respect to time of the bond strength under ambient environmental conditions with consideration of the influence of the wetting conditions of the concrete substrate, the performance of the composite systems in harsh enviroments and the effect of the different surface treatments of the concrete substrate are assessed.

\subsection{Conclusions}

It should be emphasized that the following conclusions are given for the specific UHPC used in this study (Ductal®JS1000) and no bonding agent was used. The conclusions are grouped into: splitting tensile test, slant-shear test, pull-off test and overall performance. 


\subsubsection{Combination of Splitting Tensile Test with Freeze-Thaw Cycles}

For the UHPC-NSC specimens exposed to 0, 300, 600 and 900 freeze-thaw cycles and subjected to a splitting tensile load scenario, the following conclusions were derived:

a. The moisture condition of the concrete substrate is a critical factor for attaining acceptable bond performance. A large number of composite specimens cast with the dry concrete substrate failed before applying the load. In contrast, excellent bond performance was obtained under saturated concrete substrate.

b. The exposure to a lengthy freeze-thaw cycling process does not decrease the indirect tensile strength of the bond. In all cases, the specimens with 300 freezethaw cycles have greater strength than those without cycles. While the strength of those samples subjected to 600 and 900 cycles had slightly greater or lower values than those without cycles.

c. The bond performance at old age (greater than 185 days) gives excellent results under splitting tensile stress, regardless of the degree of roughness of the concrete substrate or the exposure to freeze-thaw cycles. The bond strength broadly overcomes the minimum requirements specified by ACI 546.3R-06, even most of the specimens obtained more than the double.

d. The predominant failure modes were tensile rupture of the substrate and a mixture of bond/concrete failure or shearing of the grooves (grooved surfaces only). This is a sign that the bond strength was greater than that of the concrete substrate. Besides this, most of the composite specimens failed at tensile stress range similar to failure stress of concrete estimated by the relationship between compressive strength and splitting tensile strength given by ACI 318-11.

e. The evolution of the fundamental transversal frequency does not seem to be a good indicator of the bond strength evolution. All samples subjected to 300 freeze-thaw cycles and cast under surface saturated conditions showed an increase in bond strength as well as fundamental transverse frequency. However, some specimens cast under dry concrete substrate also experienced an increase in fundamental transverse frequency after freeze-thaw cycling, but failed during the 
cutting process showing that no bond had been developed between UHPC and concrete.

\subsubsection{Slant-shear test}

For the composite slant-shear specimens with different interface angles $\left(55^{\circ}, 60^{\circ}\right.$ and $70^{\circ}$ from horizontal) tested at different early ages (2, 3 and 8 days), the following conclusions were drawn:

a. The bond capacity at 8 days surpasses the 7 day requirements ACI 546.3R-06 and even achieves the minimum requirements at 28 days, regardless the surface treatment applied.

b. The bond strength at 8 days is greater than the concrete substrate strength. All specimens with a bond interface of $60^{\circ}$ failed in the concrete substrate.

c. There is a strong increment of the bond between the second and third day after casting. During this time, the UHPC and bond strengths exceed the concrete strength.

d. The bond capacity at 3 days widely overcomes with the requirements specified by ACI 546.3R-06 at 7 days and achieves with the minimum bond at 28 days.

e. The slant-shear test highly depends on the interface angle used. A higher angle from horizontal will produce a more severe state of shear and compression stresses. Hence, the failure mode is linked to the joint angle: a higher interface angle gives the possibility of obtaining the sliding failure (bond), achieving, thereby, the actual strength of the bond.

\subsubsection{Pull-off test}

For the direct tensile (pull-off) test, the following conclusions were derived:

a. The direct tensile strength of the bond at 10-11 days is greater than the requirements at 7 and 28 days given by ACI 546.3R-06.

b. All specimens failed in the concrete substrate, except one, showing the accomplishment performance between UHPC and NSC. 


\subsubsection{Overall performance}

a. For this formulation (Ductal®JS1000), better bond performance is expected with a saturated concrete substrate. A dry condition of the concrete substrate can negatively affect the development of the bond strength while a saturated condition of the concrete substrate is beneficial for obtaining an excellent bond performance. If the appropriate wetting condition of the substrate takes place, the roughness degree of the concrete substrate (friction) is not a critical factor to obtain a good bond strength due to the high adhesion that is developed between both materials.

b. The bond performance between UHPC and NSC is considered successful, as the strength, regardless the different loading configurations, is greater than that of the concrete substrate and largely satisfies the requirements of ACI 546.3R-06.

c. It is not possible to draw a failure envelope of the bond between UHPC and concrete due to the fact that in most cases the failure occurred in the concrete substrate. Therefore, it was only possible to have a lower bound of the real capacity.

d. When UHPC has achieved a strength greater than 14,500 psi and the concrete substrate had an adequate wetting condition at the day of placing the overlay, the NSC substrate, designed according to Michigan Department of Transportation (2009) for concrete overlays, will be the weakest part of the composite system and the bond will offer a performance that accomplish with the ACI 546.3R-06 requirements.

e. The compressive strength obtained under ambient condition for UHPC (22.5 ksi) is considerably lower than the typically expected under thermal treatment (30 ksi) for this specific formulation (Ductal JS1000). Despite this, UHPC offered good performance under freeze-thaw cycles and its strength widely surpasses to that of NSC. 


\subsection{Criticism of the bonding test and recommendations}

This section highlights the benefits and drawbacks of the different tests used in this report.

a. Splitting tensile, slant-shear and pull-off tests presented low COV's, showing a consistency in the results.

b. The splitting tensile results were in agreement with the expected splitting tensile strength, thus demonstrating, the validity of the results. However, 12 out of 240 prisms tested for the case study of saturated concrete substrate were considered outliers. The large amount of steps needed in the preparation of the specimens and the limited investigation of the bond formation process prevent the development of solid conclusions for the cause of the premature failure of the samples. Overall, this test is concluded to be a reliable and offers the possibility of including the freeze-thaw cycles in the bond performance assessment.

c. The slant-shear test seems to give reasonable outcomes in accordance with other researchers' results. This method presents the advantage of requiring less preparation than the others.

d. An interface angle of $60^{\circ}$ can be sufficient to get a sliding failure from composite specimens without high bond strength. Nevertheless, if the bond strength is especially elevated, the inclusion of more inclined surfaces could yield failures along the interface, thus, the actual bond strength, instead of a failure along the substrate.

e. According to literature, a different range of specimen dimensions can be used in the slant-shear test. This might give the possibility of casting specimens which fit in the frame of the freeze-thaw chamber, as shown by Wang and Lee (2007).

f. The pull-off test achieved this intended goal of verifying that the outstanding bond strength between UHPC and NSC. However, all specimens failed at lower direct tensile stresses as expected. According to literature, this test seems to be sensitive to several factors, including, the coring depth into substrate, the overlay thickness, concrete substrate strength, core diameter, loading rate, modulus 
mismatch and load eccentricity. Though the specifications given by ASTM C 1583 were followed, the small thickness of the overlay attached with the properties mismatch between overlay and substrate might have been a factor in the low failure stress observed in the concrete substrate. Further research is need to prove if the current specifications given by ASTM C 1583 are still valid for overlays with a shallow thickness and significant mechanical properties mismatch with the concrete substrate.

g. The modulus mismatch might cause local stress concentrations in the pull-off and slant-shear tests. Austin et al. (1999) stated that an eccentricity of the loading can occur due to a modulus mismatch between the overlay and substrate materials resulting in a lower failure load in the slant-shear test. It is convenient to develop Finite Element Models (FEM) of the different loading configurations used in this experimental program to help to understand better the stress distribution along the composite specimens.

\subsection{Further research}

This report focuses on the characterization of the bond UHPC and conventional concrete under different loading configurations, age, roughness degree of the concrete substrate and freeze-thaw cycles exposure. The outstanding bond performance has been demonstrated throughout this report. However, further research is needed to complete the understanding of the bond between these materials and to evaluate the potential use of UHPC as repair material.

a. Microstructure observations of the bond interface by using a scanning electron microscope (SEM) could provide a better understanding of the reason whereby UHPC seems to have a high adhesion to the normal concrete.

b. To repeat the bonding tests with different UHPC formulations to have a wider scenario that represent the variations in the mix designs that can exist between different UHPC's.

c. The development of new UHPC formulations that utilize local materials and can be placed in the field with a certain inclination would help to promote its use. 
d. The effect that cyclic loading might have on the bond performance should be assessed. Abu-Tair et al. (1996) utilized the slant-shear and modified modulus of rupture (MMOR) tests to study this effect.

e. The differential volume changes between the overlay and concrete substrate materials induce stresses along the interface. Further research is needed to understand the effect that thermal variations, shrinkage and creep could have in the performance of the composite system. Shann (2012) carried out preliminary study to determine the optimum overlay thickness for cast-in-place and precast applications based on a numerical analysis and experimental program. However, variables such as the effect of CTE mismatch, post-cracking propagation or the effect of existing cracks, were not included.

f. A comparative analysis, in economic and environmental impact terms, of UHPC constructive alternative against other constructive solutions that use different nonconventional concrete (such as Latex-modified Concrete, Low Slump Dense concrete or Silica Fume concrete) should be carried out. 


\section{Reference}

Abu-Tair, A. I., Rigden, S. R., and Burley, E. (1996). "Testing the bond between repair materials and concrete substrate." ACI Materials Journal, 93, 553-558.

ACI 318-11 (2011). "Building Code Requirements for Structural Concrete and Commentary." American Concrete Institute, 503.

ACI 546.3R-06 (2006). "Guide for the Selection of Materials for the Repair of Concrete." American Concrete Institute, Farmington Hills, MI, 34.

ACI 546R-04 (2004). "Concrete Repair Guide." American Concrete Institute, 53.

ASTM C31 / C31M-09 (2009). "Standard Practice for Making and Curing Concrete Test Specimens in the Field." ASTM International, ed.West Conshohocken, PA.

ASTM C33 / C33M (2011). "Standard Specification for Concrete Aggregates."West Conshohocken,PA.

ASTM C39 (2012). "Standard Test Method for Compressive Strength of Cylinderical Concrete Specimens." Annual Book of ASTM Standards,, ASTM International, West Conshohocken, PA.

ASTM C230 / C230M (2008). "Standard Specification for Flow Table for Use in Tests of Hydraulic Cement."West Conshohocken,PA.

ASTM C496 (2004). "Standard Test Method for Splitting Tensile Strength of Cylindrical Concrete Specimens."West Conshohocken,PA. 
ASTM C666 / C666M (2008). "Standard Test Method for Resistance of Concrete to Rapid Freezing and Thawing."West Conshohocken,PA.

ASTM C1583 / C1583M (2004). "Standard Test Method for Tensile Strength of Concrete Surfaces and the Bond Strength or Tensile Strength of Concrete Repair and Overlay Materials by Direct Tension (Pull-off Method)."West Conshohocken,PA.

ASTM C 882-05e1 (2005). "Standard Test Method for Bond Strength of Epoxy-Resin Systems Used With Concrete By Slant Shear." ASTM International, ed.West Conshohocken, PA.

ASTM E 965-96 (2006). "Standard Test Method for Measuring Pavement Macrotexture Depth Using a Volumetric Technique."West Conshohocken, PA.

Austin, S., Robins, P., and Pan, Y. (1999). "Shear bond testing of concrete repairs." Cement and Concrete Research, 29, 1067-1076.

Beushausen, H. (2010). "The influence of concrete substrate preparation on overlay bond strength." Magazine of Concrete Research, 62, 845-852.

Bonaldo, E., Barros, J. A. O., and Lourenco, P. B. (2005). "Bond characterization between concrete substrate and repairing SFRC using pull-off testing." International Journal of Adhesion and Adhesives, 25, 463-474.

British Standard (1999). "Products and systems for the protection and repair of concrete structures. Test methods. Determination of slant shear strength." BSI, 12.

Buitelaar, P. (2004). "Ultra High Performance Concrete: Development and application during 25 years." Plenary Session international Symposium on UHPC. 
Climaco, J. C. T. S., and Regan, P. E. (2001). "Evaluation of bond strength between old and new concrete in structural repairs." Magazine of Concrete Research, 53, 377390.

Decter, M. H., and Keeley, C. (1997). "Durable concrete repair - importance of compatibility and low shrinkage." Construction and Building Materials, 11(5-6), 267-273.

Denarié, E. (2004). "Report on preliminary studies for the use of HPFRCC for the rehabilitation of road infrastructure components - Deliverable D13." WP14:HPFRCC (High Performance Fiber Reinforced Cementitious Composites) for rehabilitation, Sustainable and Advanced MAterials for Road InfraStructure (SAMARIS).

Denarié, E., Brühwiler, E., and Znidaric, A. (2005). "Full scale applications of UHPFRC for the rehabilitation of bridges - from the lab to the field - Deliverable D22." WP14:HPFRCC (High Performance Fiber Reinforced Cementitious Composites) for rehabilitation, Sustainable and Advanced MAterials for Road InfraStructure (SAMARIS).

Denarié, E., Habert, G., and Šajna, A. (2009b). "Recommendations for the use of UHPFRC in composite structural members -Rehabilitation Log Čezsoški Bridge Deliverable D14." Assessment and Rehabilitation of Central European Highway Structures.

Denarié, E., Šuput, J., and Rossi, P. (2009a). "Recommendations for the tailoring of UHPFRC recipes for rehabilitation - Deliverable D06." Assessment and Rehabilitation of Central European Highway Structures. 
Emmons, P. H., and Vaysburd, A. M. (1996). "System concept in design and construction of durable concrete repairs." Construction and Building Materials, 10(1), 69-75.

Espeche, A. D., and Leon, J. (2011). "Estimation of bond strength envelopes for old-tonew concrete interfaces based on a cylinder splitting test." Construction and Building Materials, 25, 1222-1235.

Euclid Chemical (2012). "Concrete Surface Retarder Technical Data Sheet." $<$ http://www.euclidchemical.com/fileshare/ProductFiles/techdata/Concrete_Surfa ce_Retarders.pdf $>($ Jul 25, 2012).

Eyre, J. R., and Campos, E. S. (1996). "Upper bounds in the slant shear testing of perfectly plastic joints in concrete." Magazine of Concrete Research, 48, 181-188.

Fidjestol, P., Thorsteinsen, R. T., and Svennevig, P. (2012). "Making UHPC with local materials - The Way Forward." Proceedings of Hipermat 2012 - 3rd International Symposium on UHPC and Nanotechnology for Construction Materials, Kassel University Press, Kassel, Germany.

Fischer, G. "Characterization of Fiber-Reinforced Cement Composited by their Tensile Stress-Strain Behavior and Quantification of Crack Formation. ." Proc., 6th RILEM Symposium on Fiber-Reinforced Concretes (FRC) - BEFIB.

Geissert, D. G., Li, S. E., Frantz, G. C., and Stephens, J. E. (1999). "Splitting prism test method to evaluate concrete-to-concrete bond strength." ACI Materials Journal, 96, 359-366.

Graybeal, B. (2006). "Material Property Characterization of Ultra-High Performance Concrete." 
Graybeal, B., and Tanesi, J. (2007). "Durability of an ultrahigh-performance concrete." Journal of Materials in Civil Engineering, 19(10), 848-854.

Hindo, K. R. (1990). "In-place bond testing and surface preparation of concrete." Concrete International, 12, 46-48.

International Concrete Repair Institute (1997). "Selecting and Specifying Concrete Surface Preparation for Sealers, Coatings, and Polymer Overlays."Sterling, Virginia, 41.

Issa, M. A., Alhassan, M. A., and Shabila, H. (2008). "High-performance plain and fibrous latex-modified and microsilica concrete overlays." Journal of Materials in Civil Engineering, 20(12), 742-753.

Jones, M., Zheng, L., and Newlands, M. (2002). "Comparison of particle packing models for proportioning concrete constitutents for minimum voids ratio." Materials and Structures, 35(5), 301-309.

Julio, E. N. B. S., Branco, F. A. B., and Silva, V. D. (2005). "Concrete-to-concrete bond strength: Influence of an epoxy-based bonding agent on a roughened substrate surface." Magazine of Concrete Research, 57, 463-468.

Kamen, A. "Time Dependent Behaviour of Ultra High Performance Fibre Reinforced Concrete (UHPFRC)." Proc., 6th International PhD Symposium in Civil Engineering.

Kim, D. J., Wille, K., Naaman, A. E, and El-Tawil, S. (2011). "Strength dependent tensile behavior of strain hardening fiber reinforced concrete." Proceedings of Rilem 
International Workshop on High Performance Fiber Reinforced Cement Composites - HPFRCC6, Ann Arbor, USA, (in press).

Kollmorgen, G. A. (2004). "Impact of age and size on the mechanical behavior of an ultra high performance concrete." Master of Science in Civil Engineering, Michigan Technological University, Houghton, MI.

Kosmatka, S. H., and Wilson, M. L. (2011). Design and Control of Concrete Mixtures, Portland Cement Association, Skokie, IL.

Lafarge North America (2003). "Ductal Reference T 006, Operating Procedure Flow Test."Calgary, Canada.

Lee, M.-G., Chiu, C.-T., and Wang, Y.-C. (2005). "The study of bond strength and bond durability of reactive powder concrete." Journal of ASTM International, 2, 485494.

Li, S. E., Geissert, D. G., Frantz, G. C., and Stephens, J. E. (1999). "Freeze-thaw bond durability of rapid-setting concrete repair materials." ACI Materials Journal, 96, 242-249.

Markovic, I. (2006). "High-performance hybrid-fibre concrete : development and utilisation."PhD Thesis, Delft University of Technology Delft.

Michigan Department of Transportation (1996). "Standard Specifications for Construction."Lansing, MI.

Michigan Department of Transportation (2009). "MDOT Bridge Design Manual."Lansing, MI. 
Misson, D. (2008). "Influence of Curing Regime on the Durability of an Ultra-High Performance Concrete Material." Masters of Science in Civil Engineering, Michigan Technological University, Houghton, MI.

Momayez, A., Ehsani, M. R., Ramezanianpour, A. A., and Rajaie, H. (2005). "Comparison of methods for evaluating bond strength between concrete substrate and repair materials." Cement and Concrete Research, 35(4), 748-757.

Morgan, D. R. (1996). "Compatibility of concrete repair materials and systems." Construction and Building Materials, 10(1), 57-67.

Morin, V., Cohen-Tenoudji, F., Feylessoufi, A., and Richard, P. (2002). "Evolution of the capillary network in a reactive powder concrete during hydration process." Cement and Concrete Research, 32(12), 1907-1914.

Morin, V., Cohen Tenoudji, F., Feylessoufi, A., and Richard, P. (2001). "Superplasticizer effects on setting and structuration mechanisms of ultrahigh-performance concrete." Cement and Concrete Research, 31(1), 63-71.

Pacheco-Torgal, F., Castro-Gomes, J. P., and Jalali, S. (2008). "Adhesion characterization of tungsten mine waste geopolymeric binder. Influence of OPC concrete substrate surface treatment." Construction and Building Materials, 22(3), 154-161.

Perry, V. "Sustainable UHPC Bridges for the 22nd Century." Proc., 2011 Conference and Exhibition of the Transportation Association of Canada. Transportation Success: LET\&apos;S Build on them. 2011 Congress et Exhibition de l'Association des Transports du Canada. Les Succes en Transports: Une Tremplin vers l'Avenir 13. 
Peuse, E. (2008). "Impact of Age at Thermal Treatment on the Mechanical Properties of an Ultra-High Performance Concrete." Masters of Science in Civil Engineering, Michigan Technological University, Houghton, MI.

Ramey, G. E., and Strickland, A. M. (1984). "An experimental evaluation of rapid-setting patching materials used in the repair of concrete bridges and pavements. Final Report." F. A.-B. H. 97B, ed., 147.

Rangaraju, P. R., Pattnaik, R. R., Transportation, S. C. D. o., and Engineering, C. U. D. o. C. (2008). Evaluation of Rapid-set Patching Materials for PCC Applications, Department of Civil Engineering, Clemson University.

Richard, P., and Cheyrezy, M. (1995). "Composition of reactive powder concretes." Cement and Concrete Research, 25(7), 1501-1511.

Robins, P. J., and Austin, S. A. (1995). "Unified failure envelope from the evaluation of concrete repair bond tests." Magazine of Concrete Research, 47, 57-68.

Santos, P. M. D., and Julio, E. N. B. S. (2011). "Factors affecting bond between new and old concrete." ACI Materials Journal, 108(4), 449-456.

Schmidt, M., and Fehling, E. "Ultra-High-Performance Concrete: Research, Development and Application in Europe." Proc., 7th Int. Sym. on the utilization of HS/HPC, American Concrete Institute, 51-77.

Shann, S. (2012). "Application of Ultra High Performance Concrete (UHPC) as a ThinBonded Overlay for Concrete Bridge Decks." Masters of Science in Civil Engineering, Michigan Technological University, Houghton, MI. 
Silfwerbrand, J. (1990). "Improving concrete bond in repaired bridge decks." Concrete International, 12, 61-66.

Silfwerbrand, J. (2003). "Shear bond strength in repaired concrete structures." Materials and Structures/Materiaux et Constructions, 36, 419-424.

Sooriyaarachchi, H. P., Nishimura, T., Misra, S., and Uomoto, T. (2002). "An Experimental Study to Evaluate Failure Surface of the Concrete-Repair Material Interface." SEISAN KENKYU, 54(6), 414-417.

Sprinkel, and Ozyildirim (2000). "Evaluation of high performance concrete overlays placed on route 60 over Lynnhaven inlet in Virginia." Rep no. VTRC 01-R1, Virginia Transportation Research Council, Charlottesville,Virginia.

Sprinkel, M. M. (1997). "Preparing bridge decks for overlays." Aberdeen's Concrete Repair Digest, 8, 242-247.

Sritharan, S., Aaleti, S., Bierwagen, D., Garder, J., and Abu-Hawash, A. (2012). "Current Research on Ultra High Performance Concrete (UHPC) for Bridge Applications in Iowa." Proceedings of Hipermat 2012 - 3rd International Symposium on UHPC and Nanotechnology for Construction Materials, Kassel University Press, Kassel, Germany.

Suleiman, M., Sri Sritharan., and Vande Voort, T. L. (2008). "Design and Performance Verification of UHPC piles for deep foundations." Center for Transportation Research and Education Iowa State University. 
Wall, J. S., Shrive, N. G., and Gamble, B. R. "Testing of Bond between fresh and hardened concrete." Proc., Adhesion Between Polymers and Concrete, Proceedings of an International Symposium., Chapman \& Hall, 335-344.

Wang, Y.-C., and Lee, M.-G. (2007). "Ultra-high strength steel fiber reinforced concrete for strengthening of RC frames." Journal of Marine Science and Technology, 15, 210-218. 


\section{Appendix: NSC mix designs}

Table 7.1

1st mix for the splitting tensile test

\section{Coarse}

\begin{tabular}{lrl}
\hline Dry weight of Coarse & 196.2 & 196.2 \\
\hline SSD wt of Coarse & 199.7 & $\mathrm{lbs}$ \\
\hline Water abs by coarse & 1.9 & $\mathrm{lbs}$ \\
\hline $\begin{array}{l}\text { Free Water on } \\
\text { Coarse }\end{array}$ & 4.4 & $\mathrm{lbs}$
\end{tabular}

\begin{tabular}{lrl}
\hline Fine & & \\
\hline Dry Fine Agg Wt & 140.1 & lbs \\
\hline Moist Fine Agg Wt & 143.6 & $\mathrm{lbs}$ \\
\hline SSD Wt of Fine & 141.3 & $\mathrm{lbs}$ \\
\hline Free Water on Fine & 2.3 & $\mathrm{lbs}$
\end{tabular}

Water

Water Wt

35.7 lbs

28.9 lbs

\begin{tabular}{lll} 
Corrected Water Wt & 28.9 & $\mathrm{lbs}$ \\
\hline vinsol AEA & 18.0 & $\mathrm{ml}$ \\
\hline water reducer & 30.0 & $\mathrm{ml}$ \\
\hline
\end{tabular}

Cementitious

Portland

$79.5 \mathrm{lbs}$

\begin{tabular}{ll} 
Fly Ash & 0.0 \\
\hline GGBFS & 0.0 \\
\hline
\end{tabular}

\section{Coarse aggregate distribution}

wt\% dry moist

\begin{tabular}{crrr}
$3 / 4$ & 0.0 & 0.0 & 0.0 \\
\hline $1 / 2$ & 0.0 & 0.0 & 0.0 \\
\hline $3 / 8$ & 50.0 & 98.1 & 98.4 \\
\hline no. 4 & 45.3 & 88.9 & 89.1 \\
\hline no. 8 & 4.7 & 9.2 & 9.2 \\
\hline no. 16 & 0.0 & 0.0 & 0.0 \\
\hline & 100.0 & 195.9 & 196.8
\end{tabular}

Testing data

Temp.

(C) $\quad 71.6$

Slump

(in.) $\quad 5.8$

Pressure meter air

\begin{tabular}{cc} 
vol\% & 5.7 \\
\hline $\begin{array}{c}\text { Unit } \\
\text { weight }\end{array}$ \\
(lbs/ft3) & 145.2 \\
\hline Yield &
\end{tabular}

(ft3) $\quad 3.1$

\section{Cast samples}

Splitting tensile samples in dry conditions (15 beams for 0 F-T cycles and 15 beams for $300 \mathrm{~F}-\mathrm{T}$ cycles)

Date

$10 / 21 / 2010$ 
Table 7.2

2nd mix for the splitting tensile test

\section{Coarse}

\begin{tabular}{lrl}
\hline Dry weight of Coarse & 196.4 & 196.2 \\
\hline SSD wt of Coarse & 199.8 & $\mathrm{lbs}$ \\
\hline Water abs by coarse & 1.9 & $\mathrm{lbs}$ \\
\hline $\begin{array}{l}\text { Free Water on } \\
\text { Coarse }\end{array}$ & 4.4 & $\mathrm{lbs}$ \\
\hline & & \\
Fine & & \\
\hline Dry Fine Agg Wt & 140.2 & $\mathrm{lbs}$ \\
\hline Moist Fine Agg Wt & 143.7 & $\mathrm{lbs}$ \\
\hline SSD Wt of Fine & 141.4 & $\mathrm{lbs}$ \\
\hline Free Water on Fine & 2.3 & $\mathrm{lbs}$ \\
\hline & & \\
& & \\
Water & &
\end{tabular}

\section{Coarse aggregate distribution}

\begin{tabular}{cccc} 
& wt\% & dry & moist \\
\hline & & & \\
$3 / 4$ & 0.0 & 0.0 & 0.0 \\
\hline $1 / 2$ & 0.0 & 0.0 & 0.0 \\
\hline $3 / 8$ & 50.0 & 98.2 & 98.5 \\
\hline no. 4 & 45.3 & 88.9 & 89.2 \\
\hline no. 8 & 4.7 & 9.2 & 9.3 \\
\hline no. 16 & 0.0 & 0.0 & 0.0 \\
\hline & 100.0 & 196.1 & 196.9
\end{tabular}

\section{Testing data}

$$
\text { Temp. }
$$

Water Wt

35.7 lbs

(C)

72.5

Slump

\begin{tabular}{lll} 
Corrected Water Wt & 29.0 & $\mathrm{lbs}$ \\
\hline vinsol AEA & 18.0 & $\mathrm{ml}$ \\
\hline water reducer & 30.0 & $\mathrm{ml}$ \\
\hline
\end{tabular}

(in.)

5.3

Pressure meter air

\begin{tabular}{ll} 
vol\% & 6.0 \\
\hline Unit
\end{tabular}

\section{Cementitious} weight

Portland 79.6 lbs

\begin{tabular}{c} 
(lbs/ft3) 144.7 \\
\hline Yield
\end{tabular}

\begin{tabular}{ll} 
Fly Ash & 0.0 \\
\hline GGBFS & 0.0 \\
\hline
\end{tabular}

3.1

\section{Cast samples}

Splitting tensile samples in pre--wetting conditions (15 beams for 0 F-T cycles and 15 beams for $300 \mathrm{~F}-\mathrm{T}$ cycles)

Date $10 / 26 / 2010$ 
Table 7.3

3rd mix for the splitting tensile test

\section{Coarse}

\begin{tabular}{|c|c|c|c|c|c|c|}
\hline Dry weight of Coarse & 196.3 & 196.2 & \multirow{2}{*}{\multicolumn{4}{|c|}{ Coarse aggregate distribution }} \\
\hline SSD wt of Coarse & 199.8 & lbs & & & & \\
\hline Water abs by coarse & 1.9 & Ibs & & wt\% & dry & moist \\
\hline \multicolumn{7}{|l|}{ Free Water on } \\
\hline \multirow[t]{2}{*}{ Coarse } & 5.0 & lbs & $3 / 4$ & 0.0 & 0.0 & 0.0 \\
\hline & & & $1 / 2$ & 0.0 & 0.0 & 0.0 \\
\hline Fine & & & $3 / 8$ & 50.0 & 98.2 & 98.4 \\
\hline Dry Fine Agg Wt & 140.2 & lbs & no. 4 & 45.3 & 88.9 & 89.2 \\
\hline Moist Fine Agg Wt & 143.7 & Ibs & no. 8 & 4.7 & 9.2 & 9.3 \\
\hline SSD Wt of Fine & 141.4 & lbs & no. 16 & 0.0 & 0.0 & 0.0 \\
\hline Free Water on Fine & 2.3 & Ibs & \multirow{2}{*}{\multicolumn{2}{|c|}{ Testing data }} & 196.0 & 196.9 \\
\hline Water & & & & & & \\
\hline Water Wt & 35.7 & Ibs & $\begin{array}{l}\text { Temp. } \\
\text { (C) }\end{array}$ & 73.0 & & \\
\hline Corrected Water Wt & 28.4 & Ibs & $\begin{array}{c}\text { Slump } \\
\text { (in.) }\end{array}$ & 5.3 & & \\
\hline vinsol $A E A$ & 18.0 & $\mathrm{ml}$ & \multirow{3}{*}{$\begin{array}{c}\text { Pressure } \\
\text { meter air } \\
\text { vol\% }\end{array}$} & & & \\
\hline water reducer & 30.0 & $\mathrm{ml}$ & & & & \\
\hline \multirow{2}{*}{\multicolumn{3}{|c|}{ Cementitious }} & & 4.5 & & \\
\hline & & & Unit & & & \\
\hline Portland & 79.5 & Ibs & (lbs/ft3) & 147.4 & & \\
\hline Fly Ash & 0.0 & & $\begin{array}{l}\text { Yield } \\
\text { (ft3) }\end{array}$ & 3.1 & & \\
\hline GGBFS & 0.0 & & & & & \\
\hline
\end{tabular}

\section{Cast samples}

Splitting tensile samples in pre-wetting conditions ( 15 beams for $600 \mathrm{~F}-\mathrm{T}$ cycles and 15 beams for $900 \mathrm{~F}-\mathrm{T}$ cycles)

Date

$10 / 28 / 2010$ 
Table 7.4

4th mix for the splitting tensile test

\section{Coarse}

\begin{tabular}{|c|c|c|c|c|c|c|}
\hline Dry weight of Coarse & 193.8 & 196.2 & \multirow{2}{*}{\multicolumn{4}{|c|}{ Coarse aggregate distribution }} \\
\hline SSD wt of Coarse & 197.2 & lbs & & & & \\
\hline Water abs by coarse & 1.0 & Ibs & & wt\% & dry & moist \\
\hline \multicolumn{7}{|l|}{ Free Water on } \\
\hline \multirow[t]{2}{*}{ Coarse } & 6.2 & lbs & $3 / 4$ & 0.0 & 0.0 & 0.0 \\
\hline & & & $1 / 2$ & 0.0 & 0.0 & 0.0 \\
\hline Fine & & & $3 / 8$ & 50.0 & 98.1 & 98.4 \\
\hline Dry Fine Agg Wt & 140.1 & Ibs & no. 4 & 45.3 & 88.9 & 89.1 \\
\hline Moist Fine Agg Wt & 146.4 & Ibs & no. 8 & 4.7 & 9.2 & 9.2 \\
\hline SSD Wt of Fine & 141.3 & Ibs & no. 16 & 0.0 & 0.0 & 0.0 \\
\hline Free Water on Fine & 5.1 & Ibs & \multirow{2}{*}{\multicolumn{2}{|c|}{ Testing data }} & 195.9 & 196.8 \\
\hline Water & & & & & & \\
\hline Water Wt & 35.7 & Ibs & $\begin{array}{l}\text { Temp. } \\
\text { (C) }\end{array}$ & 68.0 & & \\
\hline Corrected Water Wt & 24.4 & lbs & $\begin{array}{c}\text { Slump } \\
\text { (in.) }\end{array}$ & 5.3 & & \\
\hline vinsol $A E A$ & 18.0 & $\mathrm{ml}$ & \multirow{3}{*}{$\begin{array}{c}\text { Pressure } \\
\text { meter air } \\
\text { vol\% }\end{array}$} & & & \\
\hline water reducer & 30.0 & $\mathrm{ml}$ & & & & \\
\hline \multirow{2}{*}{\multicolumn{3}{|c|}{ Cementitious }} & & 3.3 & & \\
\hline & & & Unit & & & \\
\hline Portland & 79.5 & Ibs & (lbs/ft3) & 151.6 & & \\
\hline Fly Ash & 0.0 & & $\begin{array}{l}\text { Yield } \\
\text { (ft3) }\end{array}$ & 3.0 & & \\
\hline GGBFS & 0.0 & & & & & \\
\hline
\end{tabular}

\section{Cast samples}

14 Monolithic samples for the splitting tensile test

Date

$2 / 8 / 2011$ 
Table 7.5

1st mix for the splitting tensile test

\section{Coarse}

Dry weight of Coarse $196.4 \quad 196.2$

SSD wt of Coarse 199.8 lbs

Water abs by

\begin{tabular}{lcl} 
coarse & 1.9 & $\mathrm{lbs}$ \\
\hline Free Water on & & \\
Coarse & 4.4 & $\mathrm{lbs}$ \\
\hline
\end{tabular}

Coarse aggregate distribution

\begin{tabular}{lrl} 
Fine & & \\
\hline Dry Fine Agg Wt & 140.2 & $\mathrm{lbs}$ \\
\hline Moist Fine Agg & & \\
Wt & 143.7 & $\mathrm{lbs}$ \\
\hline SSD Wt of Fine & 141.4 & $\mathrm{lbs}$ \\
\hline $\begin{array}{l}\text { Free Water on } \\
\text { Fine }\end{array}$ & 2.3 & $\mathrm{lbs}$ \\
\hline
\end{tabular}

Water

\begin{tabular}{cccc} 
& wt\% & dry & moist \\
\hline $3 / 4$ & 3.7 & 7.4 & 7.4 \\
\hline $1 / 2$ & 29.4 & 57.7 & 57.9 \\
\hline $3 / 8$ & 25.5 & 50.0 & 50.2 \\
\hline no. 4 & 40.4 & 79.4 & 79.6 \\
\hline & & & \\
no. 8 & 1.0 & 2.0 & 2.0 \\
\hline no. 16 & 0.0 & 0.0 & 0.0 \\
\hline & & & \\
& 100.0 & 196.1 & 196.9
\end{tabular}

\begin{tabular}{lll} 
Water & & \\
Water Wt & 35.7 & $\mathrm{lbs}$ \\
\hline $\begin{array}{l}\text { Corrected Water } \\
\text { Wt }\end{array}$ & 29.0 & $\mathrm{lbs}$ \\
\hline vinsol AEA & $18.0 \mathrm{ml}$ \\
\hline water reducer & $30.0 \mathrm{ml}$ \\
\hline & & \\
Cementitious & & \\
\hline & & \\
Portland & 79.6 & $\mathrm{lbs}$ \\
\hline & & \\
Fly Ash & 0.0 & \\
\hline GGBFS & 0.0 & \\
\hline
\end{tabular}

\begin{tabular}{ll}
\multicolumn{3}{l}{ Testing data } \\
\hline $\begin{array}{c}\text { Temp. } \\
\text { (C) }\end{array}$ & 70.0 \\
\hline $\begin{array}{c}\text { Slump } \\
\text { (in.) }\end{array}$ & 6.5 \\
\hline $\begin{array}{l}\text { Pressure } \\
\text { meter }\end{array}$ \\
air vol\% & 6.0 \\
\hline \multicolumn{2}{c}{ Unit } \\
weight \\
(lbs/ft3) & 142.2 \\
\hline Yield \\
(ft3) & 3.2 \\
\hline
\end{tabular}

\section{Cast samples}

Slant shear samples:

Brushed surface: 4 with 60 degrees and 4 with 70 degrees at 8 days Grooved surface: 4 with 60 degrees and 4 with 70 degrees at 8 days

Pull off samples Grooved surface: 2 slabs

Date

$$
9 / 6 / 2011
$$


Table 7.6

2nd mix for the splitting tensile test

\section{Coarse}

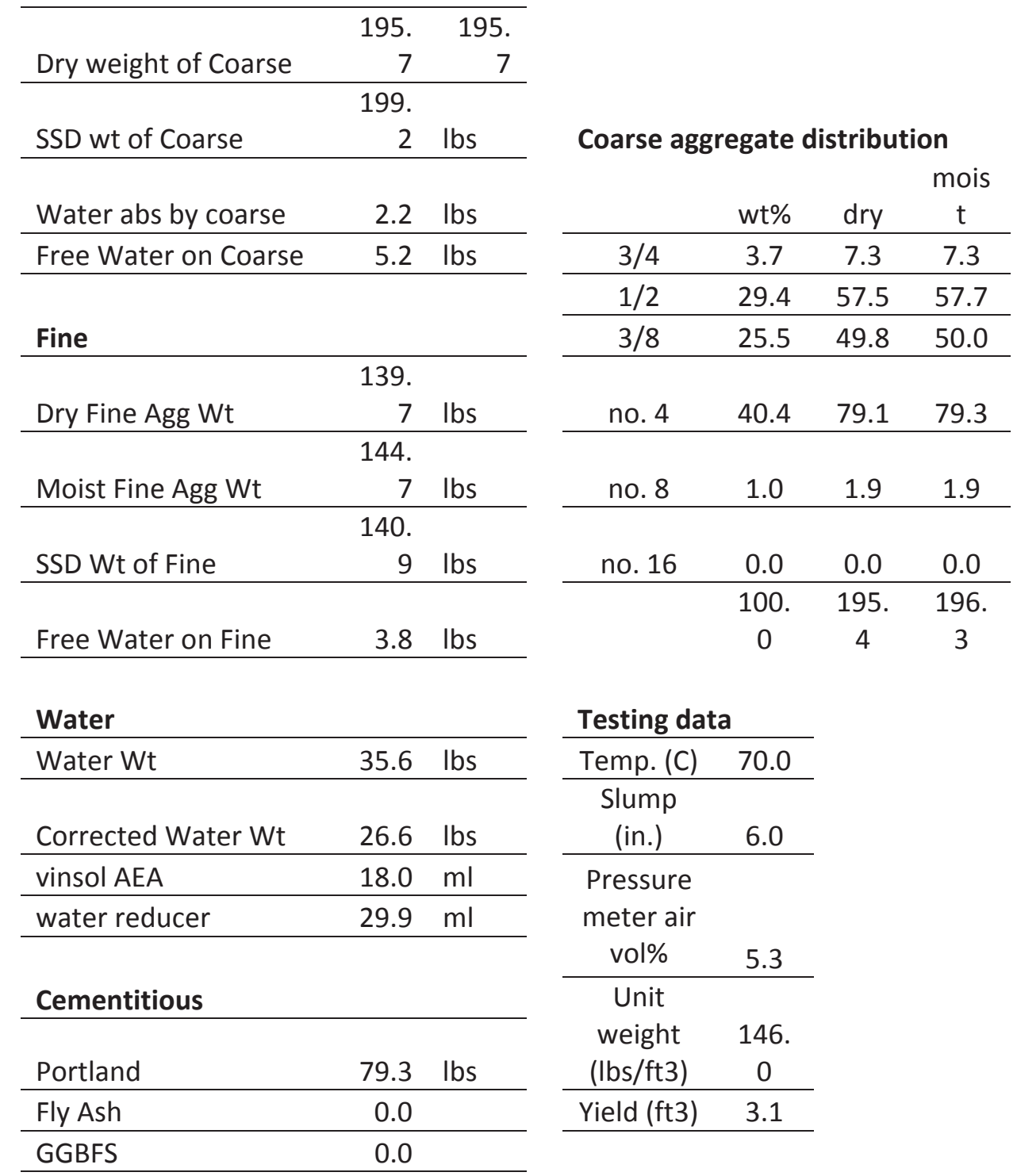

Cast samples

Slant shear samples: Sandblasted surface: 4 with 60 degrees and 4 with 70 degrees at 8 days Brushed surface: 4 with 55 degrees and 4 with 60 degrees at 3 days Brushed surface: 1 with 55 degrees and 3 with 70 degrees at 2 days

Pull off samples:

Date
Grooved surface: 3 with 70 degrees at 3 days

Brushed surface: 2 slabs

Sandblasted surface: 2 slabs

$9 / 22 / 2011$ 
Table 7.7

3rd mix for the splitting tensile test

\section{Coarse}

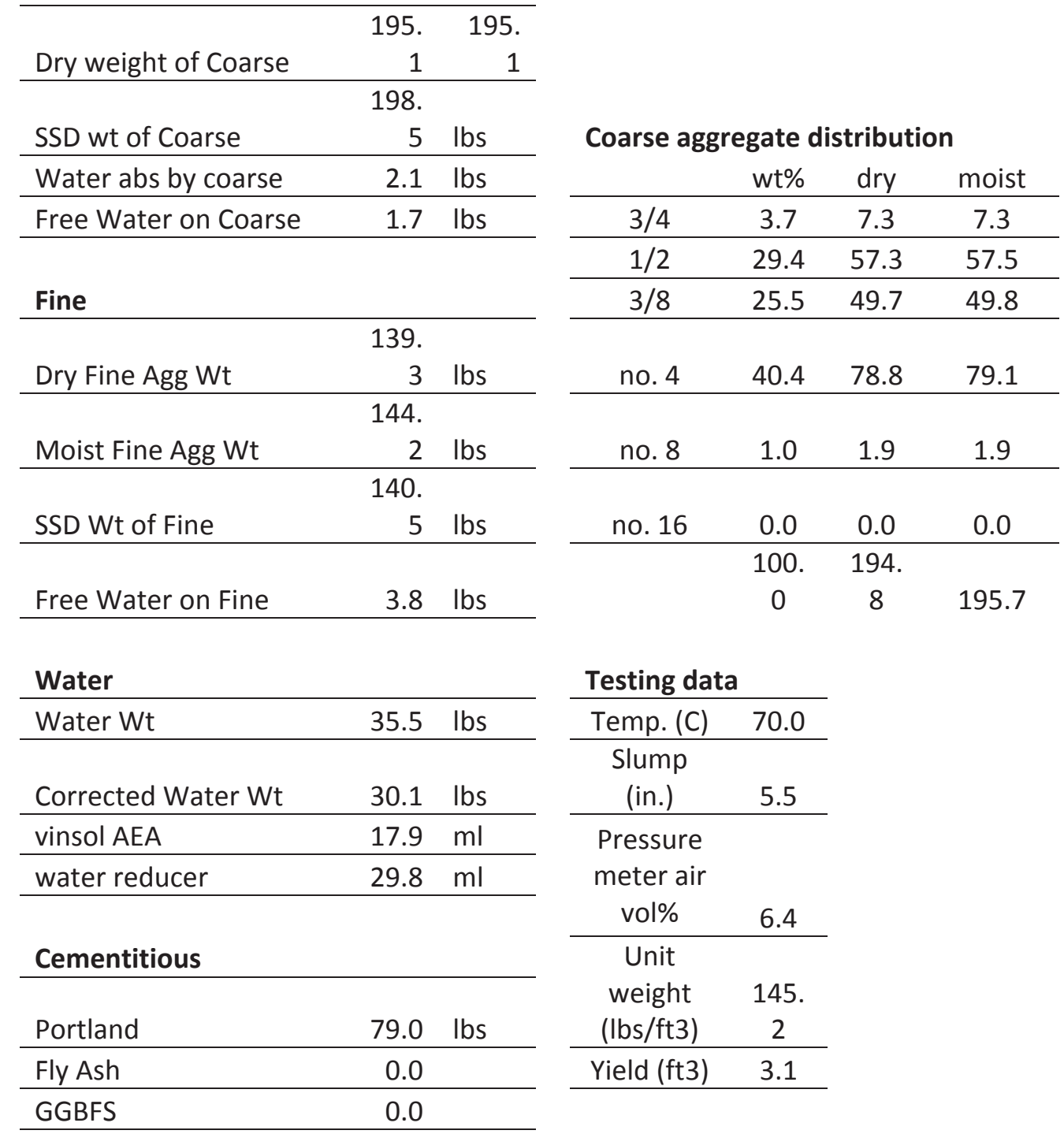

Cast samples

Slant shear samples: $\quad$ Smooth surface: 4 with 60 degrees and 4 with 70 degrees at 8 days Rough surface: 4 with 60 degrees and 4 with 70 degrees at 8 days Rough surface: 4 with 55 degrees and 1 with 70 degrees at 3 days Rough surface: 1 with 55 degrees at 2 days Grooved surface: 1 with 70 degrees at 3 days

Pull off samples:

Date

$10 / 1 / 2011$ rough surface: 4 slabs 


\section{Appendix: Concrete retarder information.}

\section{CONCRETE SURFACE RETARDERS}

Formula F \& Formula S For EXPosed Aggregate Surfaces

\section{DESCRIPTION}

CONCRETE SURFACE RETARDERS F \& $\mathbf{S}$ are chemical formulations which retard, but do not "kill" the set of the mortar at the surface of concrete. When the underlying concrete has hardened, the retarded mortar surface can be flushed off with a stream of water and/or removed by scrubbing with a stiff brush. Since these compounds do not "kill" the set, if they are left on the concrete or unintentionally splashed on other fresh concrete, they will permit the concrete to eventually attain a set and achieve full strength. These CONCRETE SURFACE RETARDERS are available in two formulations to meet varying job requirements:

Formula $\mathbf{F}$ is a paint-like emulsion designed for application directly to forms.

Formula $\mathbf{S}$ is a neutral, sprayable liquid for application to freshly placed horizontal concrete surfaces.

\section{PRIMARY APPLICATIONS}

- Creation of exposed aggregate surfaces

- Precast panels

- Decorative sidewalks and walkways

- Bond improvement for water-proofing materials

- Slip-resistant surfaces

- Formulations for both horizontal and vertical

\section{FEATURES/BENEFITS}

- Safe to use - easy to apply

- Works quickly and effectively

- Provides up to $1 / 4^{\prime \prime}(6 \mathrm{~mm})$ depth retardation

- Reduces cost of mechanically preparing surfaces for waterproofing, stucco or plaster application

- Etch depth can be adjusted as desired

\section{TECHNICAL INFORMATION}

Weight/gal

Solids Content

VOC

Appearance: CONCRETE SURFACE RETARDER Formula ' $F$ ' is a tan paint-like emulsion for application on vertical surfaces such as forms. CONCRETE SURFACE RETARDER Formula ' $S$ ' is a low viscosity green liquid for application directly on freshly placed horizontal concrete surfaces.

\section{PACKAGING}

CONCRETE SURFACE RETARDER F\&S are packaged in $55 \mathrm{gal}(208 \mathrm{~L})$ drums and $5 \mathrm{gal}(18.9 \mathrm{~L})$ pails.

CONCRETE SURFACE RETARDER $S$ is also available in cases of $6 / 1$ gal $(3.8 \mathrm{~L})$ units.

\section{SHELF LIFE}

2 years in original, unopened container.

\section{COVERAGE}

Formula 'F': 1 gal (3.8 L) will cover $150 \mathrm{ft}^{2}(3.7 \mathrm{~m}$ ') and provide up to $1 / 4$ " $(6 \mathrm{~mm})$ depth.

Formula ' $\mathrm{S}$ ': 1 gal (3.8 L) will cover 100 to $200 \mathrm{ft}^{2}$ ( 2.5 to $\left.4.9 \mathrm{~m}^{2}\right)$ and provide from $1 / 8$ " to $3 / 16$ " (3.2 to $\left.4.8 \mathrm{~mm}\right)$ depth retardation.

\section{DIRECTIONS FOR USE}

Surface Preparation: Forms to be coated should be clean and free of oil, dirt and form release agents.

Mixing: CONCRETE SURFACE RETARDERS do not require pre-blending. These products should be used directly from the container.

The Euclid Chemical Company

19218 Redwood Rd. C Cleveland, $\mathrm{OH} 44110$

Phone: [216] 531-9222 - Toll-free: [800] 321-7628 • Fax: [216] 531-9596 unw.euclidchemical.com

Figure 8.1 Concrete retarder information [1]. Euclid Chemical (2012) 
Application: CONCRETE SURFACE RETARDER Formula F should be painted on forms without thinning in a continuous unbroken film. Forms may be coated several days in advance or in as short a time as will allow complete drying of the film. Drying time varies between one and four hours depending on weather conditions. In warm weather, forms may be stripped in one day, in cooler weather allow two to three days. Immediately after stripping remove the retarded surface mortar by flushing off with a stream of water and/or remove by scrubbing with a stiff brush. Pre-cast structural members should be stripped from their forms in their usual time and the surface mortar then removed.

CONCRETE SURFACE RETARDER Formula $\mathbf{S}$ is applied to freshly placed horizontal concrete surfaces immediately after final finishing operations. It should be applied by low pressure spray and the treated surfaces then covered to prevent rapid evaporation. The retarded mortar should be flushed off with water in 12 to 24 hours after application depending upon weather conditions.

Use BROWNTONE CS to cure and seal exposed aggregate concrete to give these surfaces a subtle, earthtoned look with an attractive gloss.

CLEAN UP

Clean tools and equipment with soap and water before the material dries.

\section{Precautions/Limitations}

- These products are affected by environmental conditions. Warmer temperatures will allow earlier stripping of

forms and earlier surface flushing, while cooler temperatures delay these procedures.

- Store in a dry place and protect from freezing.

- In all cases, consult the Material Safety Data Sheet before use.

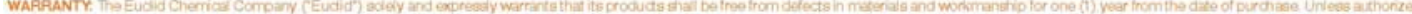

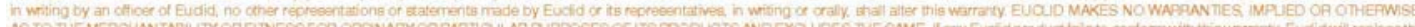

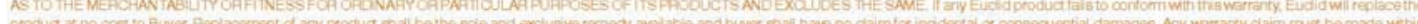

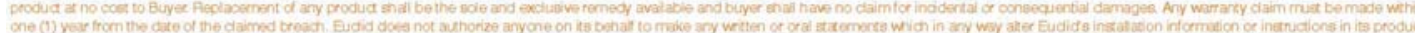

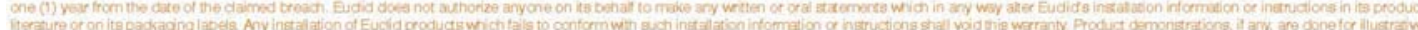

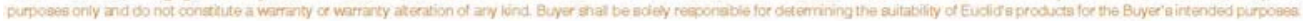

Figure 8.2 Concrete retarder information [2]. Euclid Chemical (2012) 


\section{Appendix: Macrotexture Depth test information.}

Table 9.1

Macrotexture depth results for the splitting tensile samples in wetting conditions.

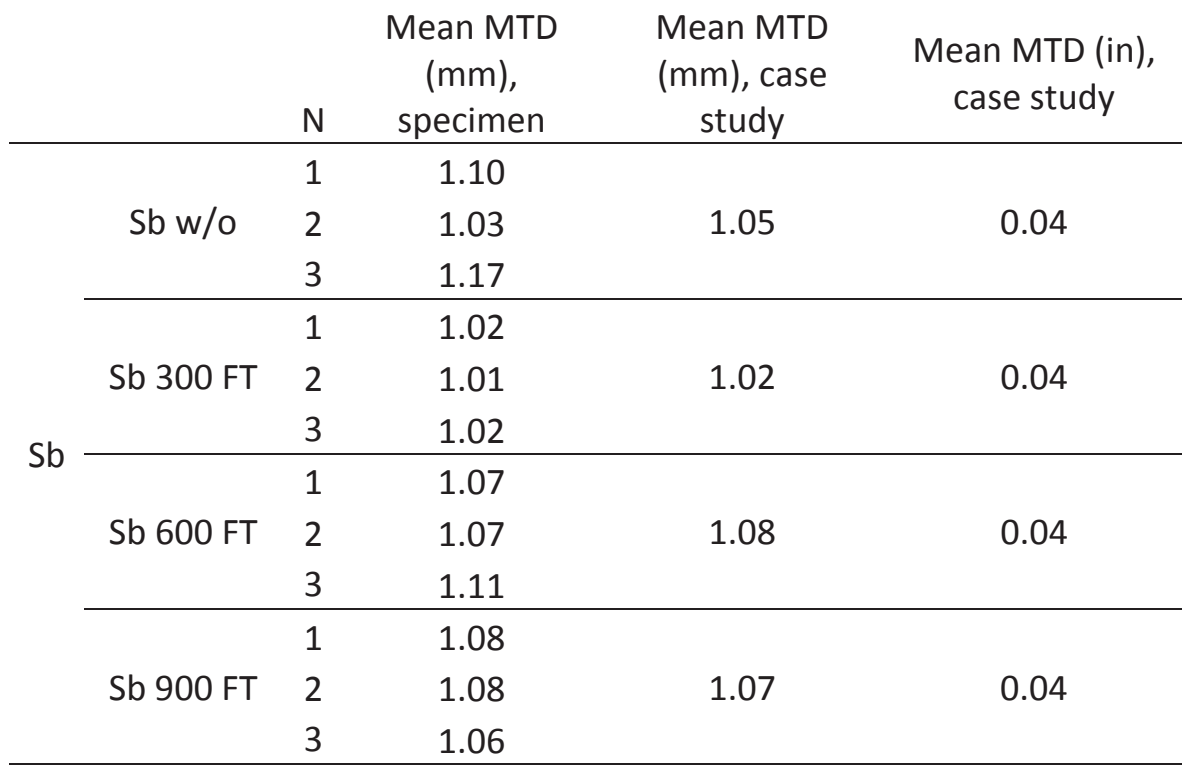

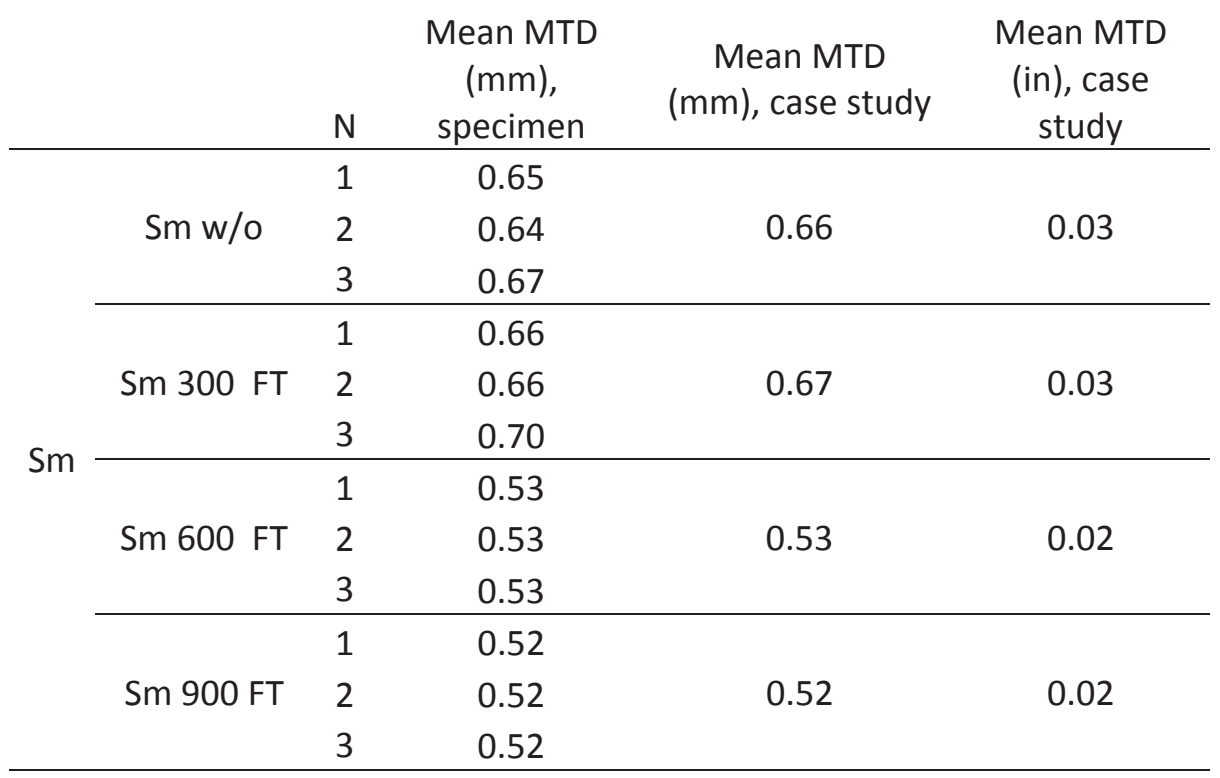


Table 9.1, continued.

\begin{tabular}{|c|c|c|c|c|c|}
\hline & & $\mathrm{N}$ & $\begin{array}{l}\text { Mean MTD } \\
(\mathrm{mm}), \\
\text { specimen }\end{array}$ & $\begin{array}{c}\text { Mean MTD } \\
(\mathrm{mm}), \text { case } \\
\text { study }\end{array}$ & $\begin{array}{c}\text { Mean MTD (in), } \\
\text { case study }\end{array}$ \\
\hline \multirow{12}{*}{$\mathrm{Br}$} & \multirow{3}{*}{$\mathrm{Br} w / \mathrm{o}$} & 1 & 0.71 & \multirow{3}{*}{0.73} & \multirow{3}{*}{0.03} \\
\hline & & 2 & 0.72 & & \\
\hline & & 3 & 0.77 & & \\
\hline & \multirow{3}{*}{$\mathrm{Br} 300 \mathrm{FT}$} & 1 & 0.85 & \multirow{3}{*}{0.78} & \multirow{3}{*}{0.03} \\
\hline & & 2 & 0.71 & & \\
\hline & & 3 & 0.77 & & \\
\hline & \multirow{3}{*}{$\mathrm{Br} 600 \mathrm{FT}$} & 1 & 0.73 & \multirow{3}{*}{0.72} & \multirow{3}{*}{0.03} \\
\hline & & 2 & 0.71 & & \\
\hline & & 3 & 0.71 & & \\
\hline & \multirow{3}{*}{$\mathrm{Br} 900 \mathrm{~T}$} & 1 & 0.83 & \multirow{3}{*}{0.75} & \multirow{3}{*}{0.03} \\
\hline & & 2 & 0.71 & & \\
\hline & & 3 & 0.71 & & \\
\hline
\end{tabular}

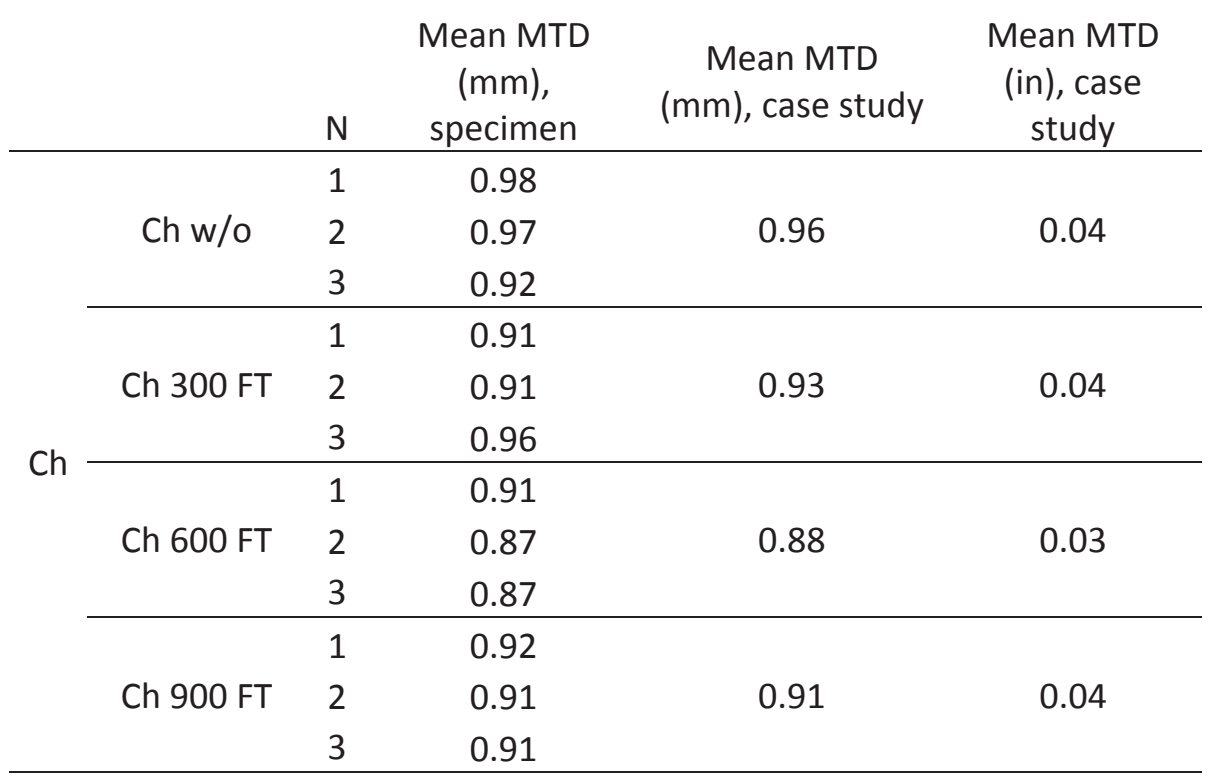


Table 9.2

Macrotexture depth results for the slant-shear and pull-off samples.

Rough $55^{\circ}$ (R155)

\begin{tabular}{|c|c|c|c|c|c|c|c|c|c|}
\hline & & \multicolumn{4}{|c|}{ Diameter $(\mathrm{mm})$} & \multirow{2}{*}{$\begin{array}{l}\text { Average } \\
\text { Diameter }\end{array}$} & \multirow{2}{*}{$\begin{array}{l}\text { MTD } \\
(\mathrm{mm})\end{array}$} & \multirow{2}{*}{$\begin{array}{c}\text { Average } \\
\text { MTD } \\
(\mathrm{mm})\end{array}$} & \multirow{2}{*}{$\begin{array}{c}\text { Average } \\
\text { MTD } \\
\text { (in) }\end{array}$} \\
\hline & & 1 & 2 & 3 & 4 & & & & \\
\hline \multirow{4}{*}{$\frac{\bar{\sigma}}{i \frac{\pi}{2}}$} & 1 & 34.84 & 35.33 & 36.90 & 33.91 & 35.25 & 2.05 & \multirow{4}{*}{2.10} & \multirow{4}{*}{0.08} \\
\hline & 2 & 33.16 & 33.03 & 34.57 & 36.49 & 34.31 & 2.16 & & \\
\hline & 3 & 35.81 & 33.50 & 34.47 & 36.15 & 34.98 & 2.08 & & \\
\hline & 4 & 33.86 & 32.04 & 35.94 & 36.65 & 34.62 & 2.12 & & \\
\hline
\end{tabular}

Rough $60^{\circ}$ (R160)

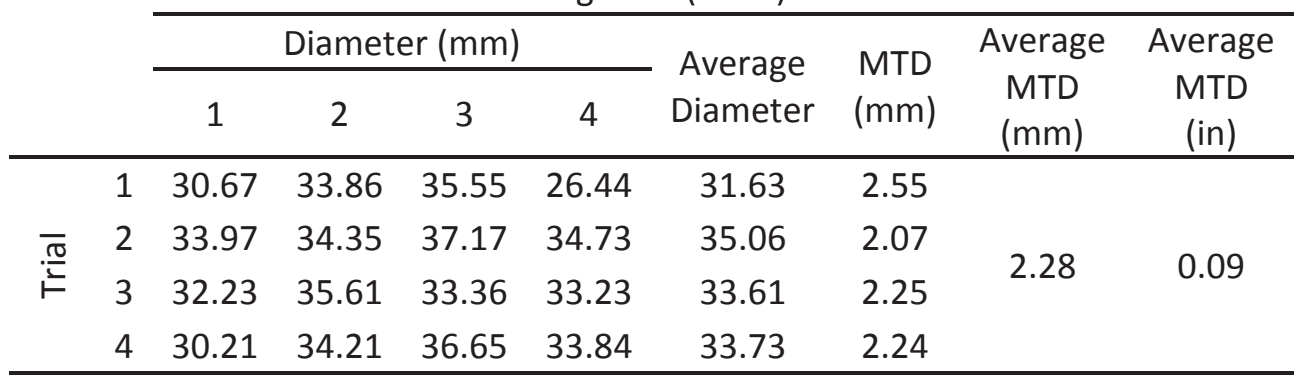

Rough $70^{\circ}$ (R170)

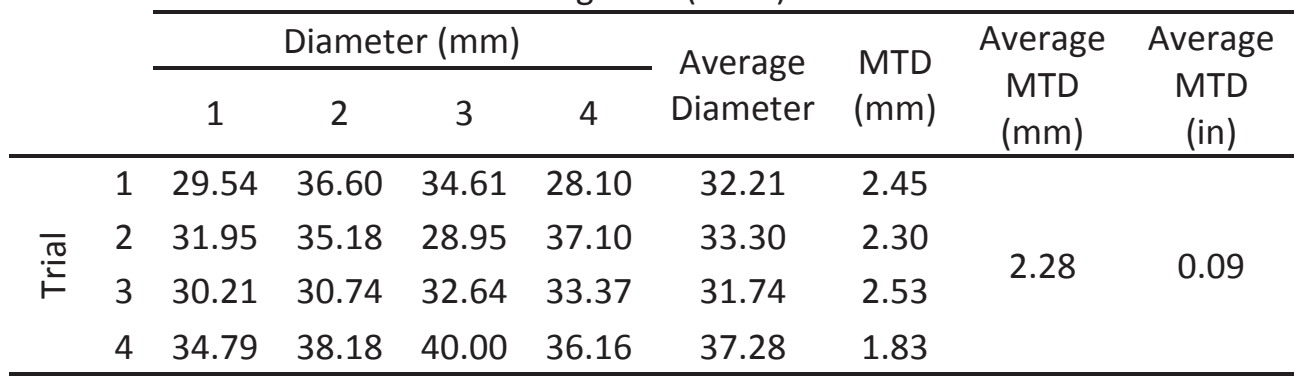

Pull off Rough (R1)

\begin{tabular}{|c|c|c|c|c|c|c|c|c|c|}
\hline & & \multicolumn{4}{|c|}{ Diameter $(\mathrm{mm})$} & \multirow{2}{*}{$\begin{array}{l}\text { Average } \\
\text { Diameter }\end{array}$} & \multirow{2}{*}{$\begin{array}{l}\text { MTD } \\
(\mathrm{mm})\end{array}$} & \multirow{2}{*}{$\begin{array}{c}\text { Average } \\
\text { MTD } \\
(\mathrm{mm})\end{array}$} & \multirow{2}{*}{$\begin{array}{c}\text { Average } \\
\text { MTD } \\
\text { (in) }\end{array}$} \\
\hline & & 1 & 2 & 3 & 4 & & & & \\
\hline \multirow{4}{*}{ 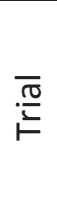 } & 1 & 38.64 & 36.40 & 39.76 & 31.96 & 36.69 & 1.89 & \multirow{4}{*}{2.15} & \multirow{4}{*}{0.08} \\
\hline & 2 & 34.37 & 31.58 & 31.03 & 37.65 & 33.66 & 2.25 & & \\
\hline & 3 & 37.43 & 37.28 & 35.71 & 27.97 & 34.60 & 2.13 & & \\
\hline & 4 & 35.03 & 32.21 & 28.41 & 36.59 & 33.06 & 2.33 & & \\
\hline
\end{tabular}


Table 9.2, continued.

\begin{tabular}{|c|c|c|c|c|c|c|c|c|c|}
\hline & & \multicolumn{6}{|c|}{ Brushed $60^{\circ}$ (B460) } & \multirow{3}{*}{$\begin{array}{c}\text { Average } \\
\text { MTD } \\
\text { (mm) }\end{array}$} & \multirow{3}{*}{$\begin{array}{c}\text { Average } \\
\text { MTD } \\
\text { (in) }\end{array}$} \\
\hline & & \multicolumn{4}{|c|}{ Diameter $(\mathrm{mm})$} & \multirow{2}{*}{$\begin{array}{l}\text { Average } \\
\text { Diameter }\end{array}$} & \multirow{2}{*}{$\begin{array}{l}\text { MTD } \\
(\mathrm{mm})\end{array}$} & & \\
\hline & & 1 & 2 & 3 & 4 & & & & \\
\hline \multirow{7}{*}{$\frac{\bar{\pi}}{\frac{\pi}{2}}$} & 1 & 58.87 & 58.89 & 58.59 & 57.57 & 58.48 & 0.74 & \multirow{4}{*}{0.73} & \multirow{4}{*}{0.03} \\
\hline & 2 & 58.73 & 56.85 & 58.13 & 57.48 & 57.80 & 0.76 & & \\
\hline & 3 & 60.62 & 59.47 & 59.01 & 60.97 & 60.02 & 0.71 & & \\
\hline & 4 & 60.83 & 59.43 & 59.43 & 60.37 & 60.02 & 0.71 & & \\
\hline & & \multicolumn{6}{|c|}{ Brushed $70^{\circ}$ (B270) } & & \\
\hline & & \multicolumn{4}{|c|}{ Diameter (mm) } & Average & MTD & \multirow{2}{*}{$\begin{array}{c}\text { Average } \\
\text { MTD } \\
\text { (mm) }\end{array}$} & \multirow{2}{*}{$\begin{array}{c}\text { Average } \\
\text { MTD } \\
\text { (in) }\end{array}$} \\
\hline & & 1 & 2 & 3 & 4 & Diameter & $(\mathrm{mm})$ & & \\
\hline \multirow{4}{*}{$\frac{\bar{\pi}}{\stackrel{2}{上}}$} & 1 & 56.67 & 59.46 & 61.12 & 54.02 & 57.82 & 0.76 & \multirow{4}{*}{0.76} & \multirow{4}{*}{0.03} \\
\hline & 2 & 60.35 & 62.56 & 57.00 & 48.96 & 57.22 & 0.78 & & \\
\hline & 3 & 58.32 & 54.28 & 56.90 & 56.56 & 56.52 & 0.80 & & \\
\hline & 4 & 59.29 & 59.83 & 57.85 & 61.80 & 59.69 & 0.71 & & \\
\hline
\end{tabular}

Pull off Brushed (B1)

\begin{tabular}{|c|c|c|c|c|c|c|c|c|c|}
\hline & & \multicolumn{4}{|c|}{ Diameter $(\mathrm{mm})$} & \multirow{2}{*}{$\begin{array}{l}\text { Average } \\
\text { Diameter }\end{array}$} & \multirow{2}{*}{$\begin{array}{l}\text { MTD } \\
(\mathrm{mm})\end{array}$} & \multirow{2}{*}{$\begin{array}{c}\text { Average } \\
\text { MTD } \\
(\mathrm{mm})\end{array}$} & \multirow{2}{*}{$\begin{array}{c}\text { Average } \\
\text { MTD } \\
\text { (in) }\end{array}$} \\
\hline & & 1 & 2 & 3 & 4 & & & & \\
\hline \multirow{7}{*}{ 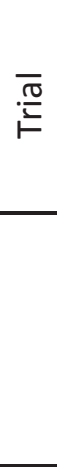 } & 1 & 60.23 & 60.14 & 62.16 & 62.96 & 61.37 & 0.68 & \multirow{4}{*}{0.66} & \multirow{4}{*}{0.03} \\
\hline & 2 & 60.98 & 61.19 & 59.13 & 64.68 & 61.50 & 0.67 & & \\
\hline & 3 & 65.00 & 63.82 & 61.33 & 61.40 & 62.89 & 0.64 & & \\
\hline & 4 & 63.41 & 62.09 & 61.71 & 63.24 & 62.61 & 0.65 & & \\
\hline & & \multicolumn{7}{|c|}{ Sandblasted $60^{\circ}$ (SB160) } & \\
\hline & & \multicolumn{4}{|c|}{ Diameter (mm) } & \multirow{2}{*}{$\begin{array}{l}\text { Average } \\
\text { Diameter }\end{array}$} & \multirow{2}{*}{$\begin{array}{l}\text { MTD } \\
(\mathrm{mm})\end{array}$} & \multirow{2}{*}{$\begin{array}{c}\text { Average } \\
\text { MTD } \\
\text { (mm) }\end{array}$} & \multirow{2}{*}{$\begin{array}{c}\text { Average } \\
\text { MTD } \\
\text { (in) }\end{array}$} \\
\hline & & 1 & 2 & 3 & 4 & & & & \\
\hline \multirow{4}{*}{$\overline{i \frac{\pi}{2}}$} & 1 & 55.01 & 55.02 & 57.15 & 54.61 & 55.45 & 0.83 & \multirow{4}{*}{0.88} & \multirow{4}{*}{0.03} \\
\hline & 2 & 54.71 & 52.97 & 55.09 & 54.70 & 54.37 & 0.86 & & \\
\hline & 3 & 52.33 & 52.63 & 53.94 & 53.15 & 53.01 & 0.91 & & \\
\hline & 4 & 52.31 & 51.77 & 50.37 & 55.64 & 52.52 & 0.92 & & \\
\hline
\end{tabular}


Table 9.2, continued.

Sandblasted $70^{\circ}$ (SB170)

\begin{tabular}{|c|c|c|c|c|c|c|c|c|c|}
\hline & & \multicolumn{4}{|c|}{ Diameter $(\mathrm{mm})$} & \multirow{2}{*}{$\begin{array}{l}\text { Average } \\
\text { Diameter }\end{array}$} & \multirow{2}{*}{$\begin{array}{l}\text { MTD } \\
(\mathrm{mm})\end{array}$} & \multirow{2}{*}{$\begin{array}{c}\text { Average } \\
\text { MTD } \\
\text { (mm) }\end{array}$} & \multirow{2}{*}{$\begin{array}{c}\text { Average } \\
\text { MTD } \\
\text { (in) }\end{array}$} \\
\hline & & 1 & 2 & 3 & 4 & & & & \\
\hline \multirow{4}{*}{$\frac{\bar{\pi}}{i \frac{2}{2}}$} & 1 & 52.80 & 56.68 & 53.12 & 51.03 & 53.41 & 0.89 & \multirow{4}{*}{0.90} & \multirow{4}{*}{0.04} \\
\hline & 2 & 53.75 & 50.57 & 58.57 & 53.23 & 54.03 & 0.87 & & \\
\hline & 3 & 52.44 & 50.41 & 49.45 & 57.26 & 52.39 & 0.93 & & \\
\hline & 4 & 52.83 & 53.16 & 50.21 & 54.76 & 52.74 & 0.92 & & \\
\hline
\end{tabular}

Pull off Sandblasted (SB1)

\begin{tabular}{|c|c|c|c|c|c|c|c|c|c|}
\hline & & \multicolumn{4}{|c|}{ Diameter $(\mathrm{mm})$} & \multirow{2}{*}{$\begin{array}{l}\text { Average } \\
\text { Diameter }\end{array}$} & \multirow{2}{*}{$\begin{array}{l}\text { MTD } \\
(\mathrm{mm})\end{array}$} & \multirow{2}{*}{$\begin{array}{c}\text { Average } \\
\text { MTD } \\
(\mathrm{mm})\end{array}$} & \multirow{2}{*}{$\begin{array}{c}\text { Average } \\
\text { MTD } \\
\text { (in) }\end{array}$} \\
\hline & & 1 & 2 & 3 & 4 & & & & \\
\hline \multirow{4}{*}{$\overline{i \frac{\pi}{2}}$} & 1 & 54.86 & 52.74 & 56.73 & 56.03 & 55.09 & 0.84 & \multirow{4}{*}{0.81} & \multirow{4}{*}{0.03} \\
\hline & 2 & 53.59 & 55.14 & 55.54 & 55.60 & 54.97 & 0.84 & & \\
\hline & 3 & 57.29 & 56.65 & 58.33 & 56.60 & 57.22 & 0.78 & & \\
\hline & 4 & 57.51 & 55.71 & 56.52 & 58.68 & 57.11 & 0.78 & & \\
\hline
\end{tabular}




\section{Appendix: Splitting tensile prisms after failure}

Table 10.1

Splitting tensile composite prisms after failure (in wetting conditions)

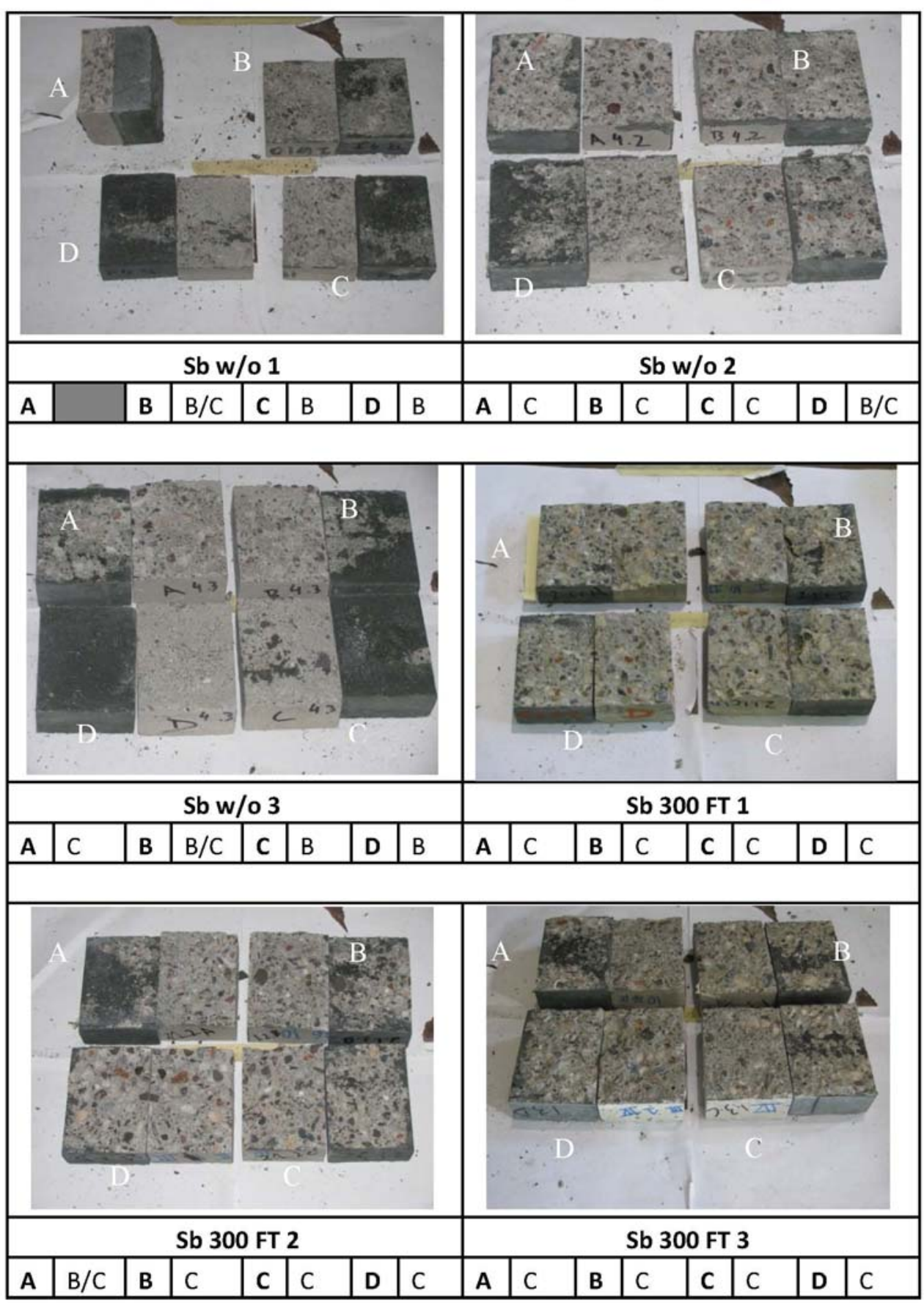


Table 10.1, continued.

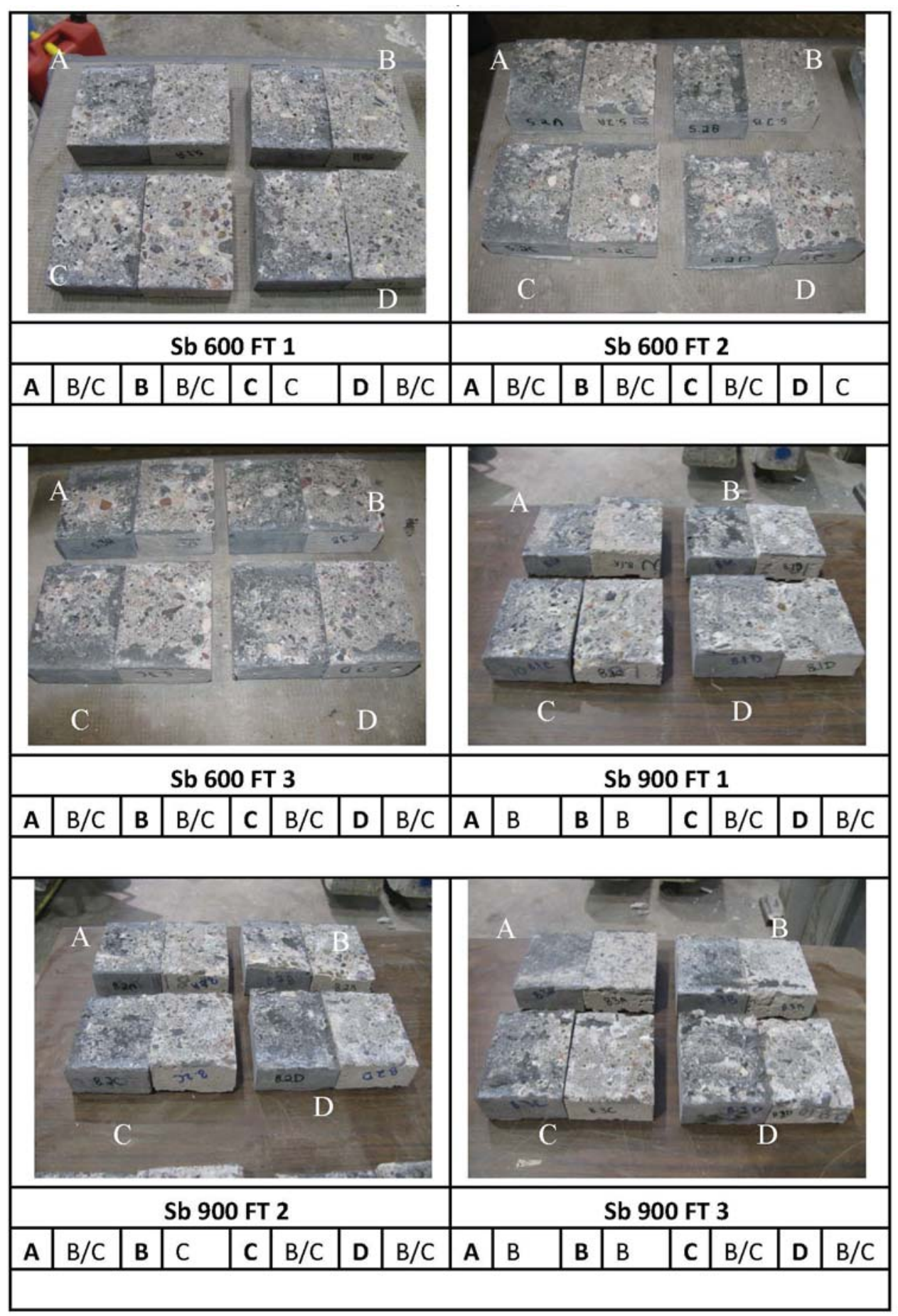


Table 10.1, continued.

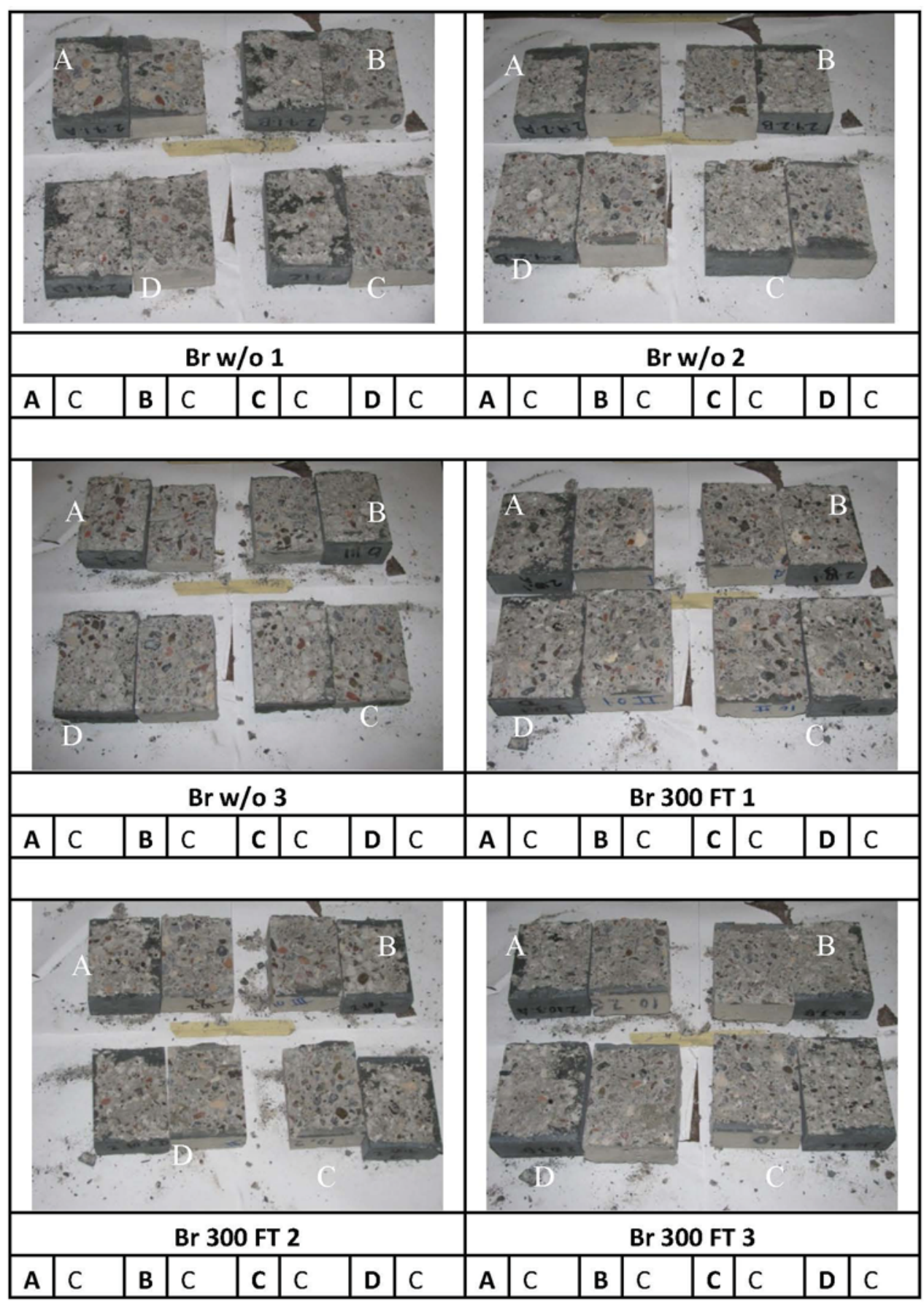


Table 10.1, continued.

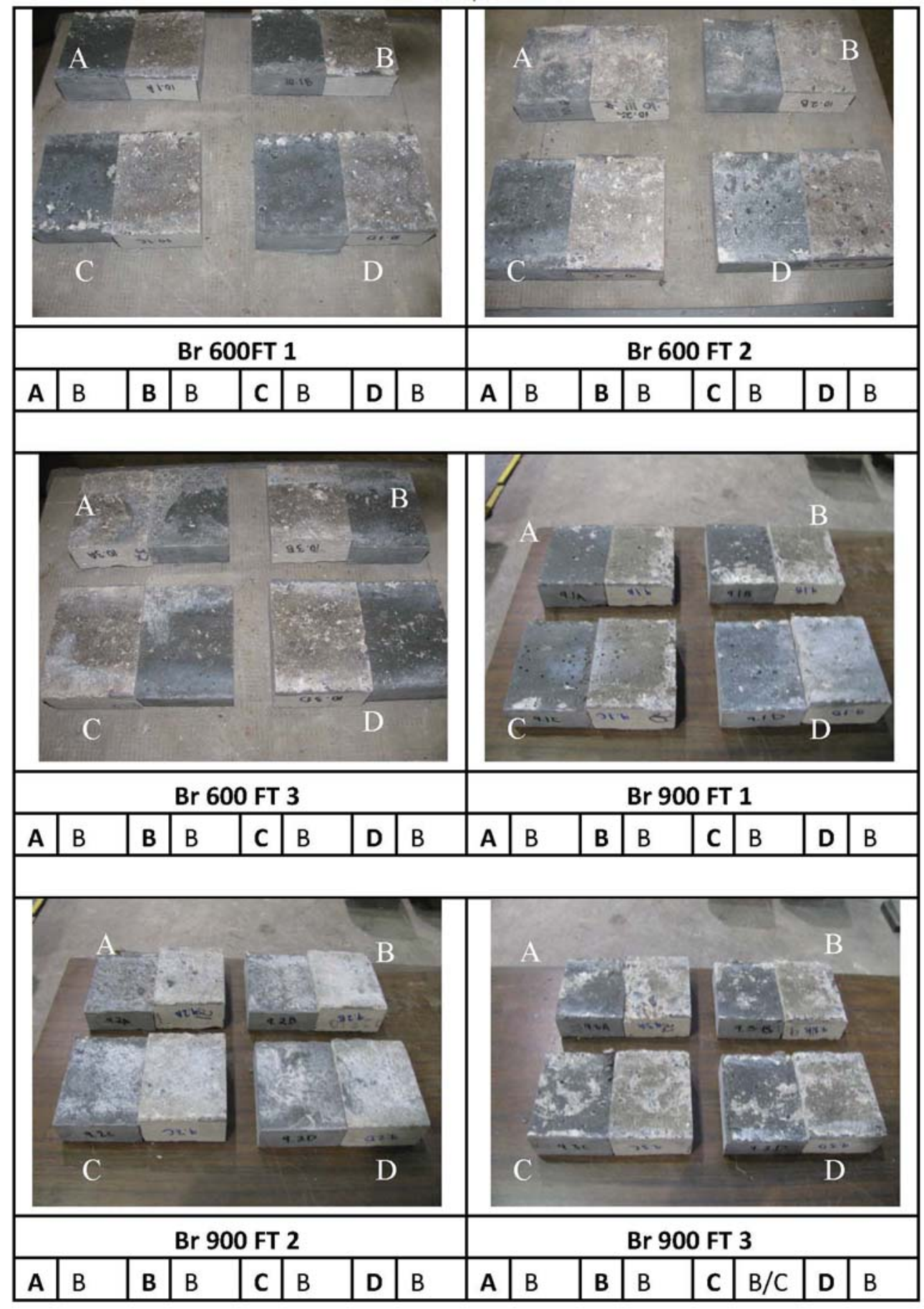


Table 10.1, continued.

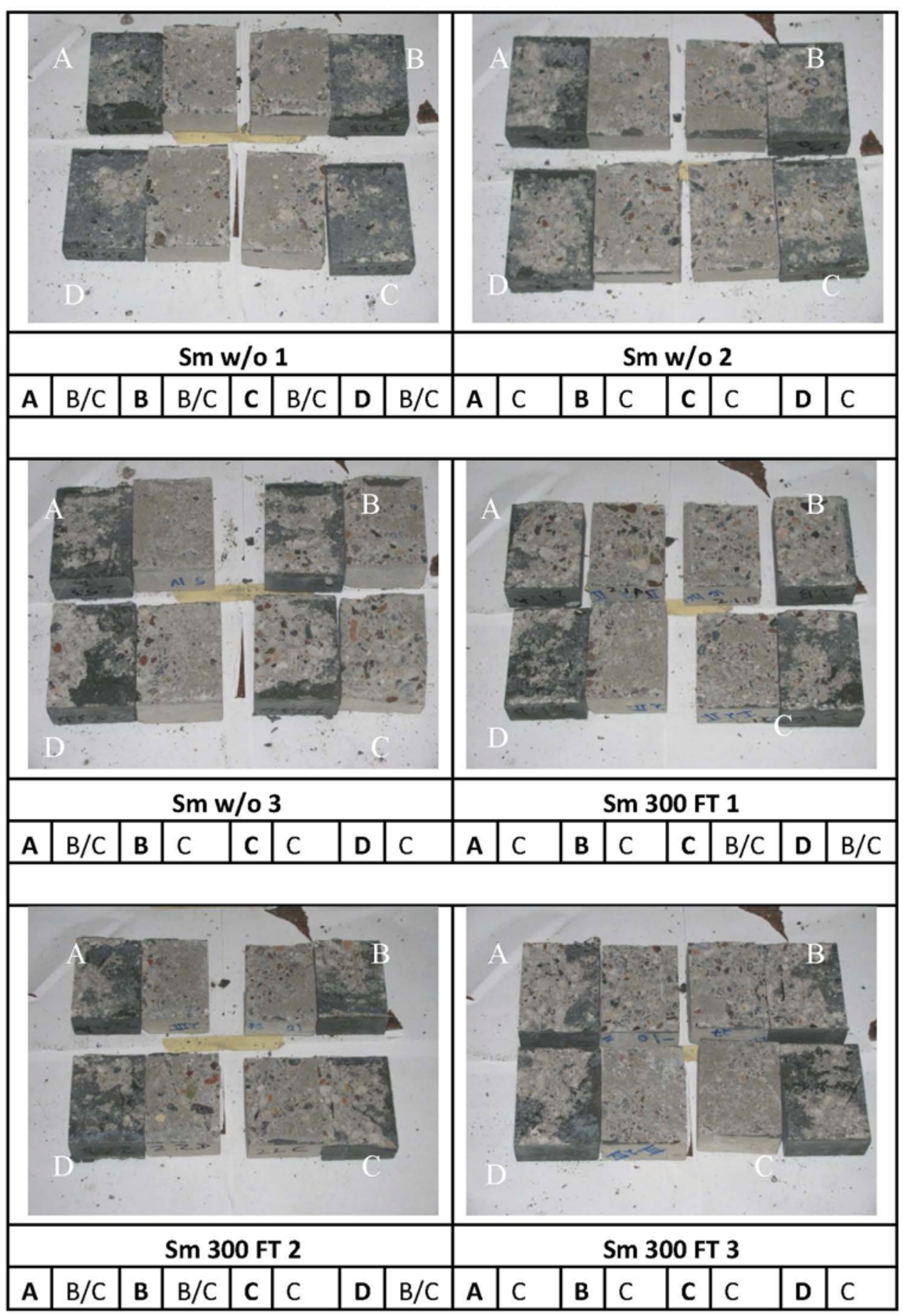


Table 10.1, continued.

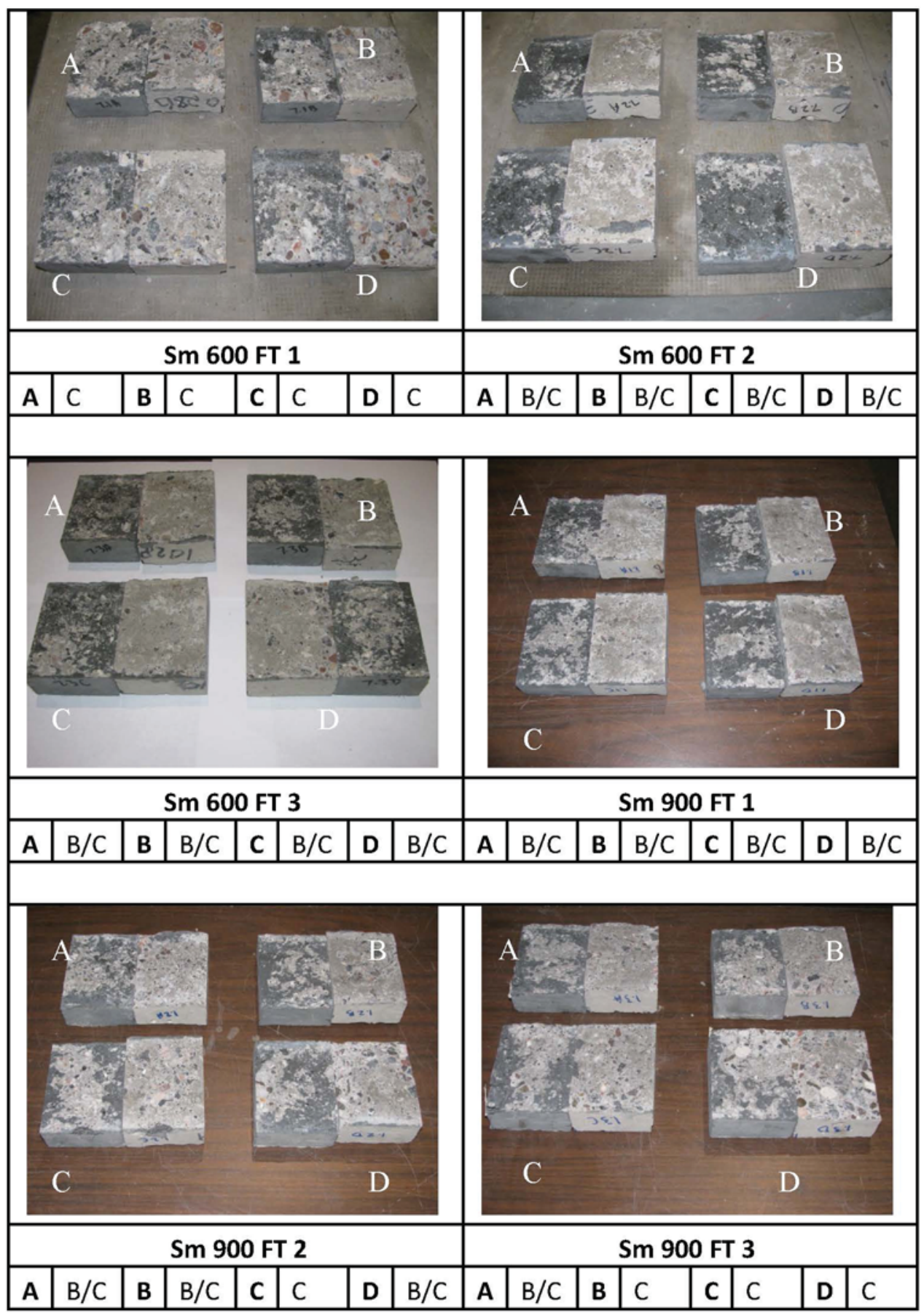


Table 10.1, continued.

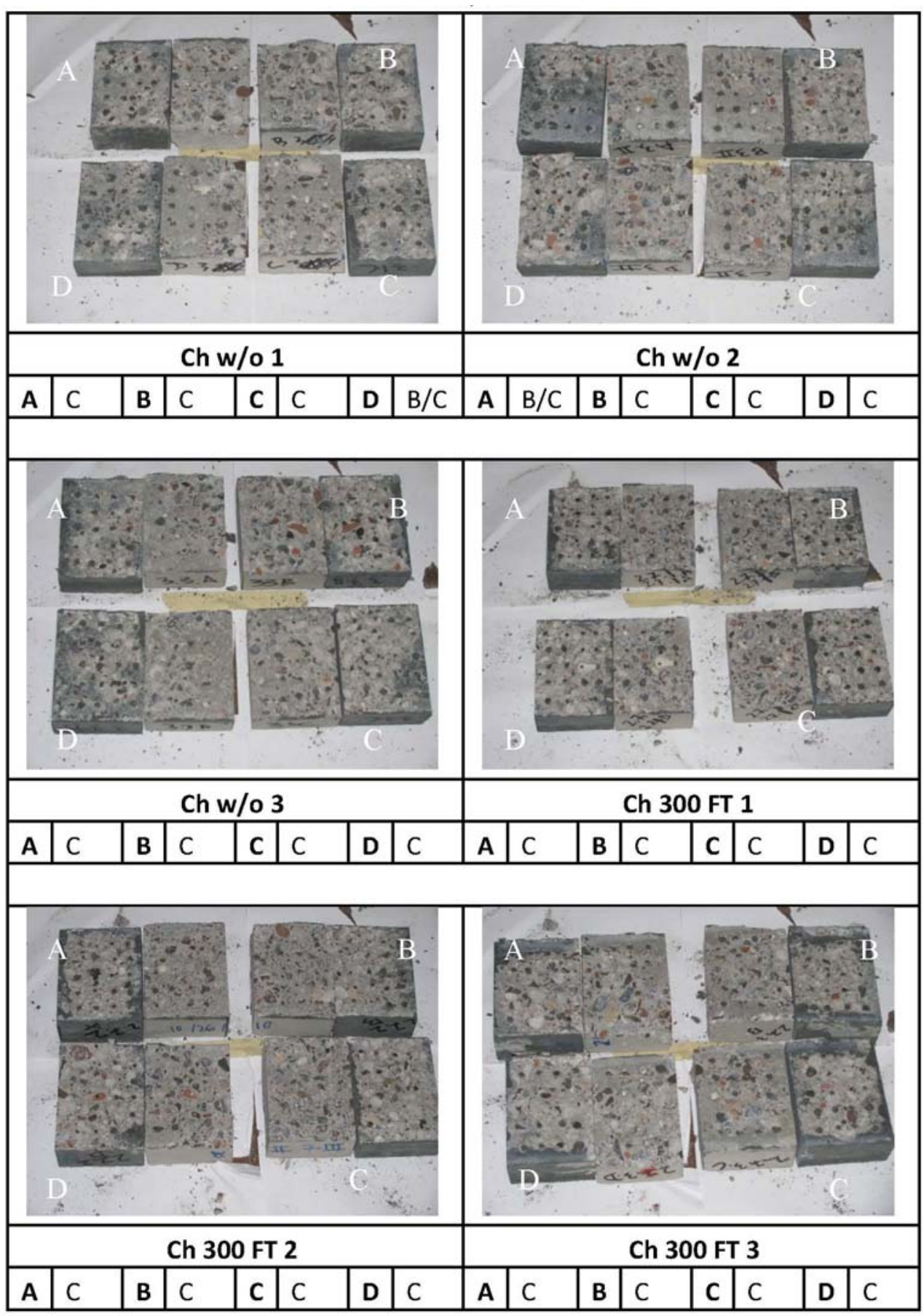


Table 10.1, continued.

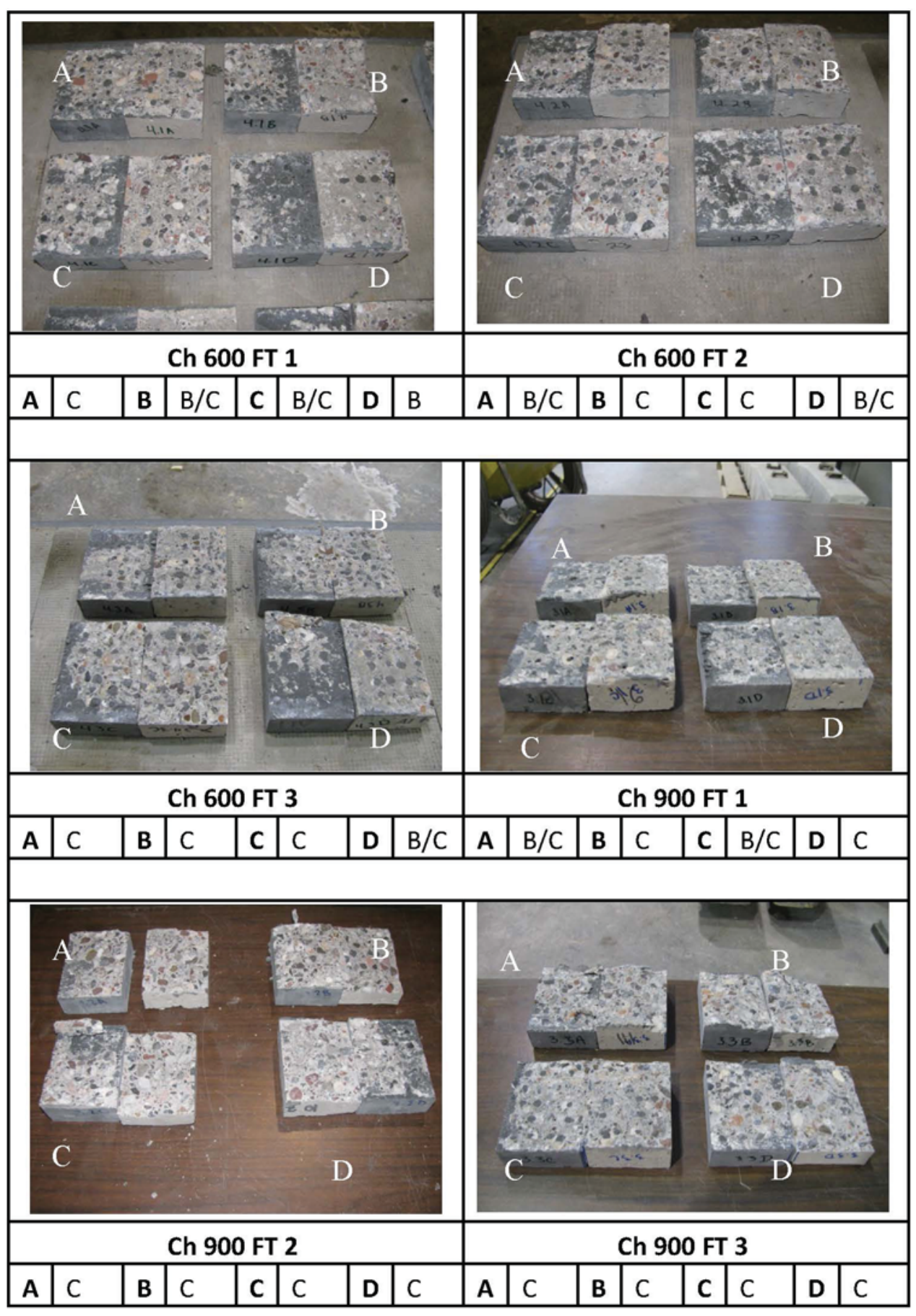


Table 10.1, continued.

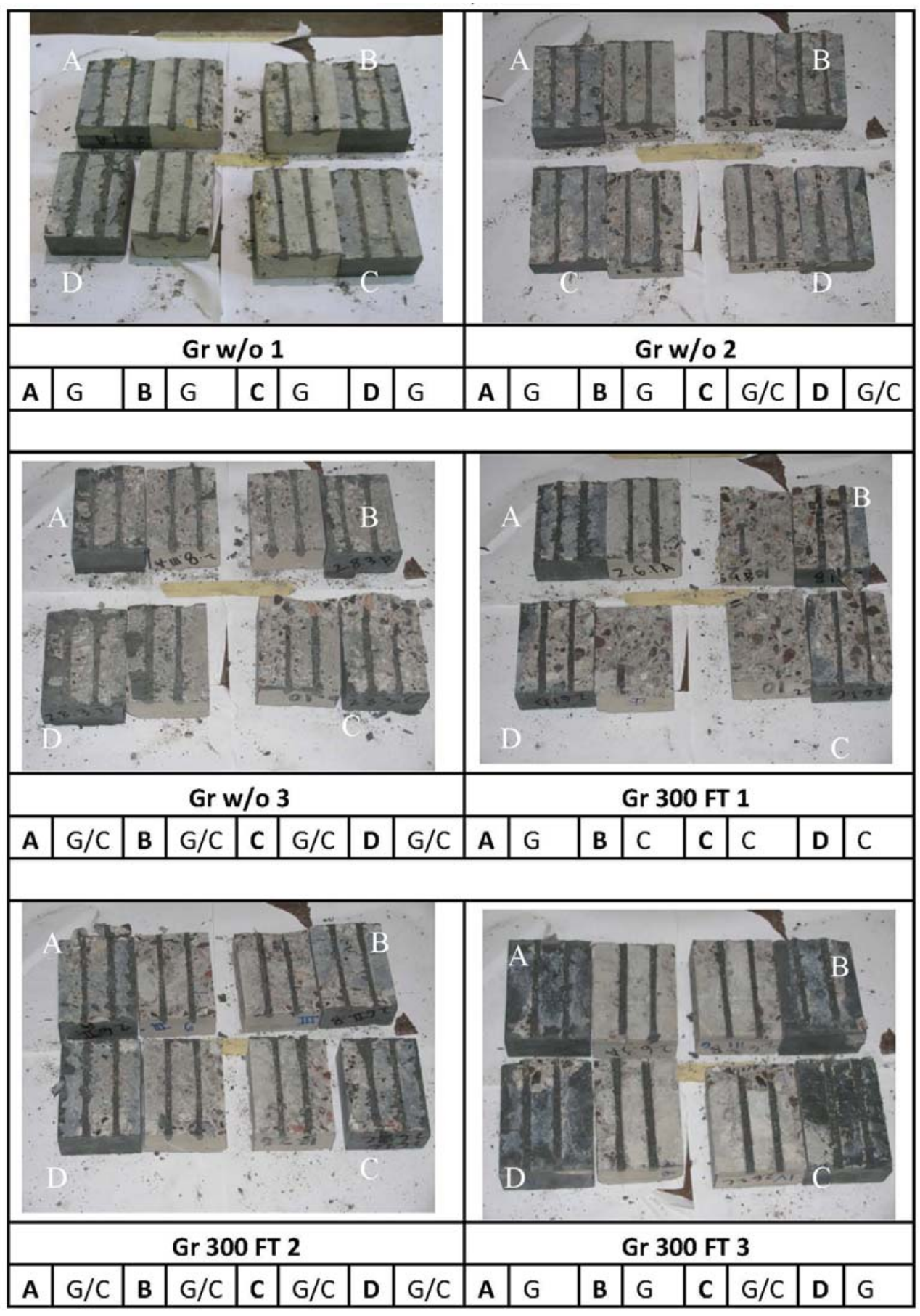


Table 10.1, continued.

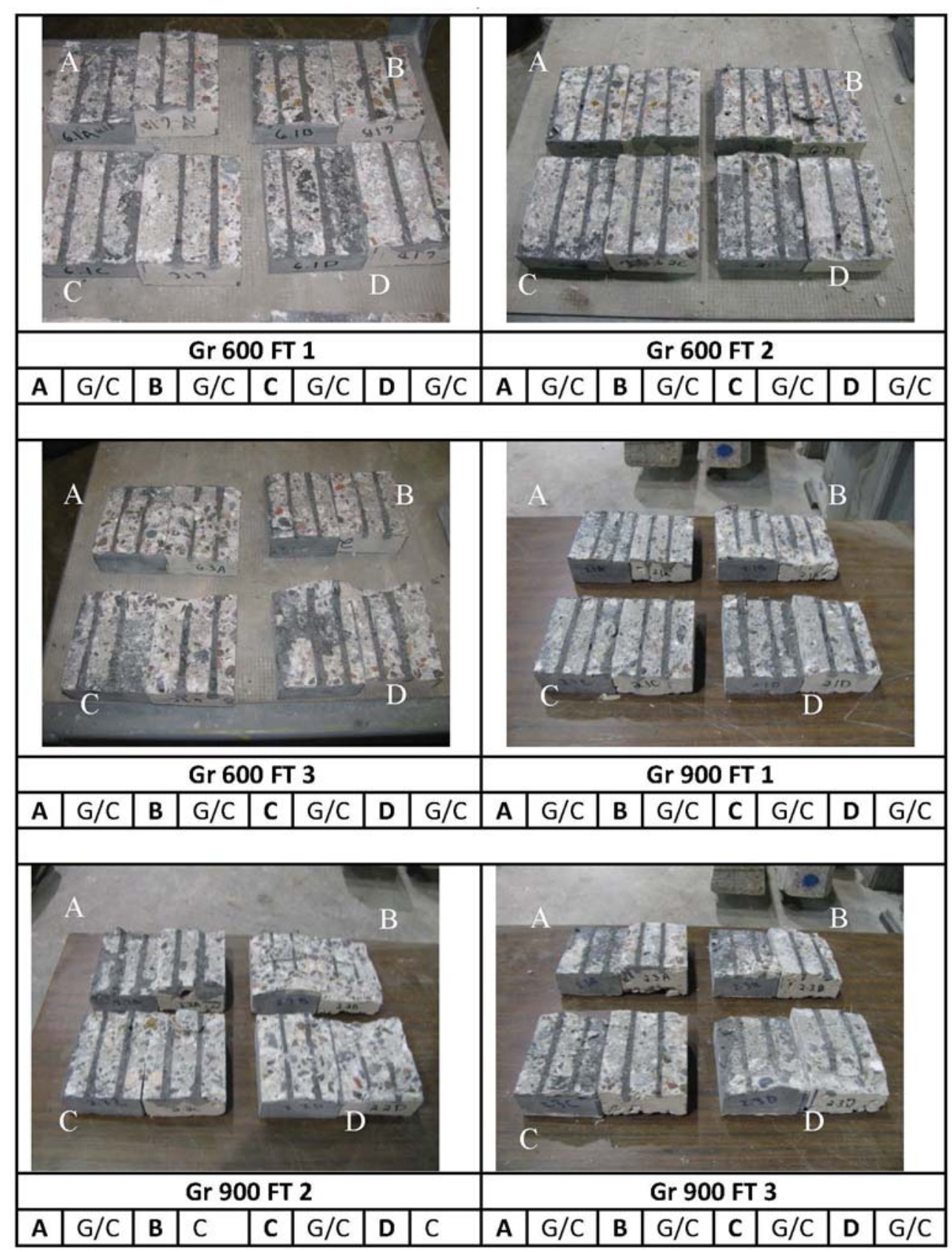


Table 10.2

Splitting monolithic NSC prisms after failure

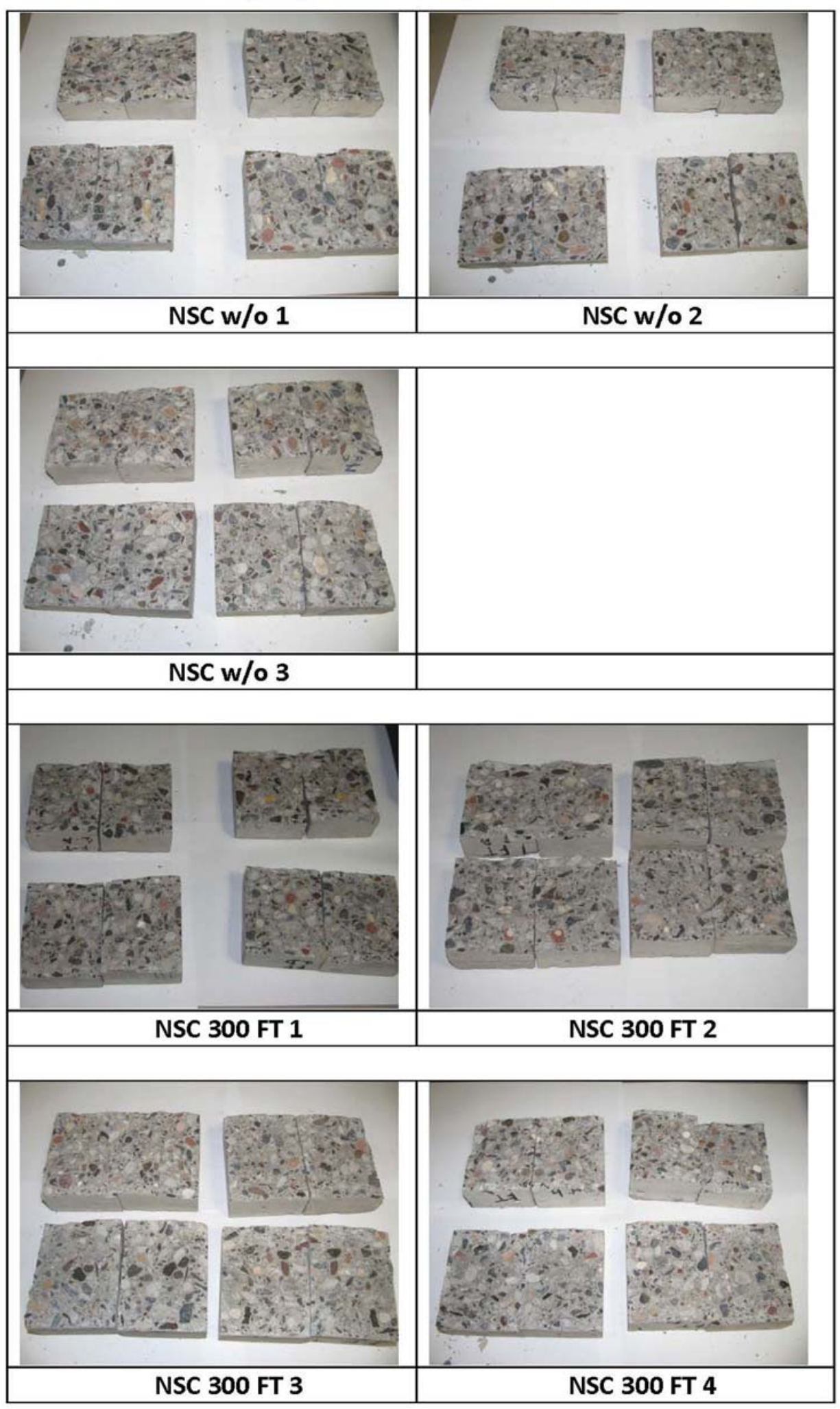


Table 10.2, continued.

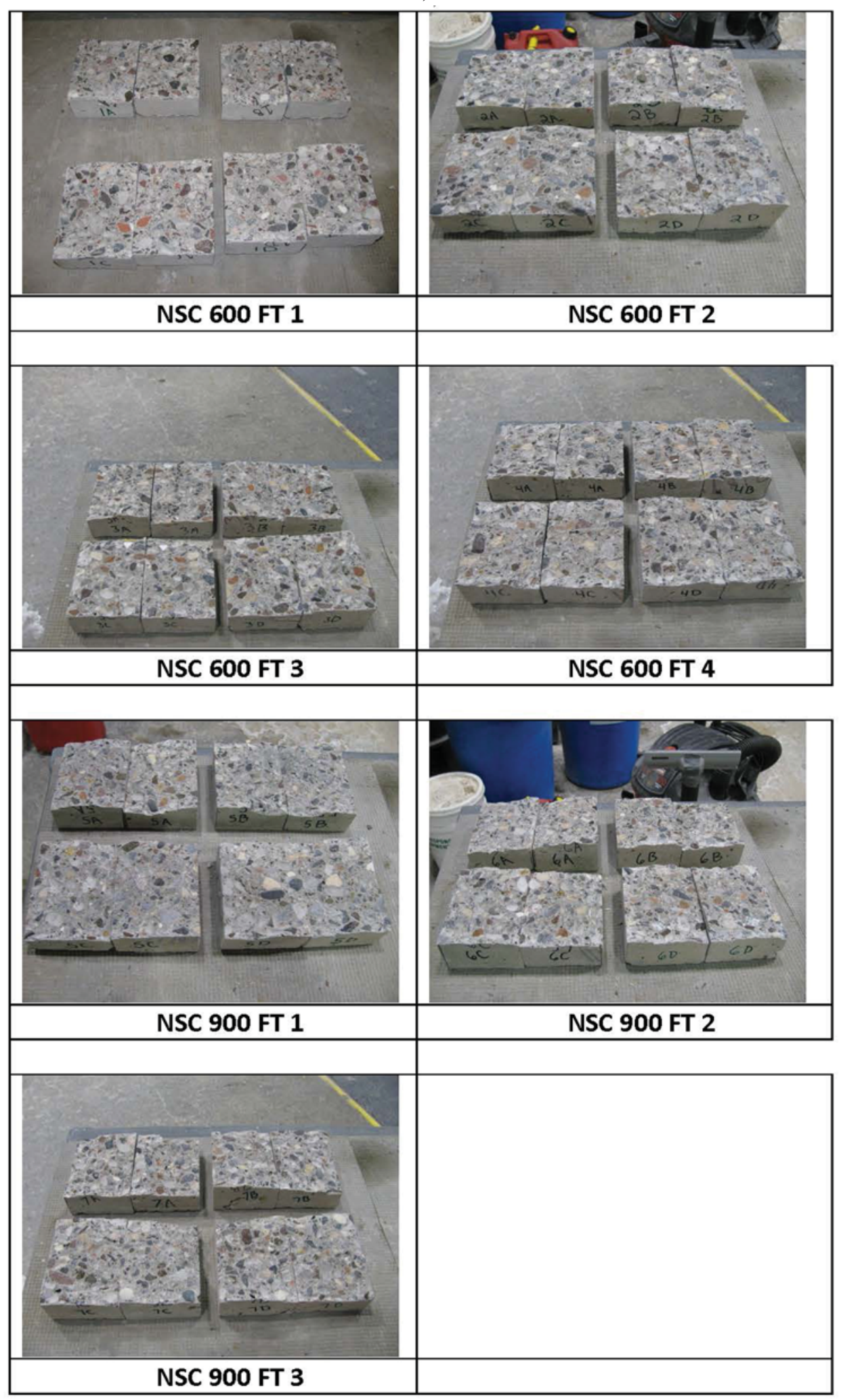


11 Appendix: Slant-shear specimens after failure

Table 11.1

Slant-shear specimens after failure

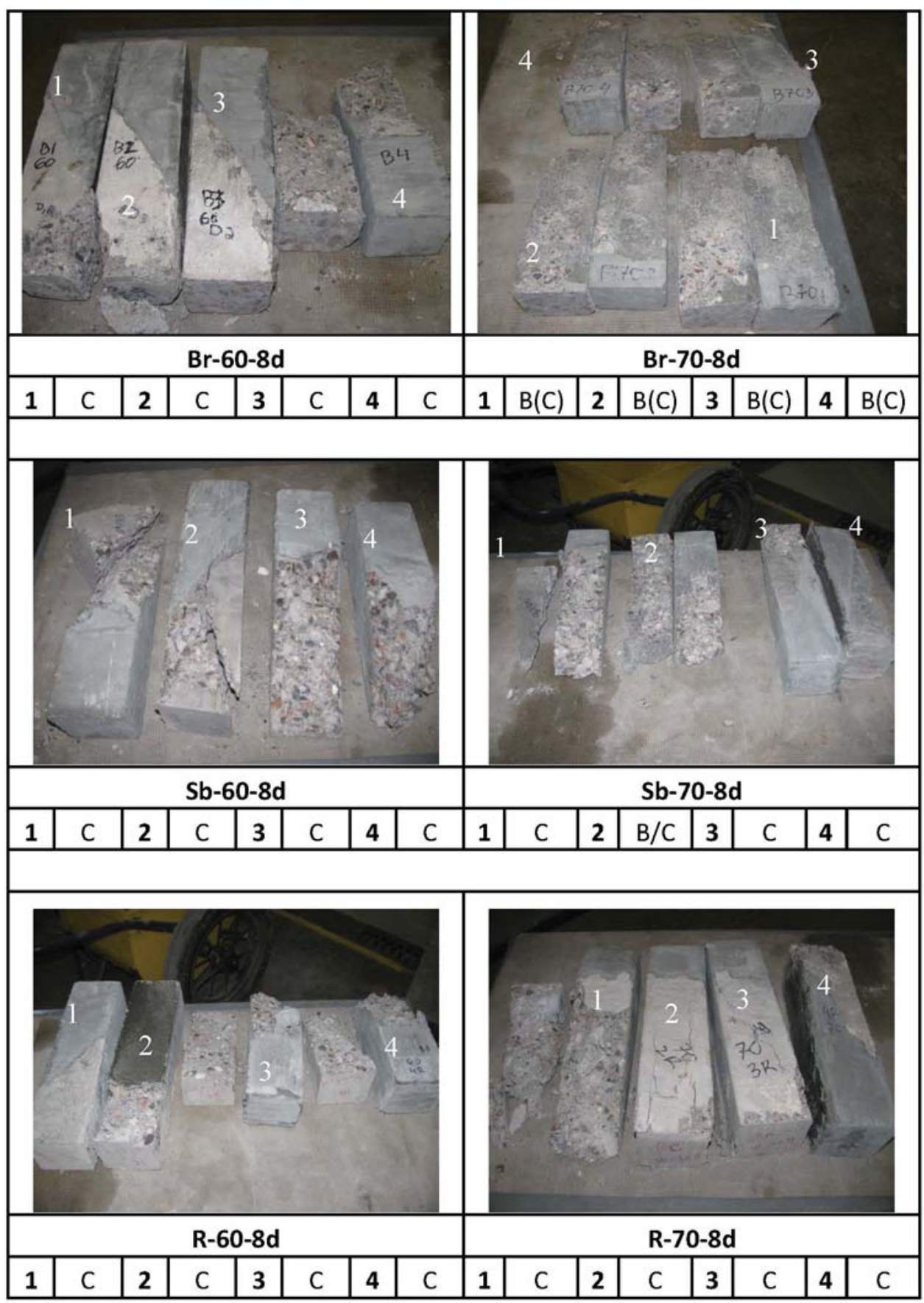


Table 11.1, continued.

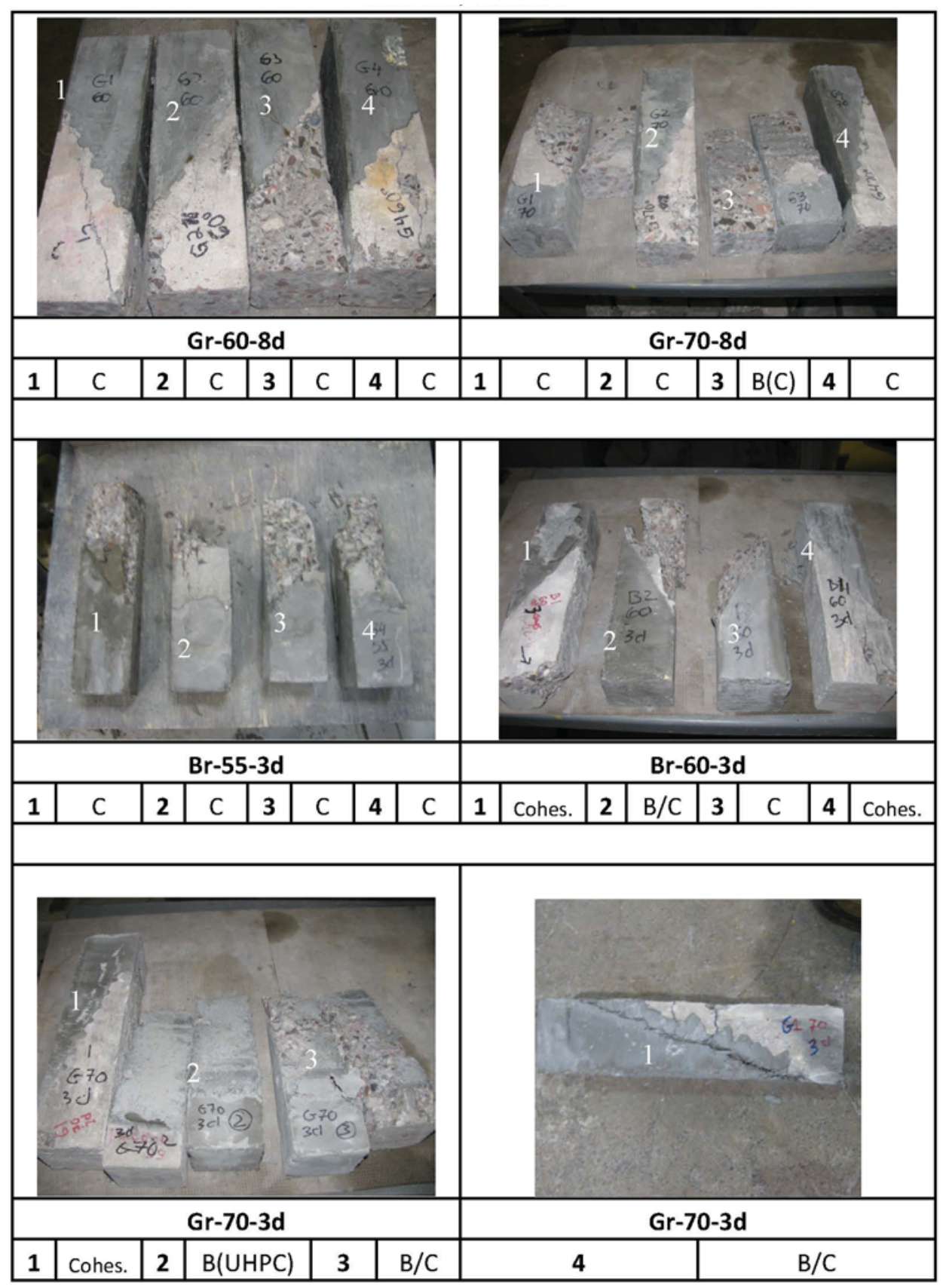


Table 11.1, continued.

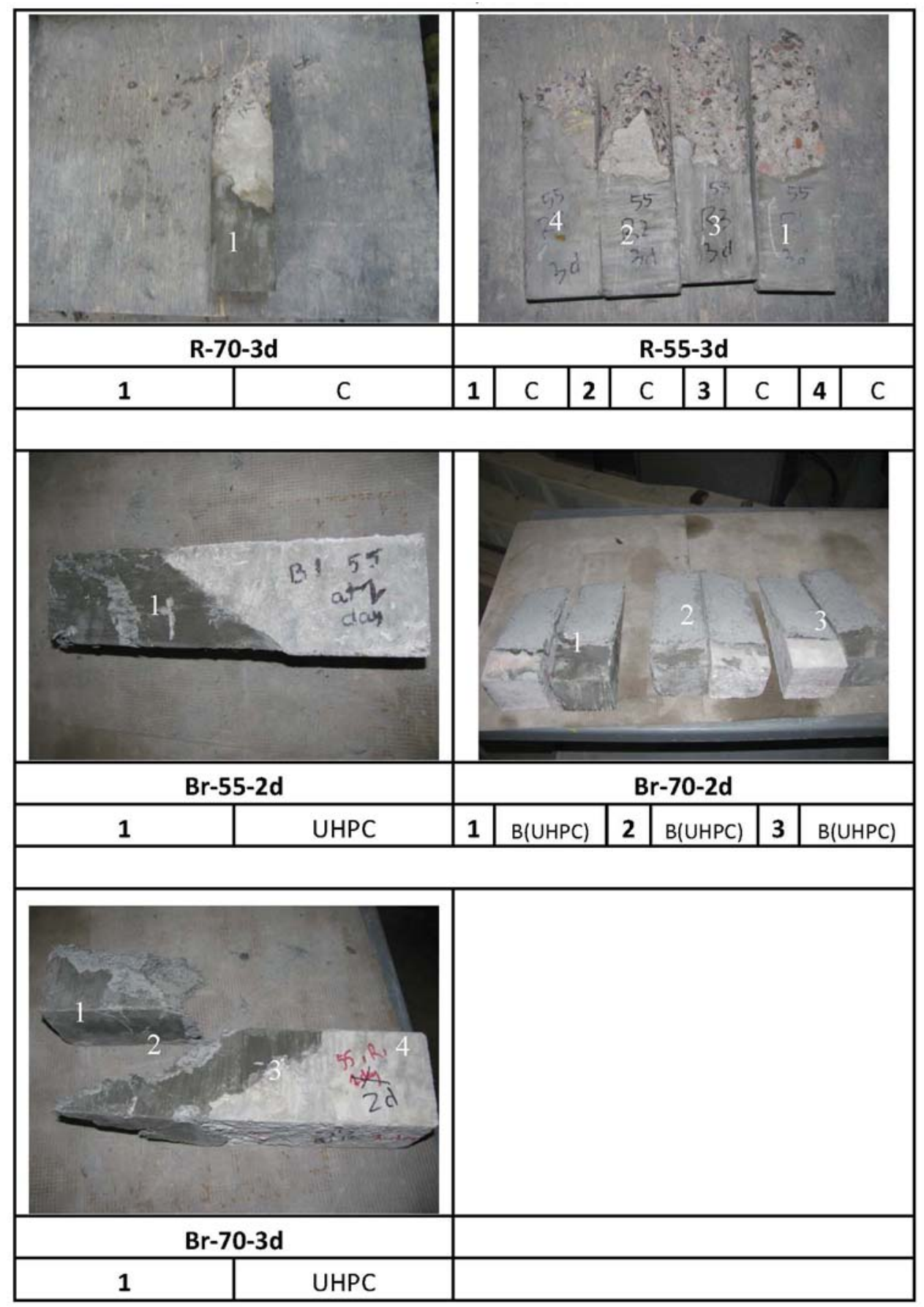




\section{Appendix: Pull-off specimens after failure}

Table 12.1

Pull-off specimens after failure

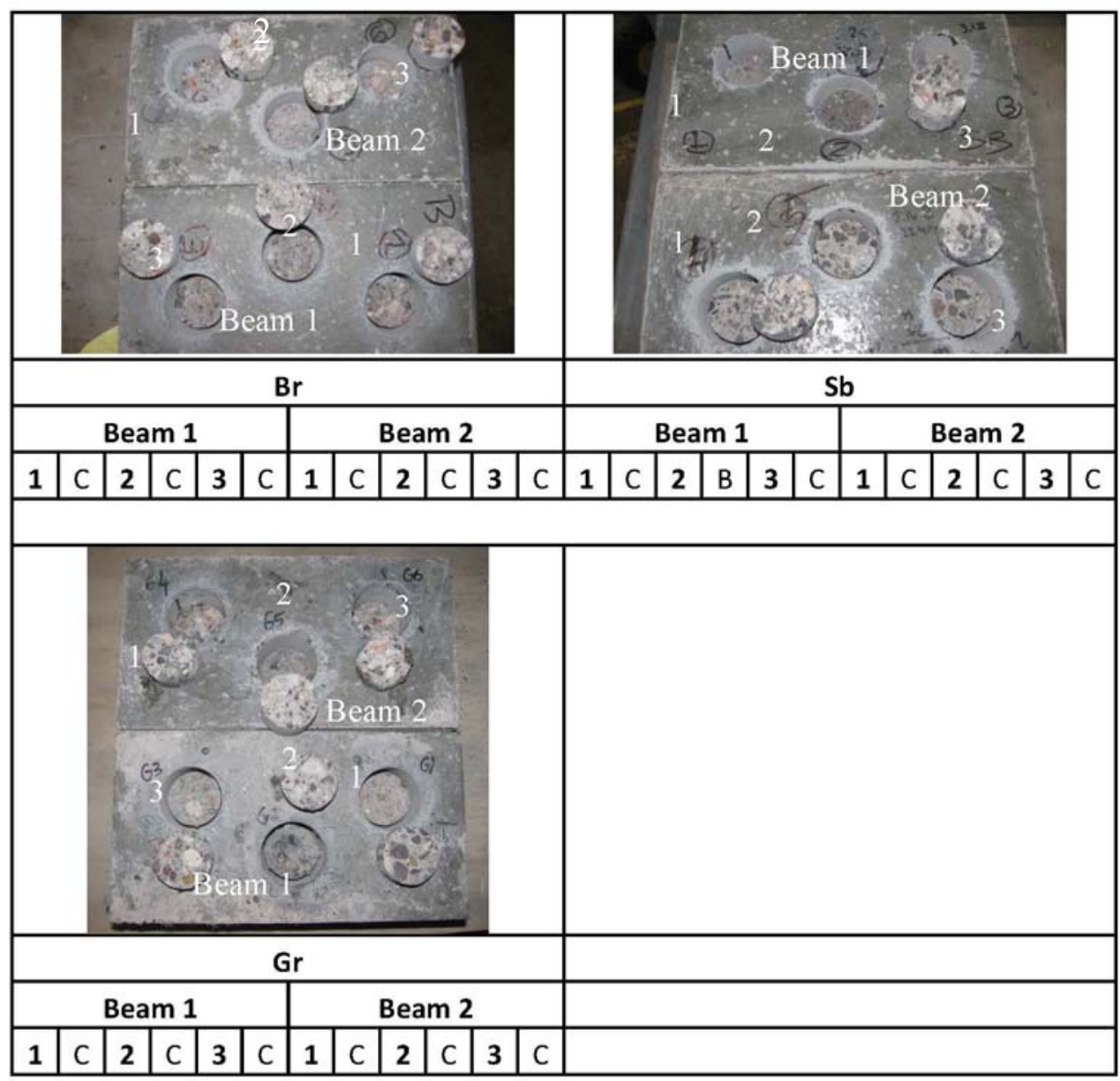


Table 12.1, continued.

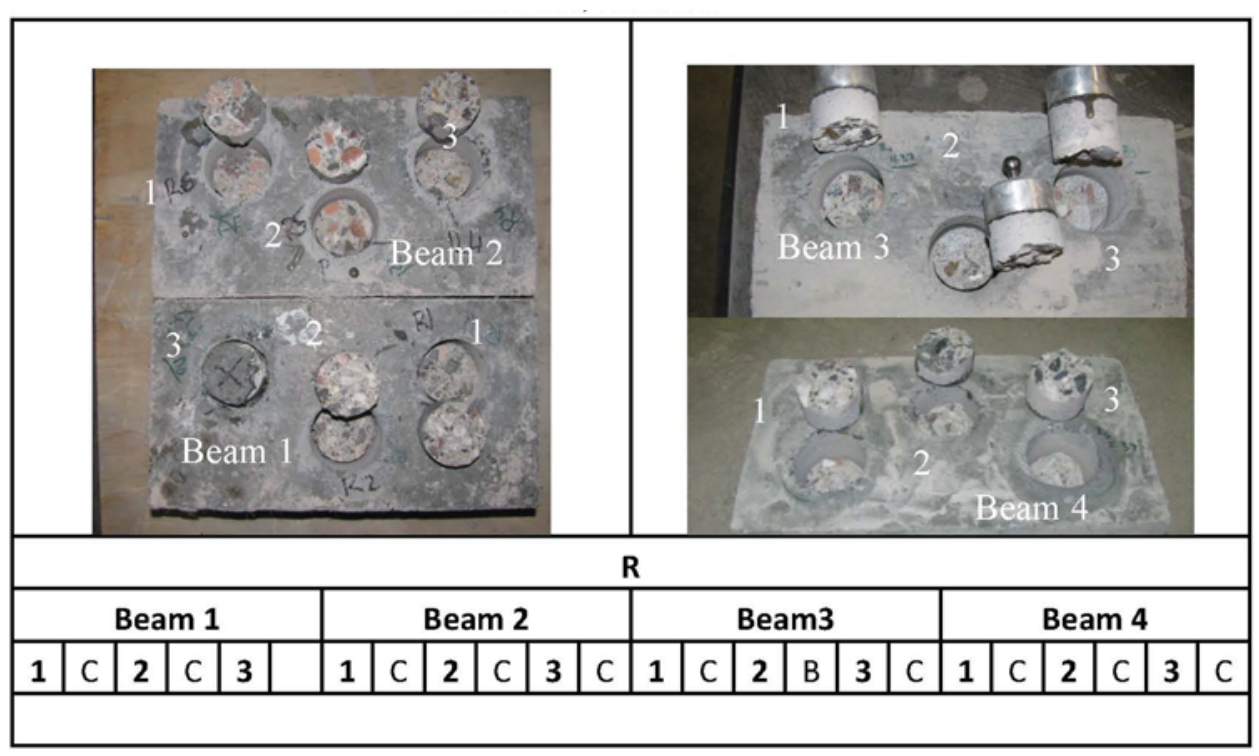




\section{Appendix: Copyrights}

\section{Figure 2.3}

This is a License Agreement between Miguel Angel Carbonell Munoz ("You") and Elsevier ("Elsevier") provided by Copyright Clearance Center ("CCC"). The license consists of your order details, the terms and conditions provided by Elsevier, and the payment terms and conditions.

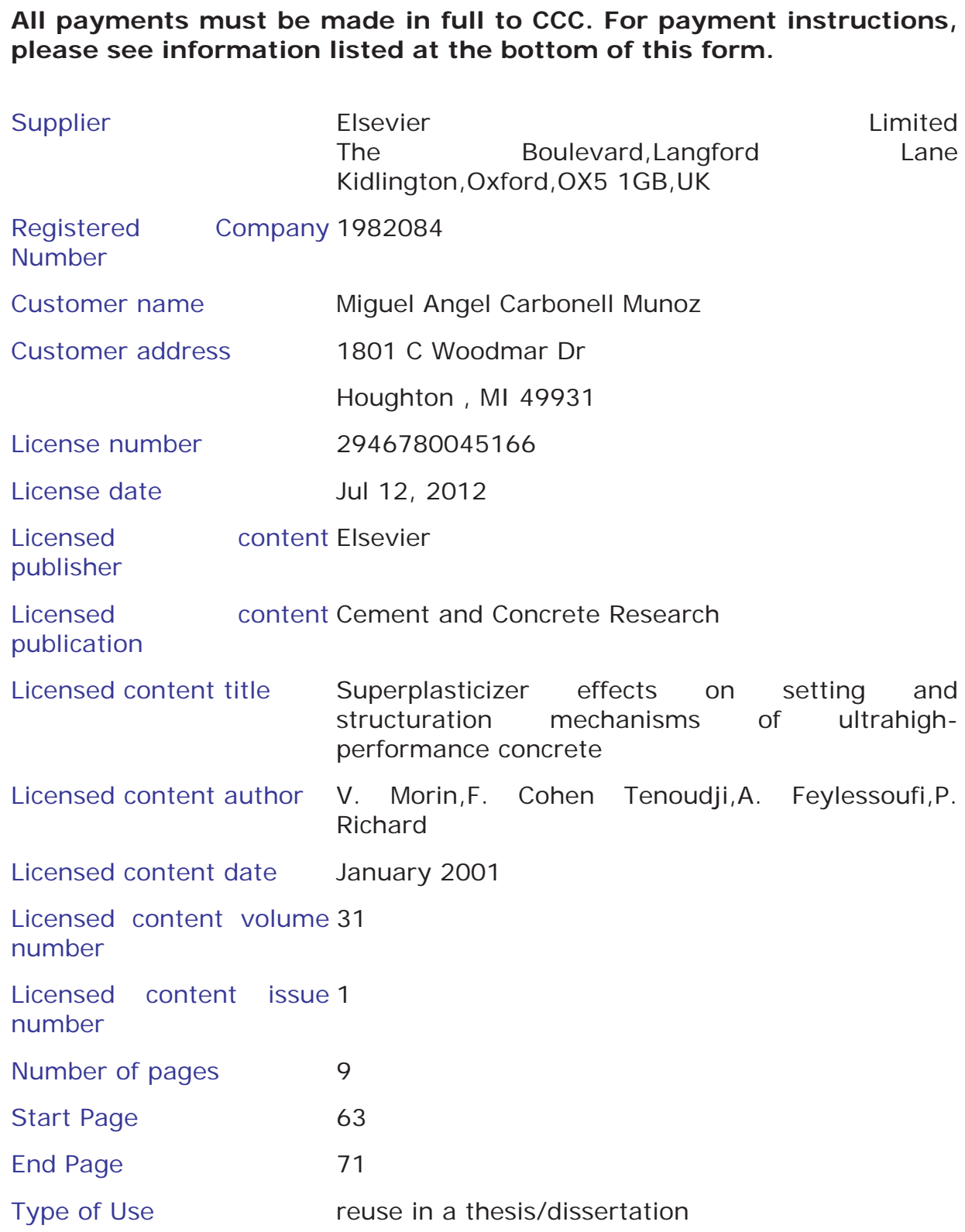




\begin{tabular}{|c|c|}
\hline Portion & figures/tables/illustrations \\
\hline \multicolumn{2}{|c|}{$\begin{array}{l}\text { Number of } 1 \\
\text { figures/tables/illustrations }\end{array}$} \\
\hline Format & both print and electronic \\
\hline \multicolumn{2}{|c|}{$\begin{array}{l}\text { Are you the author of this No } \\
\text { Elsevier article? }\end{array}$} \\
\hline Will you be translating? & No \\
\hline \multicolumn{2}{|l|}{ Order reference number } \\
\hline $\begin{array}{ll}\text { Title of } & \text { yo } \\
\text { thesis/dissertation } & \end{array}$ & $\begin{array}{l}\text { COMPATIBILITY OF ULTRA HIGH PERFORMANCE } \\
\text { CONCRETE AS REPAIR MATERIAL:BOND } \\
\text { CHARACTERIZATION WITH CONCRETE UNDER } \\
\text { DIFFERENT LOADING SCENARIOS }\end{array}$ \\
\hline \multicolumn{2}{|c|}{ Expected completion date Jul 2012} \\
\hline \multicolumn{2}{|c|}{$\begin{array}{l}\text { Estimated size } \quad \text { (number } 150 \\
\text { of pages) }\end{array}$} \\
\hline Elsevier VAT number & GB 494627212 \\
\hline Permissions price & 0.00 USD \\
\hline VAT/Local Sales Tax & 0.0 USD / 0.0 GBP \\
\hline Total & 0.00 USD \\
\hline
\end{tabular}




\section{Figure 2.4}

Miguel Angel Carbonell Munoz <mcarbone@mtu.edu>

Committee Member petition - MTU

Peter.Seibert@lafarge-na.com <Peter.Seibert@lafarge-na.com> at, Apr 21, 2012 at 10:25 PM

To: mcarbone@mtu.edu

Cc: dharris@mtu.edu

Miguel,

I would be very happy and honored to be part of your thesis defence team. I will complete the form later this week and send it back to you and Dr. Harris.

Yes, you can use the attached photo in your thesis. Please provide proper reference to Lafarge.

Have a great weekend

Peter

Peter J. Seibert, M.Sc., MBA, P.Eng.

Technical Director - Ductal ${ }^{\circledR}$

LAFARGE NORTH AMERICA

\#1200, 10655 Southport Road SW

Calgary, AB, T2W $4 \mathrm{Y} 1$

$\mathrm{Ph}:$ 403-225-5453

Fax: 403-278-7420

http://www.ductal-lafarge.com

Ductal ${ }^{\circledR}$ - The Leader in Ultra High Performance Concrete 


\section{Figure 2.5}

Miguel Angel Carbonell Munoz <mcarbone@mtu.edu>

Copyright Release

Miguel Angel Carbonell Munoz <mcarbone@mtu.edu>

Mon, Apr 30, 2012 at 9:33 PM

To: Fischer@eng.hawaii.edu

Dear Gregor Fischer,

I am completing my masters thesis at Michigan Technological University entitled "'Compatibility of Ultra High Performance Concrete as repair material: Bond characterization with concrete under different loading scenarios". I would like your permission to reprint in my literature review excerpts from the following:

Gregor Fischer, "CHARACTERIZATION OF FIBER-REINFORCED CEMENT COMPOSITES BY THEIR TENSILE STRESS- STRAIN BEHAVIOR AND QUANTIFICATION OF CRACK FORMATION", 2004, 6th RILEM Symposium on Fiber-Reinforced Concretes (FRC) - BEFIB

The excerpts to be reproduced are:

Fig.1 Schematic stress strain behavior of cementitious matrices in tension.

Sincerely, 
Gregor Fischer <gf@byg.dtu.dk> Sun, May 13, 2012 at 10:10 AM

To: Miguel Angel Carbonell Munoz <mcarbone@mtu.edu>

Hello Miguel,

Could you please send me the graph you are referring to? I just want to make sure the graph shown there is actually mine. If it is, you are certainly welcome to use it.

Best regards,

Gregor

[Quoted text hidden]

Gregor Fischer

Department of Civil Engineering

Technical University of Denmark

Brovej, Building 118

DK-2800 Kgs. Lyngby

Denmark

Email: gf@byg.dtu.dk

Phone: +45 45255007 
To: Gregor Fischer <gf@byg.dtu.dk>

Dear Dr. Fischer,

Please, find attached the article.

The figure I would like to use in my thesis is:

Fig. 1 Schematic stress strain behavior of cementitious matrices in tension.

Please, confirm your approval.

Kindest regards

Copyright Release

Gregor Fischer <gf@byg.dtu.dk> Mon, May 14, 2012 at 1:17 PM

To: Miguel Angel Carbonell Munoz <mcarbone@mtu.edu>

looks good. you can use it without any problem.

Best regards,

G.Fischer

On May 14, 2012, at 7:14 PM, Miguel Angel Carbonell Munoz wrote:

$<10.1 \cdot 1 \cdot 67.9803[1] . p d f>$

Gregor Fischer

Department of Civil Engineering

Technical University of Denmark

Brovej, Building 118

DK-2800 Kgs. Lyngby

Denmark

Email: gf@byg.dtu.dk

Phone: +45 45255007 


\section{Figure 2.6}

\section{Miguel Angel Carbonell Munoz <mcarbone@mtu.edu>}

Copyright release

Miguel Angel Carbonell Munoz <mcarbone@mtu.edu>

Wed, May 9, 2012 at 3:52 PM

To: sri@iastate.edu

Dear Dr. Sri Sritharan,

I am completing my masters thesis at Michigan Technological University entitled "Compatibility of Ultra High Performance Concrete as repair material: Bond characterization with concrete under different loading scenarios" under the supervision of Dr. Devin Harris.

I would like your permission to reprint in my literature review excerpts from the following: Suleiman, M., Sri Sritharan., and T.L. Vande Voort, Design and Performance Verification of UHPC piles for deep foundations. 2008, Center for Transportation Research and Education lowa State University.

The excerpt to be used is:

Figure 2.14. Durability properties of UHPC and HPC with respect to normal concrete I sent an email to Dr. Suleiman (suleiman@iastate.edu) but this email is not avalaible anymore.

Are you able to authorize me to reproduce this figure? Or could you give me the actual email of Dr.Suleiman, please?

Thanks for your help,

Copyright release

Sritharan, Sri [CCE E] <sri@iastate.edu> Wed, May 9, 2012 at 6:30 PM

To: Miguel Angel Carbonell Munoz <mcarbone@mtu.edu> 
Miguel - not sure what you need from me, but I authorize you to reuse the figure with acknowledgement to the original source of the figure.

\section{Sri Sritharan}

Wilson Engineering Professor and Associate Chair

Director of Graduate Education (DOGE)

376 Town Engineering Bldg.

Dept. of Civil, Construction \& Environmental Engineering

lowa State University

Ames, IA 50011-3232

Ph: (515) 294-5238; Fax: (515) 294-8216; Email: sri@iastate.edu 


\section{Copyright of figures 2.7 and 2.11}

\section{ELSEVI ER LI CENSE TERMS AND CONDITIONS}

Jul 23, 2012

This is a License Agreement between Miguel Angel Carbonell Munoz ("You") and Elsevier ("Elsevier") provided by Copyright Clearance Center ("CCC"). The license consists of your order details, the terms and conditions provided by Elsevier, and the payment terms and conditions.

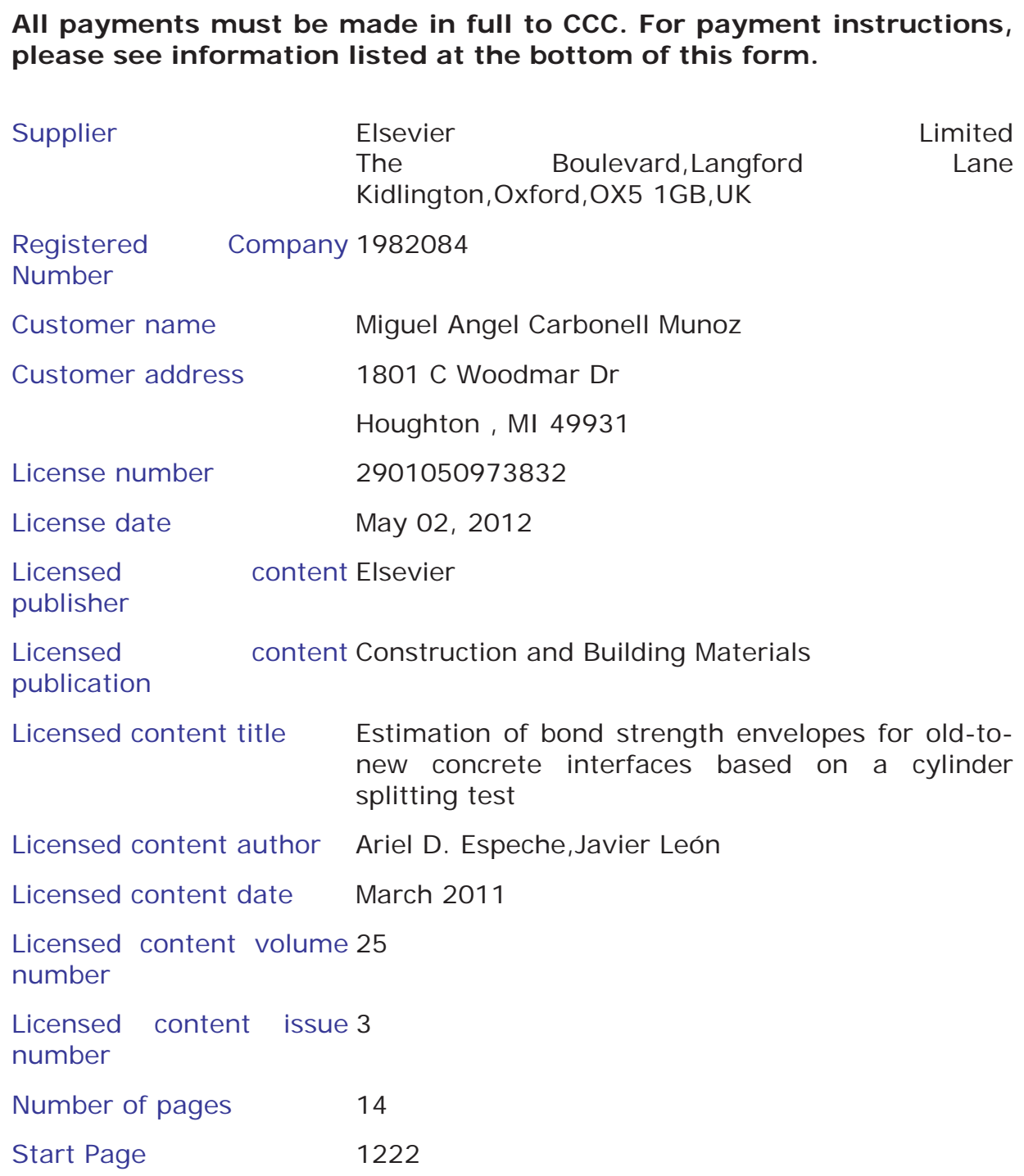




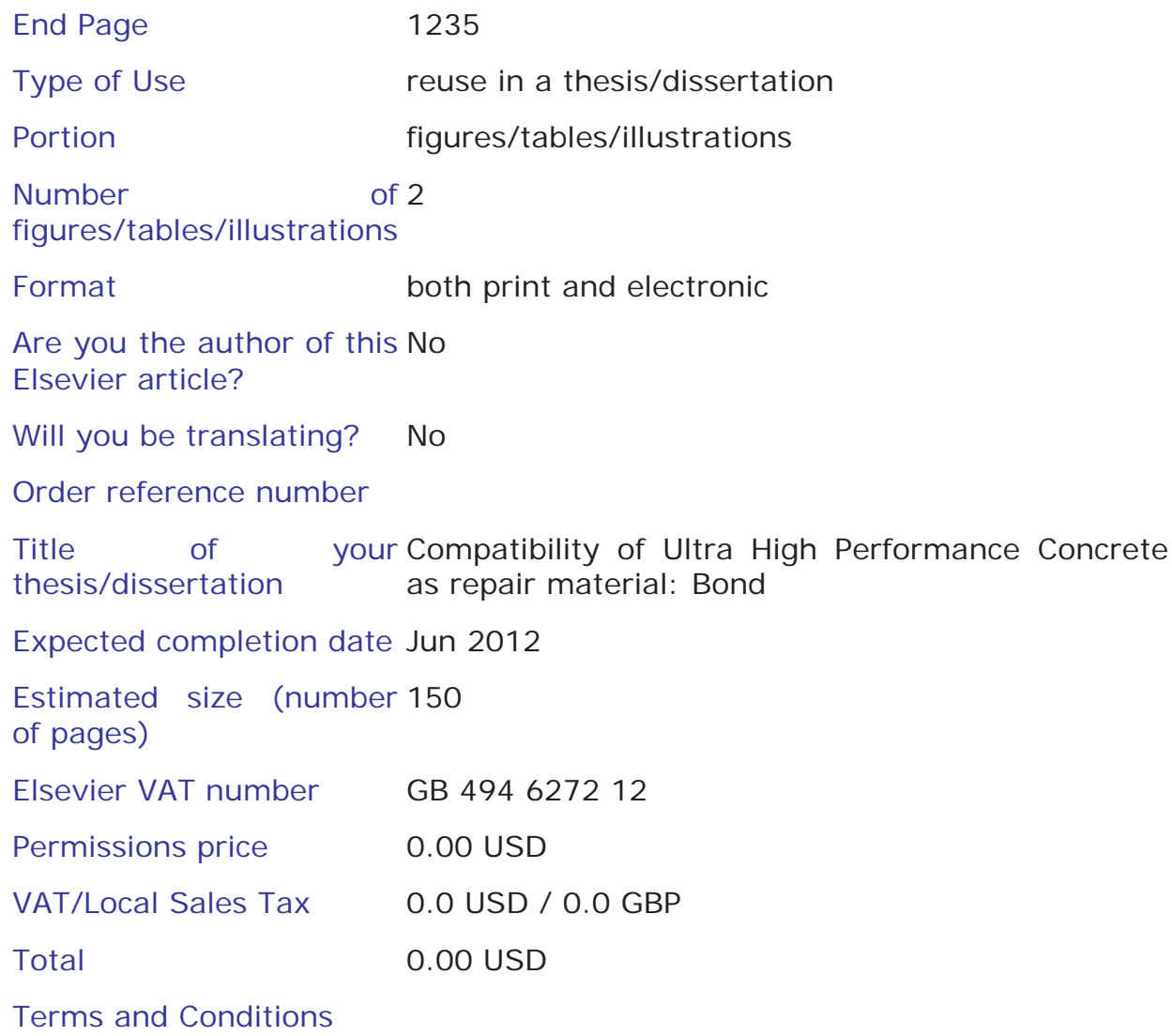

Terms and Conditions 


\section{Copyright of Figure 2.9}

\section{ELSEVI ER LI CENSE TERMS AND CONDITIONS}

Jul 23, 2012

This is a License Agreement between Miguel Angel Carbonell Munoz ("You") and Elsevier ("Elsevier") provided by Copyright Clearance Center ("CCC"). The license consists of your order details, the terms and conditions provided by Elsevier, and the payment terms and conditions.

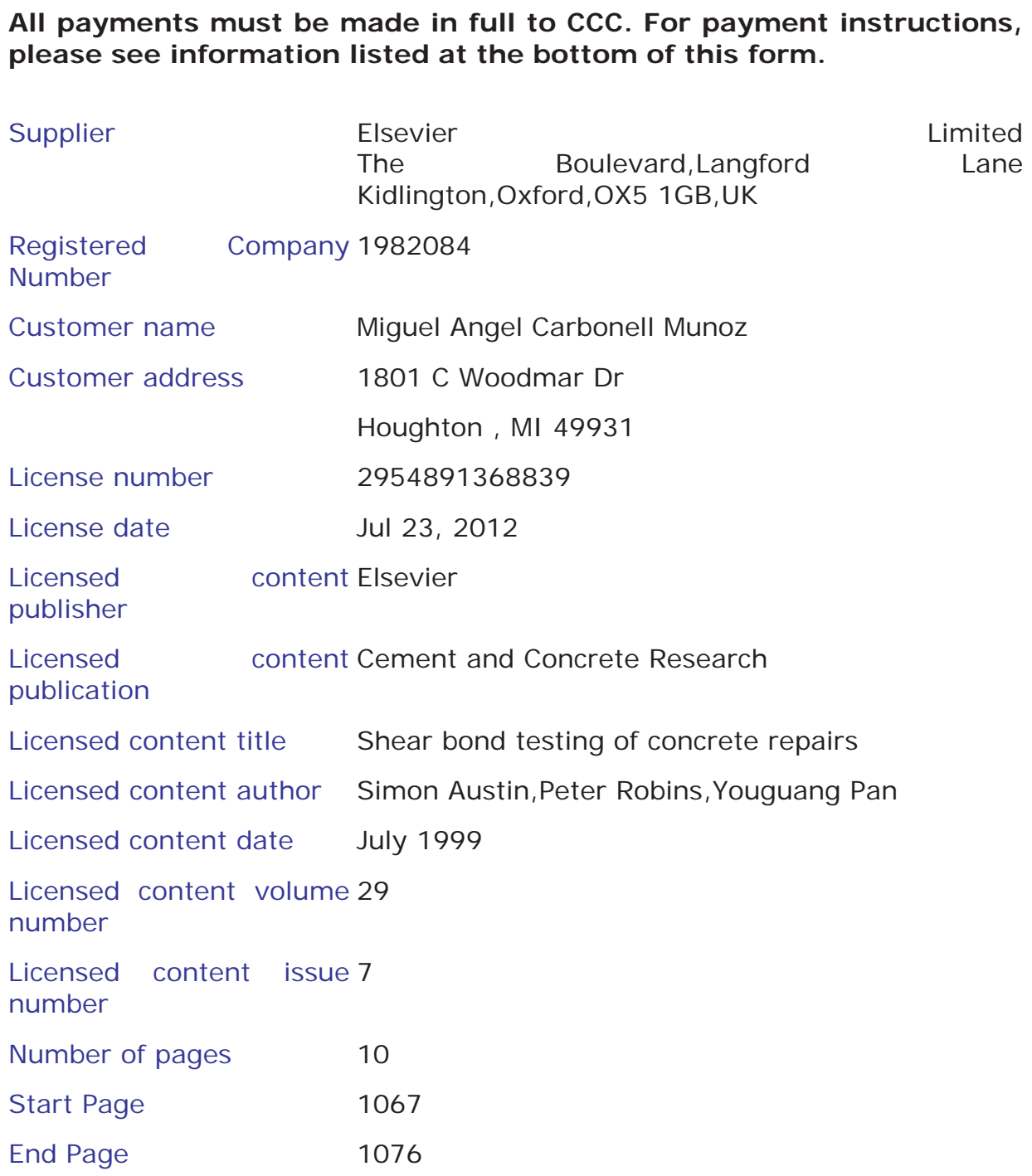




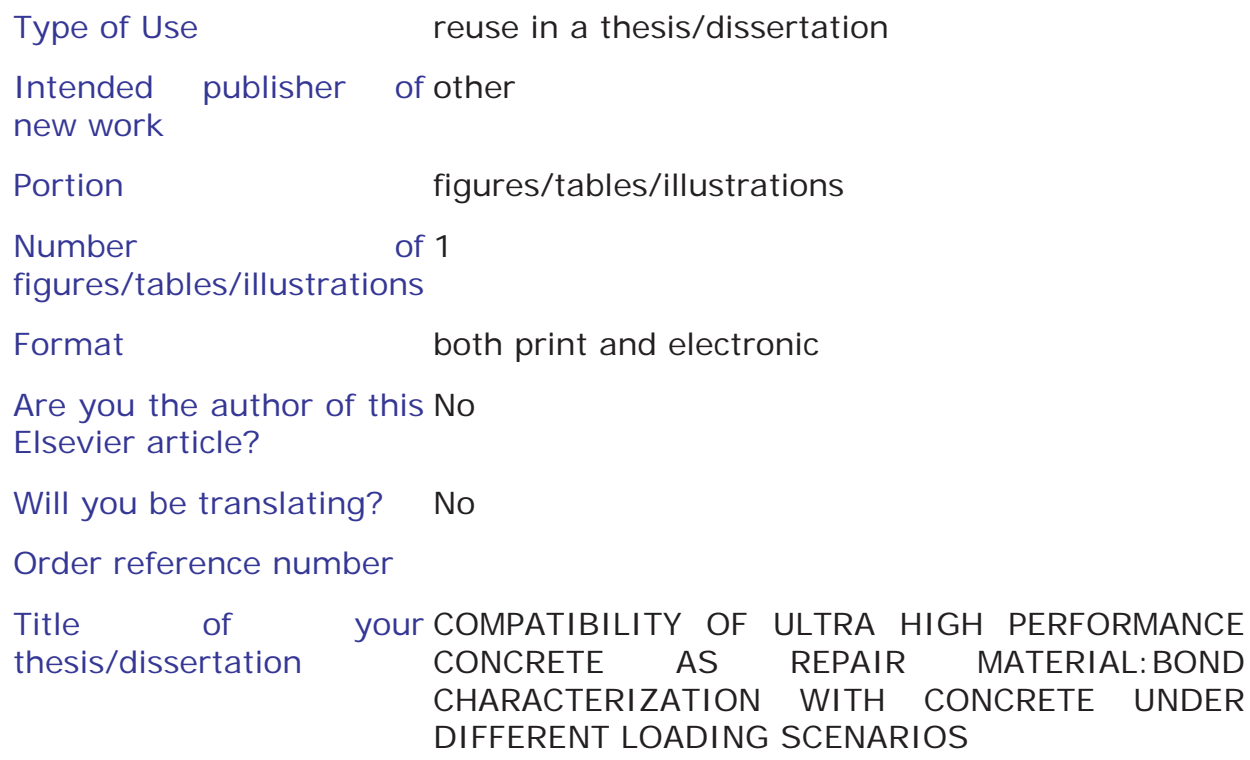

Expected completion date Jul 2012

Estimated size (number 150

of pages)

Elsevier VAT number $\quad$ GB 494627212

Permissions price $\quad 0.00$ USD

VAT/Local Sales Tax

0.0 USD / $0.0 \mathrm{GBP}$

Total

0.00 USD

Terms and Conditions 


\section{Copyright of Appendix: Concrete retarder information}

Miguel Angel Carbonell Munoz <mcarbone@mtu.edu>

Re: www.euclidchemical.com Customer Feedback

MMeermans@euclidchemical.com <MMeermans@euclidchemical.com>Tue, Jul 24, 2012 at 3:22

PM

To: mcarbone@mtu.edu

Miguel,

Any information you obtained from our website is free for you to use.

Technical Support

The Euclid Chemical Company

800-321-7628 